
Gates, Illinois River, Illinois

Deborah R. Cooper, Timothy L. Fagerburg,

Terry N. Waller, S. Wallace Guy, and Andrew Tuthill
November 2001 
The contents of this report are not to be used for advertising, publication, or promotional purposes. Citation of trade names does not constitute an official endorsement or approval of the use of such commercial products.

The findings of this report are not to be construed as an official Department of the Army position, unless so designated by other authorized documents. 
ERDC TR-01-15

November 2001

\section{Monitoring of Marseilles Dam Submersible Gates, Illinois River, Illinois}

by Deborah R. Cooper, Timothy L. Fagerburg, Terry N. Waller

Coastal and Hydraulics Laboratory

U.S. Army Engineer Research and Development Center 3909 Halls Ferry Road

Vicksburg, MS 39180-6199

S. Wallace Guy

Information Technology Laboratory

U.S. Army Engineer Research and Development Center 3909 Halls Ferry Road

Vicksburg, MS 39180-6199

Andrew Tuthill

Cold Regions Research and Engineering Laboratory

U.S. Army Engineer Research and Development Center 72 Lyme Road

Hanover, NH 03755-1290

Final report

Approved for public release; distribution is unlimited 


\section{Contents}

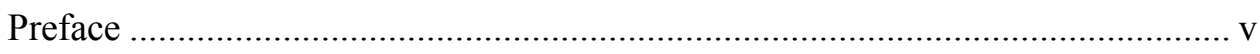

Conversion Factors, Non-SI to SI Units of Measurement ................................. vii

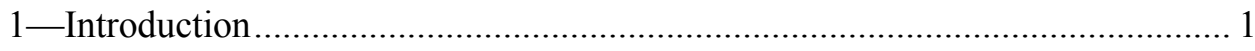

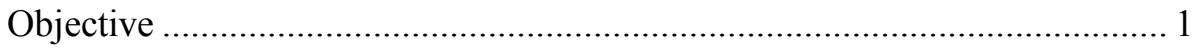

Monitoring Completed Navigation Projects Program...................................... 1

Project Location and History ................................................................ 2

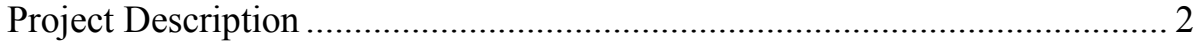

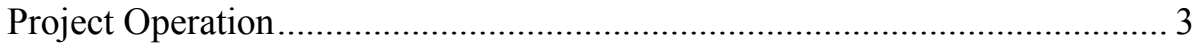

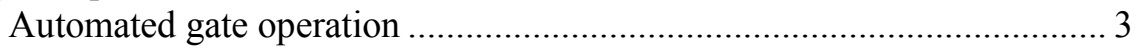

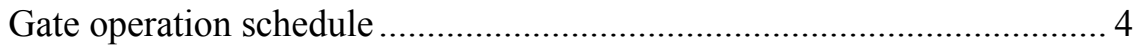

Winter operations and ice problems ........................................................... 4

Hydrometeorologic Conditions, Winter 2000 Compared to Long-Term

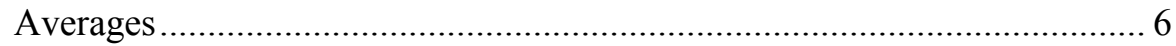

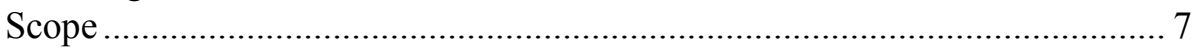

Hydraulic Model Study of the Gates ...................................................... 8

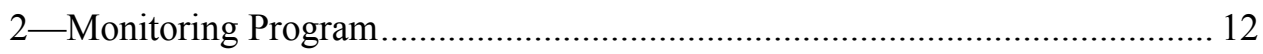

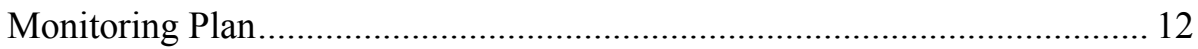

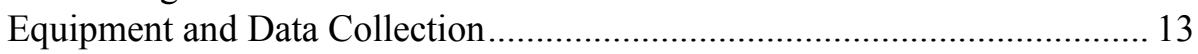

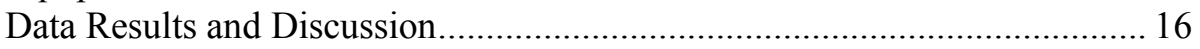

Life-Cycle Cost Analysis ......................................................................... 16

Recorded Gate Operations and Inclinometer Readings ............................... 17

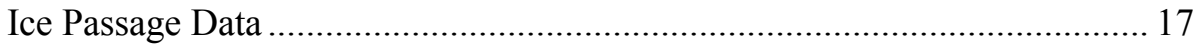

Winter of 2000 time-lapse video of ice passage ...................................... 18

February 1988 video of ice passage at Gate 1 ........................................ 19

Upper Pool and Tailwater Elevation Variation............................................ 19

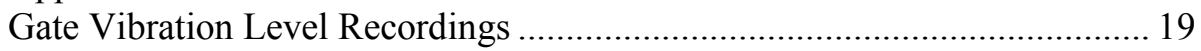

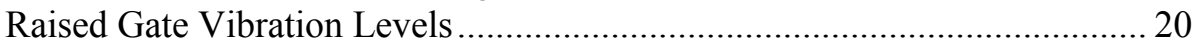

Submerged Gate Position Vibration Levels................................................. 20

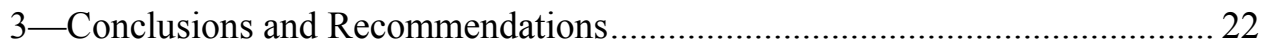

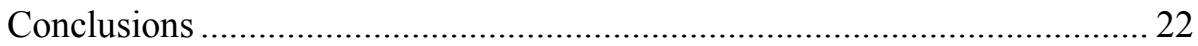

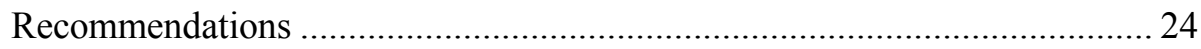


Figures 1-82

Tables 1-23

SF 298 


\section{Preface}

The study reported herein was conducted as part of the Monitoring Completed Navigation Projects (MCNP) Program (formerly Monitoring Completed Coastal Projects Program). Work was carried out under Work Unit 11M16, "Marseilles Dam, Illinois River, Illinois." Overall program management for MCNP is accomplished by the Hydraulic Design Section of Headquarters, U.S. Army Corps of Engineers (HQUSACE). The Coastal and Hydraulics Laboratory (CHL), U.S. Army Engineer Research and Development Center (ERDC), is responsible for technical and data management and support for HQUSACE review and technology transfer. Program Monitors for the MCNP Program are Messrs. Barry W. Holliday, David B. Wingerd, and Charles B. Chesnutt. The Program Manager is Mr. Ray Bottin (CHL).

The work was conducted during the period June 1999 through June 2001 under the general supervision of Dr. James R. Houston, Mr. Thomas W. Richardson, former Director and Acting Director, CHL, and under the direct supervision of Messrs. Phil Combs, Chief, Hydraulic Structures Division, James R. Leech, Chief, Spillways and Channels Branch, and Dr. Robert T. McAdory, Chief of the Tidal Hydraulics Branch, CHL. Principal investigators for the study were Ms. Deborah R. Cooper, research hydraulic engineer, and Messrs. Dave Wehrley and James Bartek, project engineers, U.S. Army Engineer District, Rock Island. The Life Cycle Cost (LCC) Analysis of the Marseilles Dam Remote Operating System was conducted by Mr. Bob Ward, electrical engineer, Rock Island District. Ice passage analysis was conducted by Mr. Andrew Tuthill, Cold Regions Research and Engineering Laboratory (CRREL). Model tests were conducted by Ms. Cooper and Mrs. Janice A. Flowers, and Mr. Earl Jefferson. Field data were obtained by Messrs. Timothy L. Fagerburg and Terry N. Waller of the Tidal Hydraulics Branch and by Messrs. S. Wallace Guy and Terry Warren of the Information Technology Laboratory. Mr. David Ray of the Information Technology Laboratory installed the time-lapse video camera and thermal equipment as well as photographed pertinent parts of the Marseilles Dam.

Ms. Cooper, Messrs. Fagerburg, Waller, Tuthill and Guy prepared this report. Acknowledgement is made to the personnel of the Rock Island District, especially Mr. James W. Hart and Rick Vesper, lock masters, and the staff at Marseilles Lock and Dam, for their assistance and information on ice operations in this investigation. 
At the time of publication of this report, Dr. James R. Houston was Director of ERDC, and COL John W. Morris III, EN, was Commander and Executive Director.

The contents of this report are not to be used for advertising, publication or promotional purposes. Citation of trade names does not constitute an official endorsement or approval of the use of such commercial products. 


\section{Conversion Factors, Non-SI to SI Units of Measurement}

Non-SI units of measurement used in figures and tables of this report can be converted to SI units as follows:

\begin{tabular}{||l|l|l||}
\hline \hline Multiply & By & To obtain \\
\hline \hline acres & 4046.856 & square meters \\
\hline cubic feet & 0.02831685 & cubic meters \\
\hline cubic feet & 28.32 & liters \\
\hline cubic yards & 0.7646 & cubic meters \\
\hline degrees (angle) & 0.01745329 & radians \\
\hline feet & 30.48 & centimeters \\
\hline feet & 0.3048 & meters \\
\hline inches & 2.54 & centimeters \\
\hline inches & 25.4 & millimeters \\
\hline miles & 1.609344 & kilometers \\
\hline pounds (force) & 4.448222 & newtons \\
\hline pounds (mass) & 0.45359 & kilograms \\
\hline square feet & 0.9290304 & square meters \\
\hline square miles & 2.589988 & square kilometers \\
\hline tons (2,000 pounds, mass) & 907.1847 & kilograms \\
\hline
\end{tabular}




\section{Introduction}

\section{Objective}

The objective of the monitoring plan was to determine if the Marseilles Dam remote operation system and the submersible tainter gates were performing efficiently and practically vibration-free, as predicted.

\section{Monitoring Completed Navigation Projects Program}

The goal of the Monitoring Completed Navigation Project (MCNP) Program (formerly Monitoring Completed Coastal Projects Program) is the advancement of coastal and inland waterways engineering technology. It is designed to determine how well projects are accomplishing their purposes and are resisting attacks of the physical environment. These determinations, combined with concepts and understanding already available, will lead to more credibility in predicting engineering solutions to coastal and inland waterways problems; to strengthening and improving design criteria and methodology; to improving operation and construction practices and cost-effectiveness; and to improving operation and maintenance techniques. Additionally, the monitoring program will identify where current technology is inadequate or where additional research is required.

To develop the direction for the program, the U.S. Army Corps of Engineers established an ad hoc committee of coastal engineers and scientists. The committee formulated the program's objectives, developed its operational philosophy, recommended funding levels, and established criteria and procedures for project selection. A significant result of their efforts was a prioritized listing of problem areas to be addressed, essentially a listing of the program's areas of interest.

Corps offices are invited to nominate projects for inclusion in the monitoring program as funds become available. A selection committee, comprised of members of the MCNP Program Field Review group (representatives from District and Division offices) and civilian members of the Coastal Engineering Research Board, reviews and prioritizes the projects nominated. The prioritized list is reviewed by the Program Monitors at Headquarters, U.S. Army Corps of Engineers (HQUSACE). Final selection is based on this prioritized list, national priorities, and the availability of funding. 
The overall monitoring program is under the management of the U.S. Army Engineer Research and Development Center (ERDC), Coastal and Hydraulics Laboratory (CHL), with guidance from HQUSACE. Operation of individual monitoring projects is a cooperative effort between the submitting Districts/ Division office and CHL. Development of monitoring plans and the conduct of data collection and analyses are dependent upon the combined resources of CHL and the Districts/Division. Marseilles Dam, IL, was nominated and subsequently approved for inclusion in the monitoring program in 1998.

\section{Project Location and History}

Marseilles Dam was designed by the State of Illinois and constructed by the State and the Federal governments. The dam was completed in 1933 at a cost of $\$ 570,725$. The Marseilles Canal was required because the rapids (downstream of the present dam) were being utilized as a source of hydropower. Hydropower generation has since been abandoned. Marseilles Dam maintains the navigation pool between Marseilles and Dresden Island locks on the Illinois Waterway. Major commodities shipped in this pool include coal, petroleum products, chemicals, and farm products.

Marseilles Dam is located near the upstream end of the Marseilles Canal at river mile 247.0 on the Illinois River, near the city of Marseilles, IL, approximately $9.6 \mathrm{~km}(6 \text { miles })^{1}$ southeast of the city of Ottawa, La Salle County, and $104.6 \mathrm{~km}$ (65 miles) southwest of Chicago, IL (Figure 1). Marseilles Lock is located at the mouth of Marseilles Canal, $3.9 \mathrm{~km}$ (2.4 miles) downstream of the dam at river mile 244.6. The lock and dam are connected by Bells Island, and maintain a 2.7-m-(9-ft-)deep channel in Marseilles Pool. Constructed between $1930-1933$, the lock is $33.5 \mathrm{~m}(110 \mathrm{ft})$ wide by $182.9 \mathrm{~m}(600 \mathrm{ft})$ long with

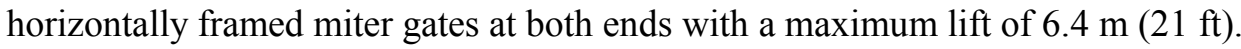
The lock concrete and mechanical and electrical systems were rehabilitated in 1977, and the lock miter gates were replaced in 1996.

\section{Project Description}

The main dam is a gated structure consisting of a 168.2-m-(552-ft-)wide section containing eight $18.3-\mathrm{m}-(60-\mathrm{ft}-)$ wide submersible tainter gates and a 14.2-m- (46.5-ft-)wide section containing an abandoned 9.1-m-(30-ft-)wide ice chute (Figures 2 and 3$)$. The normal head on the main dam is about $4.0 \mathrm{~m}(13 \mathrm{ft})$ and the upper pool is maintained at el 483.17. The submersible tainter gates (Figure 4) replaced counter weighted nonsubmersible tainter gates (Figure 5) during the 1986-1987 major rehabilitation contract that also repaired deteriorated concrete and replaced the service bridge and machinery. The spillway submersible tainter gates are $18.3 \mathrm{~m}(60 \mathrm{ft})$ wide by $4.9 \mathrm{~m}(16 \mathrm{ft})$ high with a

\footnotetext{
${ }^{1}$ Units of measurement in the text of this report are shown in SI units, followed by non-SI units in parentheses. In addition, a table of factors for converting non-SI units of measurement used in figures and tables in this report to SI units is presented on page vii.
} 
radius of $7.6 \mathrm{~m}(25 \mathrm{ft})$. Marseilles Pool has very tight tolerances $( \pm 6.1 \mathrm{~cm}(0.2 \mathrm{ft})$ "flat pool") requiring frequent gate adjustments to stay within the limits. The Marseilles pool must be maintained within these limits to prevent the overtopping of fully closed tainter gates and to maintain the 2.7-m-(9-ft-)deep navigation channel over a rock cut near Ballard's Island. Prior to the 1988-89 installation of a remote operation system, Marseilles Dam had to be attended $24 \mathrm{hr} /$ day (amounting to four full-time operating positions) because the lock and dam are $3.9 \mathrm{~km}$ (2.4 miles) apart, too distant to reasonably work both sites in a single shift.

\section{Project Operation}

\section{Automated gate operation}

The existing operation of the gates at the dam is performed remotely from the lock operation room. The gate operations can also be operated in a manual-local mode of operation where all controls for gate operation are done from the machinery service bridge located on top of the dam. The gate controls are located on the machinery bridge above each gate. The pool level is continuously displayed and recorded at the control panel in the lock operation room as well as in the old boiler house at the dam. The digitally displayed readings are averaged over time to eliminate the variability of readings due to wind and boat waves. Devices that are attached to the pinion arms measure the gate positions. These devices measure the angular rotation of each gate and convert these values to actual gate openings. The gate-opening values are then displayed in the lock operation control room. All gate operations are recorded by the lock and dam operator and include the time of day, new settings of all of the gates operated, upper pool level, and tailwater level. The more trouble-free operation of submersible tainter gates helped make it possible to operate the dam from a remote location and alleviated the need for 24-hr staffing of the dam, which was required prior to the installation of a remote system in 1988-89. Displayed readings are averaged over a period long enough to give readings accurate to $\pm 0.3 \mathrm{~cm}(0.01 \mathrm{ft})$. This requirement prevents variable readings due to waves and manually overcompensating the gate openings.

The positions of all gates are monitored by measuring the angular rotation of the gates and converting the angular rotation to actual gate openings at the lock. The gate positions are displayed and recorded in feet. Whenever a gate adjustment is made, the time of day, amount of change, new settings of all of the gates, pool level, and tailwater stage are recorded.

As a security and safety measure, the project is equipped with three intensified low light video cameras. The cameras allow the lock and dam operator to survey the upper pool, the tailwater, the dam and the landing areas at each end of the dam prior to and immediately following all gate operations. 


\section{Gate operation schedule}

The current gate operation schedule used at Marseilles Dam was developed from the combination of the experience of the operating personnel and rating curves from the physical model study. An added benefit of the current operating schedule is the improvement in the hydrodynamics in the upper pool that does not create a problem to the navigation of commercial vessels entering or exiting the lock structure. The schedule most favorable to navigation included opening the gates farthest from the Marseilles Canal first and working across the dam as flows increased.

With eight submersible tainter gates, Marseilles Dam affords a flexible gateoperating schedule. The constraints placed explicitly upon the gate operation schedule for the manual and remote operating modes were as follows:

a. The pool level is to be maintained within $6.1 \mathrm{~cm}(0.2 \mathrm{ft})$ of "flat pool" without excessive oscillations of the gates.

b. The gates should not be left in a position that could cause scour (e.g., one gate wide open while the remaining gates are closed).

c. The gates should not remain at settings in which they are vulnerable to damage from floating ice and debris (experience has shown 1.2-2.7 m (4$9 \mathrm{ft}$ ) of bottom opening results in water velocities that carry logs, ice, and debris with potentially gate damaging force)

d. The gate settings should minimize outdraft, which is a hazard to navigation.

e. The operation should result in approximately equal use of the gates.

\section{Winter operations and ice problems}

Prior to the installation of submersible tainter gates, winter operation was difficult due to ice buildup on the structural members of the gates. The gates often froze in place at the side and bottom seals. Ice removal required the application of steam produced from the boiler room at the dam. These deicing operations were hazardous, time consuming, and ineffective for thawing ice that was covered by water. The old tainter gates were not designed to pass ice without being raised nearly wide open and would result in dangerously low pool levels. To prevent this condition from occurring, the gates would be closed and the pool level allowed to build up, storing excess water. Then one or two of the gates were opened wide open to allow the ice to pass. The ice-passing problem was compounded by the low tailwater elevations that typically occurred during cold weather, low flow periods. The combination of the high discharge created from the wide-open gates and the low tailwater elevations resulted in considerable turbulence below the spillways and increased the potential for downstream scour to occur. The submersible tainter gates and the addition of the remotely operated 
system have enhanced the efficiency of the project operations for ice passage and pool regulation.

The old counter weighted nonsubmersible tainter gates needed to be raised a minimum of about $1.5 \mathrm{~m}(5 \mathrm{ft})$ in order to draw ice or debris beneath. Under conditions of heavy drifting ice, however, operators would open the gates to $3.4 \mathrm{~m}$

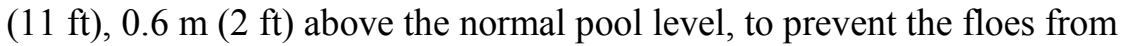
damaging the gate undersides. Under the right conditions, the large openings of one or two gates would create sufficient current to draw ice from the pool and canal entrance to the gates for passage. Also, when large ice slabs, 15.2 to $21.3 \mathrm{~m}$ (50 to $70 \mathrm{ft}$ ) in width would lodge against the dam piers, the large openings would draw down the water level in front of the gates sufficiently to break the floes in bending then pass the ice as smaller pieces.

Sometimes a free towboat or "light boat" would make a few passes in front of the dam to break the sheet into pieces small enough to pass the gates. According to Jim Hart, ${ }^{1}$ lockmaster at Marseilles, before the gate rehab, passing heavy ice through fully raised tainter gates caused noticeable vibration of the dam. Because most of the winters since the rehab have been warmer than average, the new 18.3-m- (60-ft-)wide submersible tainter gates may have not yet experienced extreme ice conditions similar to those in the mid-1970s to mid-1980s period.

The downstream sides of the old tainter gates had a lot of exposed structural members that tended to accumulate ice, either from spray from the fast water moving beneath or from leaks along the side seals. In addition, the clearance between the gate trunnion arms and the concrete pier walls was only a few inches, so a small amount of ice buildup would freeze the gate in place. The ice along the " $\mathrm{j}$ " seals and trunnion arms had to be steam-melted or chiseled off, before the gates could be moved. This work was labor intensive, slow, and at times, hazardous to personnel working out and around the gates in all weather and river conditions. Figure 10 shows an ice-encrusted gate similar to the old Marseilles gates being steamed at Dresden Island Dam in 1998.

The new submergible gates are fully enclosed front and back and therefore less prone to ice buildup than the old gates. Also the gate arms are angled away from the pier walls with the clearance distance increasing moving away from the trunnions and towards the gate face. Running in submerged mode, spray icing and seal leakage do not result in ice buildup. During periods of extreme cold, the gates are moved or cycled every $2 \mathrm{hr}$ to prevent freezing. Figure 11 shows one of the new gates at Marseilles Dam.

In the winter of 2000, the gates ran submerged from 20 January to 3 March, with typical openings in the 0.2 to $0.3-\mathrm{m}-(0.5$ to 1.0 -ft- $)$ range. To minimize outdraft on tow traffic at the canal entrance, the gate schedule favors openings on the right (north) side of the dam and moving progressively to the left as discharge increases. Figure 12 shows rating curves for the gates in underflow mode and submerged mode, based on approximate data from the Rock Island District,

${ }^{1}$ Personal Communication, August 2000, J. W. Hart, lockmaster, Marseilles, Lock and Dam. 
showing that $0.3 \mathrm{~m}(1 \mathrm{ft})$ of underflow is equal to about 0.6 to $0.9 \mathrm{~m}$ ( 2 to $3 \mathrm{ft})$ of overflow in terms of gate discharge.

According to Jim Hart, ${ }^{1}$ if drifting ice is light, it will pass the gates at even submerged openings in $0.2-0.3-\mathrm{m}-(0.5-1-\mathrm{ft}-)$ range. To pass light-to-moderate loose brash, from the canal and navigation channel, Gates 1,2 and 3 need to be submerged 0.6 to $0.9 \mathrm{~m} \mathrm{(2} \mathrm{to} 3 \mathrm{ft}$ ). To pass heavy brash, or large floes, several

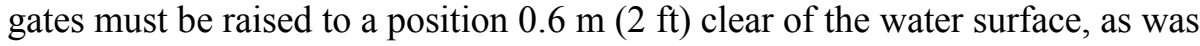
done with the old gates. This practice concentrates the flow towards the gates and develops enough water velocity to prevent arching and avoid damage due to ice impacts. Ice congestion of the canal plagues winter operations at Marseilles Lock. With a good west wind and above-freezing air temperatures, it is possible to draw ice out of the canal and through fully opened Gates 1 and 2. Unfortunately no ice was passed in this manner during the winter of 2000, so there is no video or accelerometer data for what is probably the most extreme case.

\section{Hydrometeorologic Conditions, Winter 2000 Compared to Long-Term Averages}

Although winters are often severe enough to form significant ice on the Illinois River, the winter of 2000 was the fourth mildest since 1959 and very little ice formed. Accumulated freezing degree days (AFDD's), the cumulative sum of the degrees below the freezing mark, based on daily average air temperature, are a good indicator of the relative coldness of a winter and the potential for ice growth. Figure 6 shows the AFDD curve for the winter of 2000, which peaked at 307, less than half the long-term average of 742 (Figure 7). Figure 8 plots daily average air temperature for Chicago, showing two subfreezing periods, the first from late December to early January and the second from the last week of January to midFebruary.

Ice thickness on a lake or river can be estimated from the equation:

$$
t i=\mathrm{C}(\mathrm{AFDD})^{\wedge} 0.5
$$

where $t i$ is ice thickness in inches, AFDD is accumulated freezing degree (F) days and $\mathrm{C}$ is a coefficient that usually ranges from 0.3 to 0.6 . Using 0.3 as a coefficient, theoretical ice thickness (Figure 6) reaches a maximum of only $12.7 \mathrm{~cm}$ ( 5 in). Observed ice thickness turned out to be significantly less than this, however, due possibly to upstream thermal inputs from industry.

The prevailing winter winds at Chicago are from the west and average $17.7 \mathrm{kmph}(11 \mathrm{mph})$. Average discharge on the Illinois River at Marseilles during January of 2000 was about $85 \mathrm{~m} 3 / \mathrm{s}$ (3,000 cfs), roughly one-third the

\footnotetext{
${ }^{1}$ Personal Communication, J. W. Hart, op cit.
} 
long-term average of $283.7 \mathrm{~m} 3 / \mathrm{s}(10,019 \mathrm{cfs})$. Pool stage was fairly constant at el 484.2, ${ }^{1}$ seldom varying more than several tenths of a foot (Figure 9).

\section{Scope}

Evaluation of the Operations and Maintenance Navigation Information (OMNI) data, operations and maintenance schedules and costs, hydrodynamic conditions, and validation of the model as a design tool were performed. Ice passage conditions were recorded by the Rock Island District and ERDC using time-lapse photography to document the effectiveness of the submersible tainter gates in passing ice. The video footage was obtained under the direction of ERDC and Rock Island District personnel. The Cold Regions Research and Engineering Laboratory (CRREL) provided consultation and analysis. Data recorded in the OMNI system was evaluated to determine any operational limitations of the remote operating system as well as the submersible tainter gates. Field-testing was conducted to obtain vibration data of the submersible tainter gates for various operations and flow conditions that occurred during a 12-month period. The data acquired during this period were analyzed to determine the gate vibration response to flows over or under the instrumented gates. The analysis included the determination of acceleration amplitudes and maximum displacements in the vertical, longitudinal, and transverse directions. The submersible tainter gates at Marseilles Dam do not significantly vibrate under normal operation for flows under and over the gate, or with passing ice.

To evaluate the cost savings realized by installing the remote operating system a Life Cycle Cost (LCC) analysis investigated the sum of construction, repair and labor costs of the remote system vs. the costs of the four full-time dam employees that it replaced. A qualitative analysis of ice passage was done by CRREL using February 1989 time-lapse video footage from a CRREL video camera mounted during the winter of 1988 and an ITL video camera mounted during the fall of 1999 on a pole on the north shore, upstream of the headrace gates. OMNI data and hydrodynamic conditions were used to correlate field conditions with data collection. To validate the model as a design tool, results from the physical model study conducted in 1985 were compared with field data. To perform the required data collection, four of the eight flow control gates were instrumented with accelerometers to monitor vibration and inclinometers to monitor gate motion. The lock and dam operation personnel recorded the date, time, and gate opening for each instrumented gate used in the flow release operation. An onsite data acquisition system recorded the accelerometer and inclinometer sensor outputs for flow releases that used the instrumented gates. The conditions evaluated included gates in the raised positions, gates in the submerged positions, and all combinations of single or multiple gate operations. The existing data in the OMNI system were used to examine variation in pool levels and the response time involved in changing the gate settings and the effectiveness in maintaining the pool within the tight tolerances that were established by the Rock Island District.

\footnotetext{
${ }^{1}$ All contours and elevations cited herein are in feet referred to mean sea level (msl) unless otherwise noted. (To convert feet to meters, multiply by 0.3048 )
} 


\section{Hydraulic Model Study of the Gates ${ }^{1}$}

During 1985, a 2-D physical model study of the Marseilles Dam submersible gate was conducted at ERDC to:

a. Determine the magnitude and frequency of the hydraulic forces acting on the lifting cables while the gate was submerged.

b. Verify anticipated stilling basin performance for all probable operating conditions.

c. Determine discharge characteristics and coefficients with various operating scenarios.

The Marseilles model (Figure 13) was constructed to a linear scale of 1:20, model to prototype. It reproduced a $36.6-\mathrm{m}-(120-\mathrm{ft}-)$ wide section of the spillway and stilling basin including one freely suspended $18.3-\mathrm{m}-(60-\mathrm{ft}-)$ wide by $4.9-\mathrm{m}-$ (16-ft-)high submersible tainter gate, two 2.5-m-(8-ft-)wide piers, and two 6.7-m(22-ft-)wide by $1.8-\mathrm{m}-(6-\mathrm{ft}-)$ high portions of the tainter gate on either side of the piers. The model tainter gate (Figure 14) was constructed of brass and simulated a prototype weighing $72,574.4 \mathrm{~kg}(160,000 \mathrm{lb})$ (dry weight). The upstream and downstream skin plates and trunnion arms were reproduced to scale. Originally the rubber side seals were omitted, simulating a 10.2-cm (4-in.) gap between the gate and the piers. This provision was made to avoid friction between the gate and piers and was part of the type 1 and 2 designs. However, this provision proved to be too significant a deviation from the prototype and was responsible for most of the vibration initially recorded. To reduce friction forces to a minimum, the gate trunnions were mounted in roller bearings in the adjacent piers. The gate-to-sill clearance simulated was $2.5 \mathrm{~cm}$ (1 in). The piers and ice deflectors shields (Figure 4) were constructed of transparent plastic; the portion of the model representing the spillway sill and apron was fabricated of sheet metal. The two adjacent gates were simulated schematically and reproduced only the shape and size of a nonsubmersible-type tainter gate. The gate lifting mechanism consisted of a cable at each end of the gate attached to load cells suspended by a pulley system (Figure 13). Each model cable was sized to reproduce the elastic properties of four prototype cables proposed for each end of the gate.

Water used in the operation of the model was supplied by pumps, and discharges were measured with venturi meters. The tailwater in the downstream end of the model was controlled by an adjustable tailgate. Steel rails set to grade provided reference planes. Water-surface elevations were obtained with point gages. Velocities were measured with a pitot tube. Load cells and an oscillograph recorder were used to measure and record the magnitude and frequency of the total forces acting on each end of the gate. Chart speed used during testing was $2.5 \mathrm{~cm} / \mathrm{s}(1 \mathrm{in} / \mathrm{s})$.

\footnotetext{
${ }^{1}$ U.S. Army Engineer Waterways Experiment Station. (1989). "Submersible-type tainter gate for spillway, Marseilles Lock and Dam," Vicksburg, MS.
} 
Model tests were conducted to observe the conditions with flow over and under the gate and to determine the magnitude and frequency of the hydraulic forces acting on the lifting cables with various gate openings and submergences of the gate. To measure the forces on the gate, the pool elevation was held constant while the position of the gate and the tailwater were varied.

All tests were conducted with the upper pool level maintained at a constant elevation of 483.17. Prior to the start of a test, the force-measuring equipment was checked to ensure that it was working properly, the moving parts of the test gate were examined, and the water levels of the upper pool and the lower pool below the gate were properly adjusted. After the force-measuring device was zeroed, the device was then placed in operation (raising or lowering the test gate). The force on the hoisting cables was measured by raising the crest of the gate in $0.3-\mathrm{m}$ (1-ft) increments to a desired elevation and holding it there for a measurement. All model force data presented in the tables in this report were measured in this manner.

Tests were conducted with two different spillway crest designs for the submersible-gated spillway. These designs, furnished by the Rock Island District, differed only in the shape of the spillway crest upstream from the gate. The type 1 (original) design (Figure 15) had a curved shape with an 27.1-m (89-ft) radius, and the type 2 design had a $0.8-\mathrm{m}-(2.5-\mathrm{ft}-)$ broad horizontal sill preceded by a $1 \mathrm{~V}$ on 1.2 H sloping face (Figure 15). Tests were conducted to determine discharge characteristics, stilling basin performance, loads on the gate lifting cables, and vibration tendencies of decreasing the clearance between the gate and pier and increasing the gate-to-sill clearance.

Initially, tests were conducted to assure that the natural frequency of the model cables were not in the range of the natural frequency of the exciting forces measured in the model. The prototype cable natural frequency was estimated by the Rock Island District to $4.5 \mathrm{~Hz}$.

Forces induced in the gate lifting cables by flow under and over the subject gate were measured with a normal upper pool (el 483.17) in combination with various tailwater elevations. A profile sketch and definitions of terms are presented in Figure 16. A sample oscillograph record and sample calculation are presented in Figure 17. Test results are tabulated in Tables 1 through 6.

During tests an undular jump or "rooster tail" developed immediately downstream of the gate with several combinations of gate opening and tailwater elevations with a normal upper pool (el 483.17). Vibrations of the gate with flow under the gate were recorded with these conditions. The model test results indicated the original (type 1) would likely permit the gate cables to be subjected to loads occurring at a random frequency during normal operations with flow under small gate openings due to the contact of the gate with flow. The magnitude of these vibrations, however, was very small (less than 3 percent) compared to the gate's weight. With flow over the type 1 design structure, the likelihood of forces acting on the cables at a periodic frequency was indicated for essentially all submergences and expected headwaters and tailwaters. The frequency of the induced forces $(1.6-3.4 \mathrm{~Hz})$ was considered unacceptably close to 
the natural frequency of the prototype lifting cables $(4.5 \mathrm{~Hz})$. Because of the proximity of the frequency of the flow-induced loads on the cables to the natural frequency of the prototype values, the type 1 design structure was considered unstable.

The model test results indicated the type 2 design would likely permit the gate cables to be subjected to loads occurring at a random frequency during normal operations with flow under small gate openings due to the contact of the gate with flow. The magnitude of these vibrations, however, was very small (less than 2 percent) compared to the gate's weight. With flow over the type 2 design structure, the likelihood of forces acting on the cables at a periodic frequency was indicated for gate submergences of up to and including $1.8 \mathrm{~m}(6 \mathrm{ft})$. There was some reduction in the frequency and magnitude of the periodic vibrations with the type 2-design structure. Loads began to occur at a random frequency for gate submergences of 2.1 and $2.4 \mathrm{~m}$ (7 and $8 \mathrm{ft}$ ) (fully submerged).

The type 3-design structure incorporated the type 2-design spillway crest and the extension of the gate end shields to decrease the gate-to-pier clearance from 10.2 to $1.3 \mathrm{~cm}$ ( 4 in. to $0.5 \mathrm{in}$ ). Forces induced in the gate lifting cables by flow under and over the subject gate were measured with a normal upper pool (el 483.17) in combination with various tailwater elevations.

The model test results indicated the type 3 design would likely permit the gate cables to be subjected to loads occurring at a random frequency during normal operations with flow under small gate openings due to the contact of the gate with flow. The magnitude of these vibrations, however, was very small (about 1 percent) compared to the gate's weight. With flow over the type 3-design structure, the forces acting on the cables occurred at a random frequency for submergences of $0.6,1.5,1.8$, and $2.1 \mathrm{~m}(2,5,6$, and $7 \mathrm{ft})$. The gate cables were not subjected to any vibrations for most gate submergences.

Because of the likelihood of the occurrence of random vibrations during normal operation of the gate with flow under or over the gate, ERDC suggested a brace to physically hold or lock the gate into position. A friction shoe (Figure 18) that could be installed on each side of the gate between the gate and pier was designed by the Rock Island District and was tested in the model. Although tests with the friction shoe indicated essentially no occurrence of vibrations, there was some doubt that these results were anything but qualitative because the friction in the model supplied by the friction shoe cannot be directly scaled to simulate prototype friction. The value of the friction was that it provided a factor of safety in the event that vibration occurred. Therefore, the type 3 design structure with a friction shoe installed on each side of the gate was recommended for prototype construction. The Rock Island District, however, opted not to include the friction shoe in the construction contract for the submersible tainter gates with the following rationale. The total amplitude, $\Delta_{\mathrm{p}}$, of the highest load fluctuation measured in the model was $680.4 \mathrm{~kg}(1,500 \mathrm{lb})$. Only one-half of that load fluctuation would have to be overcome by friction to negate the exciting forces and prevent vibrations (Figure 17). One-half of that, or $170.1 \mathrm{~kg}(375 \mathrm{lb})$, would have to be overcome by friction on each side of the gate. A conservatively low 
estimate of the prototype trunnion friction on each side of the gate is $272.2 \mathrm{~kg}$ $(600 \mathrm{lb})$. The side seal friction at each side of the prototype is estimated at $1,360.8 \mathrm{~kg}(3,000 \mathrm{lb})$, giving a significant factor of safety. In addition, the load fluctuations in the model acted at random frequencies rather than at periodic frequencies; thus, the deflection in the cables will not build resonantly. The first of the prototype gates was put into operation in January 1987, and the last (eighth) gate was put into operation in March 1988. All of the prototype submersible tainter gates have been operating practically vibration free. 


\section{Monitoring Program}

\section{Monitoring Plan}

Advantages of submersible gates are the capability of skimming loose ice with a minimum amount of flow, and avoiding downstream scour often associated with large underflow gate openings at low tailwater. Also, submerged operation largely avoids the problem of freezing-in of side seals. Vibration of gates has been reported at some of the 110-ft-wide submergible gates on the Ohio River. On some of these projects, a retrofit to a sharp-crested bottom seal eliminated the problem ${ }^{1}$ but at others, submerged mode of operation was discontinued. A monitoring plan was developed prior to monitoring the Marseilles Dam site. During the development of the monitoring plan specific hypotheses to be tested were laid out. The hypotheses to be tested include the following:

a. The remote operating system increased the capability of the dam to maintain operation during extreme weather or river conditions.

$b$. The remote operating system meets the operating constraints previously identified.

c. The remote operating system is a reliable system that provides considerable cost savings over the previous onsite manual operation.

d. Operational limitations of the remote operating system can be identified, with proposals to minimize these limitations.

$e$. The submersible tainter gates are more effective in passing ice than the conventional counter weighted tainter gates. An operation schedule can be developed to enhance gate operation during adverse weather conditions.

$f$. Adjustment of the submersible tainter gates in freezing conditions is less hazardous, less time consuming, and more effective and efficient than the old steam method that was used on the counter weighted tainter gates.

${ }^{1}$ U.S. Army Engineer District, Louisville. (1985). "Submergible gate use within the Corps, case histories," Louisville, KY. 
g. The submersible tainter gates at Marseilles Dam do not significantly vibrate under normal operation for flows under and over the gate, or with passing ice.

$h$. The model investigation accurately quantified vibration conditions for flows over and under the gates.

\section{Equipment and Data Collection}

After a visit to the dam and discussions with photographer David Ray, Information Technology Laboratory (ITL), it was decided to locate a time-lapse video camera on a pole on the north shore, upstream of the headrace gates. Figure 19 shows the camera location and the fields of view of both the ITL and CRREL cameras. Marseilles Lock personnel agreed to periodically change, install, and store the videotapes for the data collection personnel to retrieve on their monthly visits to check equipment and collect gate vibration data. The lockmasters also agreed to save the time-lapse videos from their surveillance cameras during the 2000 ice season for our review, but unfortunately the resolution of these images was not good enough to be of much use. They also kept a log of their gate changes during the submerged operation period. CRREL reviewed and tabulated the timelapse data from the winters of 2000 and 1988 and also analyzed the CHL accelerometer data surrounding the three ice passage events.

The monitoring plan was designed to instrument four of the eight gates (Gates 1, 3, 5, and 7) at the dam for assessing vibration levels during flow release operations. The location of the instrumented gates on the structure is shown in Figure 3. Each of the four gates was instrumented with a triaxial accelerometer, to measure three axes of gate vibrations, and an inclinometer, to measure the gate rotation. These data were recorded for all operations during a 12-month period of normal water discharge for pool regulation and ice passage with the instrumented gates in the raised and submerged position, respectively.

The accelerometers, shown in Figure 20, are PCB Model 356A08, each having a frequency response of $0.3 \mathrm{~Hz}-7000 \mathrm{kHz}$. These devices were chosen in order to obtain the low-end frequencies that are anticipated to be present during winter ice passage. The submersible tainter gates operate as a tainter gate and pivot at a trunnion pin located on each downstream pier face. The pivoting of the gate during raising or lowering operations creates an opening between the spillway crest and the gate to allow water to flow under or over the gate, respectively. The gate rotates through different gate angles required to obtain the desired flow releases. As a result of the angular displacement of the gate, a strain gage accelerometer was rejected because the DC response was too low and therefore would limit the accuracy of the analog to digital signal being recorded.

The accelerometers were mounted on the inside of the gates and located at the center of the gate as shown in Figures 21a and 21b. Access to the inside of the gates was made through a small, 61-cm-(24-in.-)dia, manhole door near the end of the upper trunnion arm. The triaxial accelerometers were enclosed in a waterproof canister, as shown in Figures $21 \mathrm{a}$ and $21 \mathrm{~b}$, and were attached to the 
middle strut inside of each instrumented gate. They were set in a level horizontal position with respect to the gates being set at zero gate opening positions. The signal cables from the instruments were routed through small holes located at the top of the structural support webbing of the gate to the air vent opening located at the trunnion arm side of the gates. Figures $22 \mathrm{a}-22 \mathrm{c}$ illustrate the space limitations inside the gate structure and the instrument cable routing during the installation. The cables were then passed through the gate air vent and up to the machinery access bridge above the gates, as shown in Figures 23a and 23b. A protective PVC conduit for the instrument cables was installed along the machinery service bridge above the gates. Approximately, $164.6 \mathrm{~m}(540 \mathrm{ft})$ of 7.6-cm-(3- in.-)PVC pipe were installed and anchored to the service bridge walkway, as shown in Figures 24a and 24b. The signal cables from each set of instruments were installed in the PVC conduit as it was assembled. At the north end of the machinery service bridge the cable conduit was routed under the stairway as shown in Figure 24c. At the north end of the dam, the cables were routed underground through an existing 5.1-cm-(2-in.-) diam metal conduit that terminated at the outside wall of the old boiler room building. A hole bored in the wall of the building allowed access of the instrument cables to the inside of the building near the data acquisition equipment table.

All the cables were connected to the data acquisition system. The cables were then checked for proper conductance prior to connecting them to the data acquisition system as shown in Figures 25a and 25b. The data acquisition system was turned on to assess the system operation and the integrity of all the instruments. The data acquisition system was found to be operating properly. However, upon checking the integrity of the instruments several problems were encountered. Accelerometer A1 (located on Gate 1) had no signal on the y-axis. Accelerometers A3 and A7 (located on Gates 3 and 7, respectively) had no signal on the $y$-axis and z-axis. The cables were again inspected for proper signal conveyance and determined to be satisfactory. The problem was determined to be within the accelerometer gage itself. It was determined that the malfunctions of the accelerometers were the result of a static electricity charge created by pulling the signal wires through the PVC pipe. This electrical charge had entered the ends of the cables and overloaded the sensors. Only one spare triaxial accelerometer and mounting bracket were available to replace the damaged instruments. Accelerometer A7 was replaced with the spare. Two replacement accelerometers were ordered for sensors A1 and A3. The replacement gages were installed 1 month later during the first service trip to download the data from the data acquisition system. A tap test was performed on the operating accelerometers as a check on the instruments signal response. The tap test is performed by gently tapping on the outside of the accelerometer housing in various directions to produce excitation of the accelerometer. The axes of acceleration are identified as follows:

$$
\begin{aligned}
& \text { Vertical }=\mathrm{x} \text { (vibration in the up and down direction; }+=\mathrm{up},-=\text { down }) \\
& \begin{aligned}
\text { Radial } & =\mathrm{y}(\text { vibration in the upstream and downstream direction; } \\
& +=\text { downstream, }-=\text { upstream) }
\end{aligned} \\
& \text { Transverse }=\mathrm{z} \text { (side-to-side direction (north-to-south) }++=\text { north, }-=\text { south) }
\end{aligned}
$$


To monitor movement of each instrumented gate, an inclinometer was installed near the accelerometers on the middle strut inside of each instrumented gate. These devices were also installed in a waterproof canister, shown in Figure 26. The inclinometer measured the angular rotation of the gate and served as a triggering device to activate the remote data acquisition system for recording the accelerometer data. Data recording did not begin immediately following any movement of the gates. A time delay of 15 min was programmed into the data acquisition system before the recording of the data would be initiated. This delay provided an ample time period for fine adjustment of the gate openings by the operator and also allowed sufficient time for the flow through the gates to stabilize. If no additional gate movements were detected by any of the inclinometers during this time delay period, the data recording was then initiated. The data were recorded for a 300-sec-period. After the completion of the data recording, the data acquisition system would remain in a standby mode until the next gate movement was detected by the inclinometers.

The signal conditioning system for the data acquisition system, Figure 27, contained the required amplifiers, filters, and analog-to-digital interfaces and received the data signals from the accelerometers and inclinometers. To provide for antialiasing of the accelerometer frequency response, each acceleration data channel was filtered with a $200 \mathrm{~Hz}$ eight pole low pass Bessel filter.

All the data signals were recorded remotely on a Gateway Pentium II Computer, Figure 28, that has a $350 \mathrm{MHz}$ clock speed, 13GB hard drive, and $128 \mathrm{MB}$ RAM. The analog data received from the signal condition system was converted to a digital signal by means of a National Instruments model MIO16XE-10, 16-bit, analog-to-digital converter. The converter was capable of providing a sampling rate of 100,000 samples per sec. To insure data collection would not be interrupted during the event of a power loss at the recording area, an uninterrupted power supply (UPS) was installed.

Software was developed by ERDC for the Marseilles Dam monitoring program to enable the data acquisition system to record data remotely. The data acquisition software was developed as a Windows program and designed to detect the gate movements and record acceleration measurements when any gate movements occurred. The program operates in the following manner. As stated previously, the inclinometers on each of four instrumented gates were used to detect gate movement and record the angular position. When a gate movement of $2 \mathrm{deg}$ was detected, a timer was started. The timer was set to run for a 15-min period. The timer would be reset each time a new gate movement of $0.03 \mathrm{rad}$ ( $2 \mathrm{deg}$ ) was detected. If the timer reached the preset length of time $(15 \mathrm{~min})$ and had not been reset due to additional gate operations, sufficient time had passed for a steady state flow condition to be established, and the data recording was initiated. Triaxial acceleration measurements and gate tilt on each gate were recorded for a $300-\mathrm{sec}$ period of time and at a sampling rate of 1,000 samples/sec. These recorded measurements were stored in a file that included the date and time of the data recording. The program was also designed to provide the user with the ability to scale, view, and print recorded data. Data can also be converted to other 
formats to enable analysis with other software products such as Matlab, Excel, DPlot, etc.

The recorded data were stored on the computer hard drive. At monthly intervals, ERDC personnel visited the project to perform routine checks of the sensors and the data acquisition system. During these visits, the data were downloaded from the hard drive on both 120 MB super disks and 100 MB Zip disks.

\section{Data Results and Discussion}

Elements of the monitoring plan included life-cycle cost of the remote operating system, collection of ice data, pool elevation variation, gate openings/submergences, and gate vibrations. More detailed information is provided in the following subparagraphs.

\section{Life-Cycle Cost Analysis}

A LCC analysis was performed to evaluate cost savings realized by installing the remote operating system (ROS). The LCC analysis investigated construction costs + repair costs + labor costs of the ROS vs. the costs of the four full-time dam employees that the ROS replaced. Advantages and disadvantages of the ROS were addressed. Recommendations were made for minimizing costs of replacement parts/down-time while maximizing operational efficiency. The benefit of ROS can be used at other dam sites to effectively reduce the labor force, especially in remote areas. A life cycle cost (LCC) analysis was conducted for three alternatives identified for operation of the Marseilles Dam: maintenance of the existing remote operation, manual operation, and replacement of the remote operating system. The design/evaluation period is indicated in Table 7, where costs associated with each alternative are listed and evaluated. Costs included in the analysis are initial capital costs (where appropriate), annual maintenance, and annual labor costs. Price levels are June 1999 and a discount rate of 6.875 percent has been used to annualize costs, where appropriate. This was a least cost analysis, rather than a benefit-to-cost analysis. Therefore, no assumptions concerning benefits or capital investment value were made. Table 7 summarizes the identified costs for the dam operational alternatives. Table 8 relates historical maintenance costs and labor requirements for operating alternatives.

a. Alternative $1-$ maintain existing remote operation. The existing operating system is a computerized remote operation, with an original cost (1988) of $\$ 1,042,500$. This is a sunk cost and was not considered in comparing alternative costs for a future operating period. Based on yearly cost records, the existing system has averaged $\$ 5,819$ in annual maintenance costs. The existing system also requires $\$ 12,074$ in annual labor costs for dam operation, which includes labor charges for operations during icing and nonicing periods. 
b. Alternative 2 - manual operation. The dam was operated manually prior to 1988. This procedure required four full-time workers for a $24-\mathrm{hr} /$ day operation. The costs associated with manual operations totaled $\$ 185,869$ annually. These costs were stated at 1999 labor rates for the appropriate average wage-grade range.

c. Alternative 3 - replace remote operating system. For comparison purposes, the costs for a replacement of the existing remote operating system were briefly reviewed. It was assumed that a replacement system purchase cost would be similar to the cost of the original system. The new system would have a life-cycle period of 25 years and would require annual maintenance and labor costs similar to the existing system. Under these assumptions, a replacement system would accrue $\$ 109,386$ in costs annually. Detailed specifications and costing of a replacement system were not pursued. However, the cost assumptions used provide a proper comparative perspective for reviewing dam operational alternatives.

Based on this analysis, the most cost efficient alternative for dam operations appears to be maintenance of the existing Remote Operation System (Alternative 1). This would be the least cost plan for the short term (5-year period of analysis) and for the longer term, under the assumption that annual maintenance costs would not increase dramatically.

\section{Recorded Gate Operations and Inclinometer Readings}

During the 12-month monitoring period, gate operations performed by the lock and dam operators were recorded on operation log sheets. The log of the recorded gate operations is listed in Table 9. The gate operation information recorded on these log sheets provided a means to correlate the displayed gate positions and times with the data recorded from the inclinometers of the instrumented gates. Figures 29 and 30 show the relationship of the raised and submerged gate openings obtained from the log sheets to the output of the inclinometers. Due to the design of the submersible tainter gates and the spillway sill, a transition zone exists for each gate between the raised position and submerged position at which no flow is initiated. This transition zone is the equivalent of $2 \mathrm{ft}$ of gate opening, $0.3 \mathrm{~m}(1 \mathrm{ft})$ in the raised position and $0.3 \mathrm{~m}$ $(1 \mathrm{ft})$ in the submerged position. As a result, a discontinuity in the linear relationship between the raised and submerged gate opening versus the angular position is evident in the plots shown in Figures 29 and 30. The transition between the raised and submerged "zero" flow position are incorporated into the digital displays of gate openings that are in the lock operation room.

\section{Ice Passage Data}

The winter months at Marseilles Dam, between 10/99 and 04/00, were characterized by little snowfall and above normal temperatures. Ice formation in 
the upper pool near the dam and the lock entrance canal was very light and

ephemeral. During this period of the data recording, the lock operation logs show only one operation for flushing of the ice through the dam. According to the operation logs, the ice flushing occurred on 01/25/2000 and lasted for $10 \mathrm{~min}$. The operations $\log$ entry $(01 / 25 / 2000)$ show that Gate 7 , an instrumented gate, was operated during the ice passage procedure and that it was lowered to a $-1.5 \mathrm{~m}$ $(-5.0 \mathrm{ft})$ position. At this position, the gate was held for only $10 \mathrm{~min}$ before being raised to the "zero" position. The preprogrammed time delay of the data acquisition system (15 $\mathrm{min}$ ) was too long to obtain the vibration levels for this submerged gate position. By the time data recording was initiated, all the gates were in the "zero" position. The $-1.5 \mathrm{~m}(-5.0 \mathrm{ft})$ gate position was the lowest submerged setting made during the winter months and no vibration data were obtained.

\section{Winter of 2000 time-lapse video of ice passage}

Table 10 summarizes the ice observations from the time-lapse videotapes. Before 21 January, the image area was ice-free. On that morning, a thin black sheet of ice covered the pool. All gates were submerged $0.2 \mathrm{~m}(0.5 \mathrm{ft})$ except for Gate 7, which was submerged $0.6 \mathrm{~m}(2 \mathrm{ft})$. The ice cover remained intact until 11:40 on 25 January when a towboat made several passes in front of the dam to fracture the ice. Gate 7, on the right hand side of the dam, was opened to $1.5 \mathrm{~m}$ ( $5 \mathrm{ft}$ ) for about $10 \mathrm{~min}$ to help clear out the ice and by 13:00, most of the ice had cleared the dam. Figure 31 shows vibration data surrounding the ice passage period. The greatest accelerations were in the 85 to 100 milli-g range occurring at Gates 3 and 1, which were submerged only $0.2 \mathrm{~m}(0.5 \mathrm{ft})$ and may have felt more impact from the passing floes than Gate 7, which was submerged $1.5 \mathrm{~m}(5 \mathrm{ft})$.

By the next morning, 26 January, thin black ice had reformed on the pool. This cover remained in place until about 13:00 on 28 January when strong easterly winds flooded the ice cover's upstream edge and moved the sheet towards the dam. Within half an hour, most of the ice on the pool had moved past the central gates on the dam, which were submerged $0.2 \mathrm{~m}(0.5 \mathrm{ft})$ at the time. The greatest accelerations, in the 95 to 145 milli-g range, occurred at centrally located Gates 5 and 3 (Figure 32).

During 29 and 30 January, the pool was open, with intermittent disperse floes passing. At dawn on the morning of 31 January, fractured floes filled the image area (Figure 33) At this time the gate openings were even at $0.4 \mathrm{~m}(1.5 \mathrm{ft})$. At 07:17, strong westerly winds caused the ice on the left side of the pool to shift upstream. At 07:27 the ice floes on the left side of the pool moved downstream and began to pass Gates 1 and 2. Between 07:30 and 07:50, the ice on the right hand side of the pool began moving, and at 07:50, the central ice moved. After 08:04, the pool was, for the most part, ice-free.

The 31 January ice passage resulted in greater accelerations than the previous two events as shown in Figure 34. It also appears from the acceleration data that a quantity of ice passed the dam in the darkness at around 04:00 a.m. Shortly after 
08:00, the maximum acceleration for Gate 7 was 570 milli-g's. Because Gate 7 lies outside of the image area, it is unclear what caused this high value.

\section{February 1988 video of ice passage at Gate 1}

During the winter of 1988, CRREL installed a video camera on top of the south embankment on the downstream side of Gate 1. The winter of 1988 was average in terms of air temperature (Figure 7). Video footage shows much light to moderate ice passing the submerged gate between 4 and 11 February. On 8 February, a towboat broke up the ice cover in front of the dam and the video

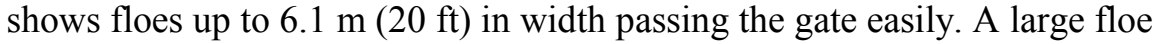
lodged itself on the right hand pier until the tow backed in and washed it past the gate (Figure 35)

\section{Upper Pool and Tailwater Elevation Variation}

The Marseilles Lock and Dam upper pool and tailwater elevations are recorded and maintained by the Rock Island District. Figures 36-39 are the tabular water level records for the 12-month study period that were posted on the Rock Island District Web site. Figure 40 is the time-history of the Illinois River stages at Marseilles, IL, for the calendar year 2000. The upper pool level elevations listed indicated a variation between 483.2 and 483.65 during the 12-month data collection period. The slight variation in the pool level is the result of the strict "flat pool" elevation requirements to meet the required navigation depth for commercial navigation. During the data collection period, no significant rises in river stage occurred until the spring of 2000 requiring gate openings as large as $2.1 \mathrm{~m}(7.0 \mathrm{ft})$ on one of the instrumented gates to pass the high river flows.

\section{Gate Vibration Level Recordings}

During the data collection period, the project operations personnel, to regulate the upper pool elevations, used various gate openings and combinations of gates. In general, the strict tolerances for maintaining the level of the upper pool resulted in the majority of the gate openings (raised or submerged) to be less than $\pm 0.6 \mathrm{~m}$ $(2.0 \mathrm{ft})$.

Due to the voluminous amount of data recorded during the 12-month study period, it would be impractical to reproduce multiple redundant listings and plots of vibration levels recorded for the same gate openings. Therefore, only representative data are provided in this report to illustrate the vibration effects of the more typical gate operations as well as those of the maximum gate openings. Tables 11 - 23 list the vibration levels for a representative selection of the gate operations. Figures $41-82$ are graphical representations of the vibration magnitudes and resulting displacements. 


\section{Raised Gate Vibration Levels}

Flow releases from Marseilles Dam, during the spring, summer and fall of the year, are generally performed with the gates operated in the raised position. The gate operations during these seasonal periods can be characterized as typically small gate openings for short durations (hours) to maintain the upper pool water levels. The majority of the raised position gate openings for discharge of normal river inflows were recorded to be no greater than $0.9 \mathrm{~m}(3.0 \mathrm{ft})$. The vibration levels recorded at these small openings indicated no significant increase from background noise levels recorded when the gates were in the closed position. This is illustrated through a comparison of the vibration levels shown in Table 11 (no instrumented gates open) with those vibration levels presented in Tables 1214 for various single gate openings.

In general the vibration levels and displacements were extremely small (less than $0.3 \mathrm{~g}$ 's and less than $0.002 \mathrm{~cm}(0.001 \mathrm{in}$.), respectively). These values represent the predominant vibration levels and displacements to which the gates are subjected for the particular gate openings during a particular segment of time.

For periods when a significant rise in river stage occurs, as indicated in Figure 40 between the periods April - July 2000, multiple gate operations are required to pass the inflows. These gate operations are characterized by larger raised gate openings $1.5-2.1 \mathrm{~m}(5.0-7.0 \mathrm{ft})$ for longer periods of time (days) to maintain the upper pool water levels.

The summaries of vibration levels recorded for the various instrumented gates operated at the larger openings during this period are presented in Tables $15-19$. Tables 15-16 and Figures $41-52$ are representative sampling of vibration levels occurring with two-gate operation for gate openings ranging from $0.6-1.5 \mathrm{~m}(2.0$ $-5.0 \mathrm{ft}$ ). Tables 17- 19 and Figures $53-79$ are a representative sampling of the vibration levels occurring with a three-gate operation and gate openings ranging from $0.3-2.1 \mathrm{~m}(1.0-7.0 \mathrm{ft})$. The maximum values of vibration level and displacement observed during these operations were $0.20 \mathrm{~g}$ 's and $0.005 \mathrm{~cm}(0.002$ in.), respectively. These values represent the predominant vibration levels and displacements to which the gates are subjected for the particular gate openings during a particular segment of time and indicate that very insignificant movement is occurring for these raised gate operation conditions.

\section{Submerged Gate Position Vibration Levels}

Flow releases from Marseilles Dam, during the winter months of the year, are generally performed with the gates operated in the submerged position. The gate operations during these seasonal periods can be characterized as typically small gate openings for short durations (hours) to maintain the upper pool water levels. The majority of the submerged position gate openings for discharge of normal river inflows were recorded to be no greater than $-0.6 \mathrm{~m}(-2.0 \mathrm{ft})$. 
The vibration levels recorded at these small openings indicated a relative increase above those observed from background noise levels recorded when the gates were in the closed position. This is illustrated through a comparison of the vibration levels shown in Table 20 (no instrumented gates open) with those vibration levels presented in Tables 21-23 for various single and multiple gate openings.

In general the vibration levels and displacements were extremely small (less than $0.3 \mathrm{~g}$ 's and less than $0.002 \mathrm{~cm}$ (0.001 in.), respectively). Tables 21-23 and Figures $80-82$ are a representative sampling of the vibration levels occurring with a four-gate submerged operation and gate openings ranging from $0.4-0.6 \mathrm{~m}$ $(1.5-2.0 \mathrm{ft})$. The maximum values of vibration level and displacement observed during these operations were $0.06 \mathrm{~g}$ 's and $0.005 \mathrm{~cm}$ (0.002 in.), respectively. These values represent the predominant vibration levels and displacements to which the gates are subjected for the particular gate openings during a particular segment of time and indicate that very insignificant movement is present for these submerged gate operation conditions. 


\section{Conclusions and Recommendations}

\section{Conclusions}

The monitoring program for Marseilles Dam on the Illinois River was very successful. The following is a summary of the observations made from the data collected over the 2-year duration of the program.

A Life Cycle Cost (LCC) analysis was conducted for three alternatives identified for operation of the Marseilles Dam: maintenance of the existing remote operation, manual operation, and replacement of the remote operating system. The LCC analysis investigated construction costs + repair costs + labor costs of the Remote Operating System (ROS) vs. the costs of the four full-time dam employees that the ROS replaced.

a. Alternative 1 - maintain existing remote operation. The original cost of the ROS is a sunk cost and was not considered in comparing alternative costs for a future operating period. Based on yearly cost records, the existing system has averaged $\$ 5,819$ in annual maintenance costs. The existing system also requires $\$ 12,074$ in annual labor costs for dam operation, which includes labor charges for operations during icing and nonicing periods.

b. Alternative 2 - manual operation. The dam was operated manually prior to 1988. This procedure required four full-time workers for a $24-\mathrm{hr} /$ day operation. The costs associated with manual operations totaled $\$ 185,869$ annually. These costs were stated at 1999 labor rates for the appropriate average wage-grade range.

c. Alternative 3 - replace remote operating system. The costs for a replacement of the existing remote operating system were briefly reviewed. Assuming that a replacement system purchase cost would be similar to the cost of the original system, the new system would have a life-cycle period of 25 years and would require annual maintenance and labor costs similar to the existing system. Under these assumptions, a replacement system would accrue $\$ 109,386$ in costs annually. However, the cost assumptions used provide a proper comparative perspective for reviewing dam operational alternatives. 
Based on this analysis, the most cost-efficient alternative for dam operations appears to be maintenance of the existing Remote Operation System (Alternative 1). This would be the least cost plan for the short term (5-year period of analysis) and for the longer term, under the assumption that annual maintenance costs would not increase dramatically.

The submergible gates at Marseilles Dam have greatly improved winter operation of the project. Submerging the gates during cold, low flow periods, with periodic cycling, eliminates freezing in the gates and the need for personnel to be on site. The costs and hazards of chipping ice, or thawing the gates with steam, have been eliminated by the new gate design. The remote operation system allows operation of the Marseilles Dam from a control room at the Marseilles Lock, approximately $3.9 \mathrm{~km}(2.4 \mathrm{mi})$ away, eliminating the need for $24-\mathrm{hr}$ shifts on the dam site and the costs associated with those shifts. The remote operating system was proven to be efficient and effective in maintaining the strict pool tolerance and improving winter operation of the dam. Trespassing at the dam site has increased, perhaps because of the lack of an official human presence at the dam, but the three surveillance cameras serve as a deterrent.

At typical winter discharges, the gates effectively pass fragmented floes and loose brash, in the submerged mode without loss of pool, or scour damage to the downstream channel. To pass heavy brash however, it is still necessary to concentrate the flow by opening one or two gates nearest the canal in the raised mode. To draw ice beneath requires an opening of at least $1.5 \mathrm{~m}(5 \mathrm{ft})$, and it may be necessary to pull the gate clear of the water, similar to the practice with the old tainter gates.

The videotape analysis used to analyze ice passage was successful. The technique is relatively low cost, logistically simple, and provided a valuable visual record for analysis of the efficiency of the gates to pass ice in the submerged mode.

When passing light ice, measurable vibration in the 0.1-to 0.3-g range occurred above a background range of 0.006 to 0.02 g's. Unfortunately, due to the mildness of the winter of 2000, no data were obtained while passing moderate or heavy ice.

Mild winter weather conditions resulted in very light ice formation in the upper pool near the dam and the lock. The project operations log for the instrumented gates indicated a very short duration of gate submergence (-1.5 m ($5.0 \mathrm{ft}$ ) for a 10 -min period) was used to initiate ice passage. The 10-min period was less than the data acquisition time delay $(15 \mathrm{~min})$ for steady flow to establish and the recording to be initiated. No vibration data were obtained for this operation.

The upper pool level elevations listed indicated a variation between 483.2 and 483.65 during the 12 -month data collection period. This indicates that the remote operation system meets the constraint of a tight pool tolerance. 
A significant rise in river stage occurred, as indicated in Figure 40, between the periods April - July 2000, and required multiple gate operations to pass the inflows. These gate operations are characterized by larger raised gate openings $1.5-2.1 \mathrm{~m}(5.0-7.0 \mathrm{ft})$ for longer periods of time (days) to maintain the upper pool water levels.

The vibration levels indicated that for these raised gate operation conditions very insignificant gate movement is present. The maximum vibration level values and displacement observed during these operations were $0.20 \mathrm{~g}$ 's and $0.005 \mathrm{~cm}$ (0.002 in.), respectively.

Flow releases from Marseilles Dam, during the winter months of the year, were generally performed with the gates operated in the submerged position. The gate operations during these seasonal periods are characterized as typically small gate openings for short durations (hours) to maintain the upper pool water levels. The majority of the submerged position gate openings for discharge of normal river inflows were recorded to be no greater than $-0.6 \mathrm{~m}(-2.0 \mathrm{ft})$. In general the vibration levels and displacements were extremely small (less than $0.3 \mathrm{~g}$ 's and less than $0.002 \mathrm{~cm}$ (0.001 in.), respectively).

Vibration levels were found to increase with four-gate submerged operation and gate openings ranging from $0.4-0.6 \mathrm{~m}(1.5-2.0 \mathrm{ft})$. The maximum values of vibration level and displacement observed during these operations were 0.06 g's and $0.005 \mathrm{~cm}$ (0.002 in.), respectively. The values represent very insignificant movement for these submerged gate operation conditions.

Failure to continuously operate the gates in the submerged mode for periods exceeding $15 \mathrm{~min}$ had a negative impact on the collection and analysis of data for submerged operation during ice passage. Extended operation exceeding $15 \mathrm{~min}$ was required to activate remote collection of data to validate model results.

The absence of significant movement obtained during normal operation of the gates in the raised position appeared to validate the two-dimensional model study, which indicated only random vibrations of less than 1 percent of the gate's weight.

\section{Recommendations}

The relatively warm winters during the period of this monitoring effort produced a significant reduction in ice, which limited the need for submergence of the gates. This reduced the value of the monitoring effort at Marseilles Dam. In the future, the duration of the monitoring effort should be flexible enough to allow extension to capture more incidents for ice passage. Additional time and costs associated with this extension should be considered. The monitoring effort should be conducted in areas where there are colder winters, higher volumes of ice, larger submersible gates, and known incidences of vibrations to increase the knowledge of operating constraints and better define the variables that induce vibrations at Corps projects. 


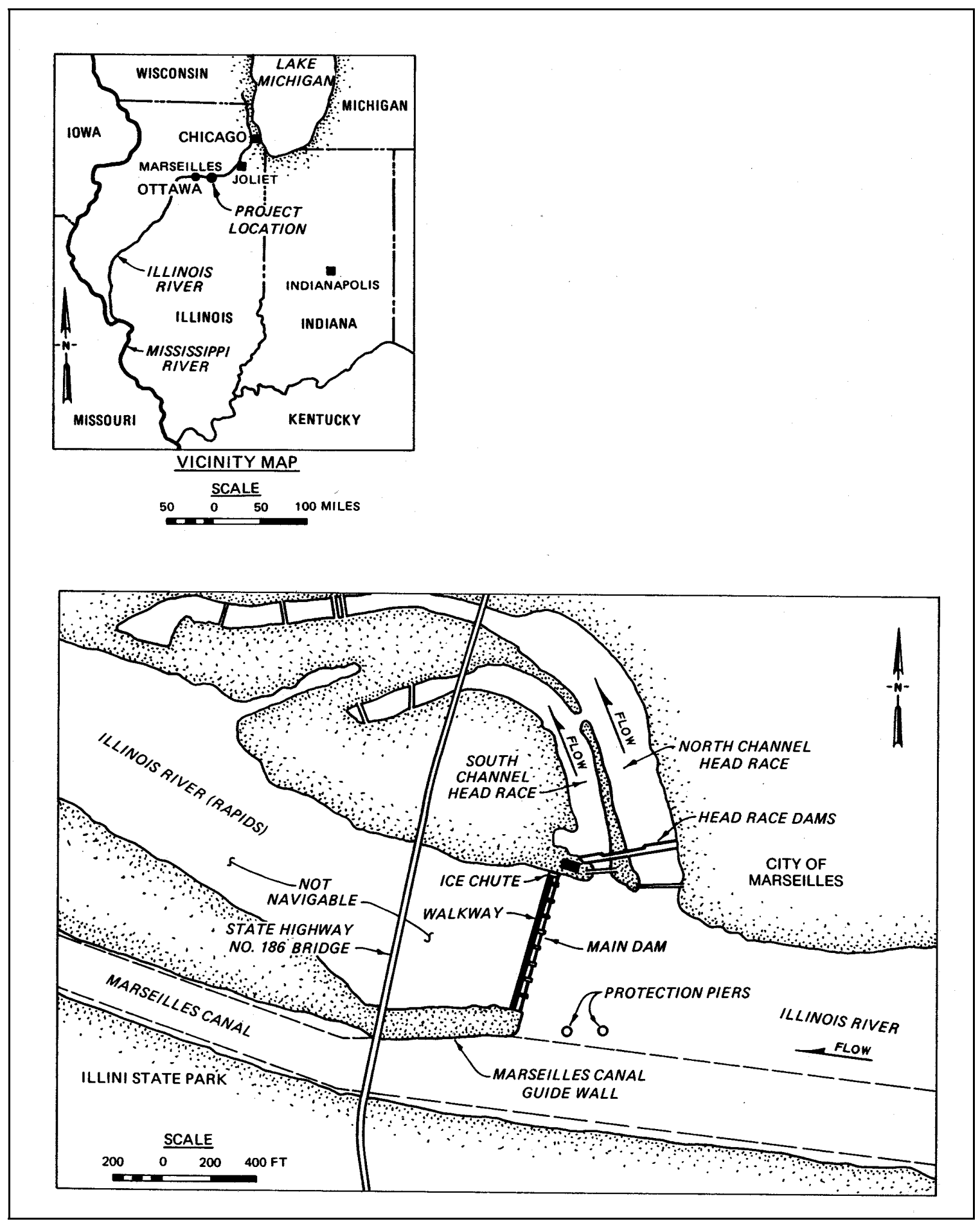

Figure 1. Project location 


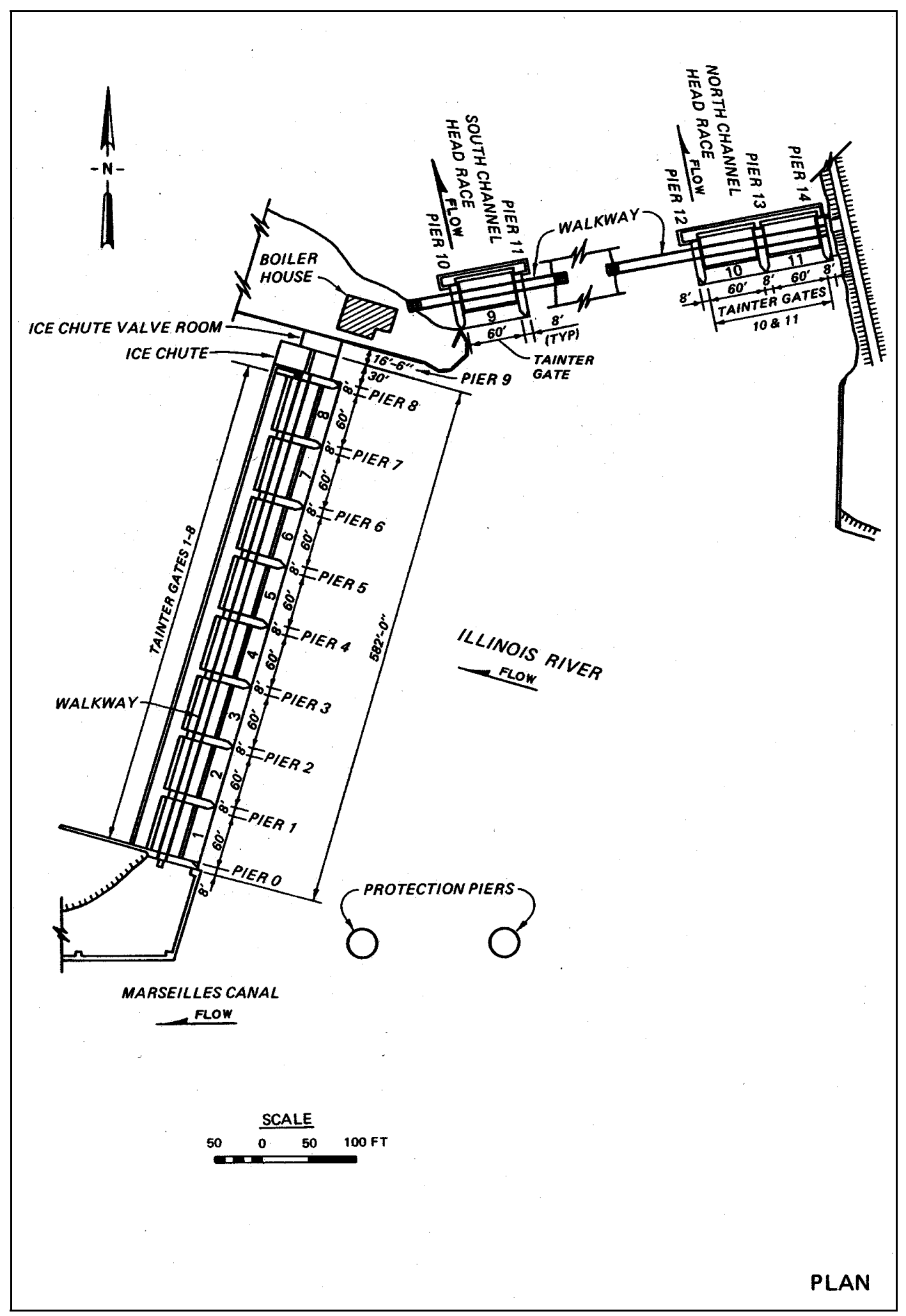

Figure 2. Plan view of Marseilles Dam 


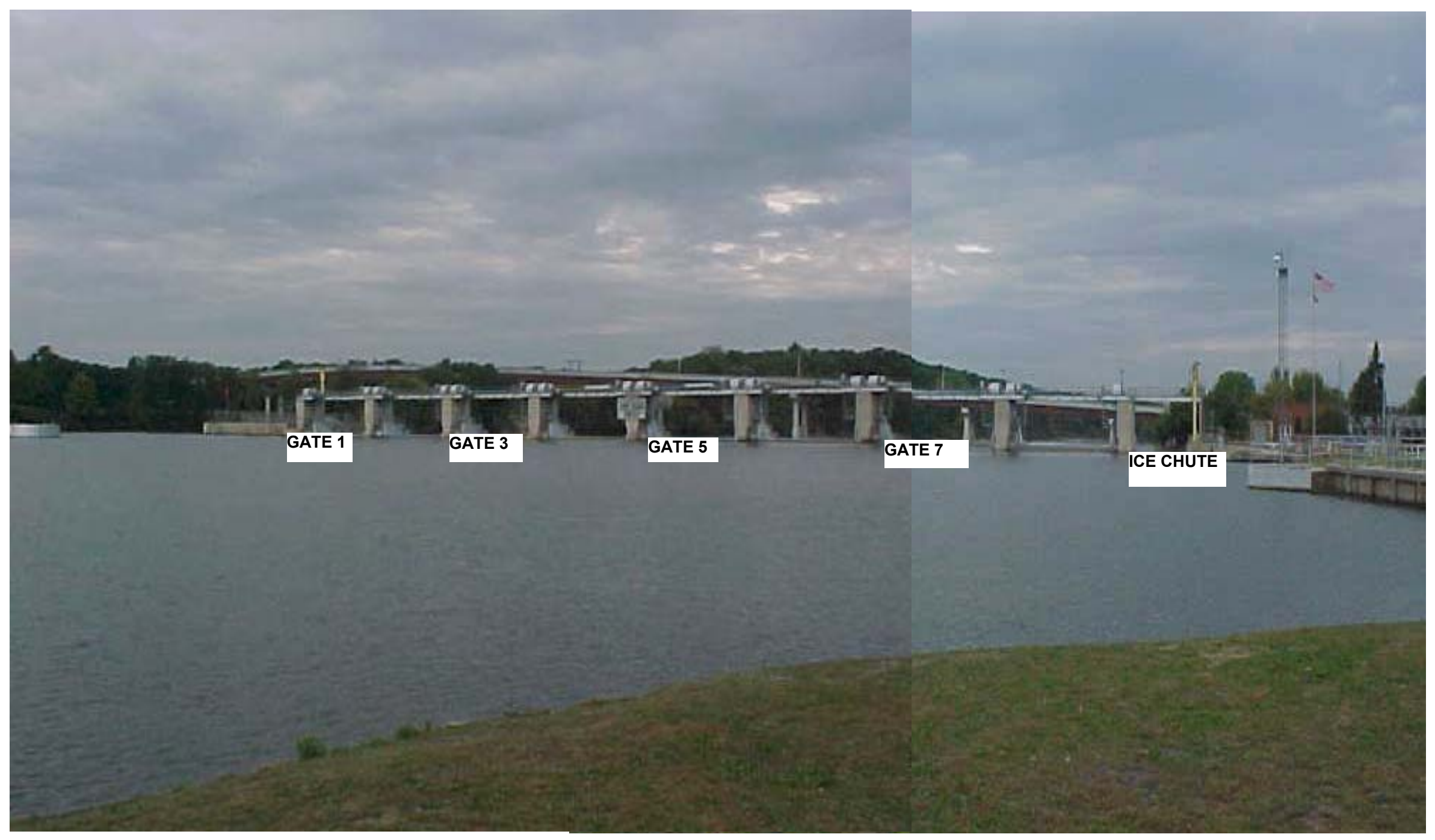

Figure 3. Upstream view of Marseilles Dam with instrumented gates identified 


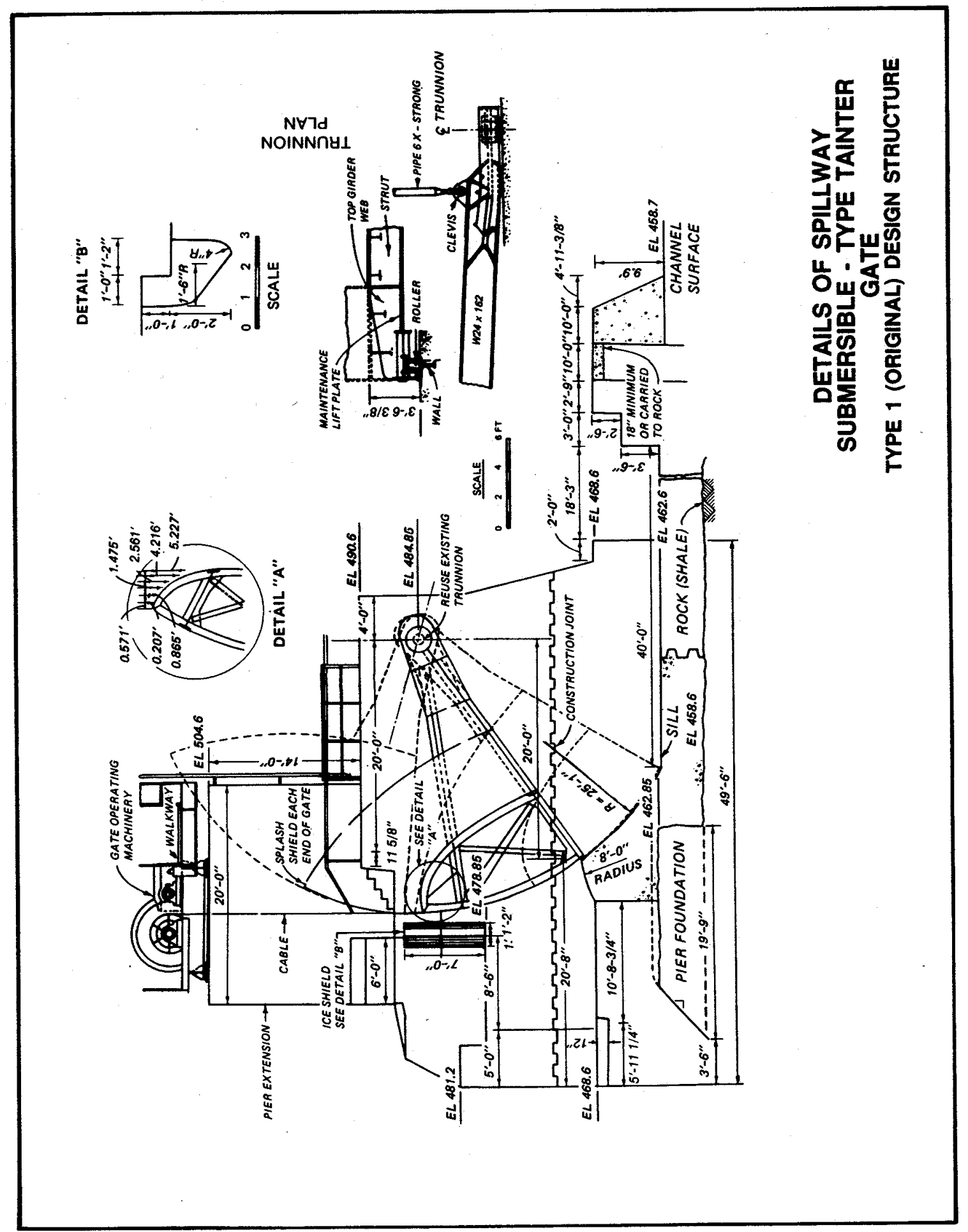

Figure 4. Submersible-type gate 


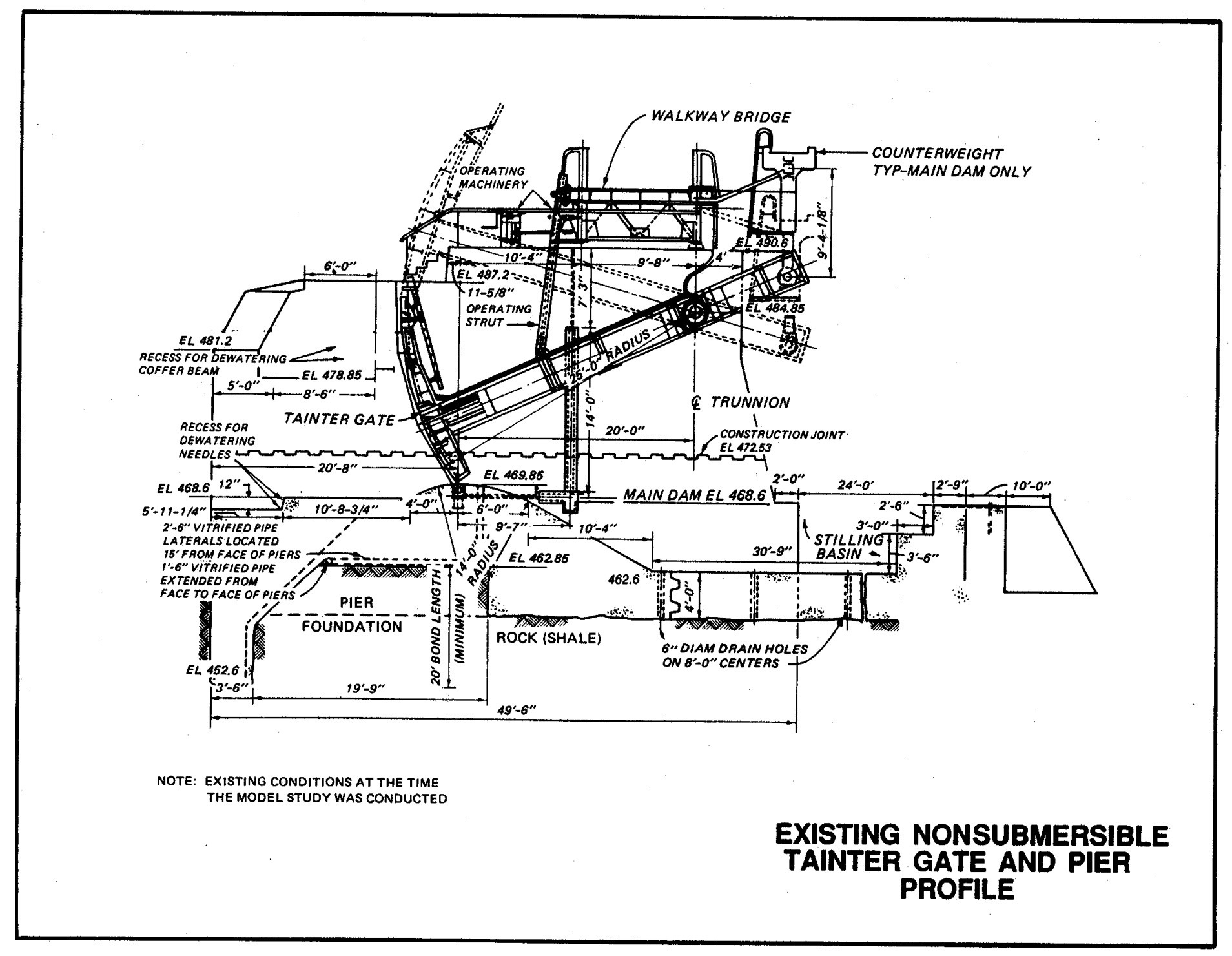

Figure 5. Nonsubmersible-type gate 


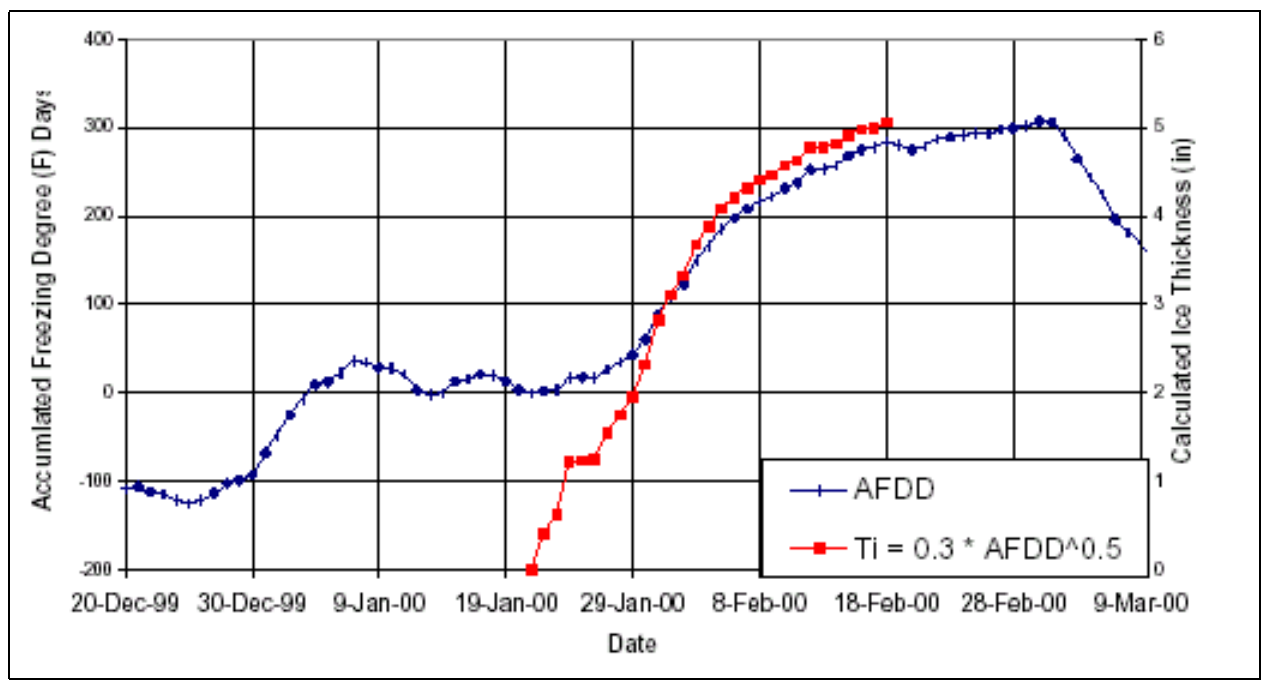

Figure 6. Accumulated freezing degree days at Chicago, IL, winter of 2000

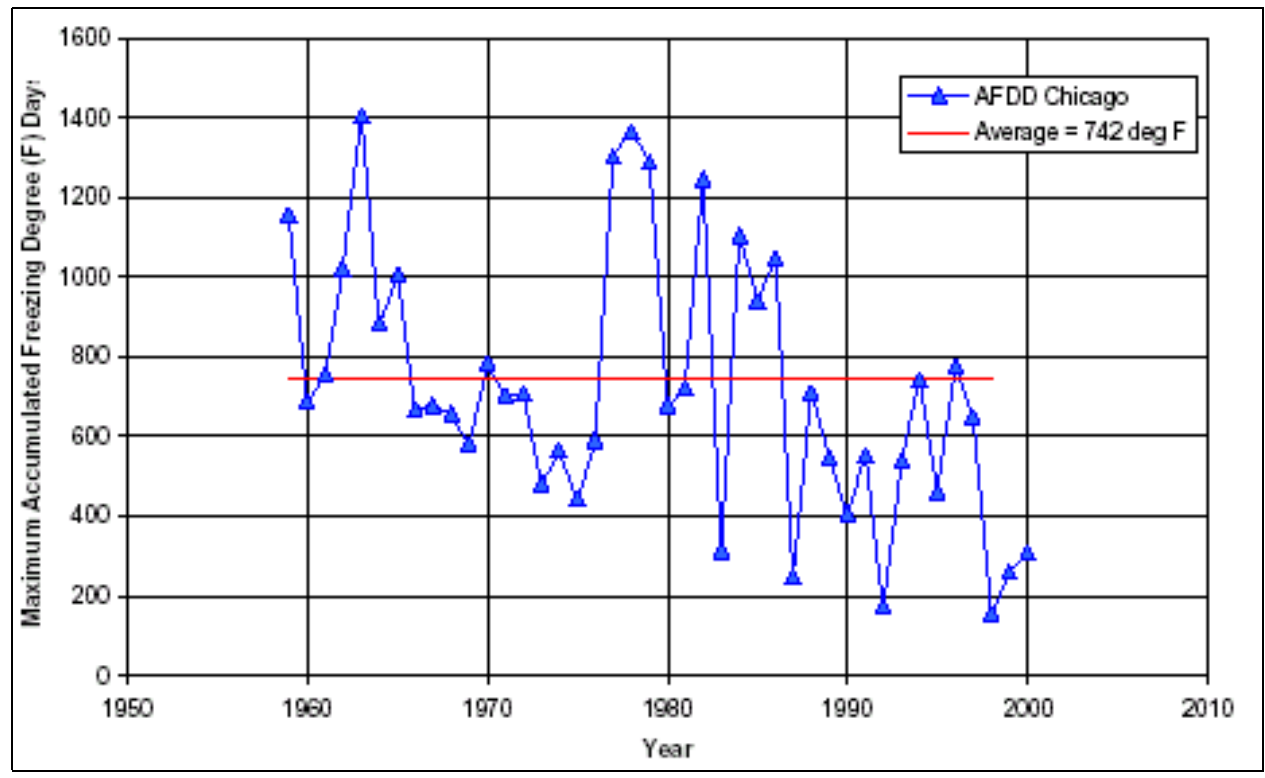

Figure 7. Maximum accumulated freezing degree days at Chicago, IL, 1959-2000 


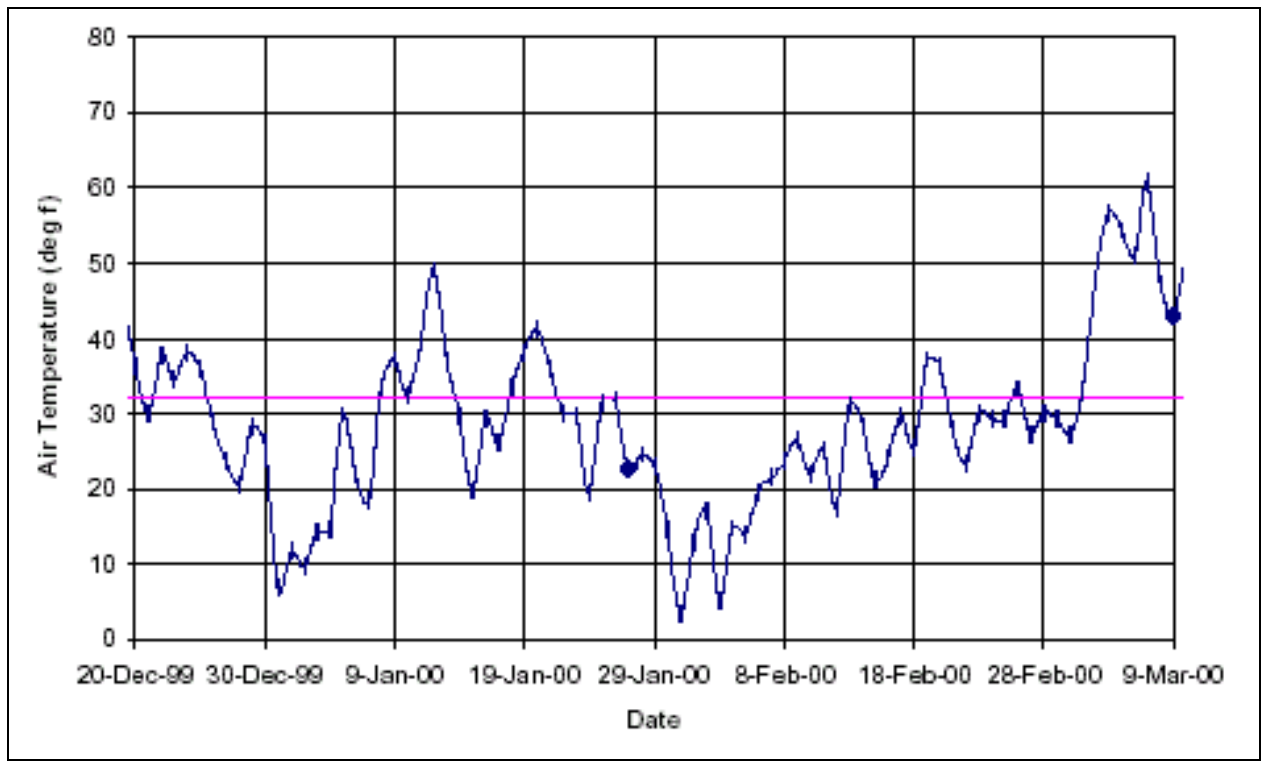

Figure 8. Daily average air temperatures at Chicago, IL, winter 2000

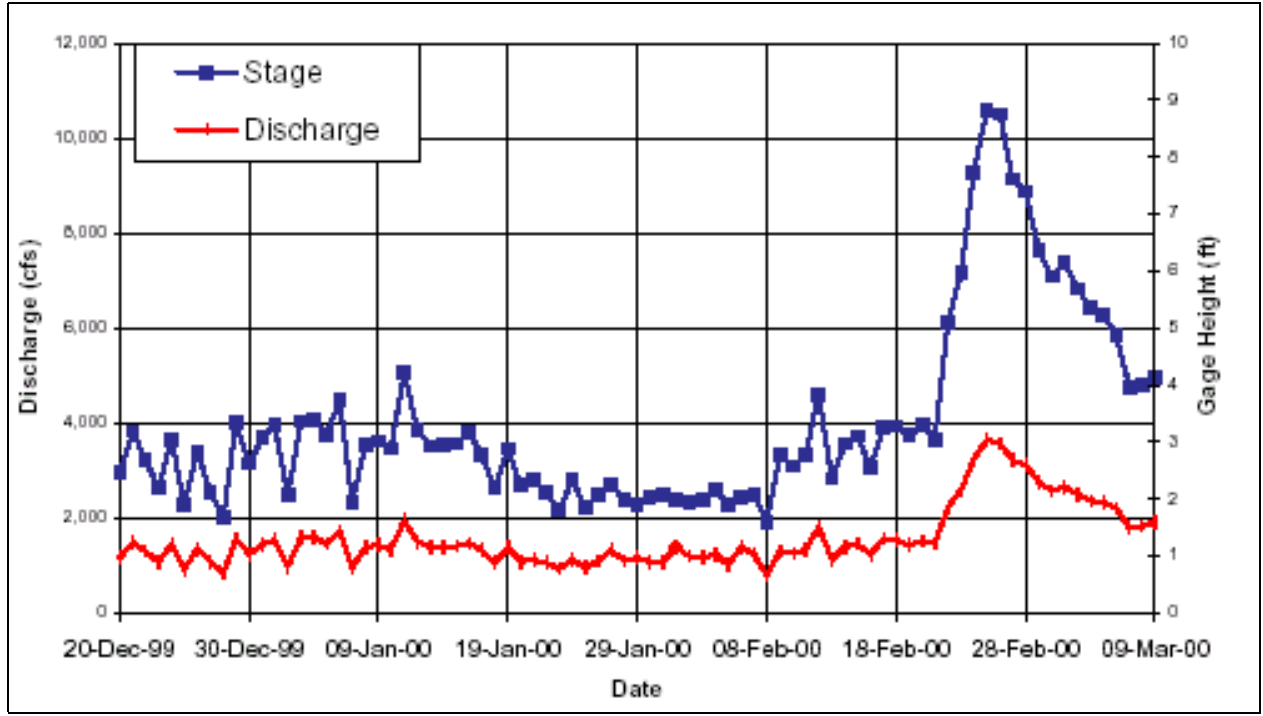

Figure 9. Daily average stage and discharge, Illinois River at Marseilles, IL, winter, 2000 


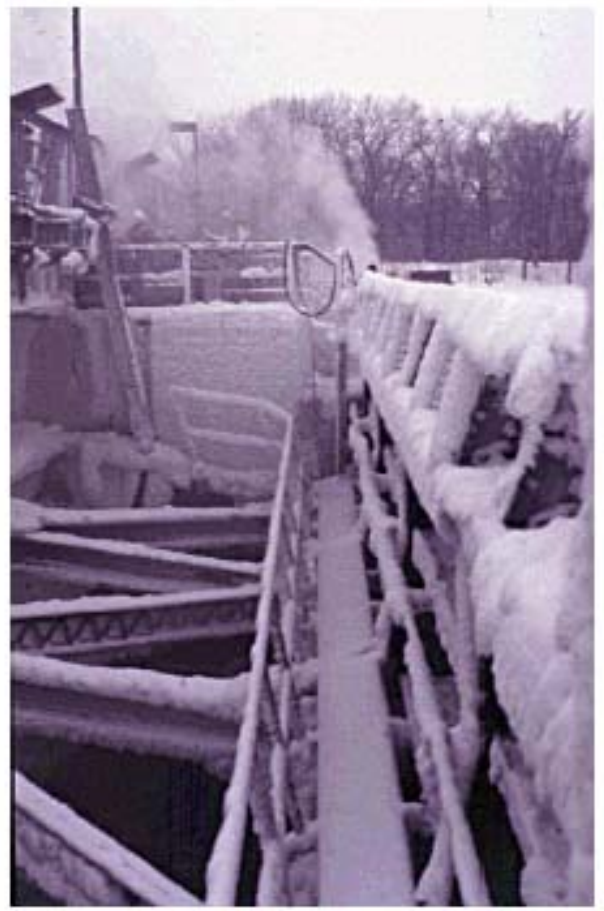

Figure 10. Steaming tainter gates at Dresden Island Dam

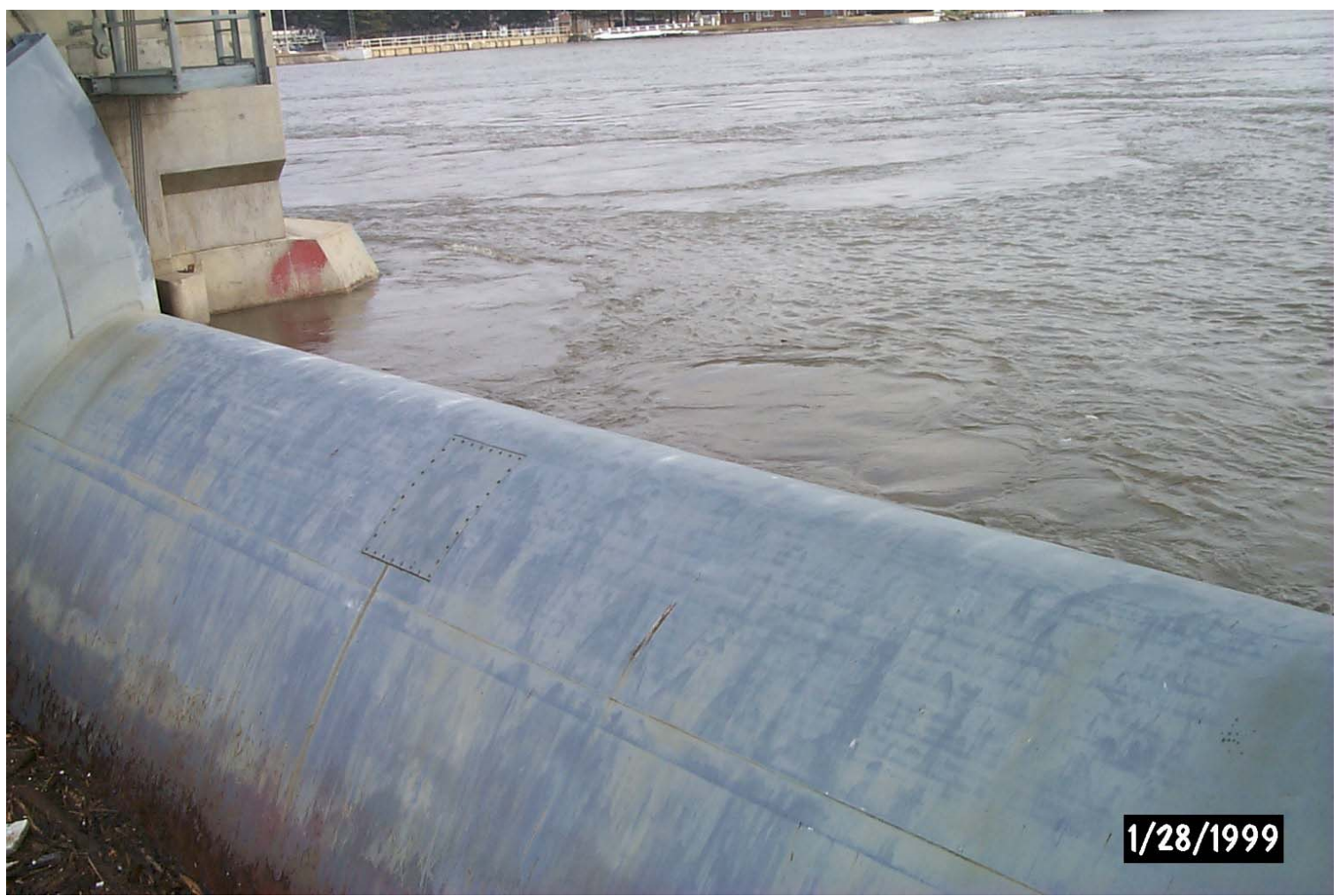

Figure 11. Submersible gate at Marseilles Dam in underflow mode 


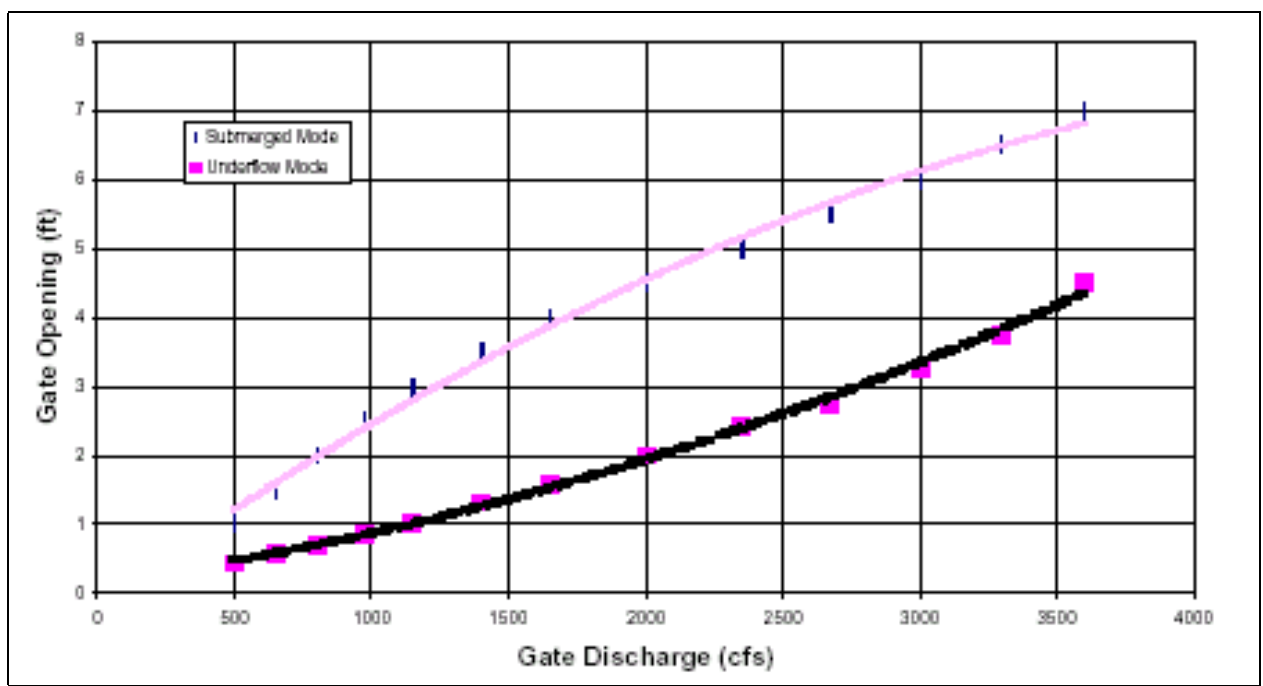

Figure 12. Approximate gate discharge vs. opening height at Marseilles

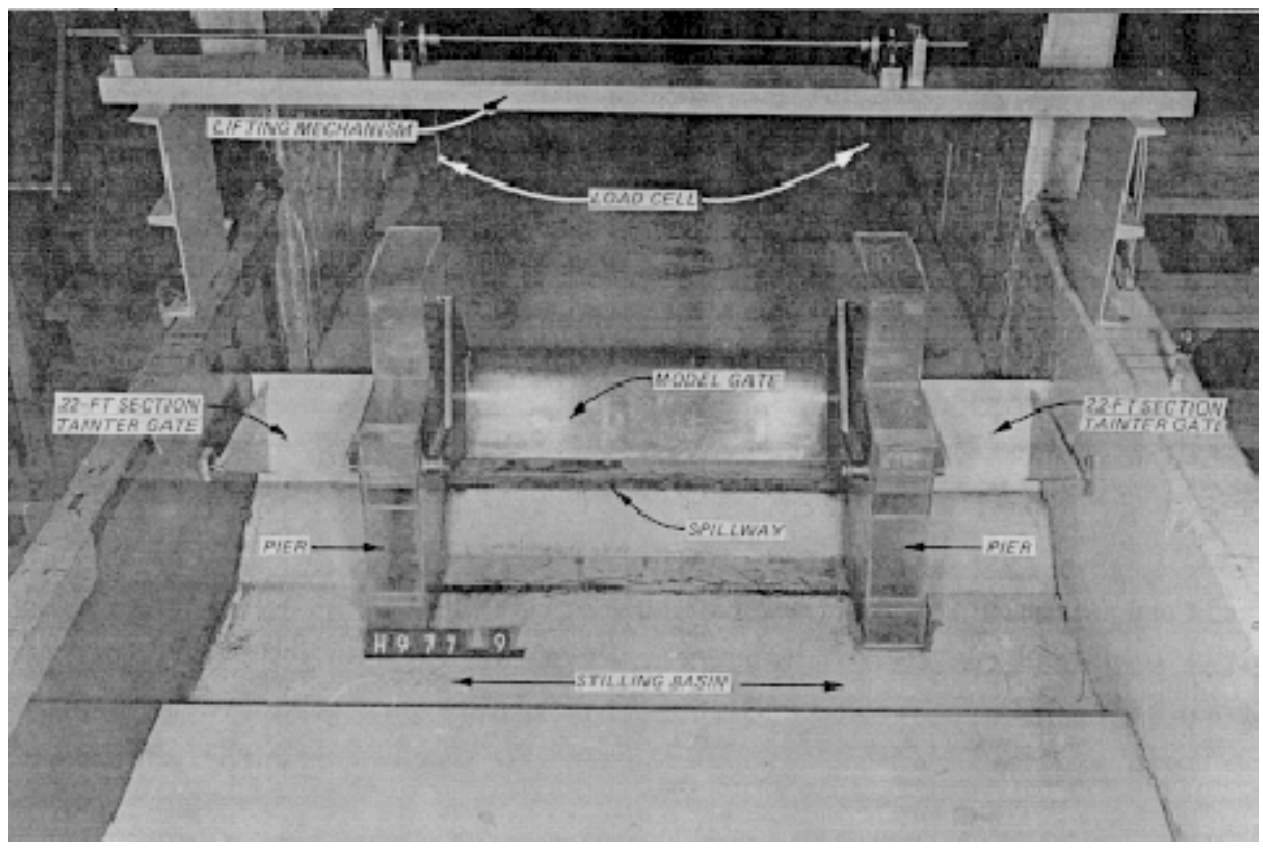

Figure 13. 1:20-scale 3-D physical model 


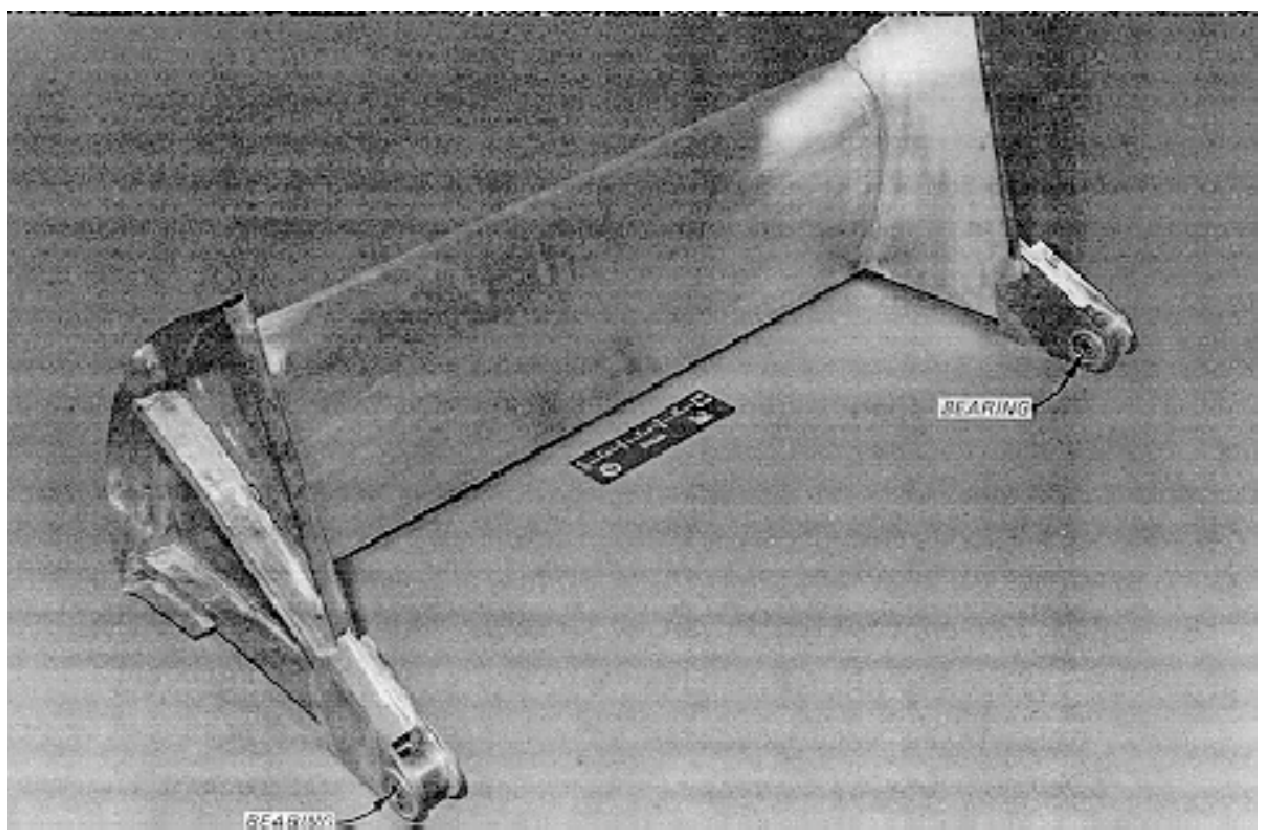

Figure 14. 1:20-scale model submersible tainter gate 


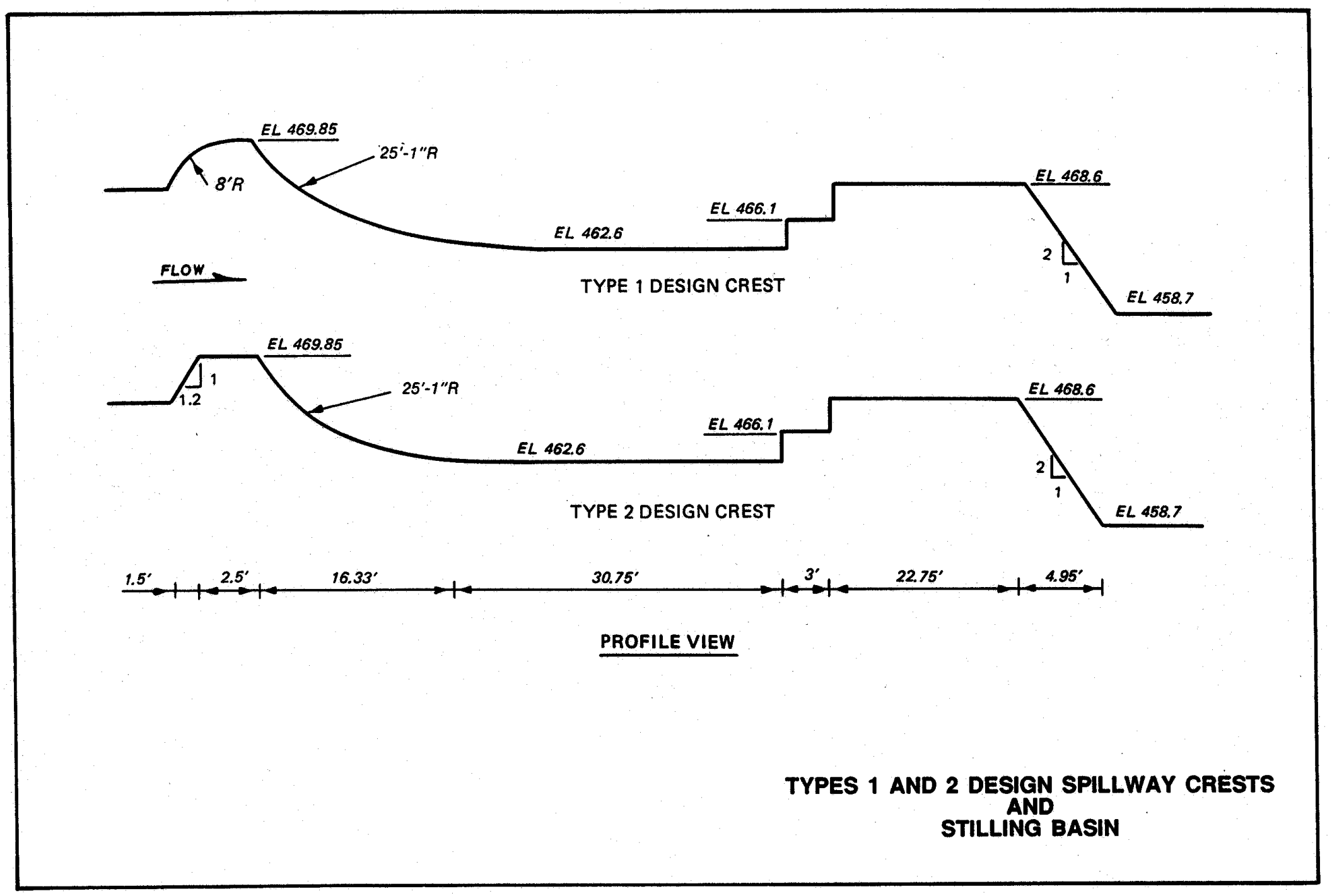

Figure 15. Types 1 and 2 design spillway crests and stilling basin 


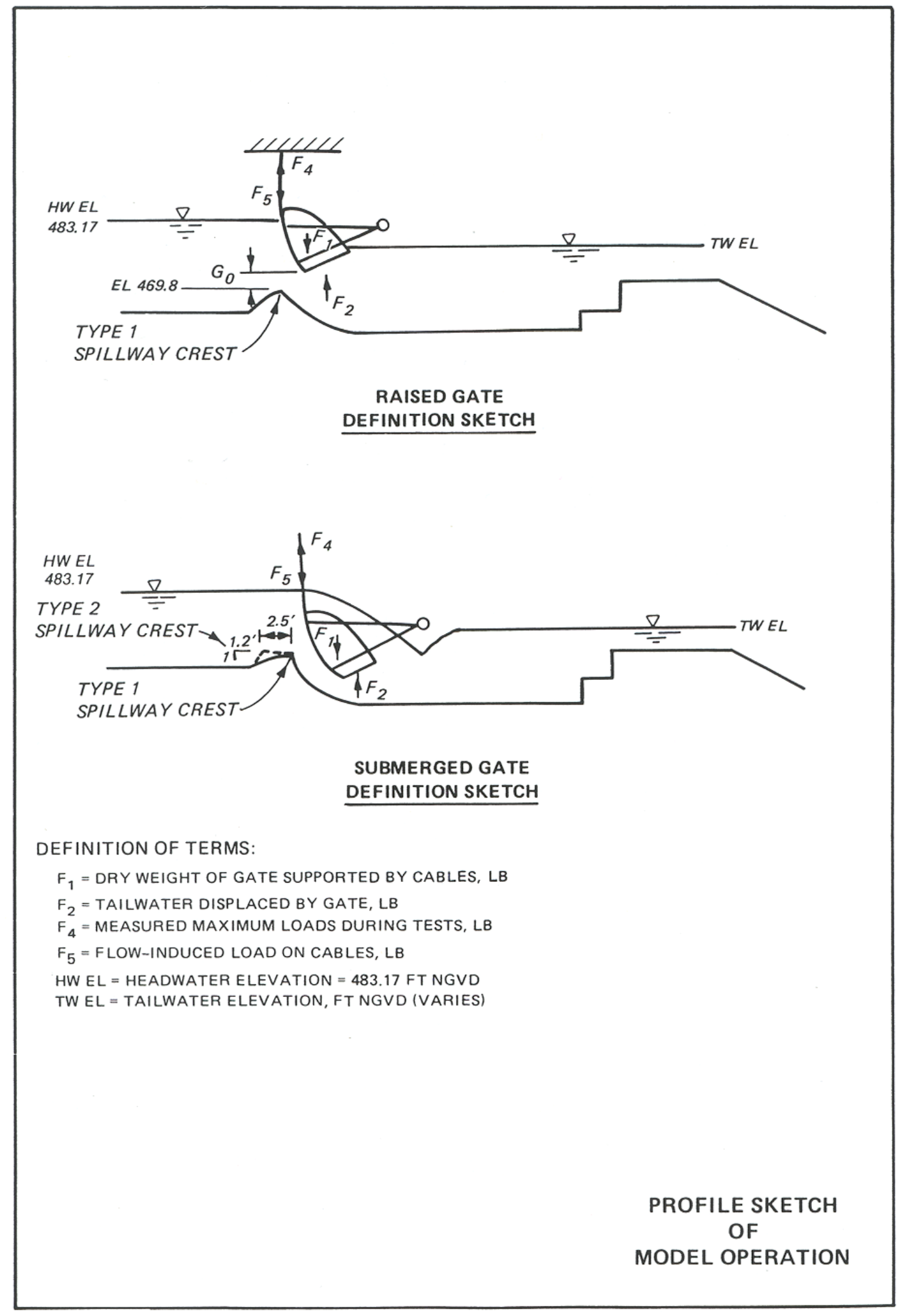

Figure 16. Profile sketch of model operation 


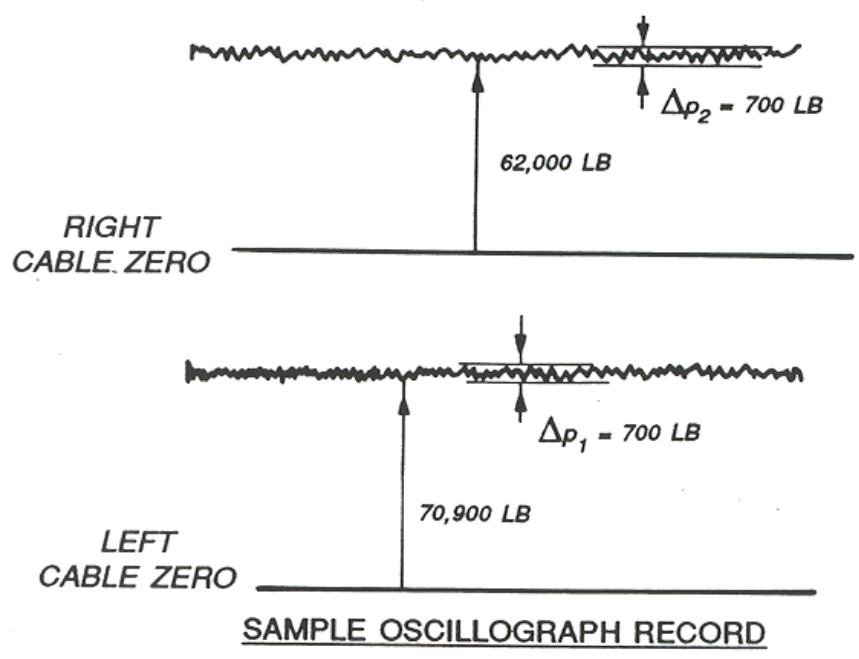

SAMPLE CALCULATION

GIVEN: GATE SUBMERGENCE $=1$ FT TW 470

TYPE 1 (ORIGINAL) APPROACH

$F_{1}=115,300 \mathrm{LB}$

$F_{2}=2,900$ LB

$F_{3}=F_{1}-F_{2}$

$\Delta \mathrm{p}=\Delta \mathrm{p}_{1}+\Delta \mathrm{p}_{2}$

$\Delta \mathrm{p}=700+700$

$F_{3}=115,300-2,900$

$\Delta p=1,400$ LB

$F_{3}=112,400 \mathrm{LB}$

$$
\begin{aligned}
& F_{4}=132,900 \mathrm{LB} \\
& F_{5_{\text {MAX }}}=F_{4}-F_{3} \\
& F_{5_{\text {MAX }}}=132,900-112,400
\end{aligned}
$$

$F_{5_{\text {MAX }}}=20,500$ LB

$F_{5_{\text {MIN }}}=F_{5_{\text {MAX }}}-\Delta_{p}$

$F_{5_{\text {MIN }}}=20,500 \mathrm{LB}-1,400 \mathrm{LB}$

$F_{5_{\text {MIN }}}=19,100$ LB

$f=3.4 \mathrm{HZ}$
DEFINITION OF TERMS:

$F_{3}=\left(F_{1}-F_{2}\right)$, SUBMERGED WEIGHT OF GA.TE SUPPORTED BY CABLES, LB

$\Delta_{p}=$ AMPLTUDE OF LOAD FLUCTUATINS, LB

$F_{5_{\text {MAX }}}=$ MAXIMUM FLOW-INDUCED LOAD ON CABLES $\left(F_{4}-F_{3}\right)$, LB

$F_{5_{\text {MIN }}}=$ MINIMUM FLOW-INDUCED LOAD ON CABLES $\left(F_{5 \text { MAX }}-\Delta_{p}\right)$, LB

$f=$ frequency of vibration

$\mathrm{HZ}=\mathrm{Hert}, \mathrm{cyles} / \mathrm{sec}$

SAMPLE FORCE

CALCULATION

AND

OSCILLOGRAPH RECORD

Figure 17. Model sample force calculation and oscillograph record 


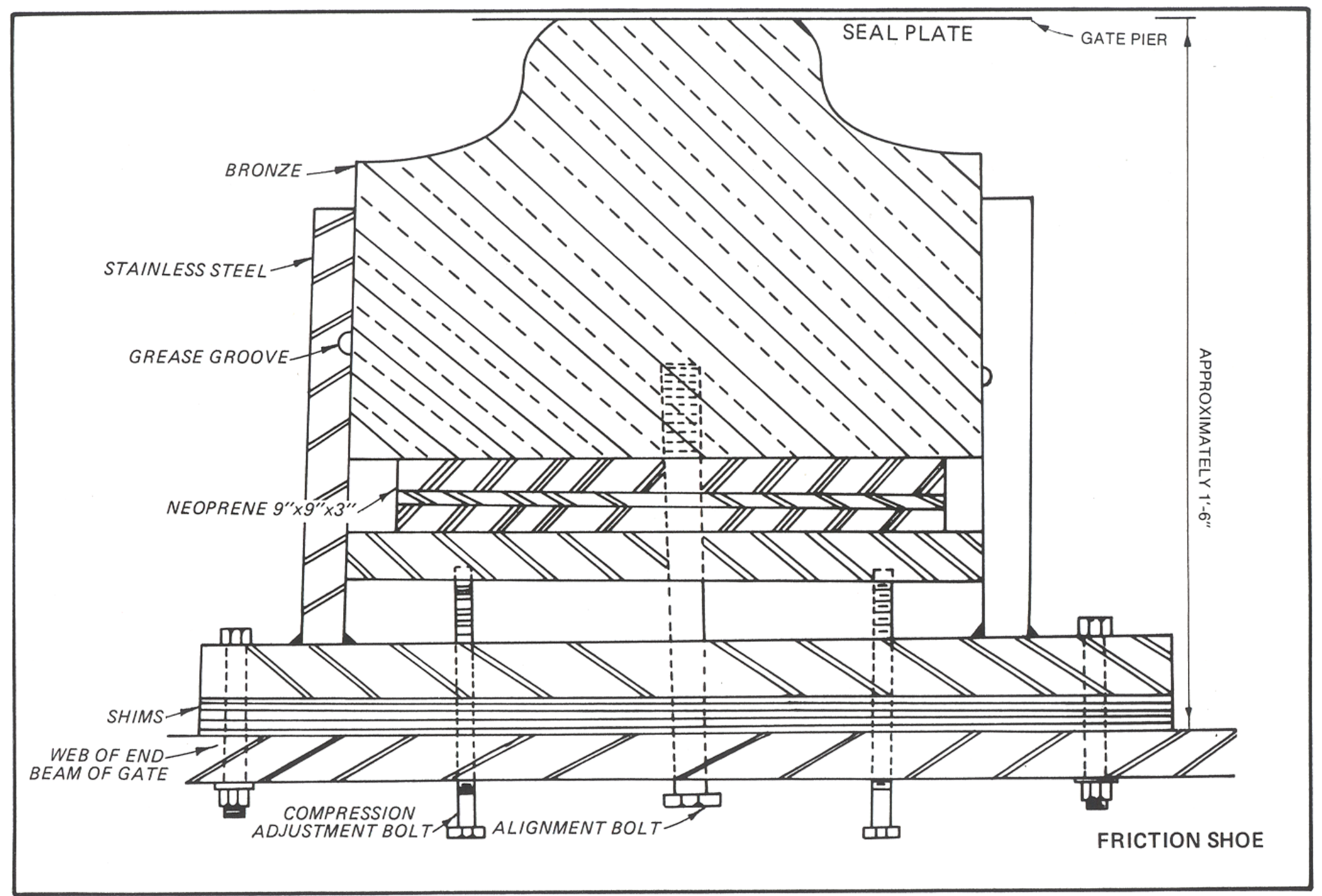

Figure 18. Friction shoe 


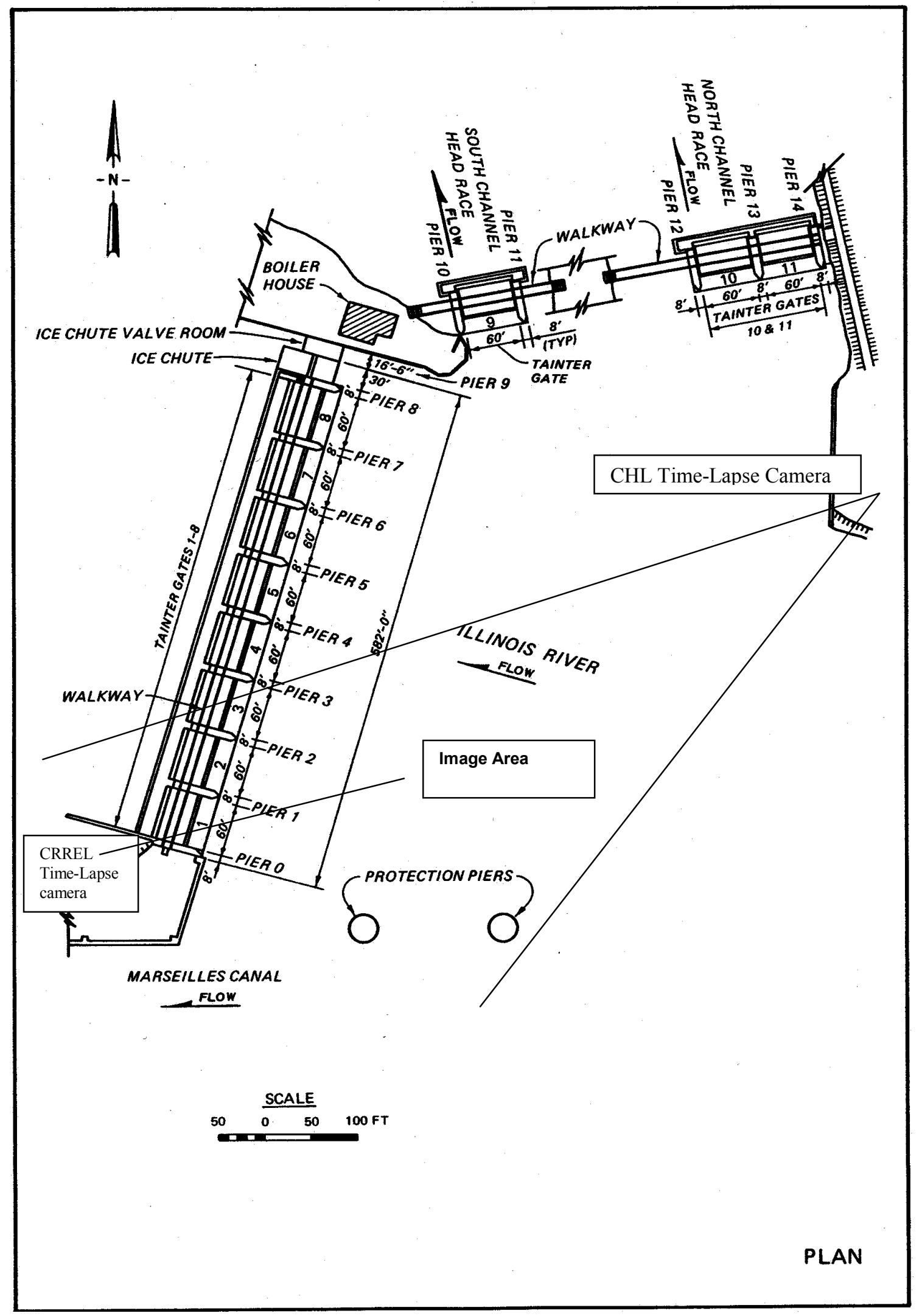

Figure 19. Site plan showing camera locations and fields of view 


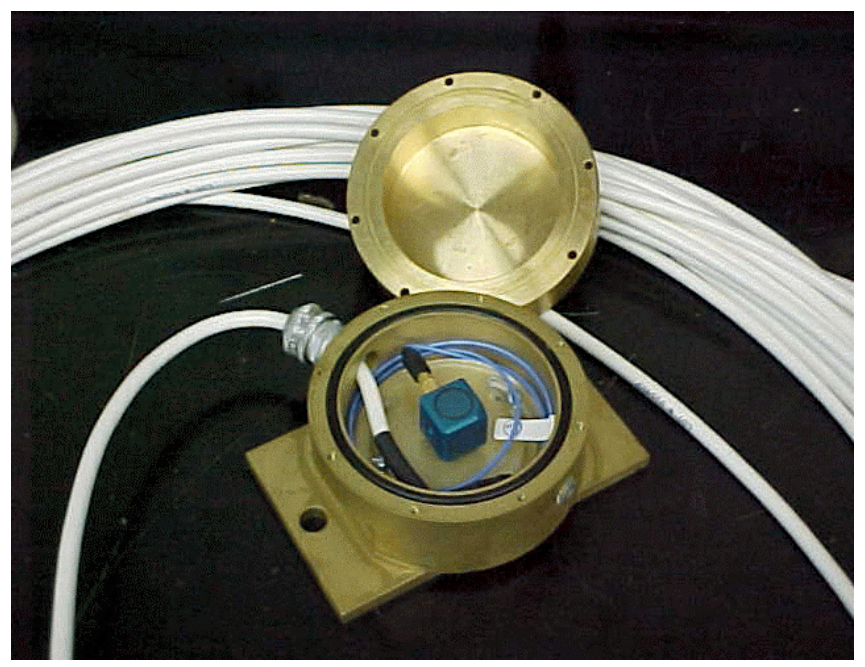

Figure 20. Triaxial accelerometer and protective housing

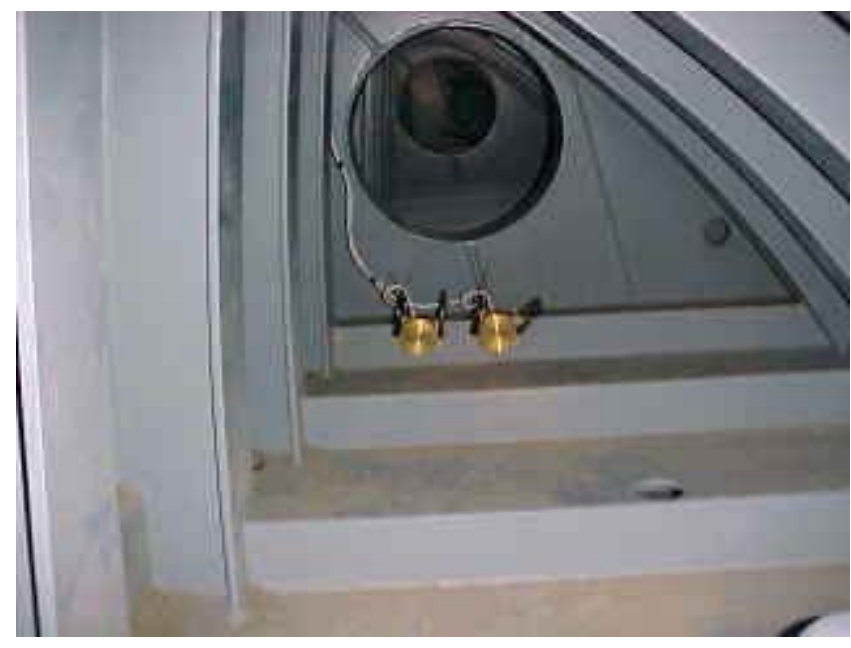

a. Sensors at the center of the gate

Figure 21. Accelerometer and tilt meter

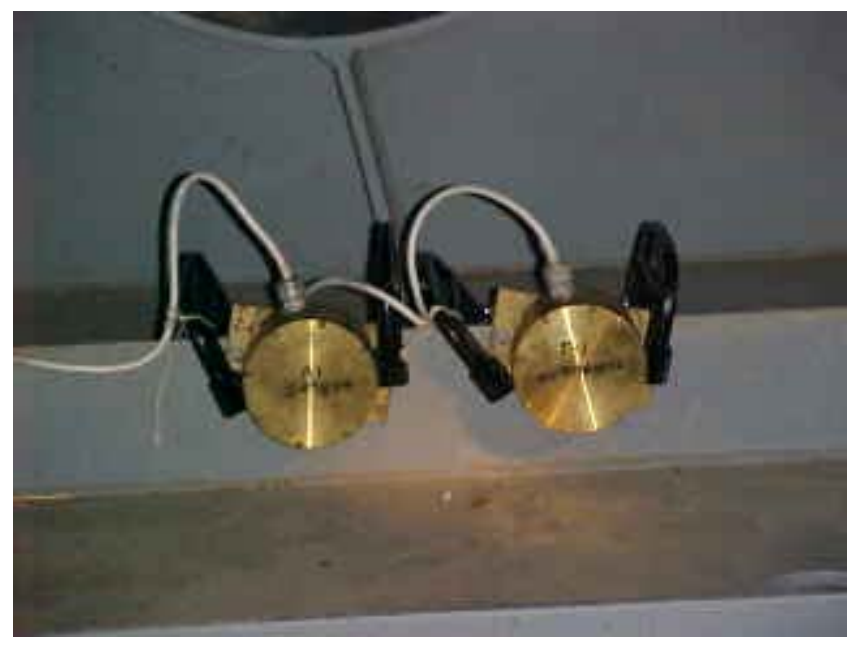

b. Accelerometer (left) and tilt meter (right) as installed inside the gate at Marseilles Dam 


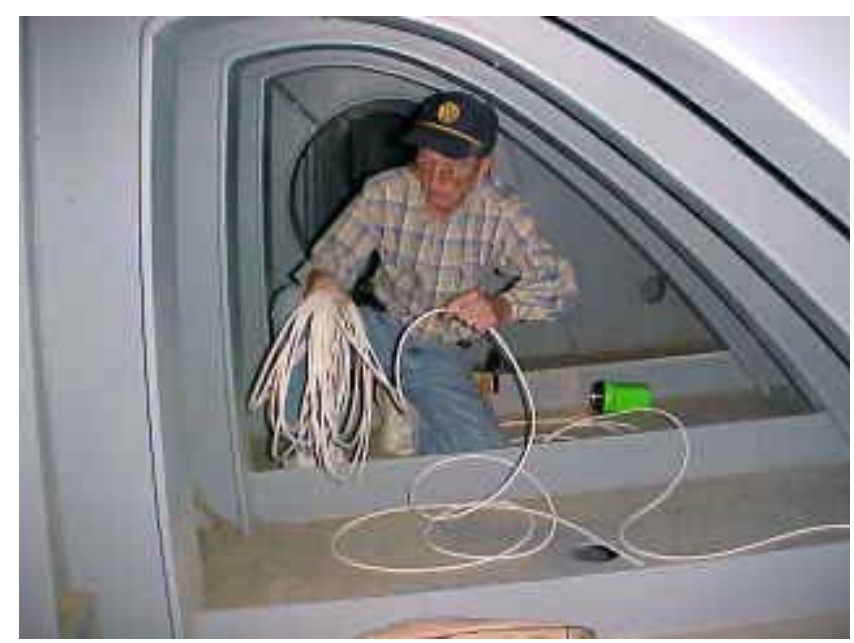

a. Getting instrument cable ready to pull to the top of the machinery access bridge

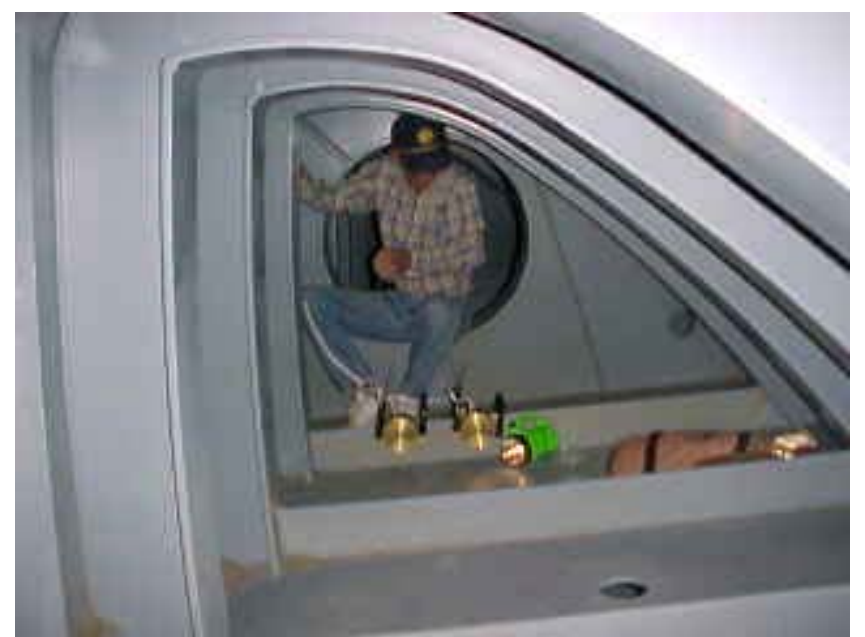

b. Pulling cable through the gate to the machinery access bridge

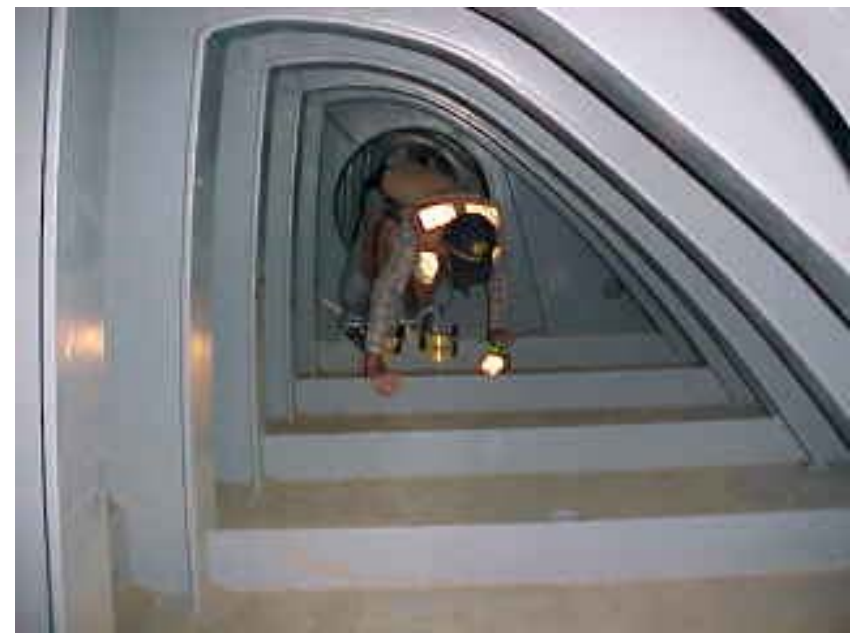

c. Exiting the gate after installing the instruments

Figure 22. Space limitations inside gate structure and instrument cable routing during installation 


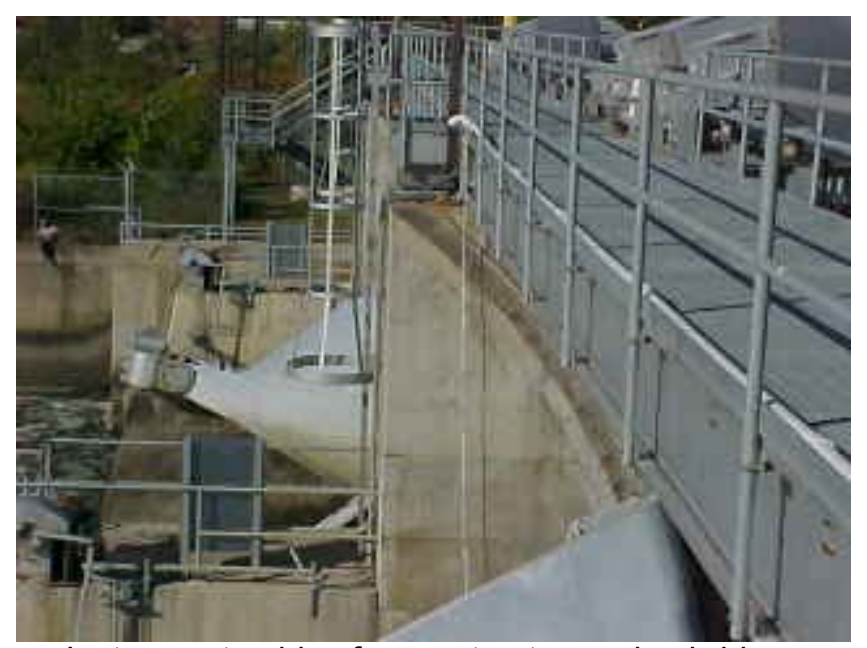

a. Instrument cables from gates to service bridge

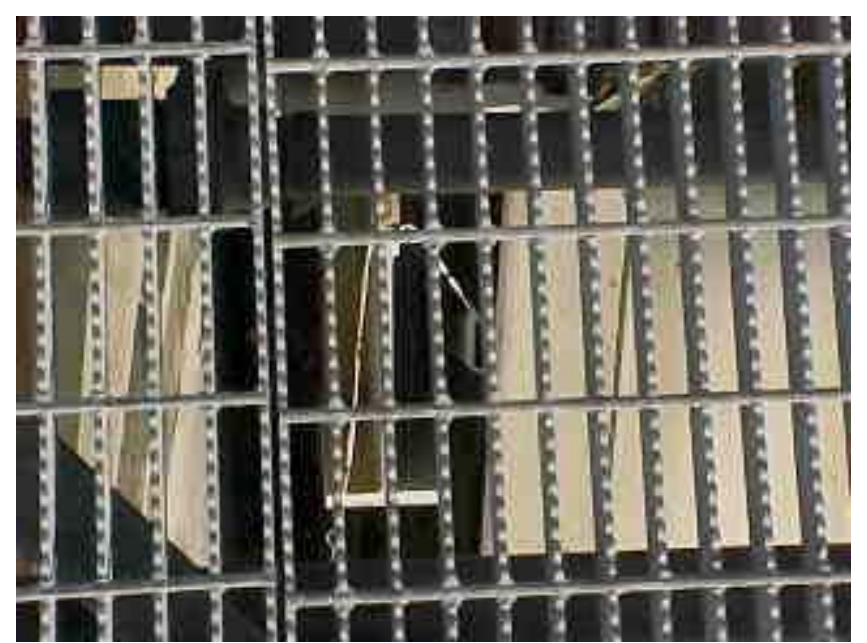

b. Instrument cables exiting gate air vent (looking down through bridge grating)

Figure 23. Instrument cables 


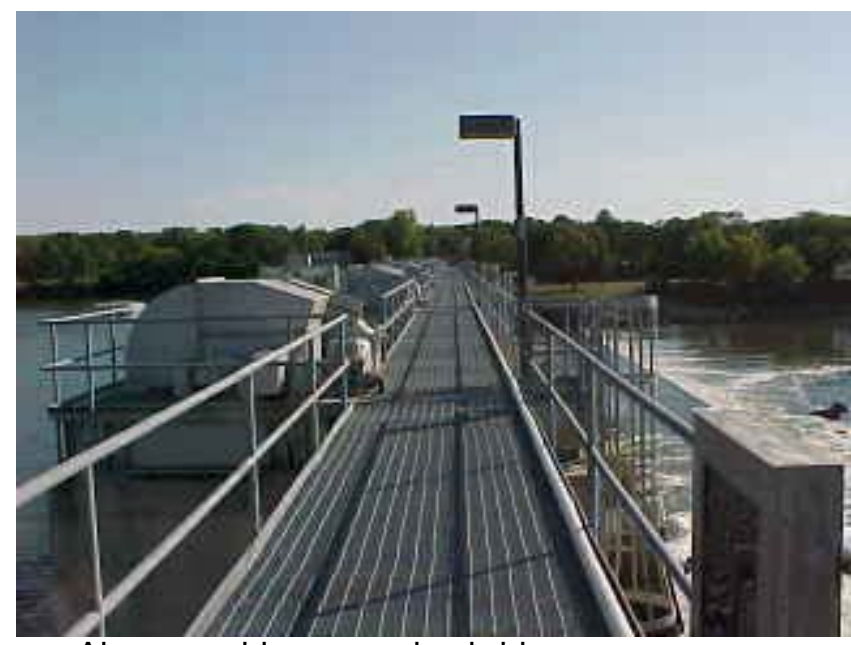

a. Along machinery service bridge

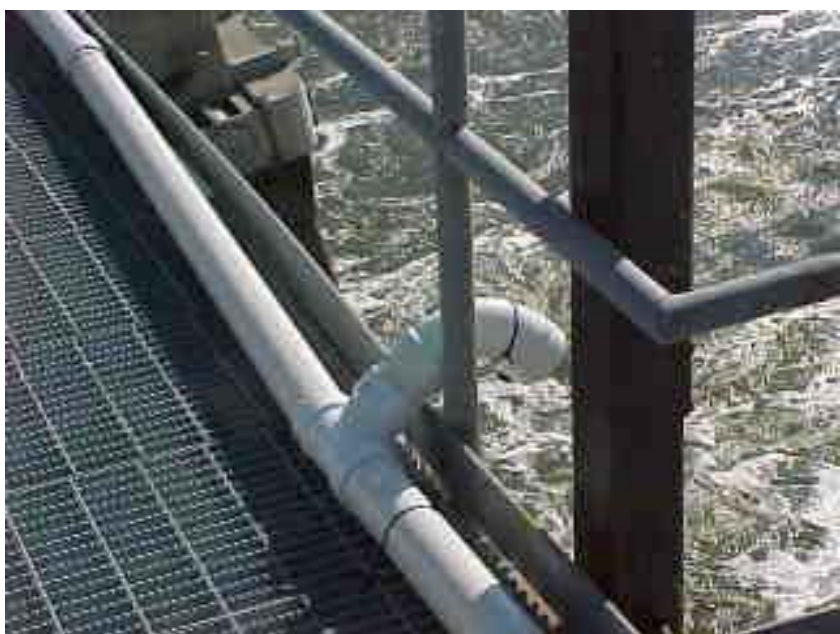

b. Access over the machinery access bridge

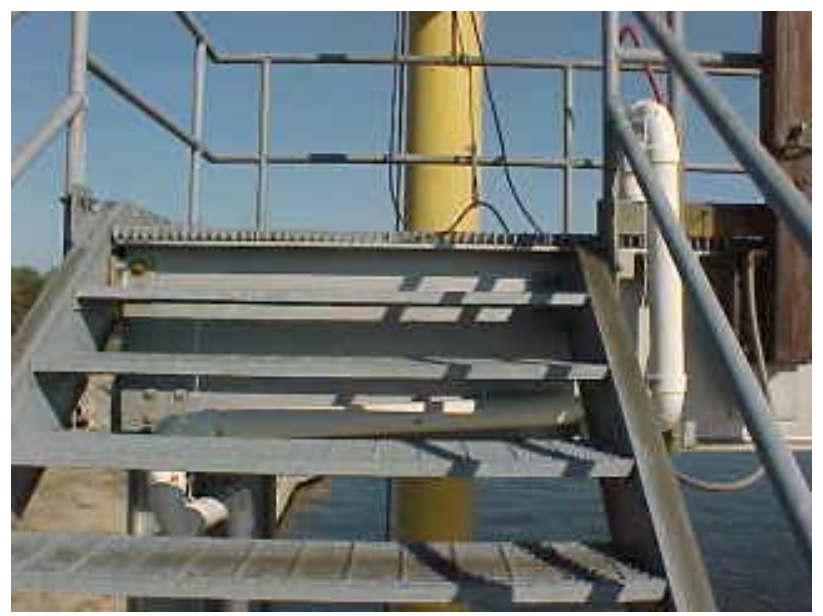

c. Under the stairwell to machinery access bridge

Figure 24. Instrument cable PVC conduit 


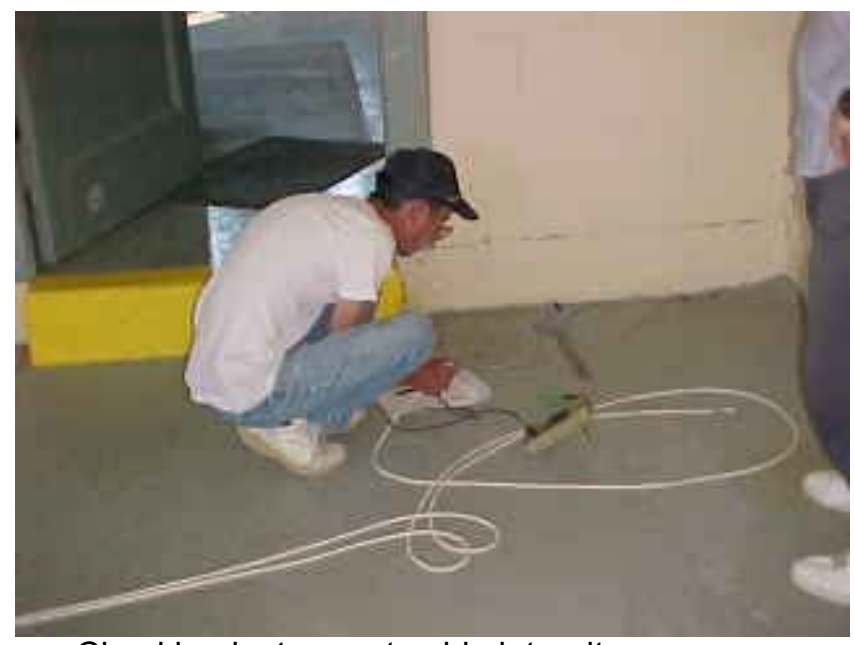

a. Checking instrument cable integrity

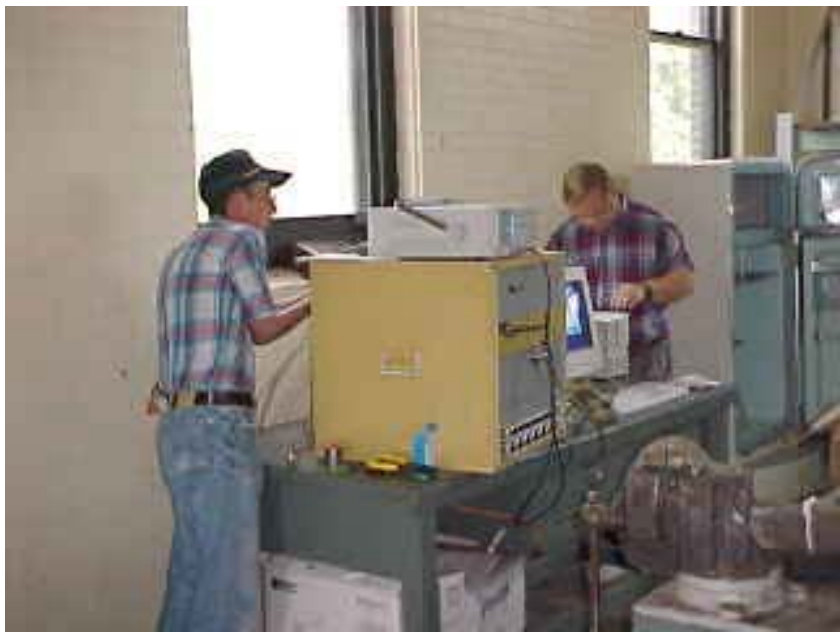

b. Connecting instrument cables to the data acquisition system

Figure 25. Instrument cable connection 


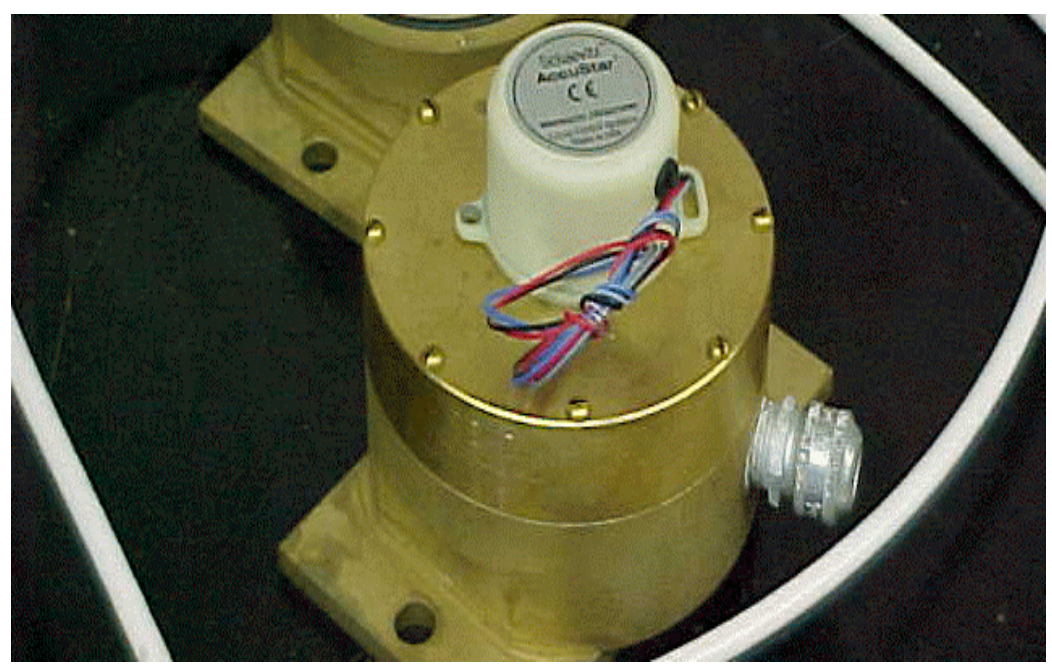

Figure 26. Inclinometer and protective housing

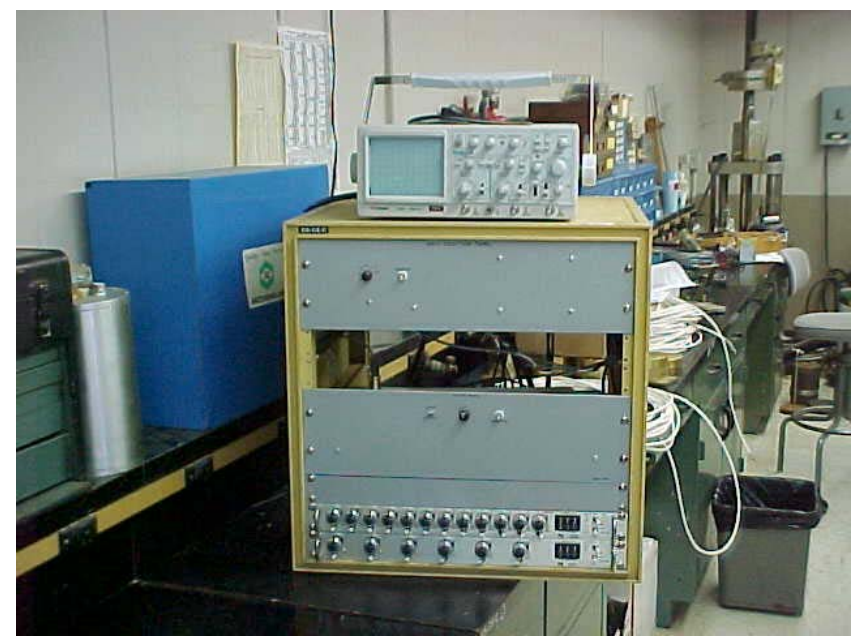

Figure 27. Data acquisition signal conditioning interface system

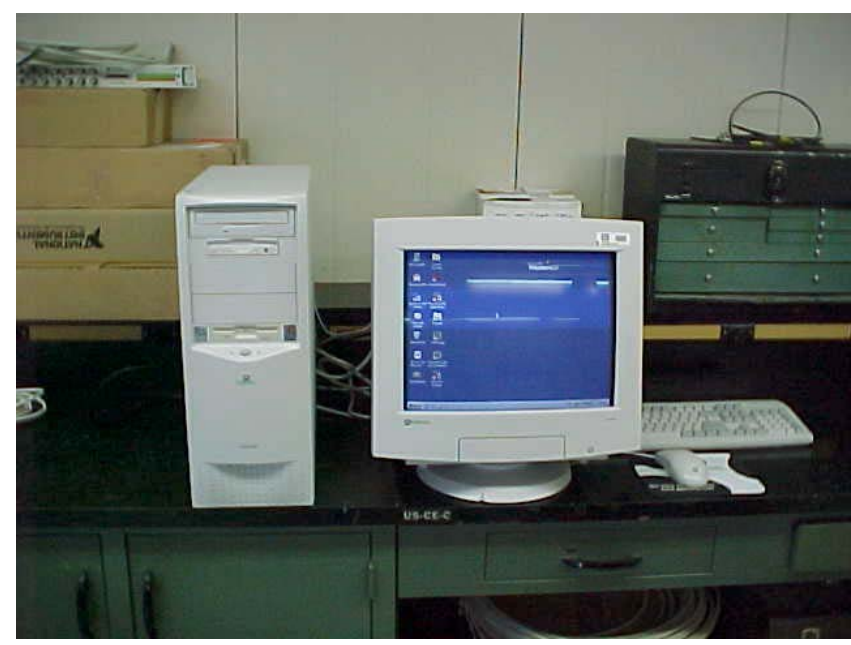

Figure 28. Data recording and storage central processing unit 


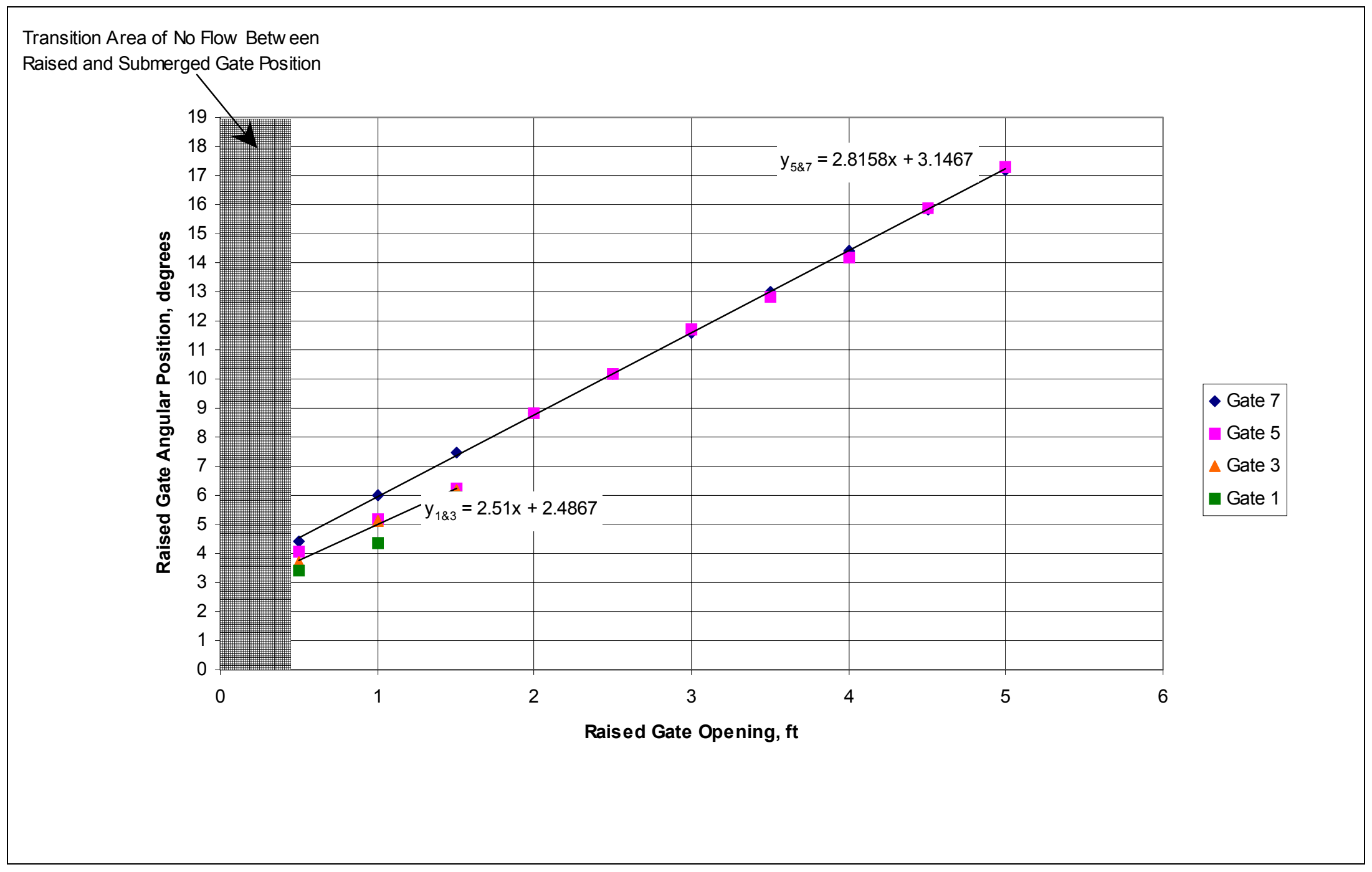

Figure 29. Marseilles Dam raised gate operation, gate opening vs. angular position 


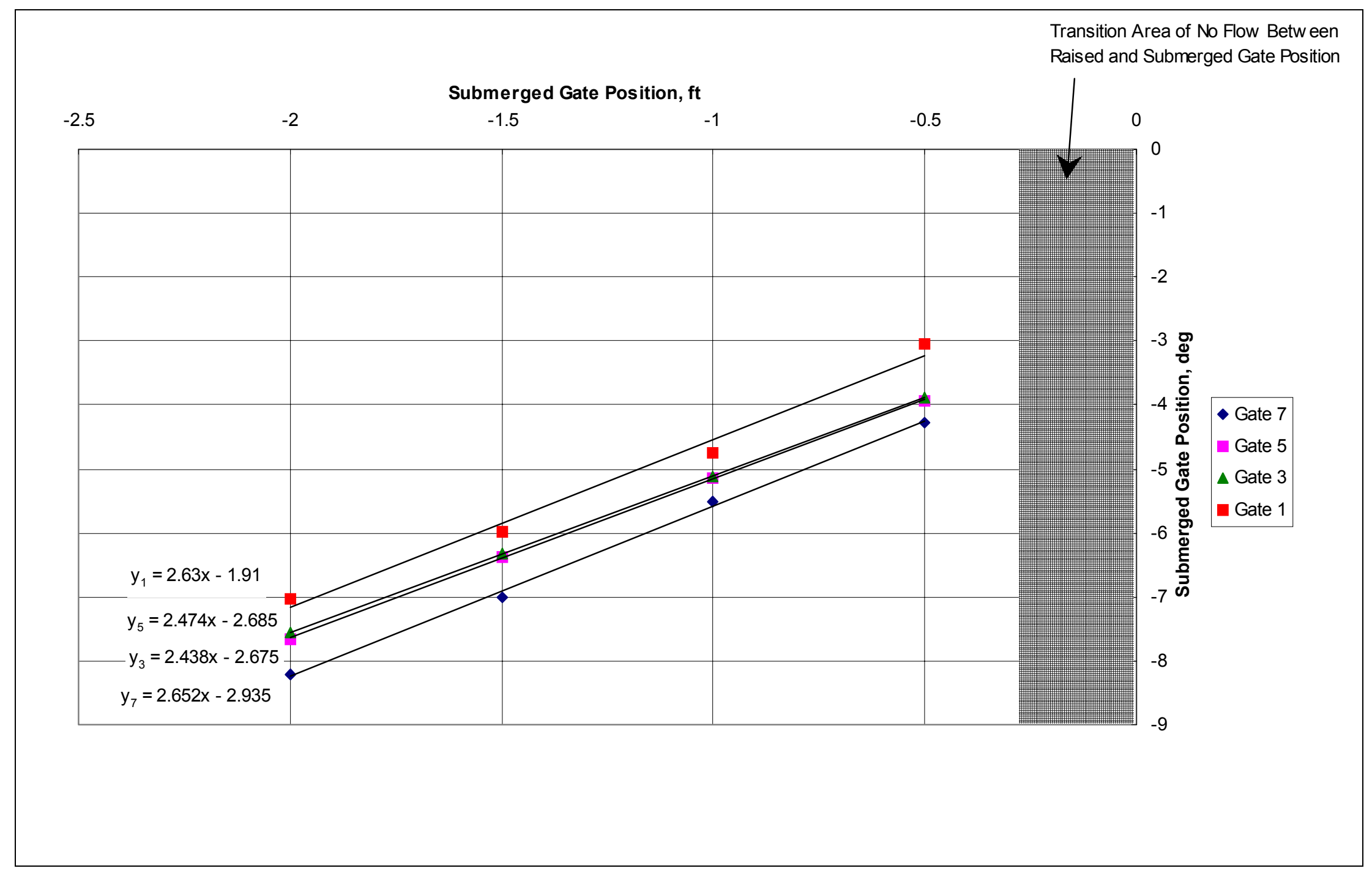

Figure 30. Marseilles Dam submerged gate operation, gate opening versus angular position 


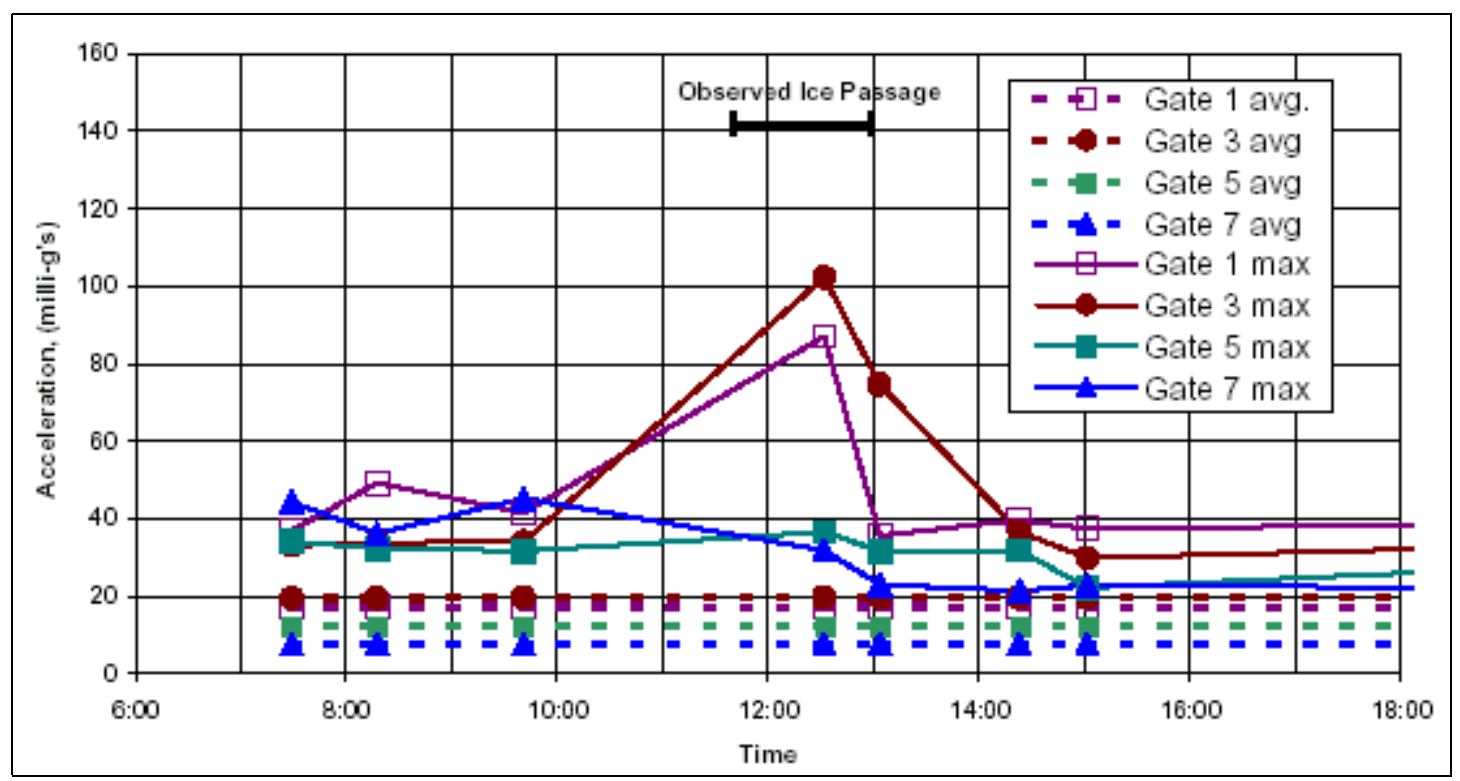

Figure 31. Maximum gate accelerations, 25 January 2000

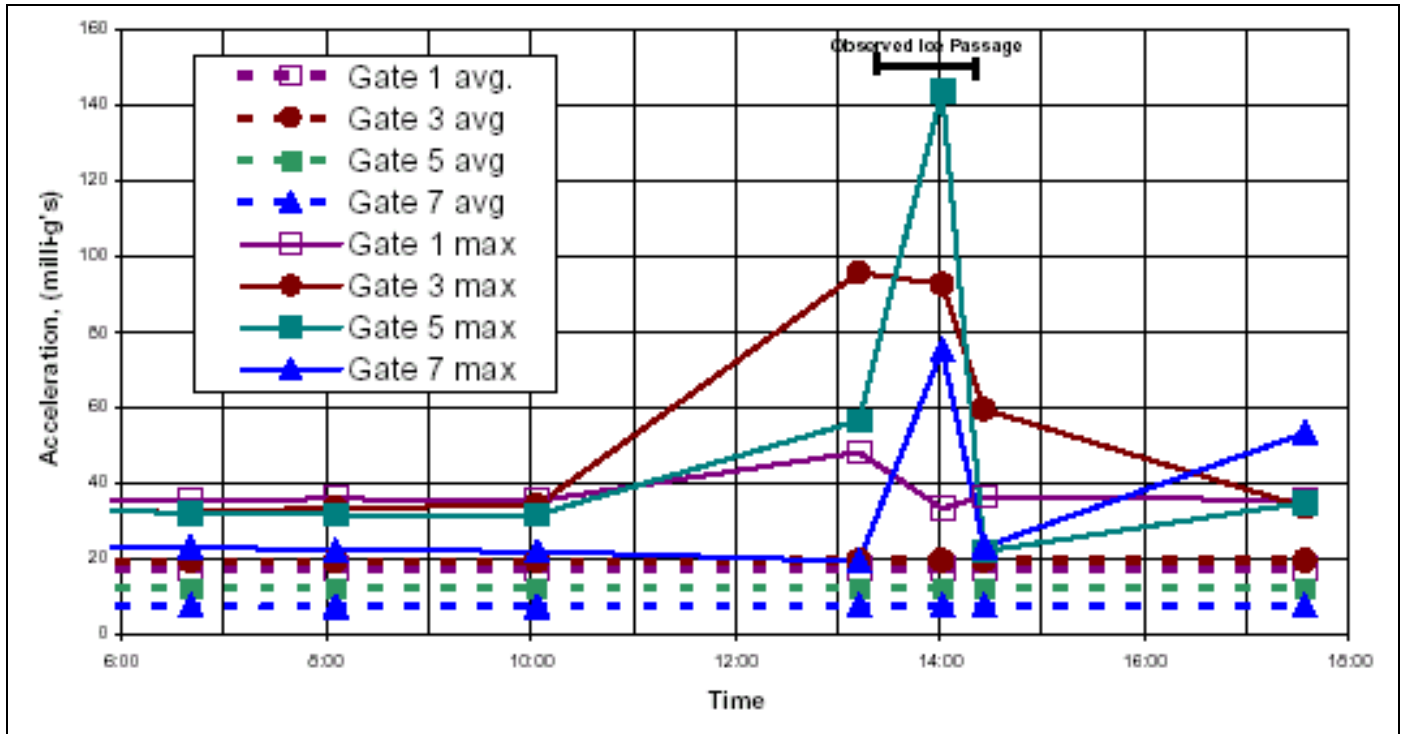

Figure 32. Maximum gate accelerations, 28 January 2000 


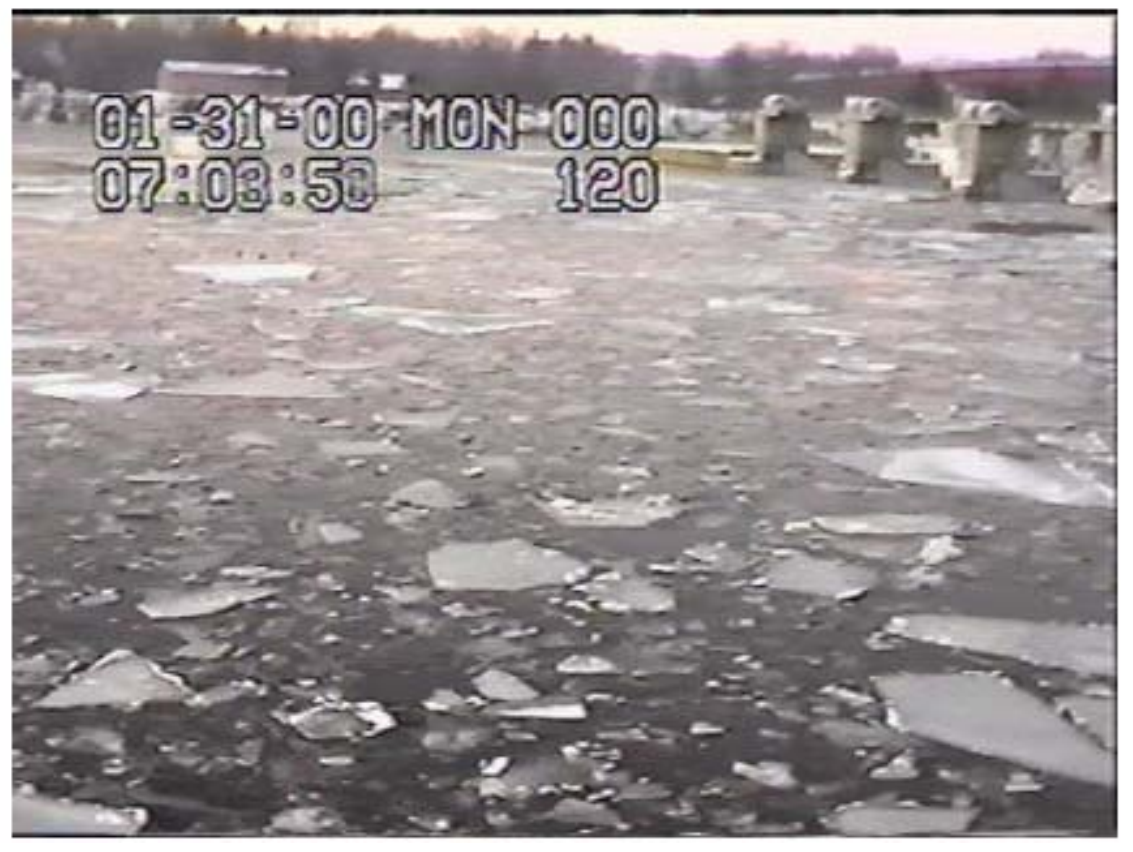

Figure 33. Fragmented ice in pool, morning of 31 January 2001

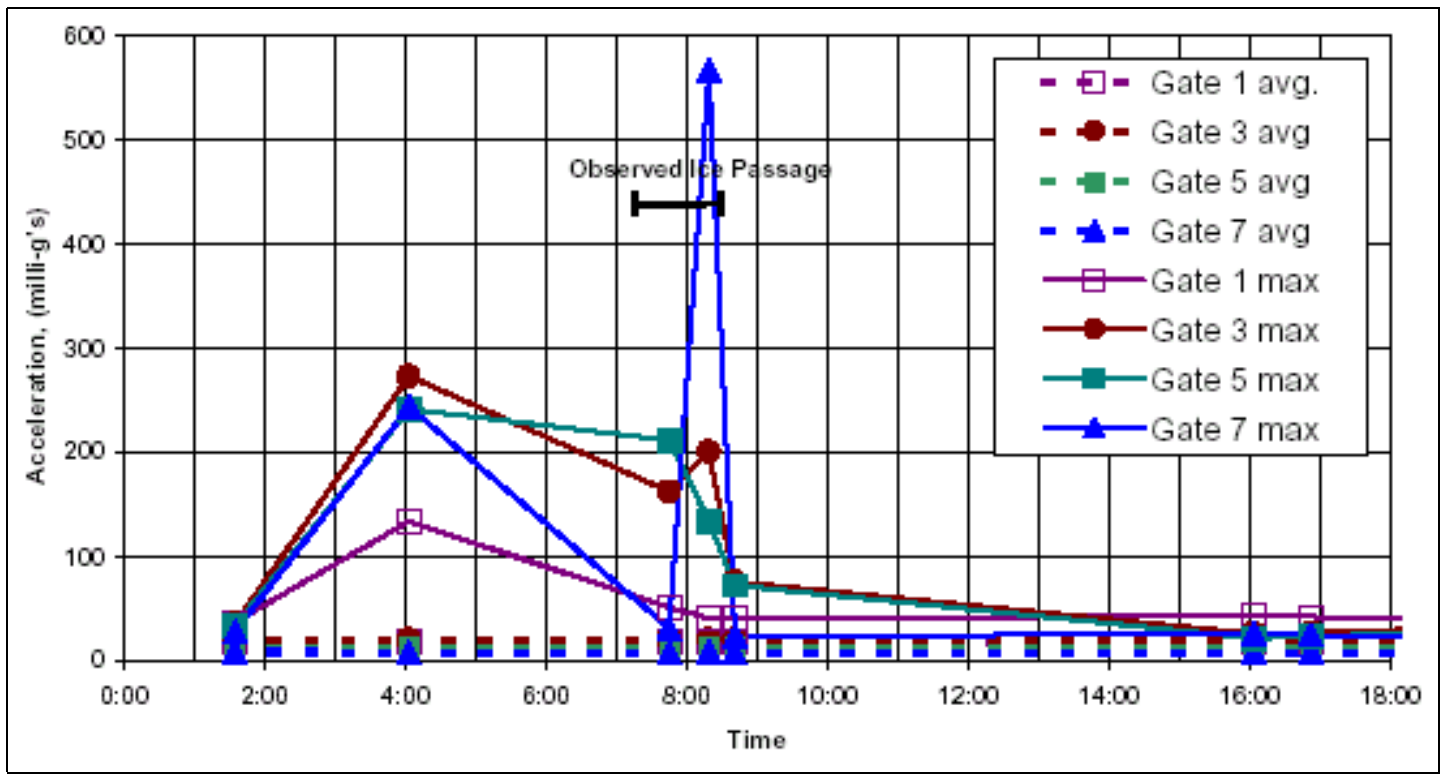

Figure 34. Maximum gate accelerations, 31 January 2000 


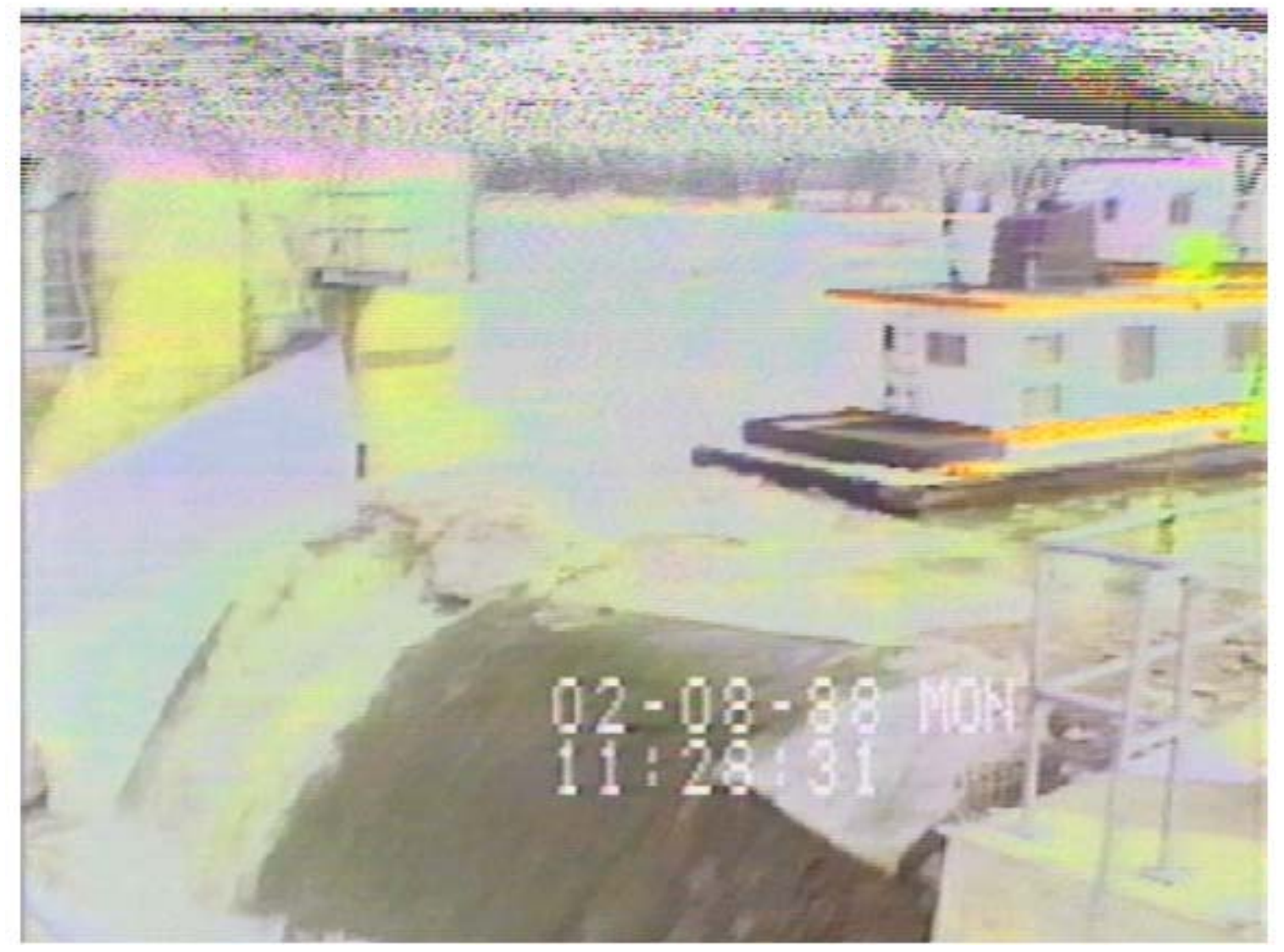

Figure 35. Tow washing ice floe off pier nose on 8 Feb 1988 


\begin{tabular}{|c|c|c|c|c|c|c|c|c|c|c|c|c|}
\hline & AN & FEB & MAR & APR & MAY & JUN & JUL & AUG & SEP & OCT & NOV & DEC \\
\hline 1 & 3.41 & & & 483.52 & 483.31 & 483.43 & 483.40 & 483.50 & 483.53 & 483.30 & 483.50 & 483.35 \\
\hline 2 & 3.35 & 483.27 & 483.32 & 483.50 & 483.27 & 483.51 & 483.43 & 483.40 & 483.54 & 483.50 & 483.50 & 483.51 \\
\hline 3 & 3.33 & & 483.47 & 483.48 & 483.50 & 483.34 & 483.42 & 483.43 & 483.40 & 483.52 & 483.50 & 483.55 \\
\hline 4 & 3.40 & & 483.47 & 483.41 & 483.27 & 483.36 & 483.40 & 483.53 & 483.52 & 483.50 & 483.37 & 483.53 \\
\hline 5 & 3.40 & & & 483.40 & 483.39 & 483.40 & 483.41 & 483.60 & 483.46 & 483.30 & 483.51 & 483.58 \\
\hline ( & & & & & & & & & & & & 483.37 \\
\hline 7 & & & & & & & & & & & & 483.32 \\
\hline 8 & & & & & & & & 483.40 & & & & 483.52 \\
\hline 9 & & & & & & 483 & & 483 & & & 483.50 & 483.58 \\
\hline 1 & 483.48 & 483.47 & 483. & 483.43 & 483.49 & 483.46 & 483.29 & 483.36 & 483.42 & 483.59 & 483.52 & 483.47 \\
\hline 11 & 483.41 & 483.49 & 483.50 & 483.46 & 483.40 & 483.50 & 483.52 & 483.42 & 483.30 & 483.59 & 483.59 & 483.42 \\
\hline 12 & 483.42 & 483.35 & 483.42 & 483.30 & 483.40 & 483.30 & 483.60 & 483.40 & 483.51 & 483.48 & 483.32 & 483.52 \\
\hline 13 & 83.43 & 483.47 & 483.48 & 483.39 & 483.43 & 483.52 & 483.34 & 483.26 & 483.50 & 483.58 & 483.53 & 483.43 \\
\hline 12 & 83.55 & 483.39 & 483.44 & 483.48 & 483.42 & 483.46 & 483.40 & 483.35 & 483.55 & 483.43 & 483.59 & 483.52 \\
\hline 1 & 83.28 & 483.32 & 483.33 & 483.50 & 483.29 & 483.10 & 483.57 & 483.44 & 483.49 & 483.46 & 483.60 & 483.60 \\
\hline 1 & 483.47 & 483 & 483 & & 483 & 483.39 & 483.42 & 483.49 & 48 & & & 483.56 \\
\hline 1 & 483.31 & & & & & & & 483.39 & & & & 483.68 \\
\hline 18 & 483.33 & 483 & & & & 483 & 483.30 & 483.46 & & & 483.58 & 483.50 \\
\hline 1 & 483.32 & 483 & 483 & & & 483.47 & 483.27 & 483.37 & 483.53 & & & 483.47 \\
\hline 2 & 483.35 & 483.57 & 483.42 & 483.30 & 483.20 & 483.33 & 483.54 & 483.50 & 483.51 & 483.4 & 483.64 & 483.42 \\
\hline 21 & 483.51 & 483.36 & 483.47 & 483.14 & 483.08 & 483.48 & 483.34 & 483.44 & 483.58 & 483.55 & 483.68 & 483.45 \\
\hline 22 & 483.47 & 483.31 & 483.13 & 483.32 & 483.42 & 483.41 & 483.27 & 483.43 & 483.57 & 483.22 & 483.58 & 483.40 \\
\hline 23 & 483.16 & & 483.25 & 483.44 & 483.28 & 483.36 & 483.59 & 483.48 & & & 483.43 & 483.53 \\
\hline 2. & 483.41 & 483.52 & 483.26 & & 483.30 & 483.32 & 483.50 & 483.49 & 483.68 & 483.37 & 483.61 & 483.48 \\
\hline 2 & 483.29 & & & & & & 483.50 & 483.46 & & & & 483.53 \\
\hline & & & & & & & & & & & & \\
\hline & & & & & & & & & & & & 483.53 \\
\hline 2 & 483.35 & 483.45 & & & & & 483.50 & & & & & 483.48 \\
\hline 2 & 483.20 & --- & 483.30 & & & & 483.10 & 483.51 & & & & 483.47 \\
\hline 3 & 483.55 & --- & 483.55 & 483.28 & 483.38 & 483.41 & 483.39 & 483.54 & 483.50 & 483.40 & 483.34 & 483.45 \\
\hline 31 & 483.53 & --- & 483.33 & --- & 483.43 & --- & 483.42 & 483.50 & --- & 483.40 & --- & 483.39 \\
\hline
\end{tabular}

\begin{tabular}{|c|l|l|l|l|l|l|l|l|l|l|l|l|}
\hline MIN & 483.16 & 483.15 & 483.13 & 483.06 & 483.08 & 483.10 & 483.10 & 483.26 & 483.30 & 483.22 & 483.32 & 483.32 \\
\hline MAX & 483.55 & 483.57 & 483.55 & 483.52 & 483.50 & 483.52 & 483.60 & 483.60 & 483.68 & 483.59 & 483.68 & 483.68 \\
\hline MEAN & 483.39 & 483.39 & 483.40 & 483.34 & 483.35 & 483.41 & 483.43 & 483.44 & 483.50 & 483.47 & 483.53 & 483.48 \\
\hline
\end{tabular}

Figure 36. Marseilles Lock and Dam 1999 Pool Elevations 


\begin{tabular}{|c|c|c|c|c|c|c|c|c|c|c|c|c|}
\hline & JAN & FEB & MAR & APR & MAY & JUN & JUL & AUG & SEP & OCT & NOV & DEC \\
\hline 1 & 8.79 & 462.03 & 459.98 & 459.27 & 462.56 & 459.66 & 459.39 & 458.79 & 458.93 & 459.39 & 458.93 & $459 .($ \\
\hline 2 & 459.00 & 461.84 & 459.72 & 459.26 & 462.33 & 460.54 & 459.61 & 459.23 & 458.78 & 459.20 & 458.90 & 458.78 \\
\hline 3 & 458.90 & 462.21 & 459.80 & 459.31 & 461.51 & 461.94 & 459.73 & 459.03 & 458.98 & 458.90 & 458.92 & 458.84 \\
\hline 4 & 459.01 & 461.76 & 459.89 & 459.31 & 461.31 & 460.96 & 459.36 & 458.83 & 458.82 & 459.55 & 459.02 & 459.01 \\
\hline 5 & 459.08 & 461.28 & 459.74 & 459.37 & 460.81 & 460.56 & 459.28 & 458.85 & 458.88 & 459.25 & 458.82 & 459.45 \\
\hline 6 & 9.13 & 460.87 & 460.06 & 459.32 & & 460.06 & 459.36 & & & & & 459.40 \\
\hline 7 & 9.20 & & 460.03 & & & & & & & & & 459.45 \\
\hline 8 & 9.06 & & 460.12 & & & & & & & & & 459.10 \\
\hline 9 & 459.08 & & 460.25 & & & & & & & & & \\
\hline 10 & 459.15 & 460.78 & 460.10 & 460.29 & 460.00 & 459.12 & 459.24 & & & & & 458.90 \\
\hline 11 & 459.26 & 460.66 & 459.90 & 460.32 & 459.79 & 459.70 & 459.40 & 458.96 & 459.16 & 458.77 & 459.03 & 459.04 \\
\hline 12 & 459.42 & 461.09 & 459.69 & 460.13 & 460.29 & 461.21 & 459.11 & 459.15 & 458.94 & 458.85 & 458.77 & 459.11 \\
\hline 13 & 459.06 & 461.06 & 459.69 & 459.79 & 461.83 & 461.40 & 459.00 & 459.17 & 458.96 & 458.91 & 458.76 & 458.91 \\
\hline 14 & 458.91 & 460.33 & 460.04 & 459.73 & 462.08 & 465.05 & 459.12 & 459.16 & 458.89 & 458.81 & 458.84 & 459.03 \\
\hline 15 & 459.51 & 460.33 & 459.73 & 459.77 & 461.29 & 465.03 & 459.08 & 459.37 & 458.96 & 458.82 & 458.89 & 459.11 \\
\hline 16 & 459.01 & 460.1 & & 460.94 & & & & & 458 & & & 459.12 \\
\hline 17 & 459.51 & 460.26 & 460.29 & 464 & & & & & 458.88 & & & 459.16 \\
\hline 18 & 459.28 & 45 & 461 & 465 & & & & & & & & 458.96 \\
\hline 19 & 459.54 & 459 & 461.30 & 464 & 460 & 460 & & 45 & 45 & & 45 & 458.88 \\
\hline 20 & 458.93 & 459.86 & 460.55 & 463.25 & 460.30 & 459.86 & 459.19 & 459.03 & 458.84 & 458.87 & 458.98 & 459.15 \\
\hline 21 & 459.09 & 459.56 & 460.27 & 462.62 & 460.09 & 459.75 & 459.57 & 459.30 & 458.99 & 458.92 & 458.86 & 459.07 \\
\hline 22 & 459.40 & 459.23 & 460.26 & 462.63 & 460.59 & 459.94 & 459.87 & 459.04 & 458.99 & 458.88 & 458.94 & 458.97 \\
\hline 23 & 461.81 & 459.75 & 459.90 & 464.01 & 460.70 & 460.24 & 459.39 & 458.98 & 458.81 & 458.93 & 458.84 & 458.82 \\
\hline 24 & 465.70 & 459.56 & 459.52 & 466.87 & 460.74 & 460.17 & 459.84 & 459.38 & 458.72 & 458.95 & 458.81 & 459.11 \\
\hline 25 & 466.52 & 459.50 & 459.53 & 465.52 & 460.29 & 459.76 & 459.28 & 459.34 & 458.94 & 459.11 & 458.85 & 458.47 \\
\hline 26 & 466.04 & 459.80 & 459.79 & 463.92 & 459.91 & 459.38 & 459.48 & 459.07 & 458.86 & 458.87 & 458.89 & 459.24 \\
\hline 27 & 464.98 & 459.96 & 459.59 & 462.94 & 459.65 & 459.41 & 458.93 & 459.34 & 458.87 & 458.88 & 458.89 & 458.79 \\
\hline 28 & 464.98 & 459.60 & 459.41 & 463.69 & 459.21 & 459.43 & 459.09 & 459.17 & 459.19 & 458.85 & 458.90 & 458.90 \\
\hline 29 & 464.90 & --- & 459.73 & 464.33 & 459.44 & 459.32 & 459.21 & 458.95 & 459.78 & 458.80 & 459.10 & 458.94 \\
\hline 30 & 463.58 & --- & 459.42 & 463.68 & 459.25 & 459.43 & 459.05 & 458.84 & 459.34 & 458.90 & 459.10 & 459.13 \\
\hline 31 & 462.52 & --- & 459.31 & --- & 459.30 & --- & 458.91 & 458.99 & --- & 458.85 & --- & 459.01 \\
\hline MIN & 458.79 & 459.23 & 459.31 & 459.11 & 459.21 & 459.12 & 458.91 & 458.79 & 458.72 & 458.72 & 458.76 & 458.47 \\
\hline MAX & 466.52 & 462.21 & 461.37 & 466.87 & 462.56 & 465.05 & 459.87 & 459.38 & 459.78 & 459.55 & 459.10 & 459.45 \\
\hline EAN & 60.72 & 460.46 & 459.96 & 461.75 & 460.59 & 460.54 & 459.28 & 459.07 & 458.96 & 458.97 & 458.90 & 459.04 \\
\hline
\end{tabular}

Figure 37. Marseilles Lock and Dam 1999 tailwater elevations 


\begin{tabular}{|c|c|c|c|c|c|c|c|c|c|c|c|c|}
\hline & Jan & FEB & MAR & APR & MAY & JUN & JUL & $\mathbf{A U G}$ & SEP & OCT & NOV & DEC \\
\hline 1 & 483.45 & 483.41 & 483.48 & 483.53 & 483.48 & 483.49 & 483.34 & 483.46 & -M- & 483.52 & 483.42 & 483.36 \\
\hline 2 & 483.45 & 483.58 & 483.41 & 483.54 & 483.56 & 483.37 & 483.40 & 483.36 & -M- & 483.44 & 483.38 & 483.47 \\
\hline 3 & 483.44 & 483.40 & 483.50 & 483.51 & 483.49 & 483.46 & 483.49 & 483.47 & $-\mathrm{M}-$ & 483.55 & 483.43 & 483.48 \\
\hline 4 & 483.38 & 483.29 & 483.55 & 483.52 & 483.50 & 483.35 & 483.45 & 483.49 & $-\mathrm{M}-$ & 483.55 & 483.53 & 483.40 \\
\hline 5 & 483.45 & 483.33 & 483.60 & 483.57 & 483.40 & 483.41 & 483.28 & 483.43 & $-\mathrm{M}-$ & 483.48 & 483.37 & 483.32 \\
\hline 6 & 483.47 & 483.53 & 483.58 & 483.48 & 483.34 & 483.41 & 483.44 & 483.34 & $-\mathrm{M}-$ & 483.52 & 483.56 & 483.57 \\
\hline 7 & 483.48 & 483.40 & 483.57 & 483.60 & 483.53 & 483.34 & 483.30 & 483.36 & -M- & 483.53 & 483.53 & 483.31 \\
\hline 8 & 483.55 & 483.33 & 483.55 & 483.47 & 483.40 & 483.37 & 483.39 & 483.55 & 483.41 & 483.41 & 483.55 & 483.52 \\
\hline 9 & 483.38 & 483.30 & 483.54 & 483.49 & 483.48 & 483.40 & 483.35 & 483.52 & 483.43 & 483.32 & 483.55 & 483.51 \\
\hline 10 & 483.50 & 483.40 & 483.50 & 483.47 & 483.33 & 483.65 & 483.47 & 483.36 & 483.40 & 483.56 & 483.47 & 483.32 \\
\hline 11 & 483.55 & 483.35 & 483.50 & 483.46 & 483.53 & 483.28 & 483.50 & 483.35 & 483.49 & 483.49 & 483.53 & 483.58 \\
\hline 12 & 483.55 & 483.44 & 483.46 & 483.42 & 483.48 & 483.50 & 483.11 & 483.44 & 483.56 & 483.41 & 483.43 & 483.52 \\
\hline 13 & 483.53 & 483.43 & 483.37 & 483.42 & 483.50 & 483.47 & 483.15 & 483.63 & 483.54 & 483.42 & 483.40 & 483.59 \\
\hline 14 & 483.44 & 483.37 & 483.41 & 483.34 & 483.40 & 483.39 & 483.42 & 483.45 & 483.27 & 483.52 & 483.56 & 483.49 \\
\hline 15 & 483.34 & 483.38 & 483.55 & 483.50 & 483.46 & 483.44 & 483.48 & 483.52 & 483.46 & 483.55 & 483.51 & 483.43 \\
\hline 16 & 483.43 & 483.50 & 483.52 & 483.45 & 483.20 & 483.25 & 483.55 & 483.41 & 483.52 & 483.48 & 483.53 & 483.20 \\
\hline 17 & 483.44 & 483.43 & 483.46 & 483.43 & 483.28 & 483.25 & 483.42 & 483.48 & 483.41 & 483.58 & 483.38 & 483.46 \\
\hline 18 & 483.49 & 483.40 & 483.22 & 483.60 & 483.50 & 483.30 & 483.41 & 483.54 & 483.46 & 483.56 & 483.40 & 483.38 \\
\hline 19 & 483.45 & 483.24 & 483.38 & 483.51 & 483.58 & 483.33 & 483.57 & 483.43 & 483.44 & 483.49 & 483.39 & 483.25 \\
\hline 20 & 483.45 & 483.40 & 483.50 & 483.45 & 483.38 & 483.46 & 483.41 & 483.54 & 483.41 & 483.67 & 483.40 & 483.38 \\
\hline 21 & 483.49 & 483.45 & 483.36 & 483.31 & 483.51 & 483.53 & 483.47 & 483.55 & 483.54 & 483.60 & 483.38 & 483.40 \\
\hline 22 & 483.54 & 483.53 & 483.50 & 483.37 & 483.50 & 483.35 & 483.51 & 483.52 & 483.41 & 483.41 & 483.40 & 483.41 \\
\hline 23 & 483.53 & 483.43 & 483.46 & 483.26 & 483.39 & 483.24 & 483.38 & 483.51 & 483.44 & 483.43 & 483.42 & 483.35 \\
\hline 24 & 483.38 & 483.38 & 483.46 & 483.30 & 483.34 & 483.28 & 483.47 & 483.46 & 483.34 & 483.34 & 483.49 & 483.38 \\
\hline 25 & 483.50 & 483.51 & 483.38 & 483.52 & 483.55 & 483.41 & 483.47 & 483.46 & 483.46 & 483.33 & 483.32 & 483.33 \\
\hline 26 & 483.48 & 483.52 & 483.25 & 483.43 & 483.56 & 483.24 & 483.51 & 483.40 & 483.34 & 483.33 & 483.47 & 483.33 \\
\hline 27 & 483.47 & 483.39 & 483.48 & 483.33 & 483.42 & 483.34 & 483.40 & 483.40 & 483.31 & 483.35 & 483.45 & 483.37 \\
\hline 28 & 483.39 & 483.49 & 483.57 & 483.38 & 483.58 & 483.34 & 483.33 & 483.44 & 483.32 & 483.25 & 483.44 & 483.32 \\
\hline 29 & 483.37 & 483.39 & 483.55 & 483.48 & 483.60 & 483.38 & 483.48 & 483.46 & 483.49 & 483.50 & 483.49 & 483.40 \\
\hline 30 & 483.38 & --- & 483.52 & 483.45 & 483.56 & 483.43 & 483.34 & 483.45 & 483.38 & 483.32 & 483.44 & 483.34 \\
\hline 31 & 483.42 & --- & 483.55 & --- & 483.43 & --- & 483.37 & -M- & --- & 483.48 & --- & 483.28 \\
\hline MIN & 483.34 & 483.24 & 483.22 & 483.26 & 483.20 & 483.24 & 483.11 & 483.34 & 483.27 & 483.25 & 483.32 & 483.20 \\
\hline MAX & 483.55 & 483.58 & 483.60 & 483.60 & 483.60 & 483.65 & 483.57 & 483.63 & 483.56 & 483.67 & 483.56 & 483.59 \\
\hline MEAN & 483.46 & 483.41 & 483.48 & 483.45 & 483.46 & 483.38 & 483.41 & 483.46 & 483.43 & 483.46 & 483.45 & 483.40 \\
\hline
\end{tabular}

Figure 38. Marseilles Lock and Dam 2000 Pool Elevations 


\begin{tabular}{|c|c|c|c|c|c|c|c|c|c|c|c|c|}
\hline & $\mathbf{J A N}$ & FEB & MAR & APR & MAY & $\mathbf{J U N}$ & JUL & $\mathbf{A U G}$ & SEP & OCT & NOV & DEC \\
\hline 1 & 458.97 & 459.06 & 459.64 & 459.24 & 459.55 & 461.89 & 459.79 & 459.21 & -M- & 459.53 & 459.30 & 459.36 \\
\hline 2 & 458.98 & 458.95 & 459.36 & 458.87 & 459.66 & 462.13 & 459.63 & 459.37 & -M- & 459.43 & 459.59 & 459.23 \\
\hline 3 & 458.95 & 458.76 & 459.00 & 459.07 & 459.48 & 460.99 & 460.28 & 459.54 & -M- & 459.48 & 459.46 & 459.37 \\
\hline 4 & 459.14 & 458.89 & 459.20 & 459.15 & 459.52 & 460.50 & 460.47 & 459.41 & -M- & 459.89 & 459.44 & 459.52 \\
\hline 5 & 459.10 & 458.98 & 459.25 & 459.07 & 459.23 & 460.14 & 461.26 & 459.05 & -M- & 459.85 & 459.34 & 459.49 \\
\hline 6 & 459.02 & 458.89 & 459.20 & 459.02 & 459.39 & 460.35 & 461.11 & 459.30 & -M- & 460.03 & 459.30 & 459.14 \\
\hline 7 & 458.94 & 458.91 & 459.00 & 459.00 & 459.30 & 460.34 & 460.90 & 459.88 & -M- & 459.73 & 459.90 & 459.60 \\
\hline 8 & 458.93 & 458.78 & 459.12 & 459.32 & 459.40 & 459.83 & 460.67 & 459.76 & 459.45 & 459.85 & 459.84 & 459.21 \\
\hline 9 & 458.91 & 458.90 & 459.27 & 459.04 & 459.58 & 459.80 & 460.40 & 459.48 & 459.39 & 459.60 & 459.62 & 459.27 \\
\hline 10 & 459.04 & 458.80 & 459.08 & 459.13 & 460.03 & 459.72 & 460.91 & 459.20 & 459.46 & 459.34 & 460.10 & 459.26 \\
\hline 11 & 459.34 & 458.89 & 459.00 & 459.07 & 459.65 & 459.64 & 466.12 & 459.30 & 459.42 & 459.40 & 460.75 & 459.17 \\
\hline 12 & 458.94 & 459.06 & 459.06 & 459.19 & 460.00 & 459.81 & 464.87 & 459.36 & 460.70 & 459.51 & 459.91 & 459.33 \\
\hline 13 & 459.04 & 458.79 & 458.96 & 459.00 & 460.27 & 460.33 & 462.57 & 459.09 & 460.29 & 459.24 & 459.67 & 459.07 \\
\hline 14 & 458.97 & 459.07 & 459.07 & 459.12 & 460.18 & 461.38 & 461.43 & 459.02 & 460.36 & 459.67 & 459.73 & 459.02 \\
\hline 15 & 459.02 & 458.96 & 459.12 & 459.12 & 460.06 & 461.91 & 460.58 & 459.04 & 460.20 & 459.33 & 459.55 & 459.47 \\
\hline 16 & 458.99 & 458.94 & 459.13 & 459.01 & 459.80 & 461.70 & 460.06 & 458.96 & 459.56 & 459.48 & 459.38 & 459.03 \\
\hline 17 & 458.86 & 458.92 & 458.98 & 459.25 & 459.80 & 460.93 & 459.51 & 458.97 & 459.66 & 459.31 & 459.79 & 459.62 \\
\hline 18 & 458.76 & 458.96 & 458.91 & 459.39 & 459.20 & 460.69 & 459.40 & 459.31 & 459.52 & 459.35 & 459.46 & 459.33 \\
\hline 19 & 459.07 & 458.85 & 459.07 & 459.00 & 459.54 & 460.16 & 459.44 & 459.16 & 459.55 & 459.38 & 459.29 & 459.23 \\
\hline 20 & 459.04 & 459.15 & 459.18 & 459.86 & 459.87 & 459.87 & 459.41 & 459.25 & 459.67 & 459.25 & 459.46 & 459.48 \\
\hline 21 & 458.91 & 459.10 & 459.15 & 462.92 & 459.67 & 460.85 & 459.35 & 459.09 & 459.82 & 459.25 & 459.42 & 459.72 \\
\hline 22 & 459.01 & 459.10 & 459.23 & 463.79 & 460.10 & 462.96 & 459.28 & 459.00 & 459.65 & 459.42 & 459.52 & 459.45 \\
\hline 23 & 458.94 & 459.01 & 459.20 & 462.67 & 459.70 & 462.06 & 459.30 & 458.96 & 460.36 & 459.34 & 459.34 & 459.59 \\
\hline 24 & 458.99 & 459.40 & 459.03 & 462.10 & 459.61 & 460.97 & 459.07 & 459.62 & 460.09 & 459.65 & 459.30 & 459.98 \\
\hline 25 & 459.01 & 459.86 & 459.14 & 461.11 & 459.70 & 463.21 & 459.23 & 459.35 & 459.91 & 459.60 & 459.25 & 460.00 \\
\hline 26 & 459.01 & 460.15 & 459.26 & 460.64 & 459.35 & 463.89 & 459.19 & 459.42 & 459.87 & 459.51 & 459.40 & 459.76 \\
\hline 27 & 459.00 & 459.86 & 459.35 & 460.15 & 459.40 & 462.38 & 459.08 & 459.47 & 459.83 & 459.43 & 459.17 & 459.95 \\
\hline 28 & 458.97 & 459.73 & 459.27 & 459.96 & 459.81 & 461.14 & 459.14 & 459.33 & 459.80 & 459.40 & 459.44 & 460.01 \\
\hline 29 & 458.85 & 459.44 & 458.87 & 459.85 & 459.97 & 460.64 & 459.12 & 459.43 & 459.90 & 459.42 & 459.48 & 459.12 \\
\hline 30 & 458.99 & --- & 459.01 & 459.74 & 460.05 & 460.12 & 459.32 & 459.44 & 459.59 & 459.30 & 459.52 & 459.56 \\
\hline 31 & 459.10 & --- & 458.93 & --- & 459.84 & --- & 459.44 & -M- & --- & 459.55 & --- & 459.24 \\
\hline MIN & 458.76 & 458.76 & 458.87 & 458.87 & 459.20 & 459.64 & 459.07 & 458.96 & 459.39 & 459.24 & 459.17 & 459.02 \\
\hline MAX & 459.34 & 460.15 & 459.64 & 463.79 & 460.27 & 463.89 & 466.12 & 459.88 & 460.70 & 460.03 & 460.75 & 460.01 \\
\hline MEAN & 458.99 & 459.11 & 459.13 & 459.86 & 459.70 & 461.01 & 460.33 & 459.29 & 459.83 & 459.50 & 459.56 & 459.44 \\
\hline
\end{tabular}

Figure 39. Marseilles Lock and Dam 2000 tailwater elevations 


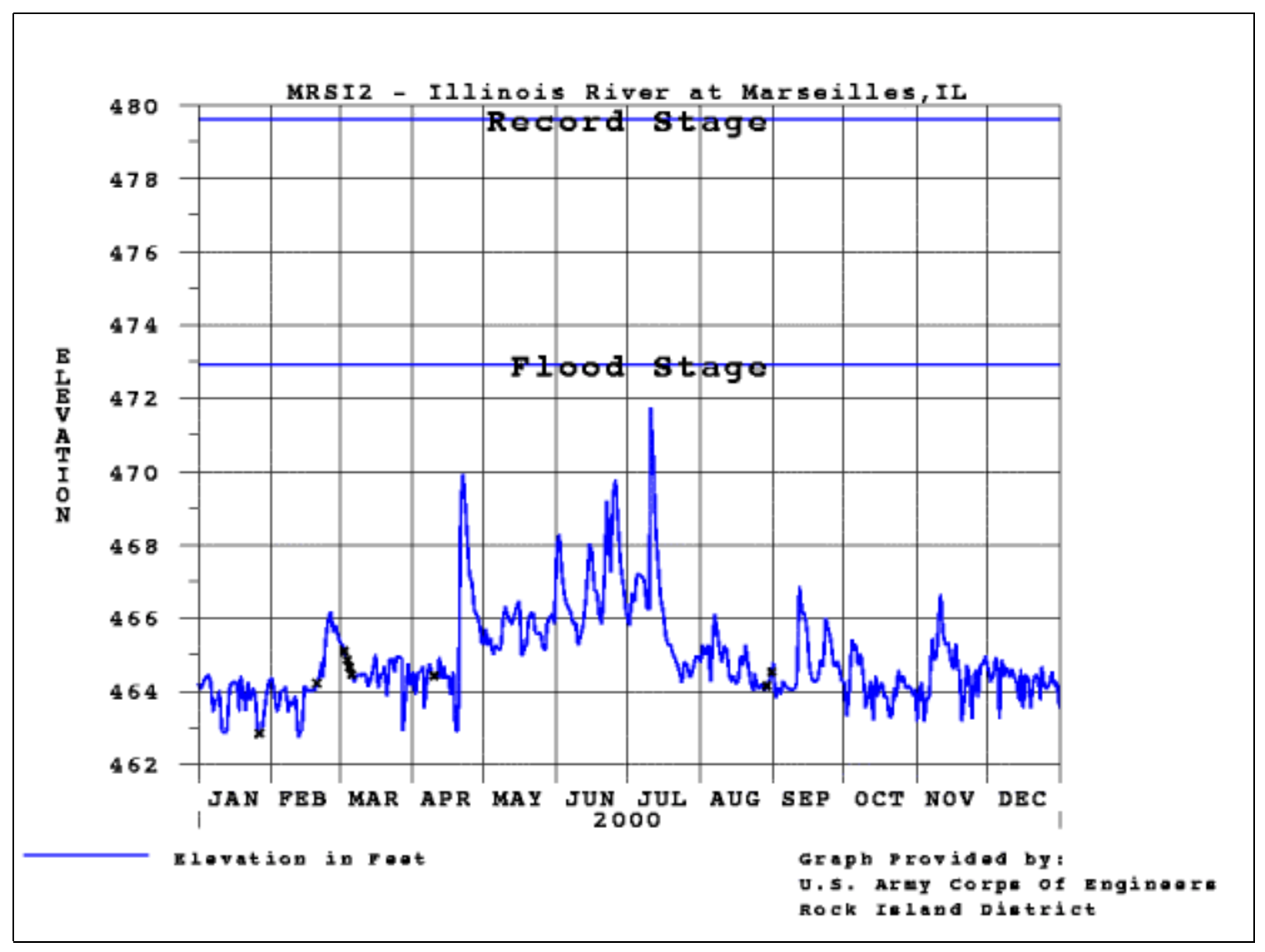

Figure 40. Time-history Illinois River stages at Marseilles 

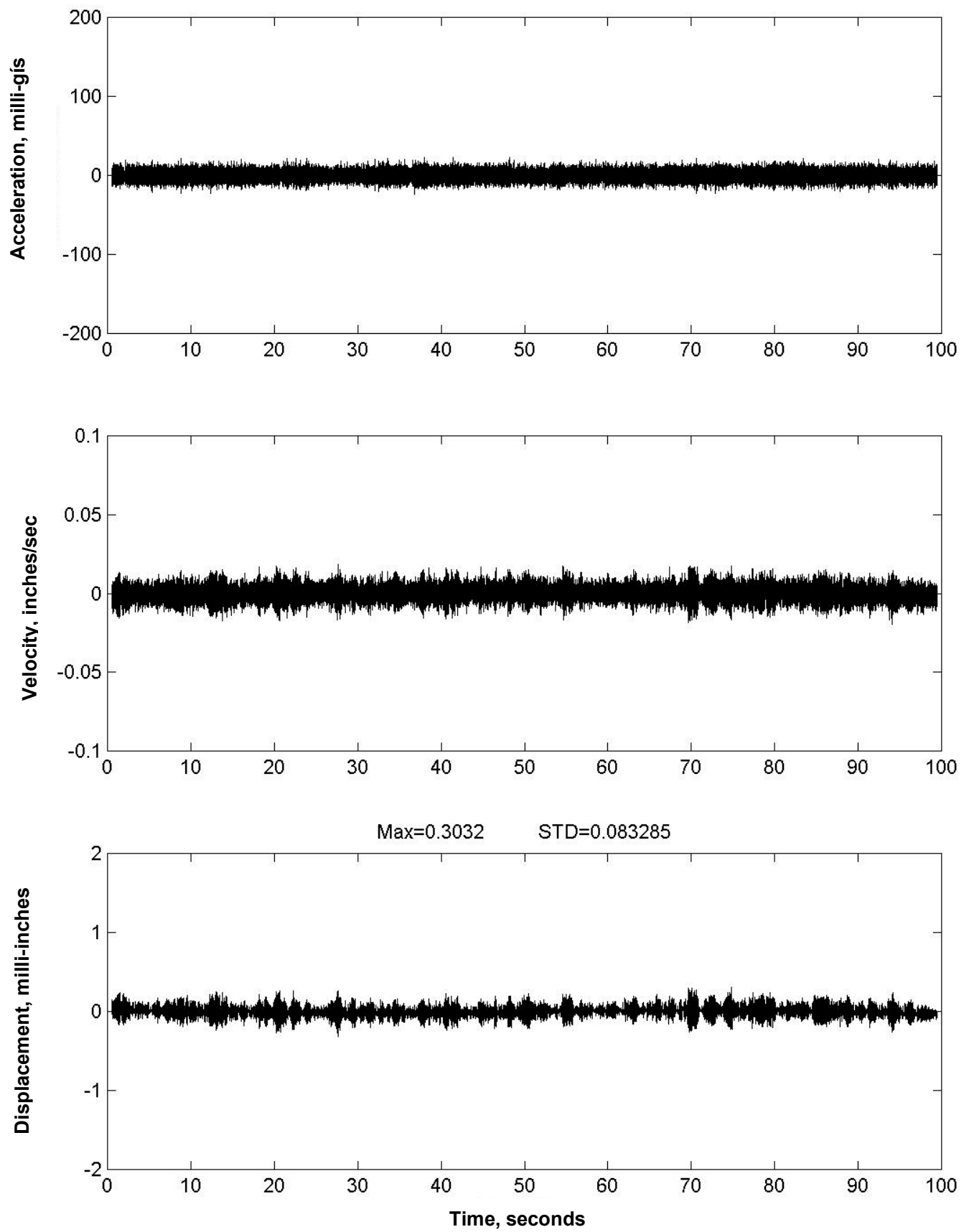

Figure 41. Vertical accelerations, Gate 5 raised position, 2.0-ft opening, 06/02/00 

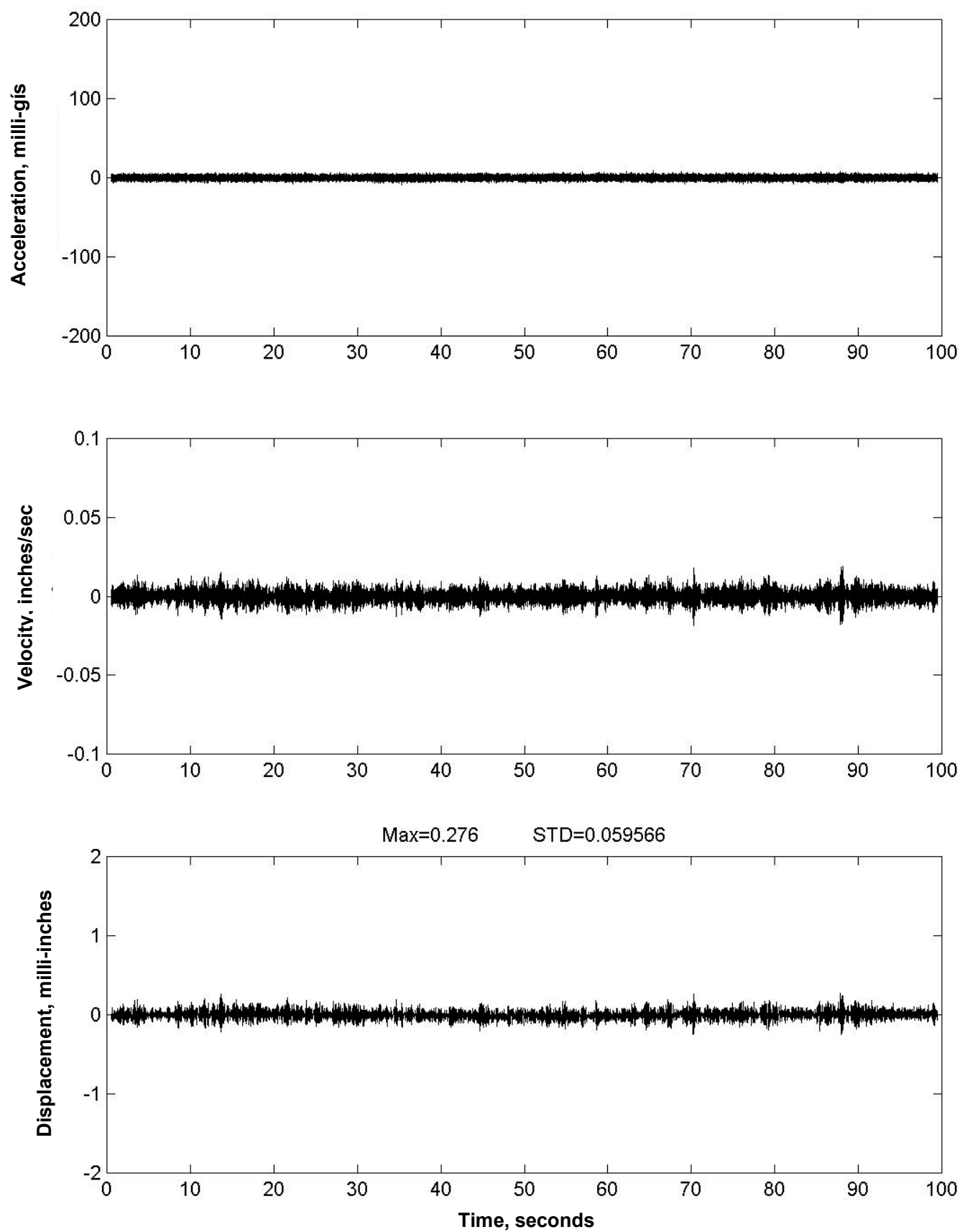

Figure 42. Radial accelerations, Gate 5, raised position, 2.0-ft opening, 06/02/00 


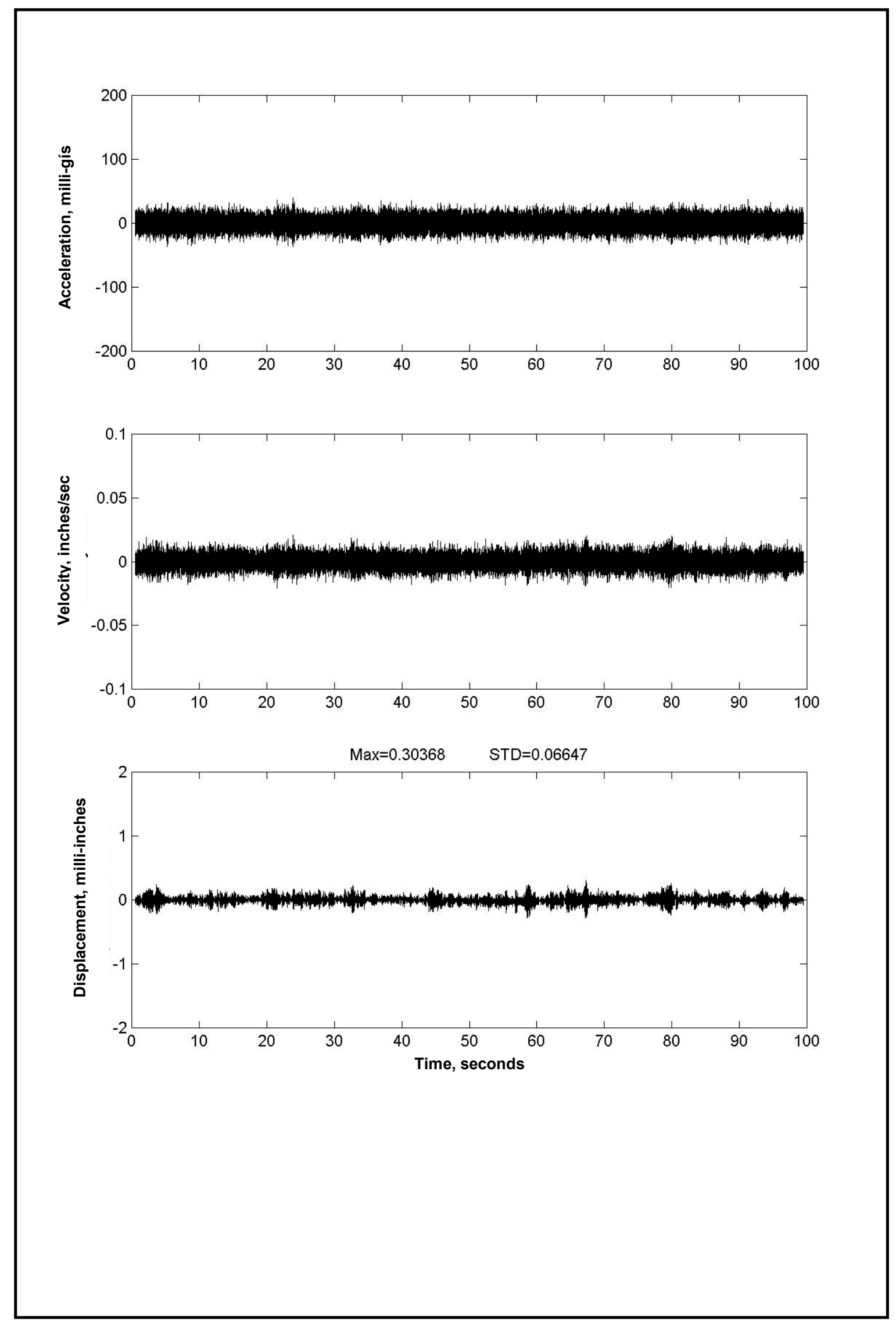

Figure 43. Transverse accelerations, Gate 5, raised position, 2.0-ft opening, 06/02/00 


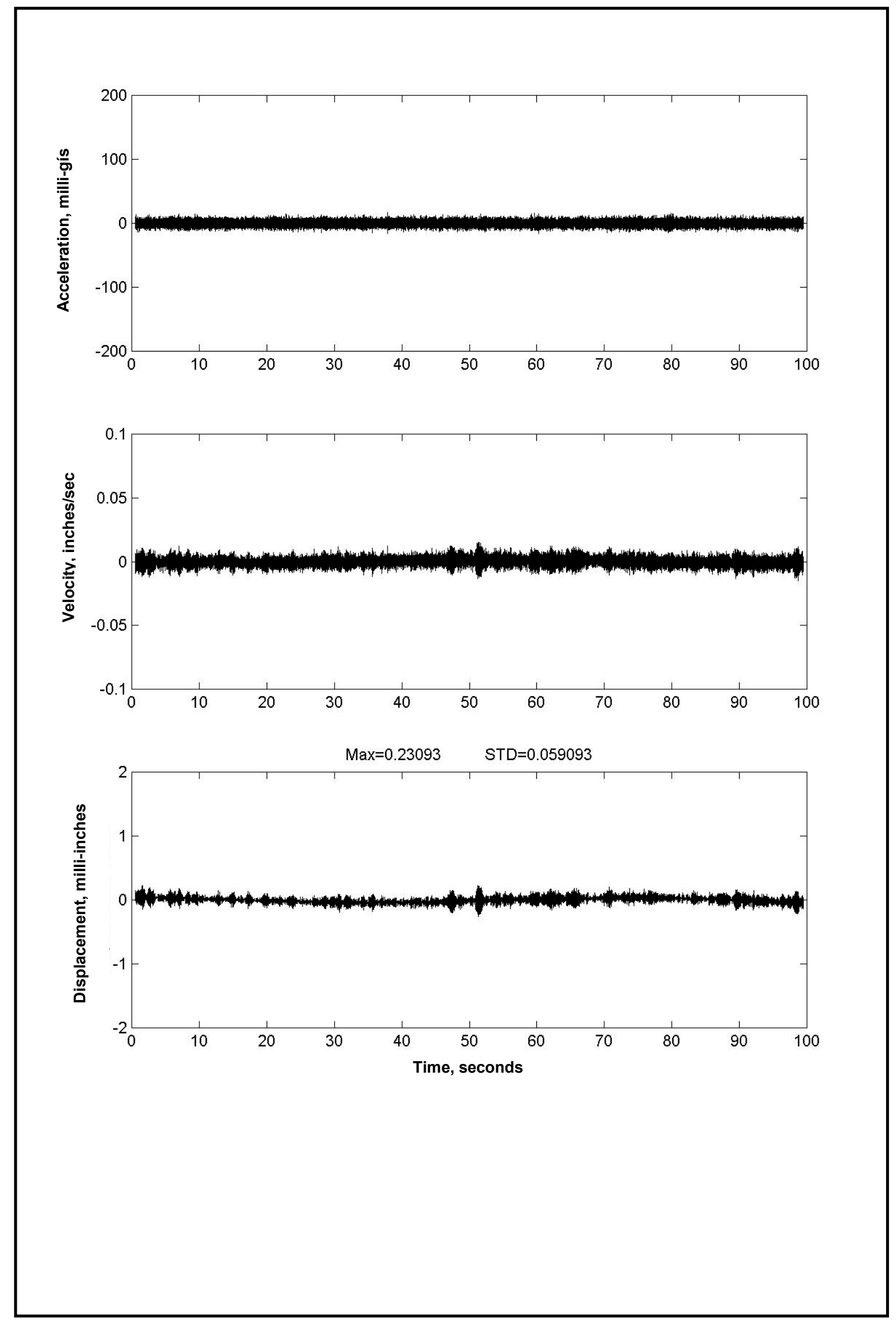

Figure 44. Vertical accelerations, Gate 7, raised position, 5.0-ft opening, 06/02/00 

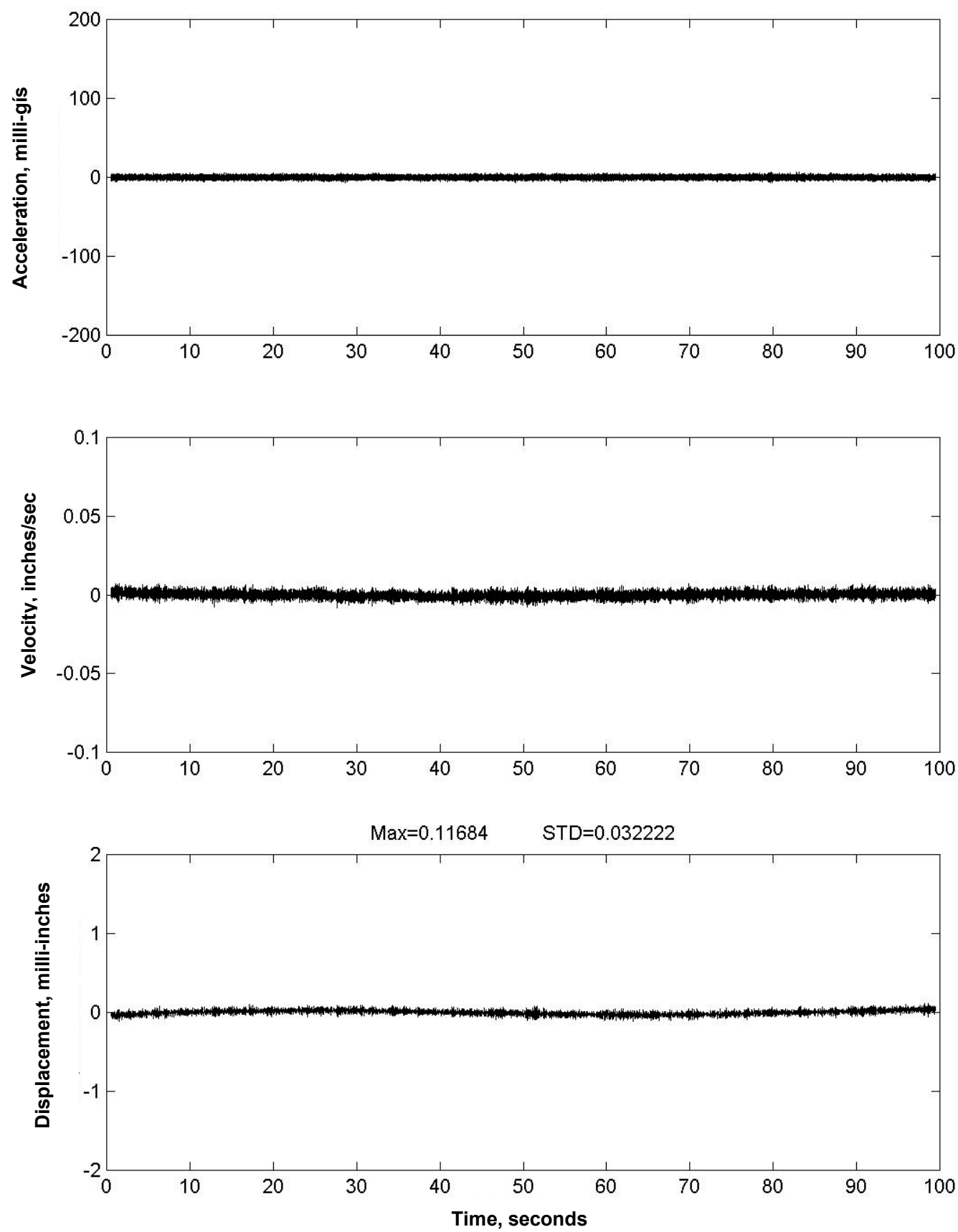

Figure 45. Radial accelerations, Gate 7, raised position, 5.0-ft opening, 06/02/00 

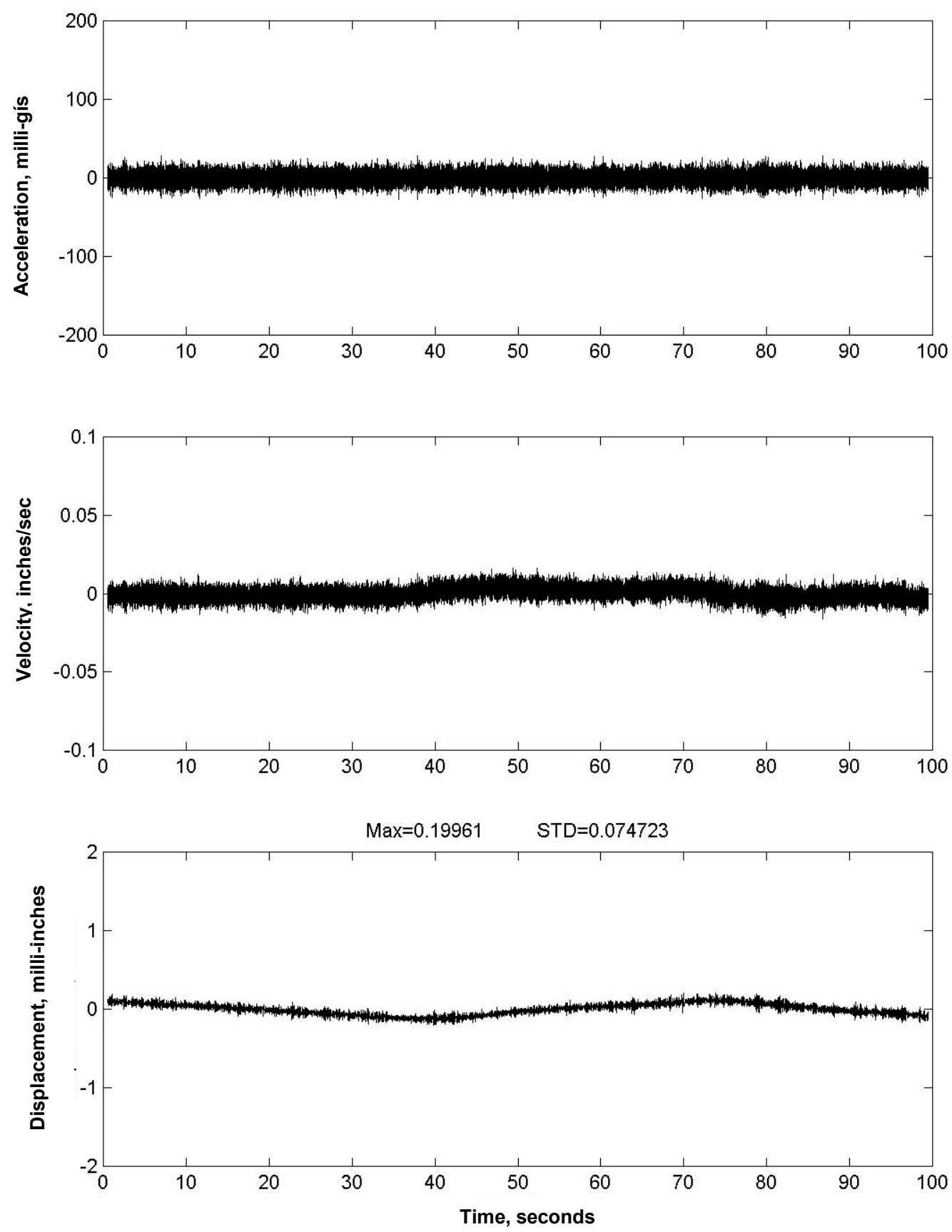

Figure 46. Transverse accelerations, Gate 7, raised position, 5.0-ft opening, 06/02/00 

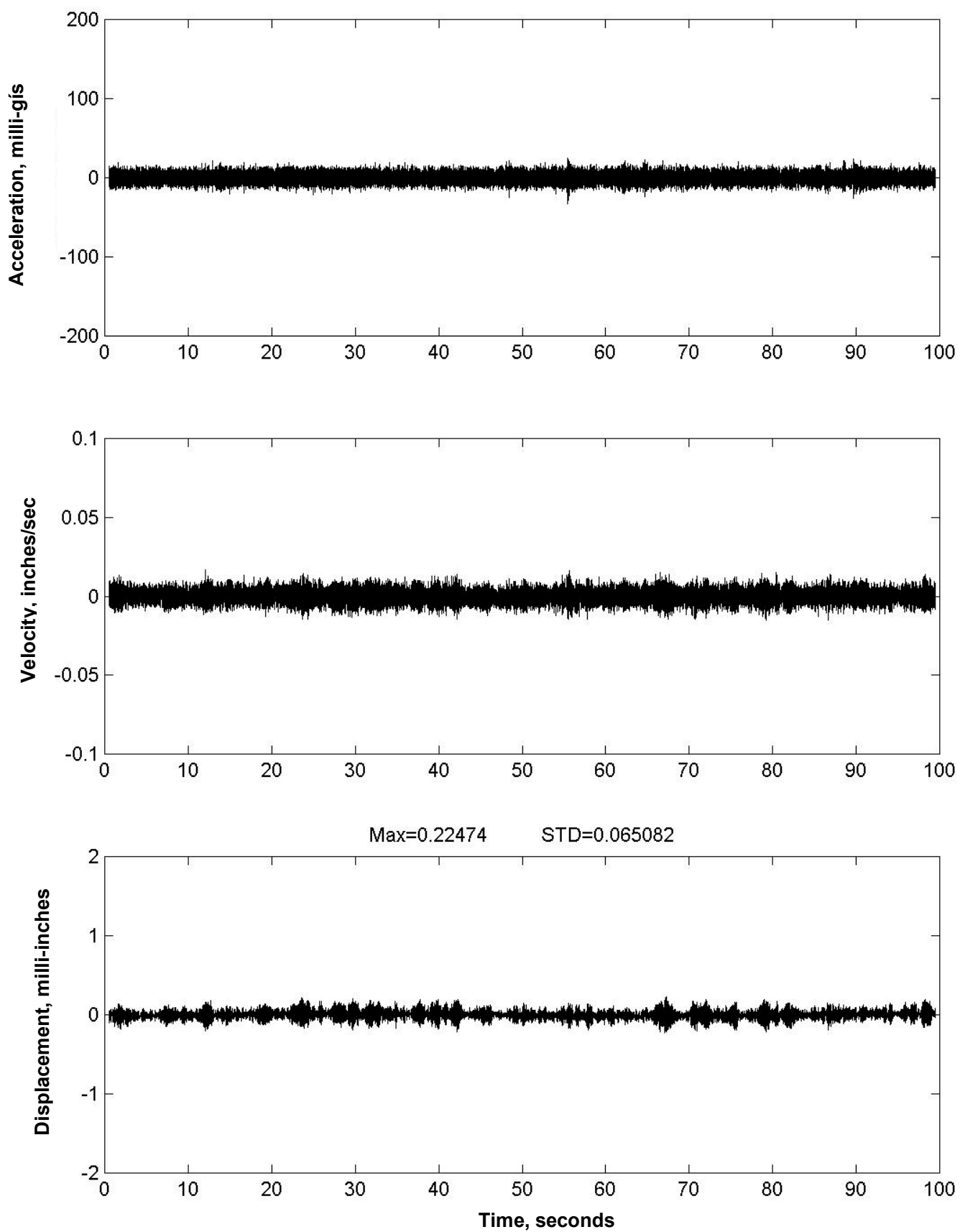

Figure 47. Vertical accelerations, Gate 5, raised position, 5.0-ft opening, 04/21/00 

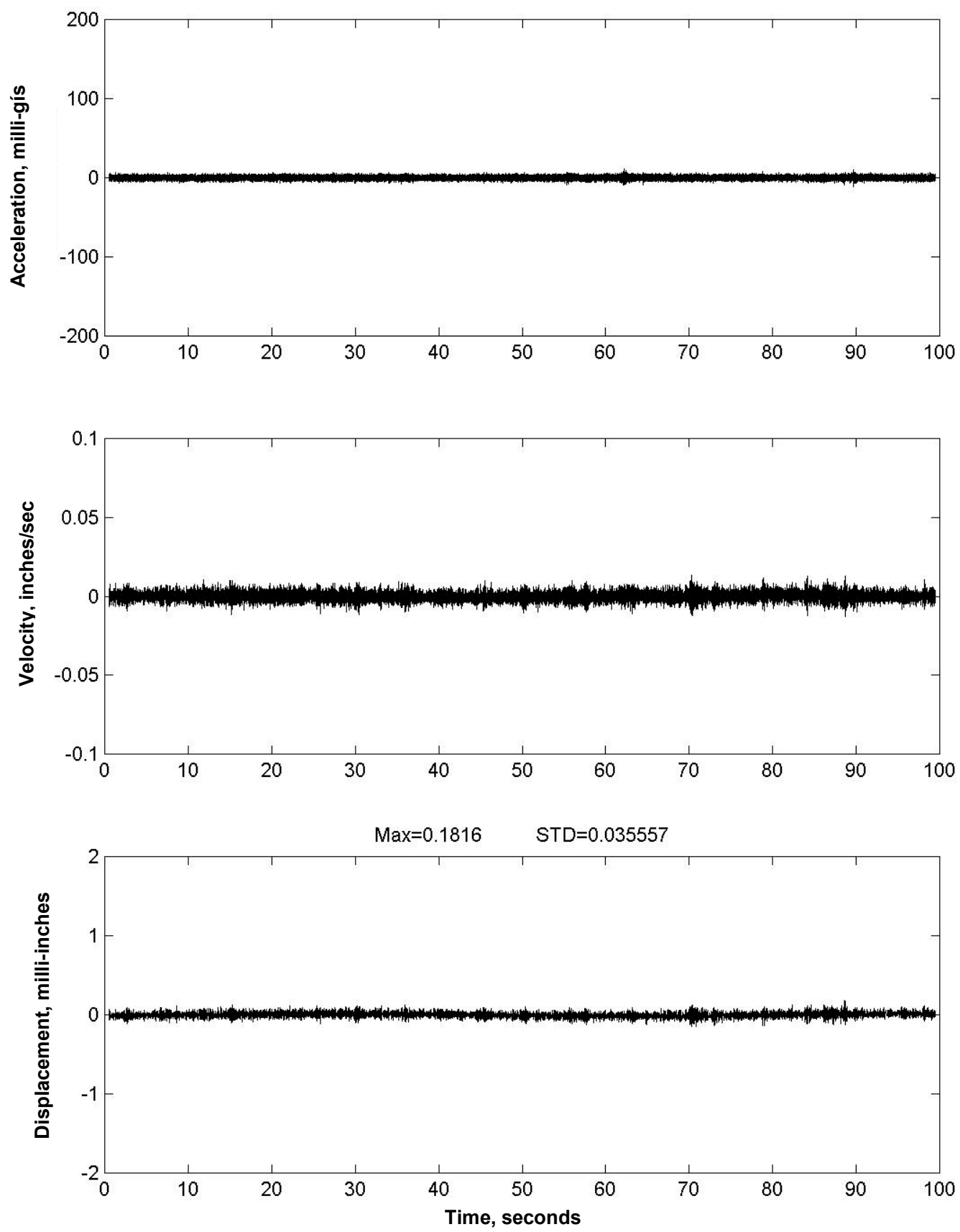

Figure 48. Radial accelerations, Gate 5, raised position, 5.0-ft opening, 04/21/00 

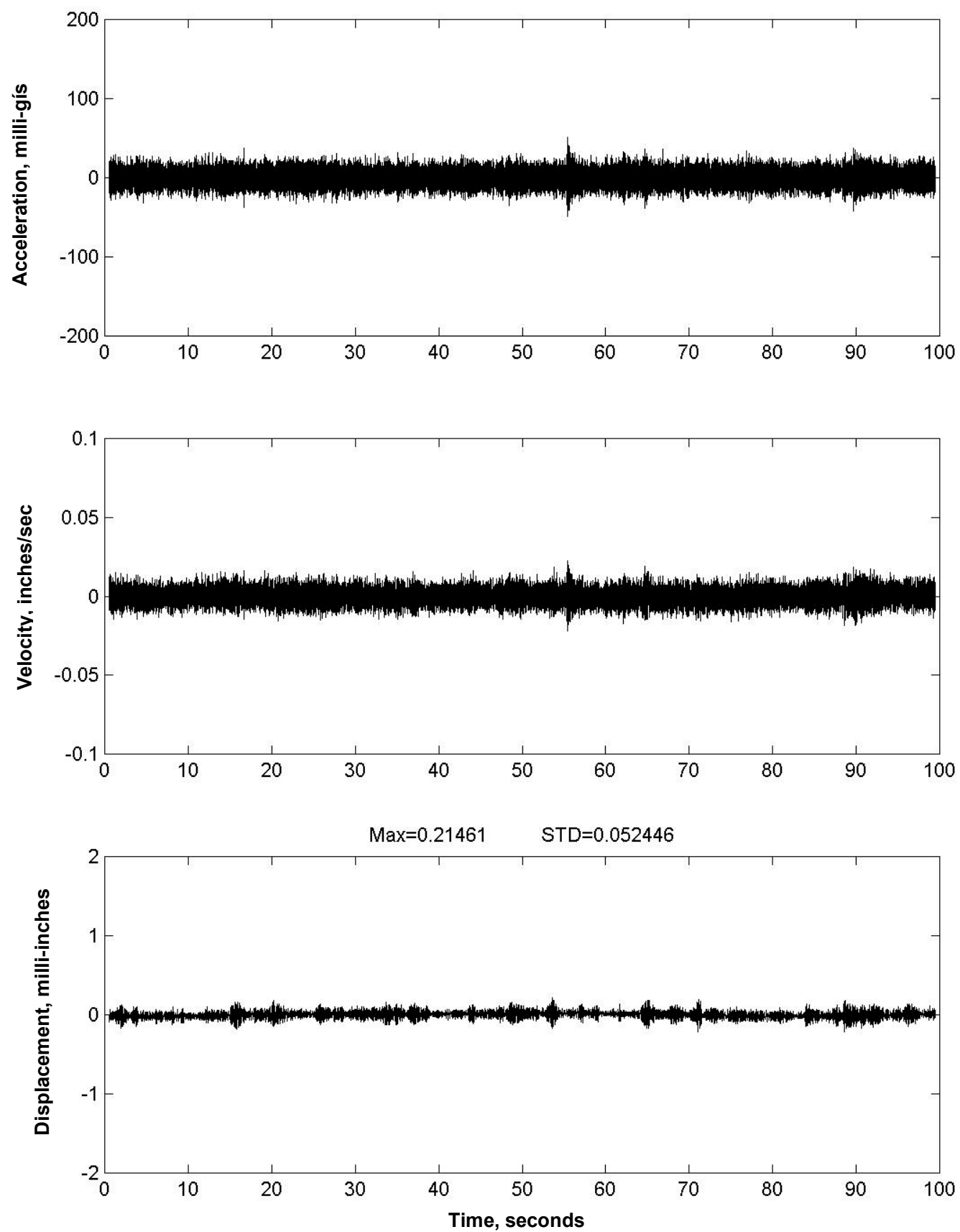

Figure 49. Transverse accelerations, Gate 5, raised position, 5.0-ft opening, 04/21/00 

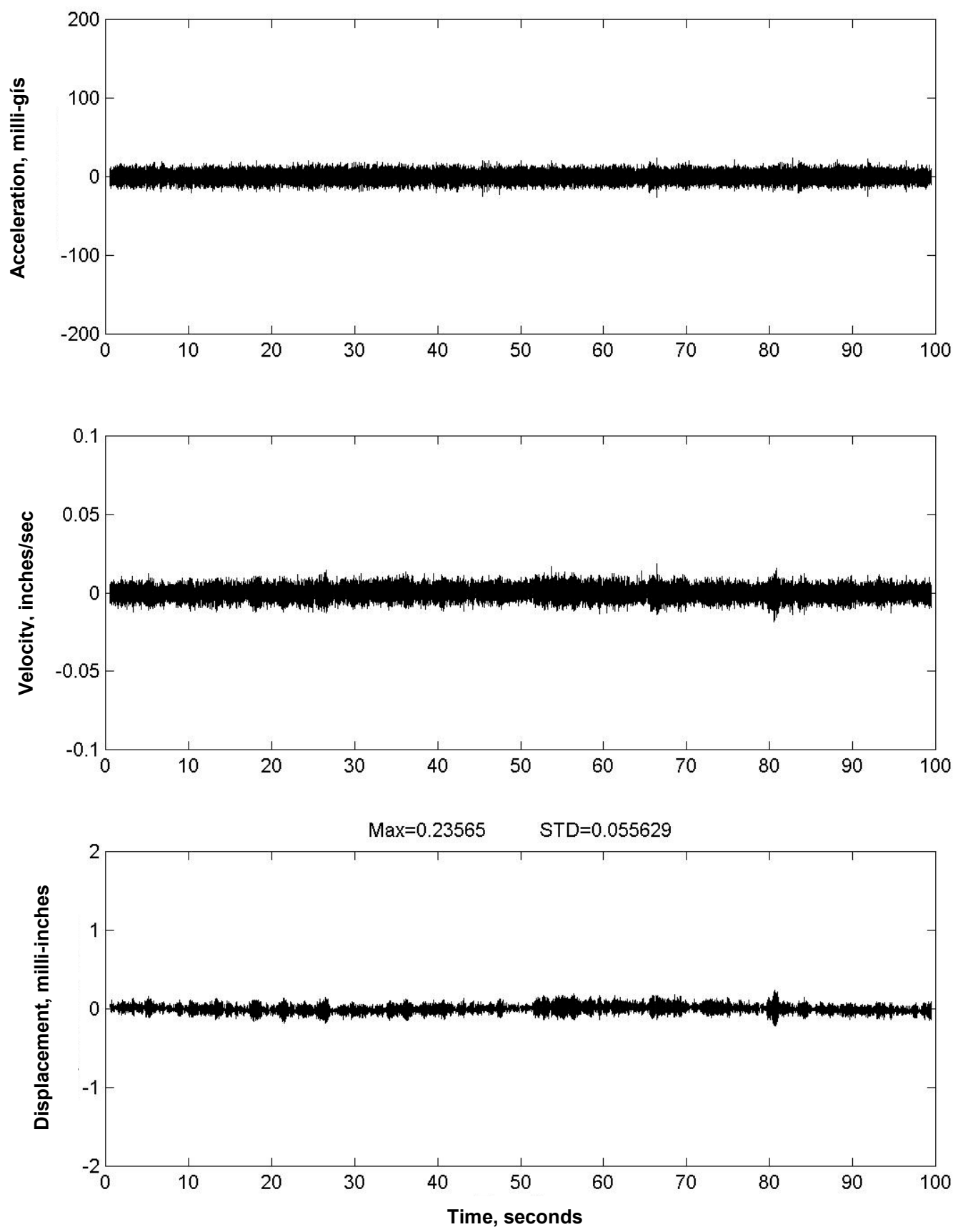

Figure 50. Vertical accelerations, Gate 7, raised position, 5.0-ft opening, 04/21/00 

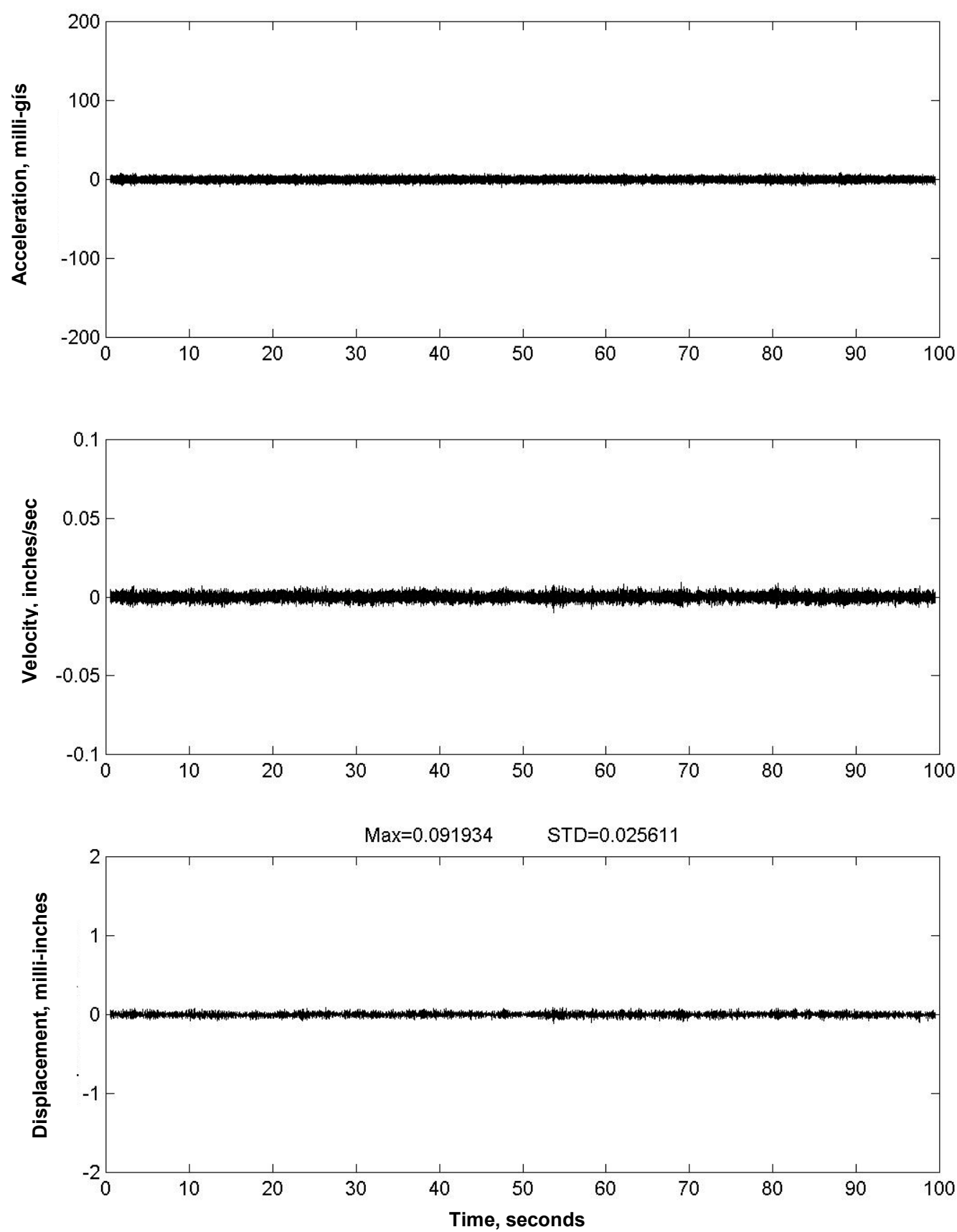

Figure 51. Radial accelerations, Gate 7, raised position, 5.0-ft opening, 04/21/00 

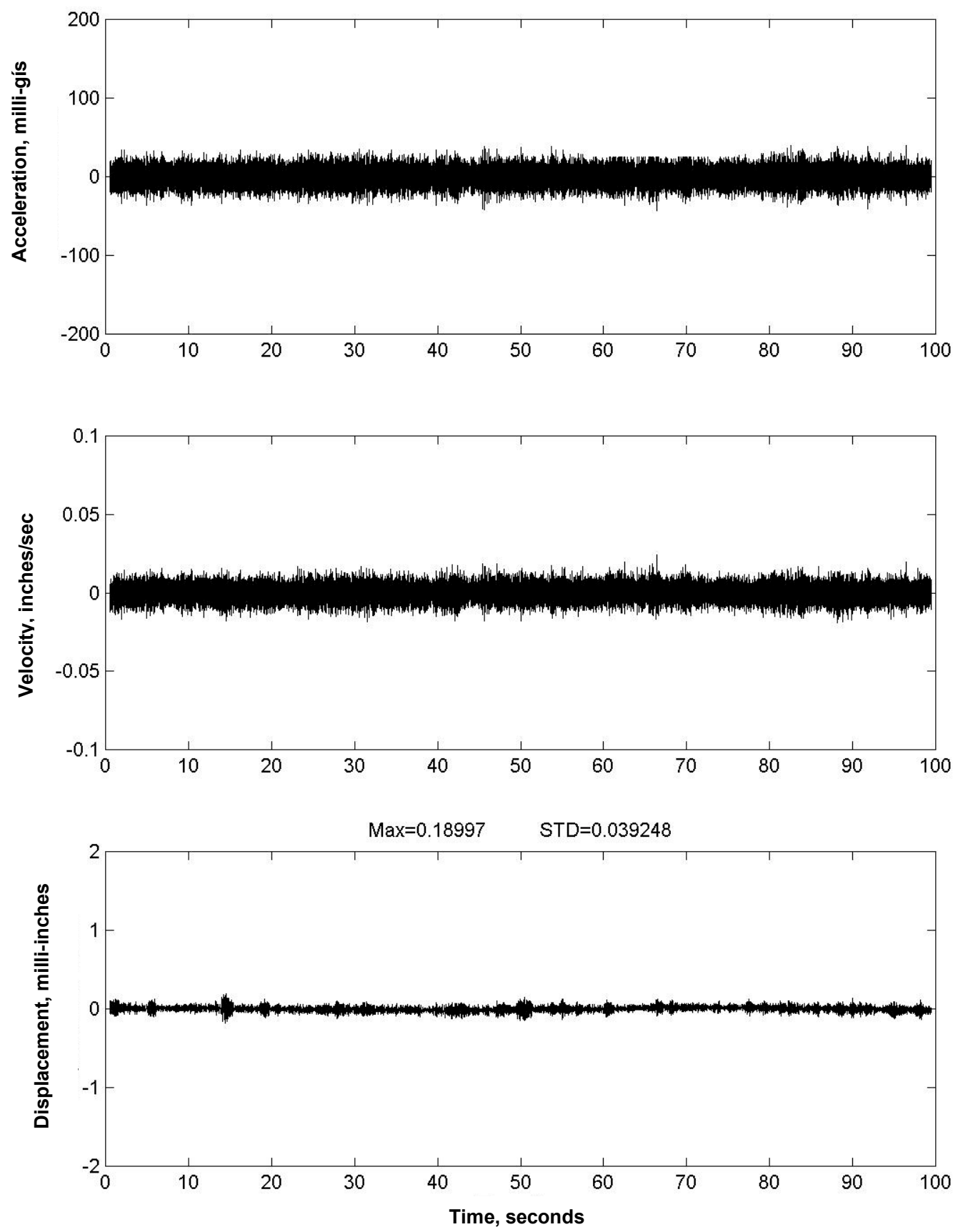

Figure 52. Transverse accelerations, Gate 7, raised position, 5.0-ft opening, 04/21/00 

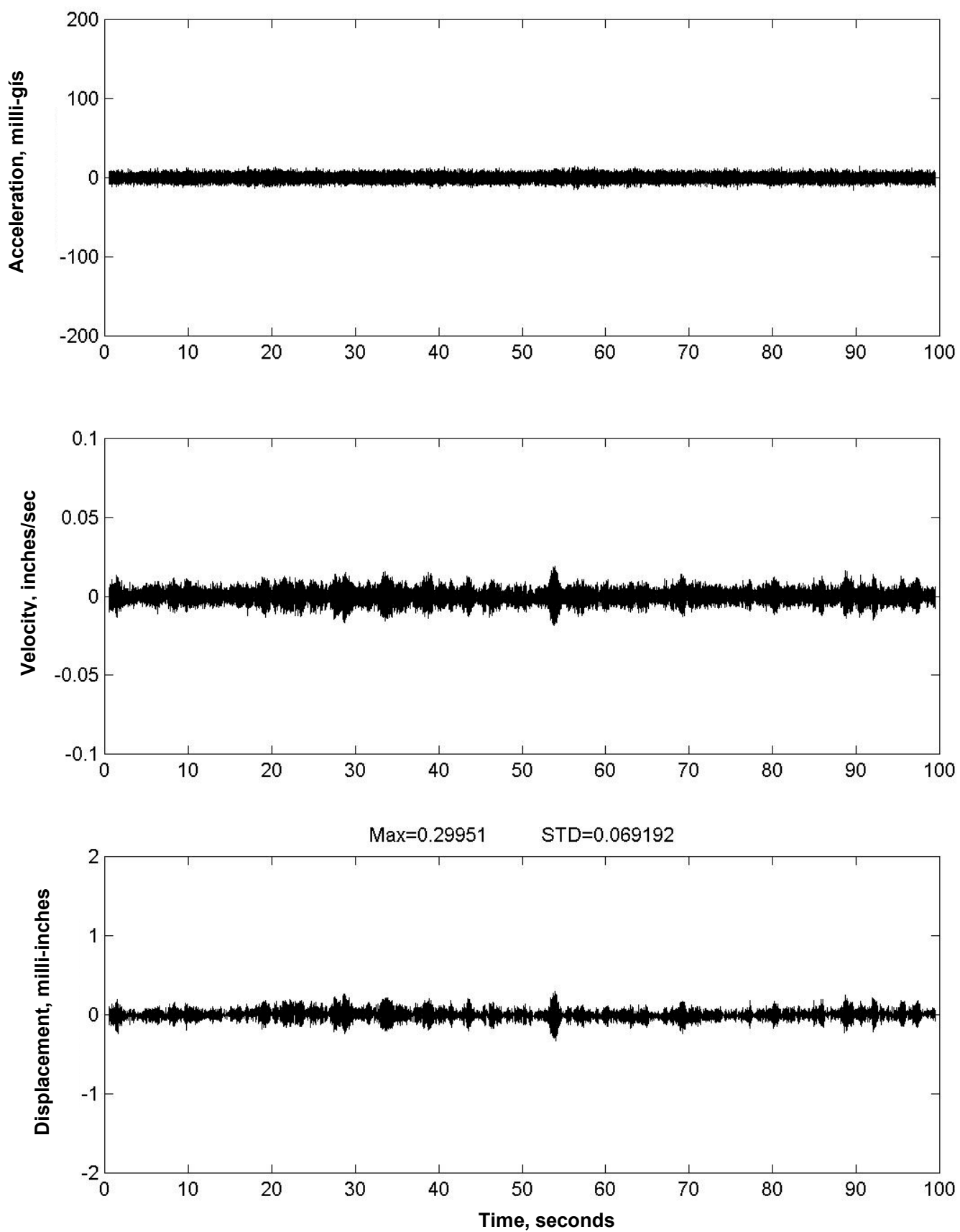

Figure 53. Vertical accelerations, Gate 3, raised position, 1.0-ft opening, 04/22/00 

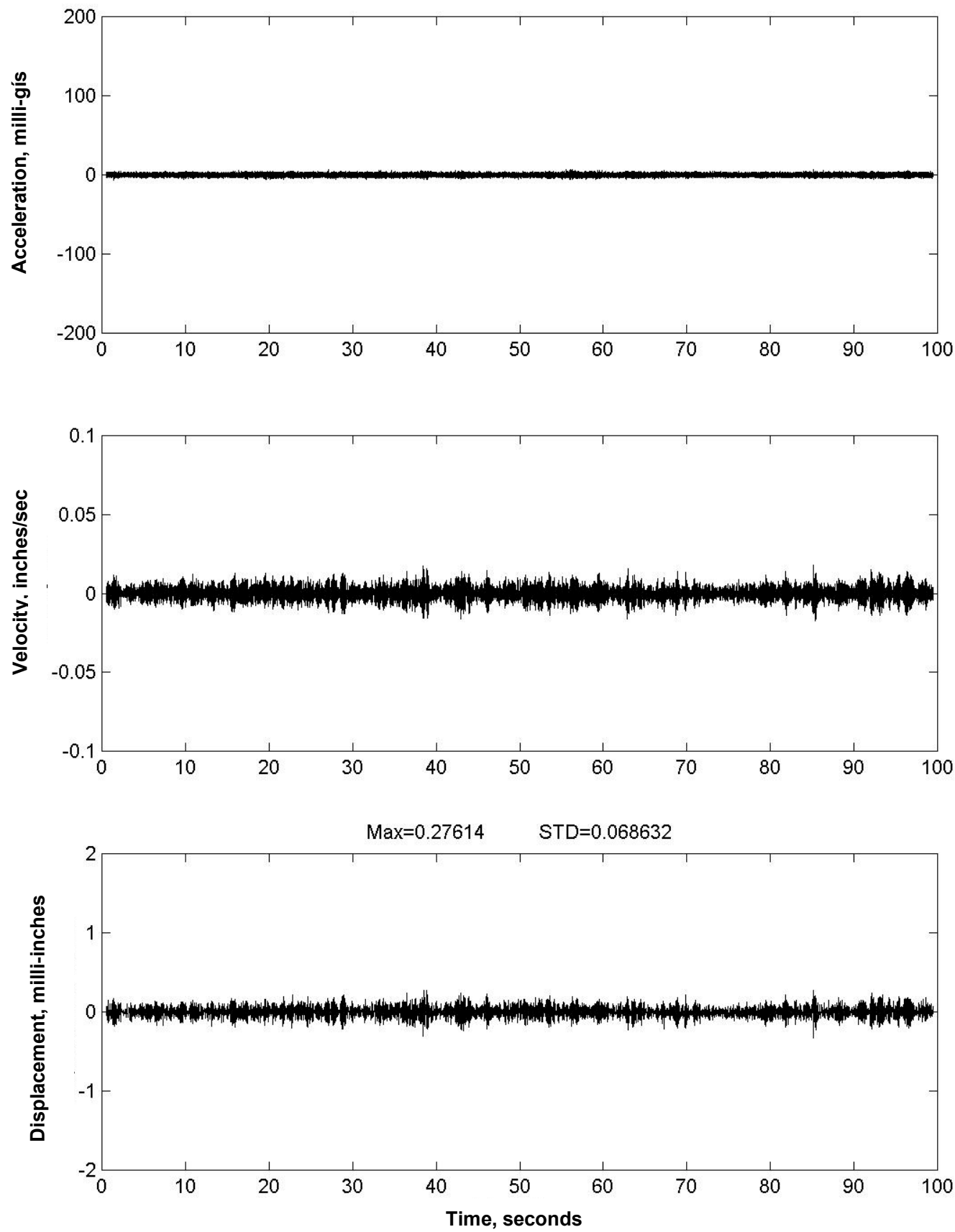

Figure 54. Radial accelerations, Gate 3, raised position, 1.0-ft opening, 04/22/00 

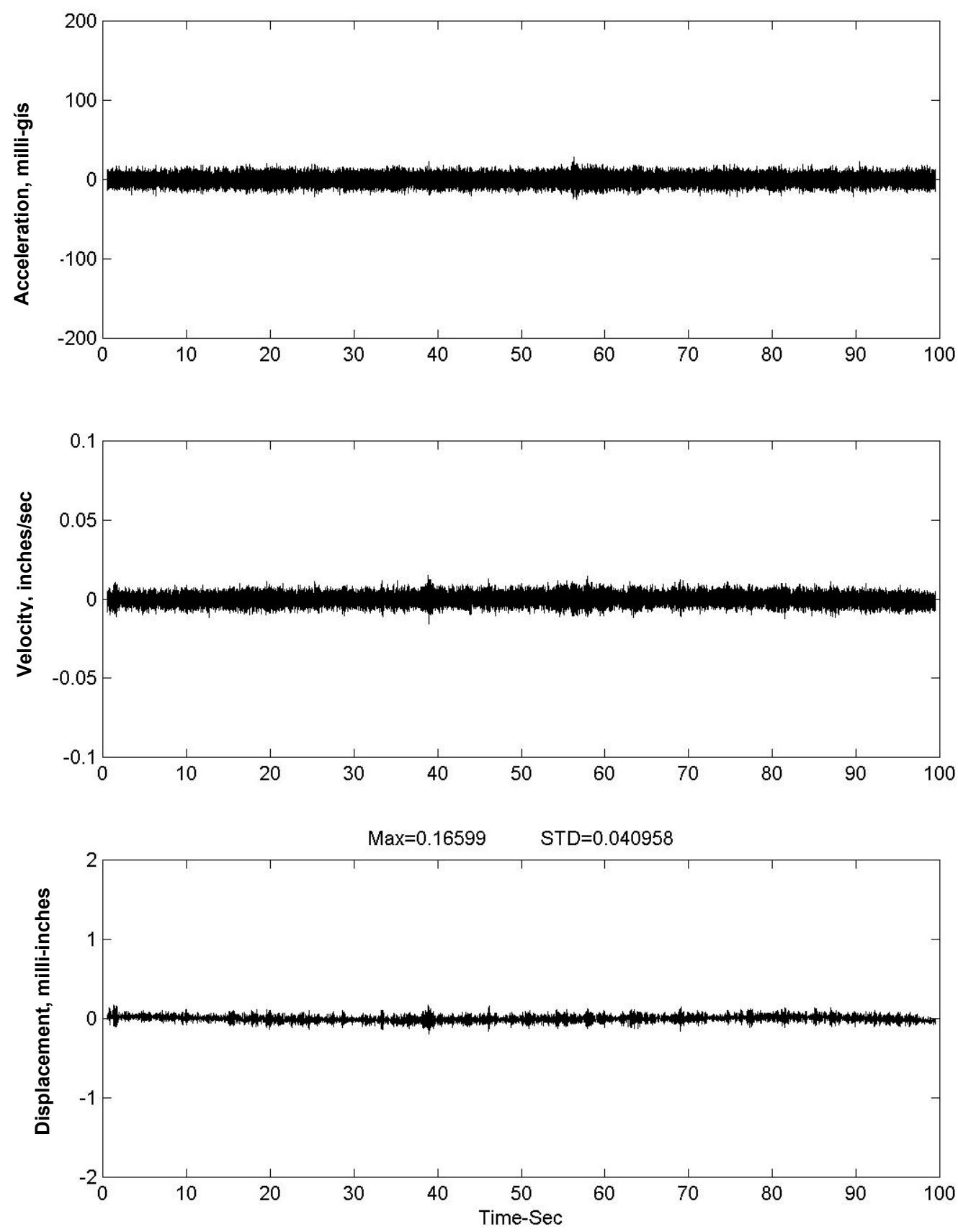

Time, seconds

Figure 55. Tansverse accelerations, Gate 3, raised position, 1.0-ft opening, 04/22/00 

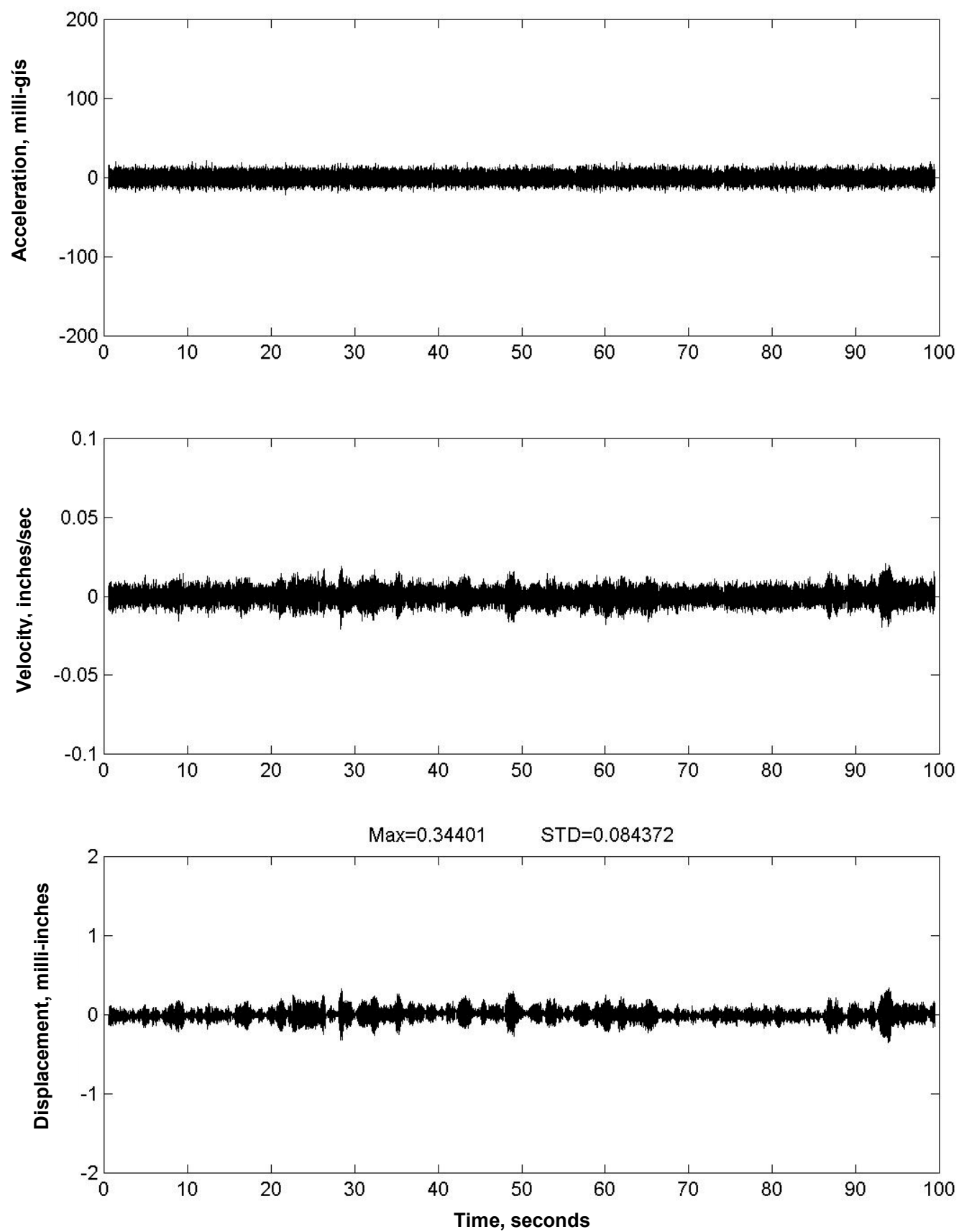

Figure 56. Vertical accelerations, Gate 5, raised position, 5.0-ft opening, 04/22/00 

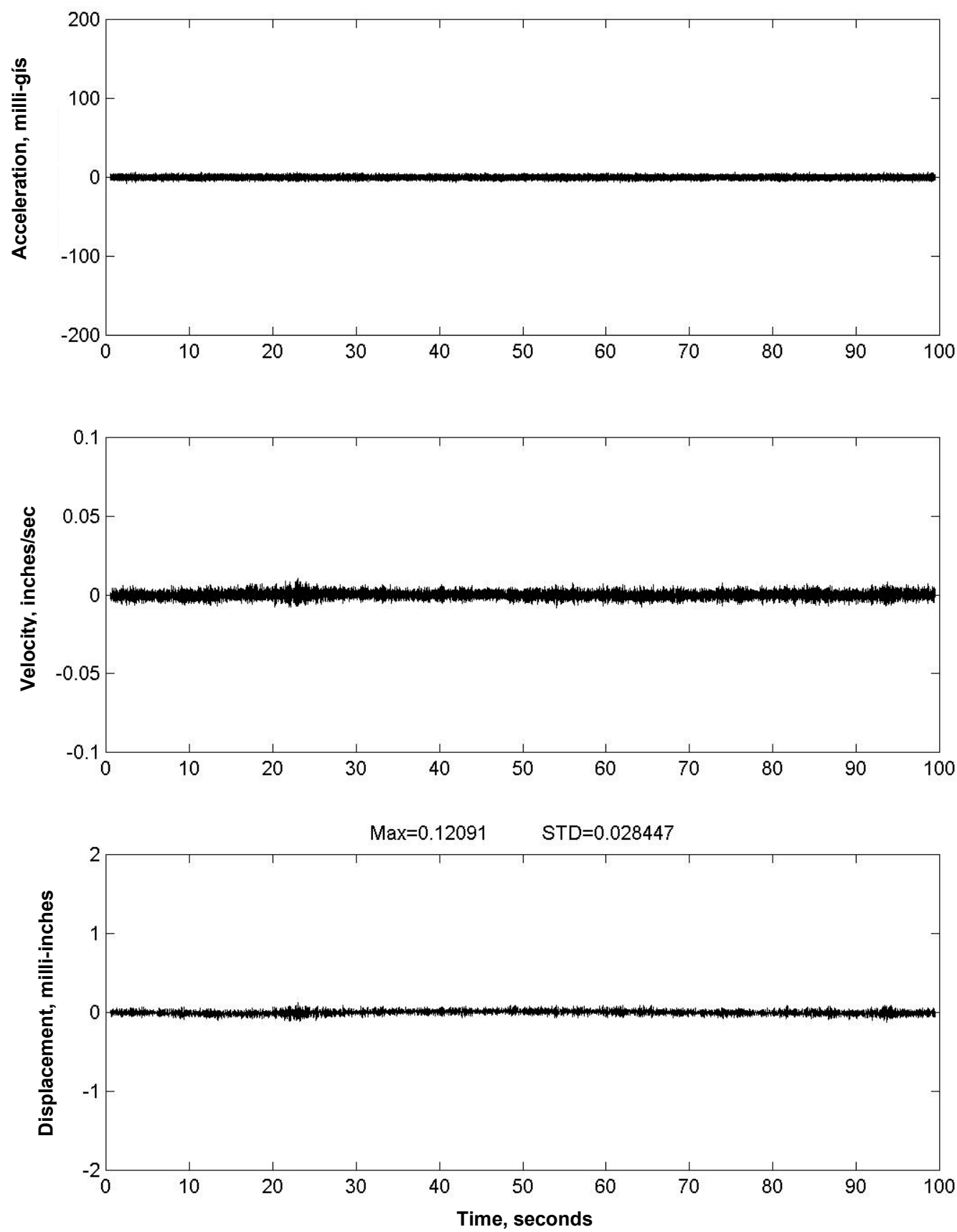

Figure 57. Radial accelerations, Gate 5, raised position, 5.0-ft opening, 04/22/00 

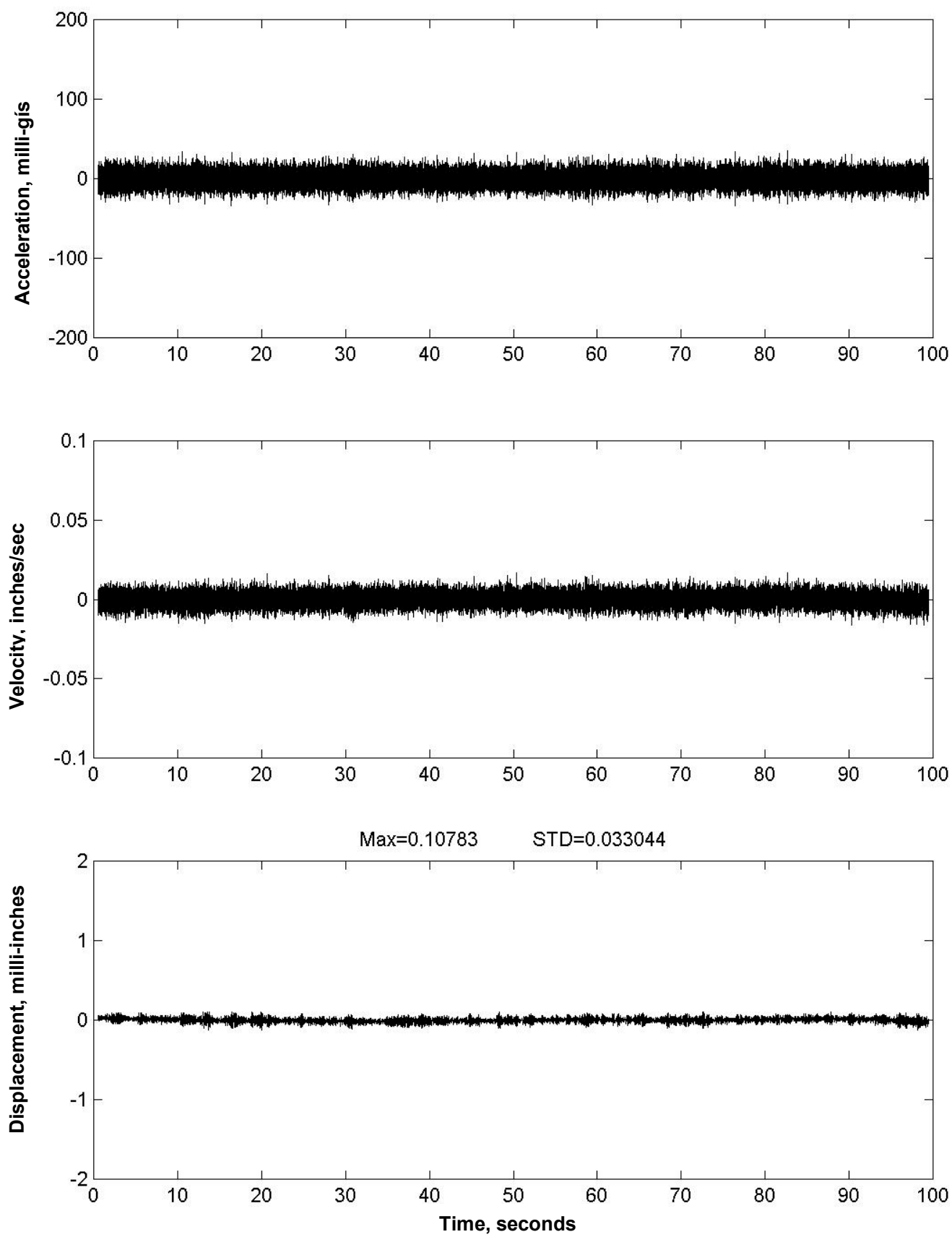

Figure 58. Transverse accelerations, Gate 5, raised position, 5.0-ft opening, 04/22/00 

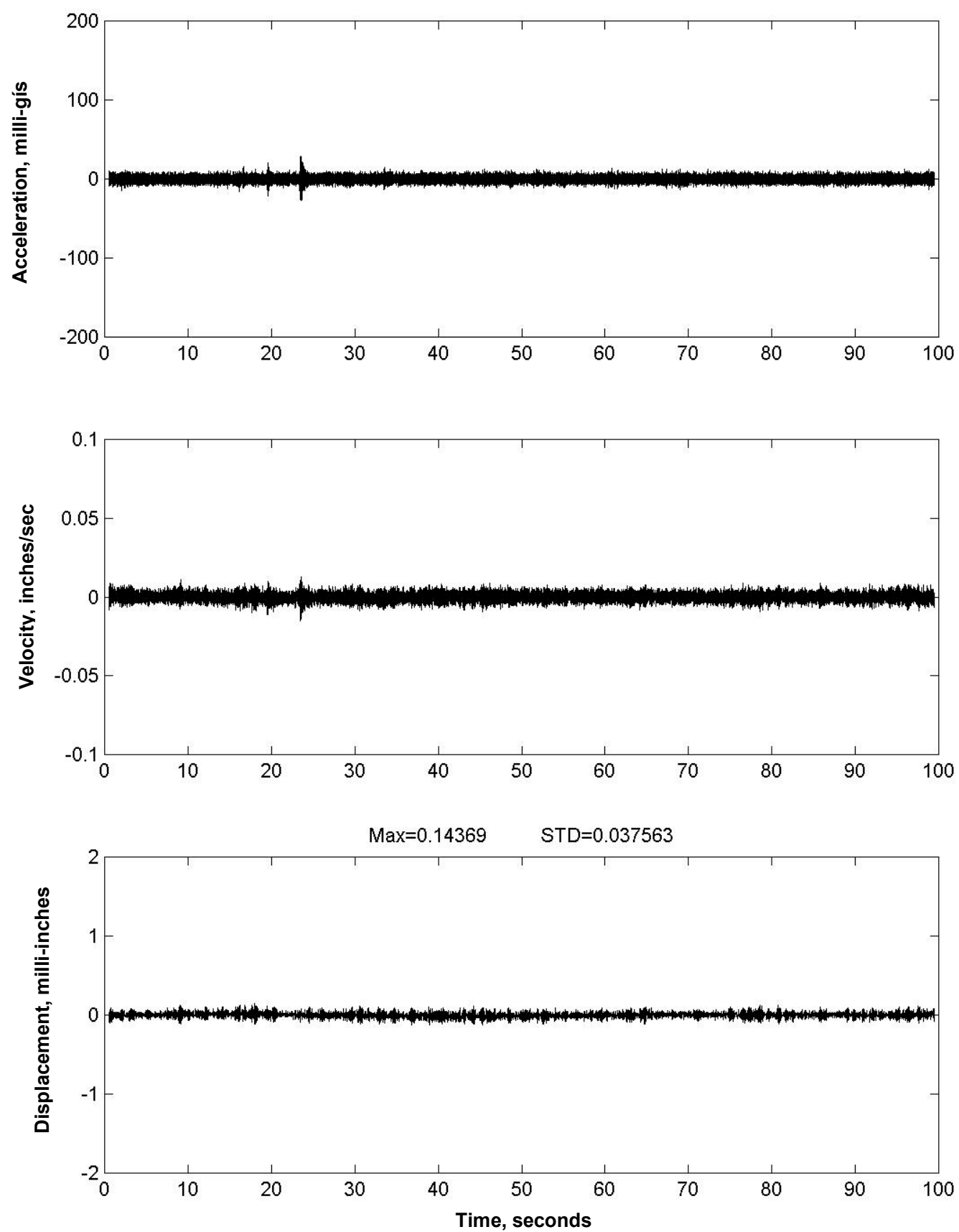

Figure 59. Vertical accelerations, Gate 7, raised position, 5.0-ft opening, 04/22/00 

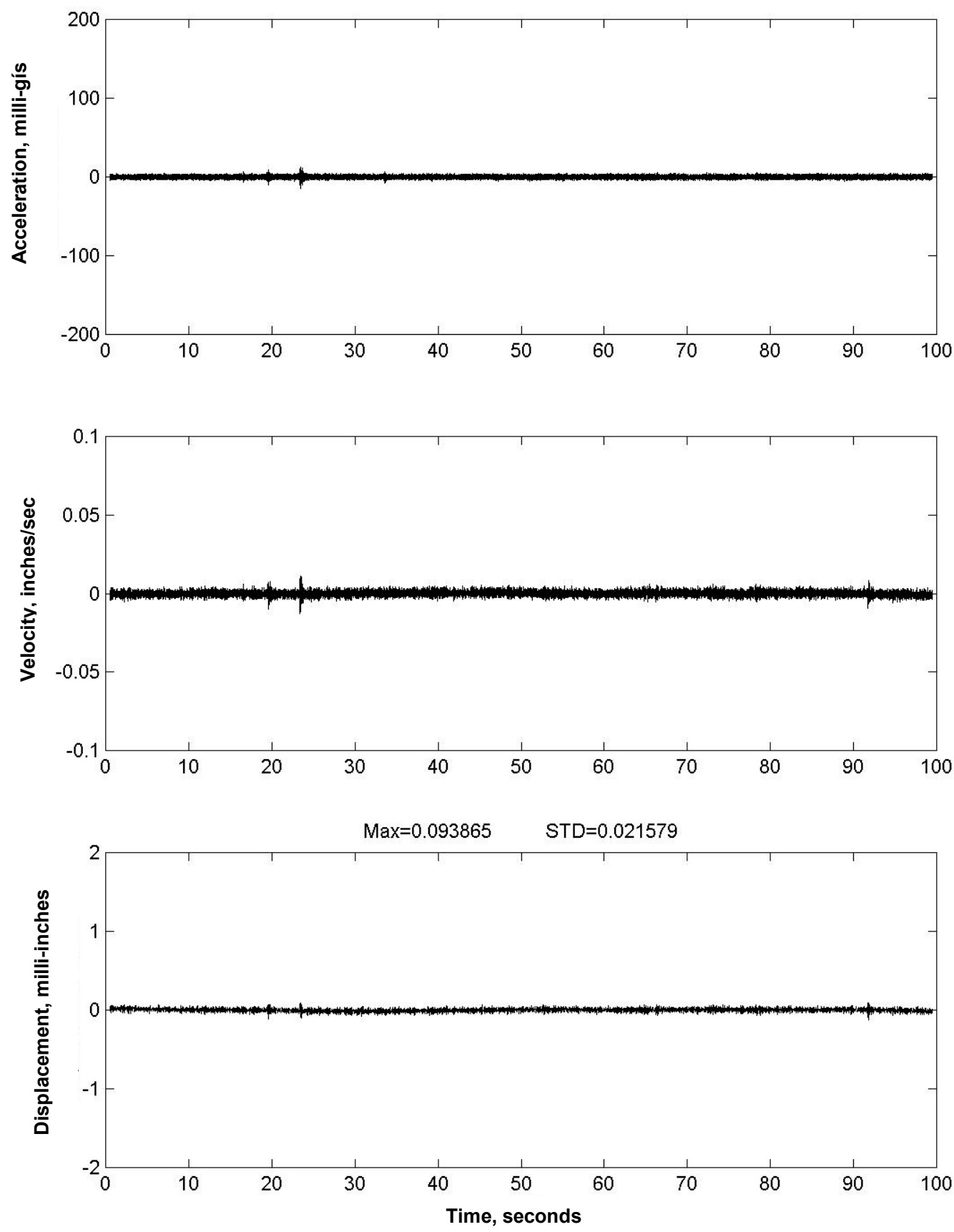

Figure 60. Radial accelerations, Gate 7, raised position, 5.0-ft opening, 04/22/00 


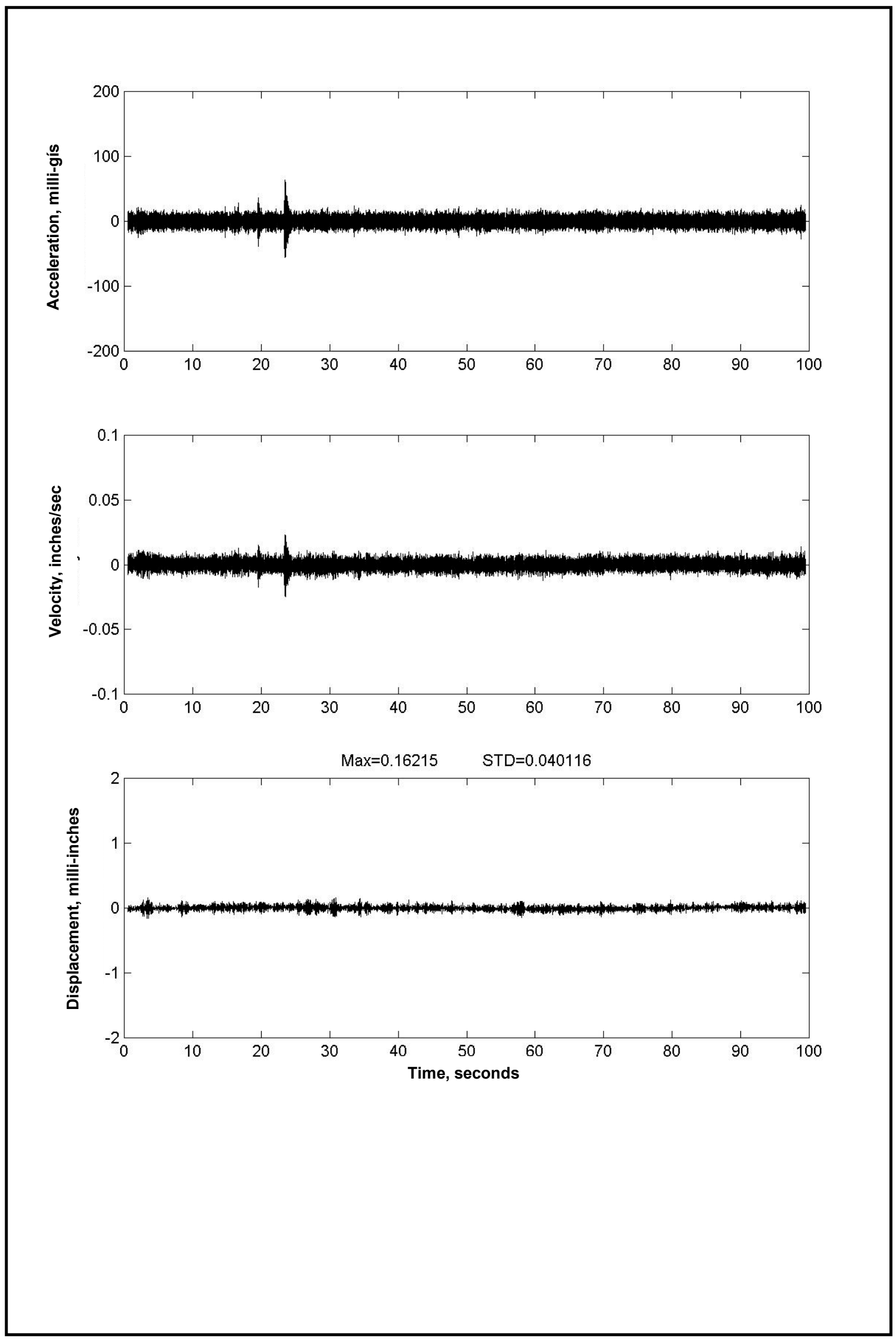

Figure 61. Transverse accelerations, Gate 7, raised position, 5.0-ft opening, 04/22/00 

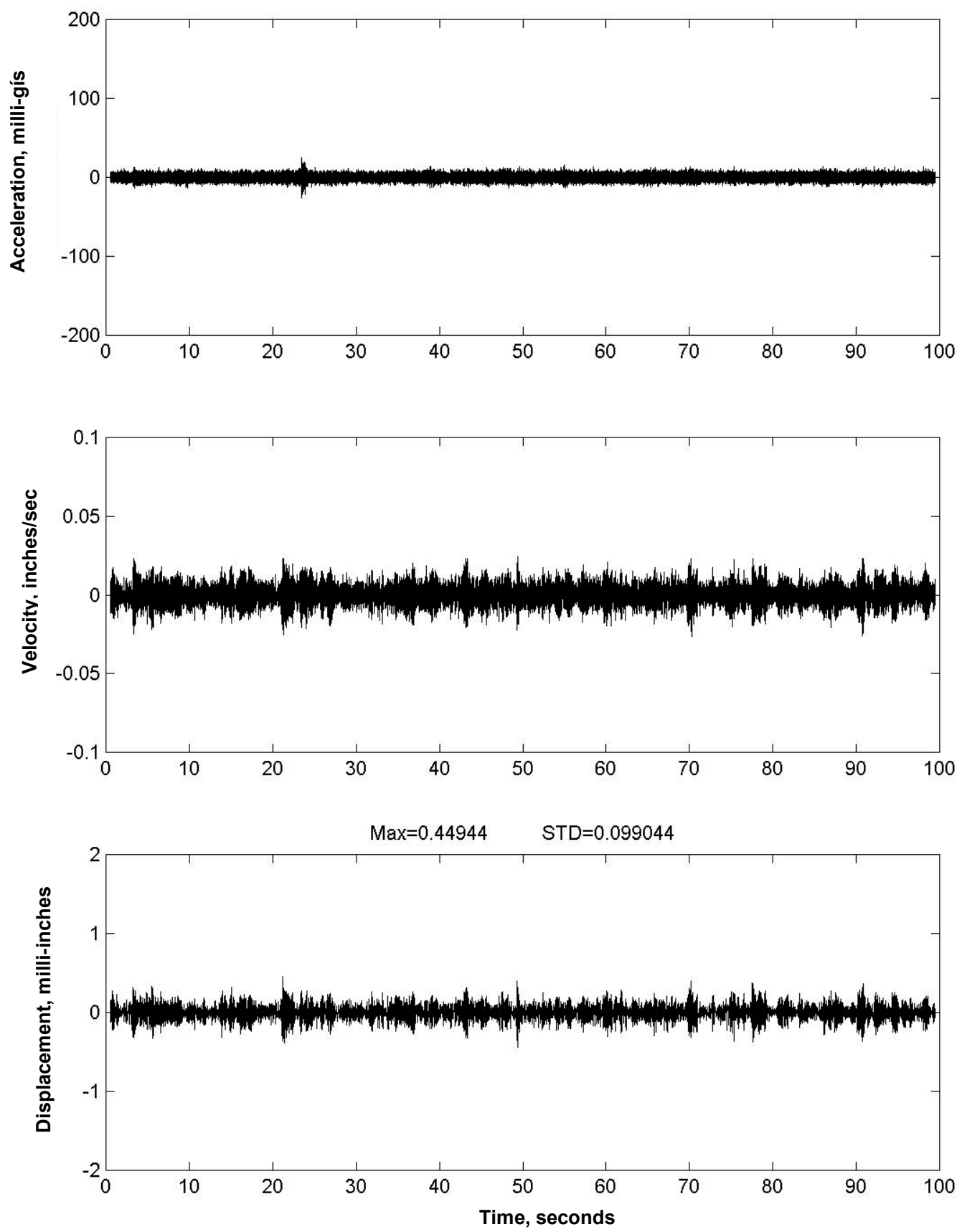

Figure 62. Vertical accelerations, Gate 3, raised position, 5.0-ft opening, 07/11/00 

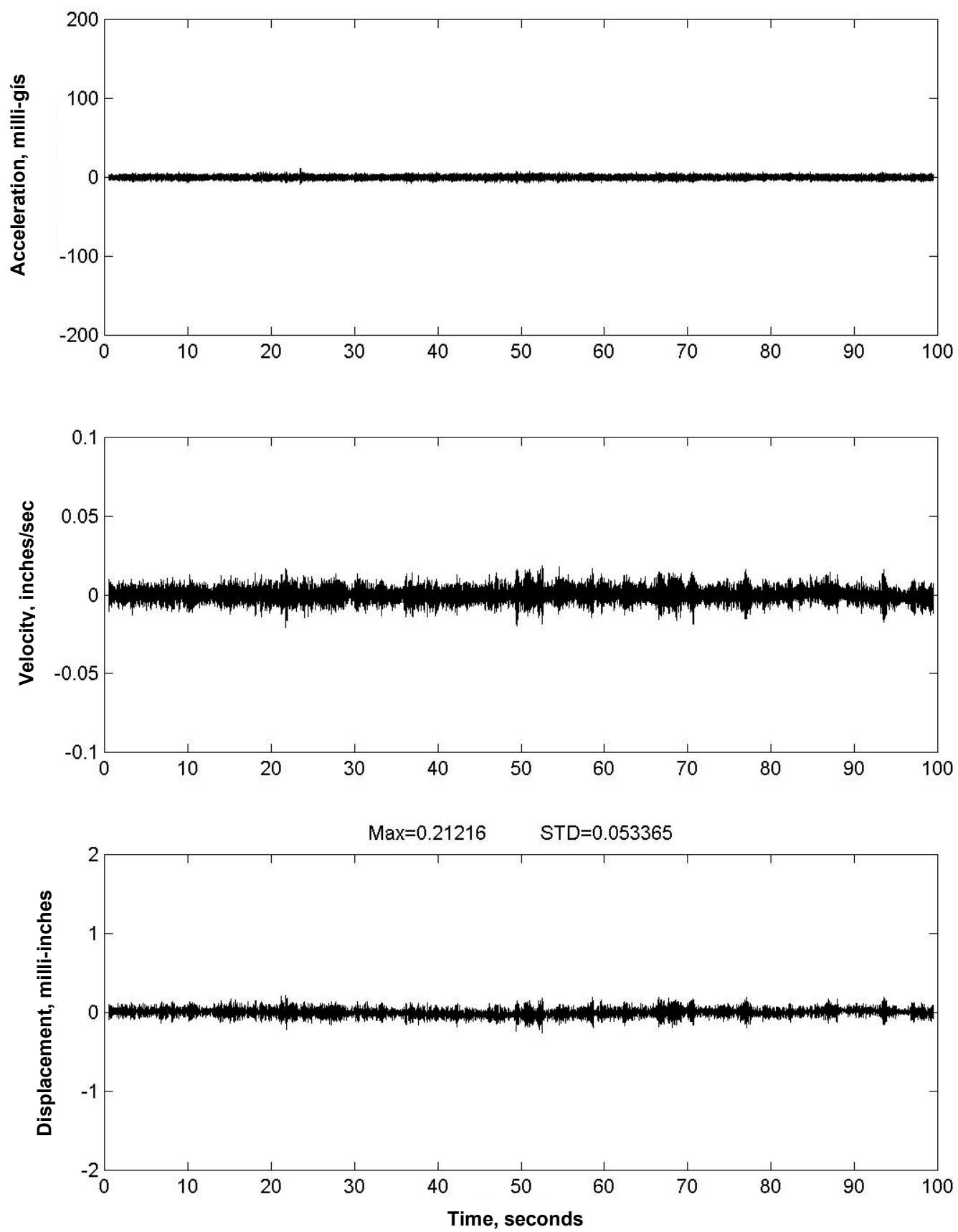

Figure 63. Radial accelerations, Gate 3, raised position, 5.0-ft opening, 07/11/00 


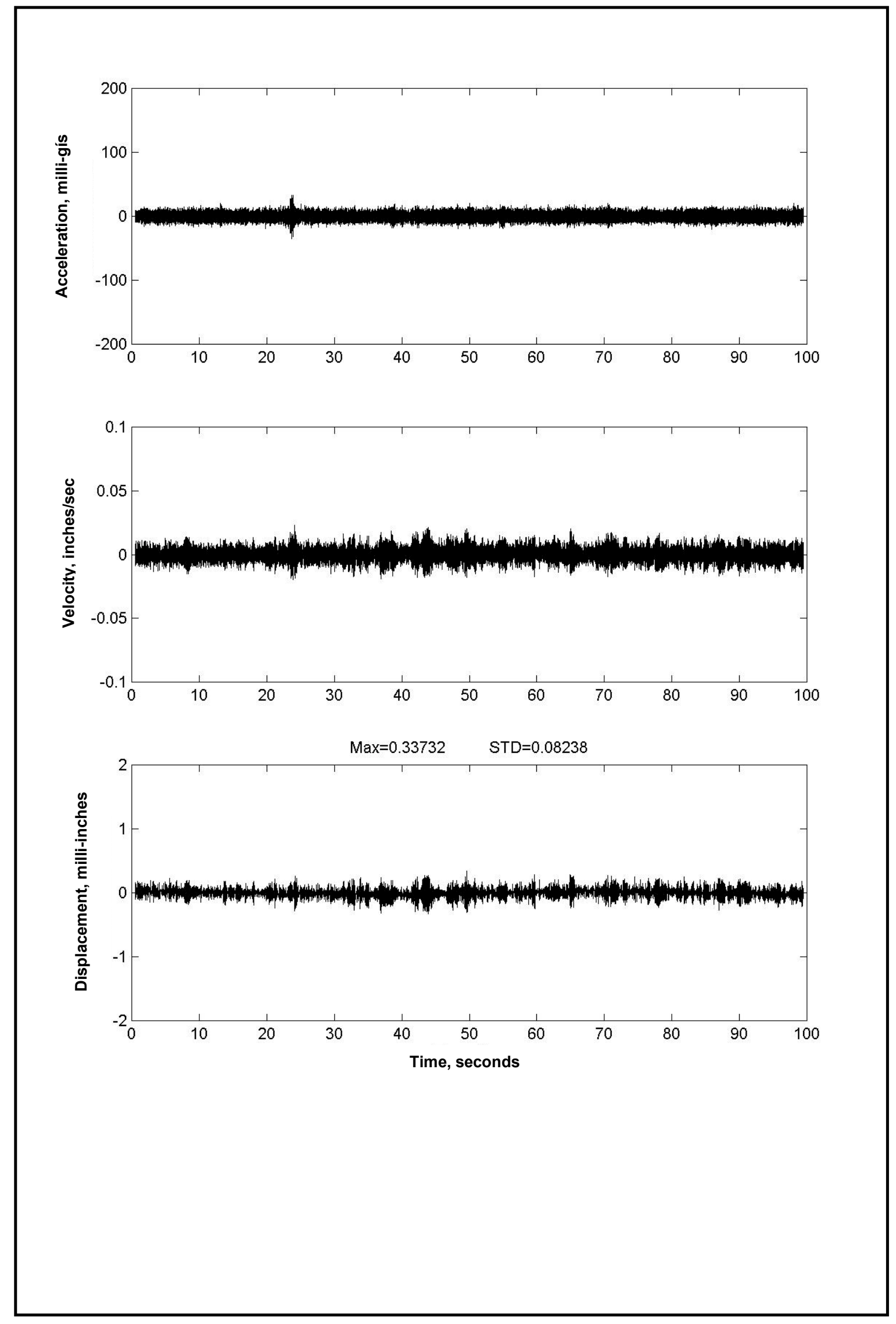

Figure 64. Transverse accelerations, Gate 7, raised position, 5.0-ft opening, 07/11/00 

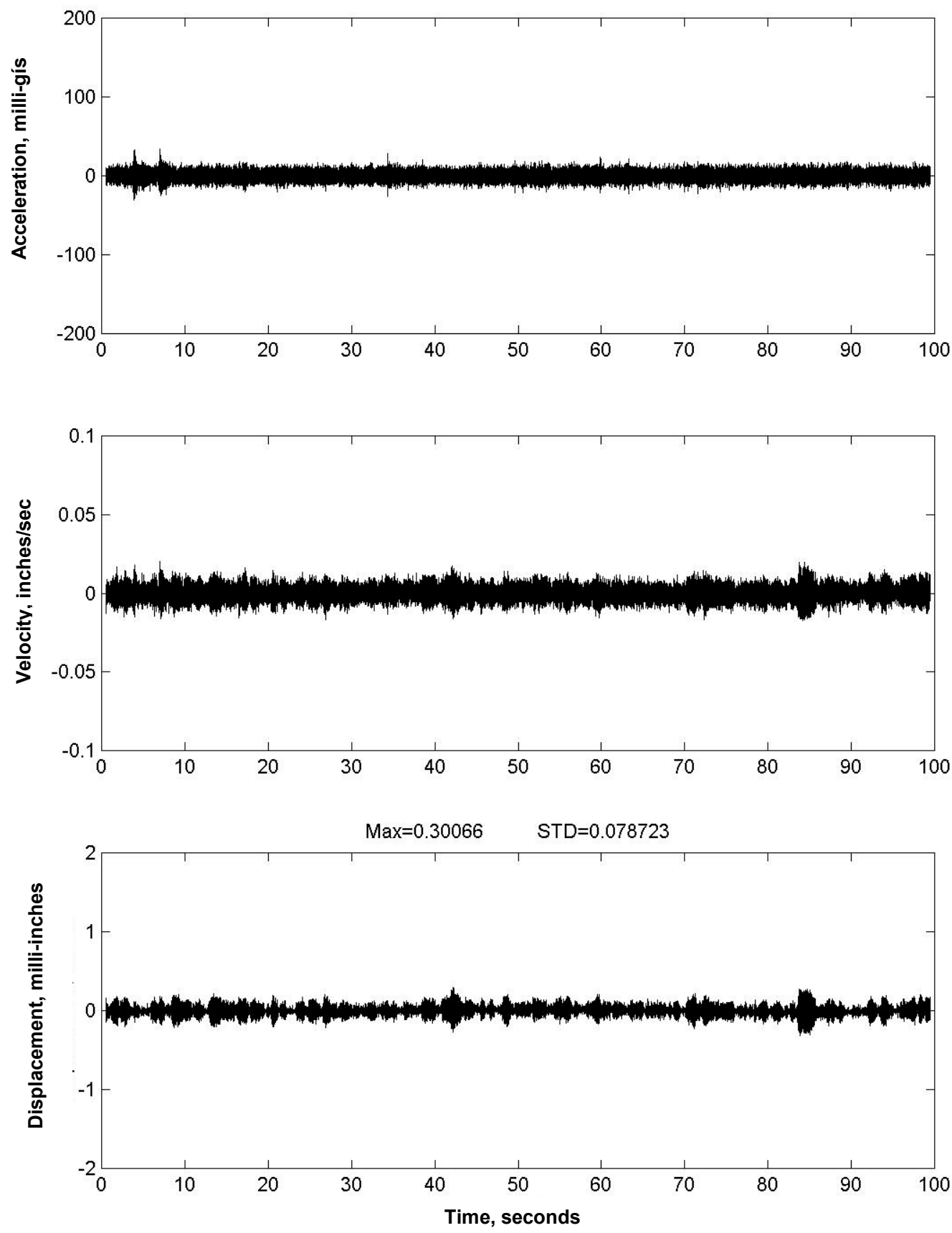

Figure 65. Vertical accelerations, Gate 5, raised position, 5.0-ft opening, 07/21/00 

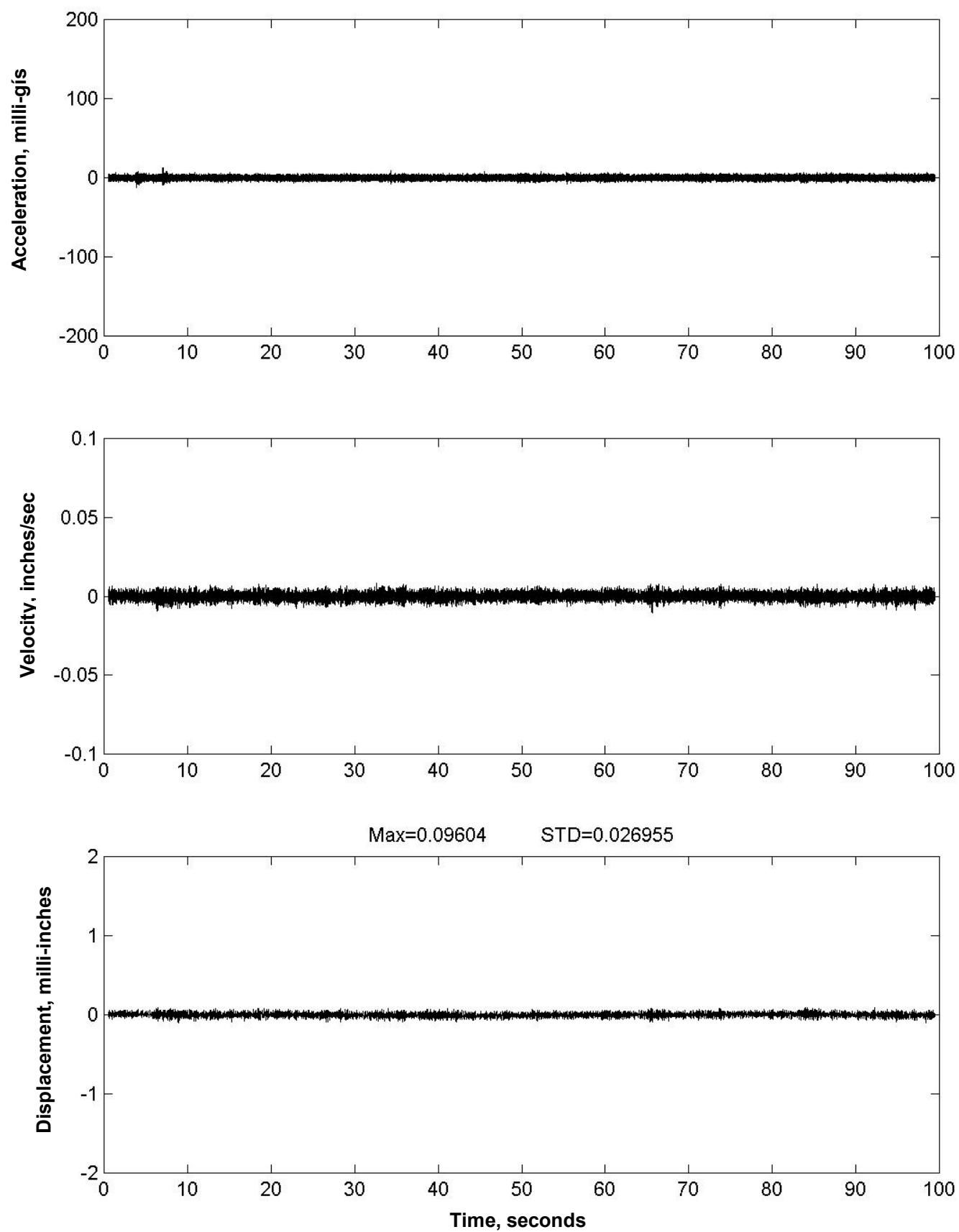

Figure 66. Radial accelerations, Gate 5, raised position, 5.0-ft opening, 07/11/00 

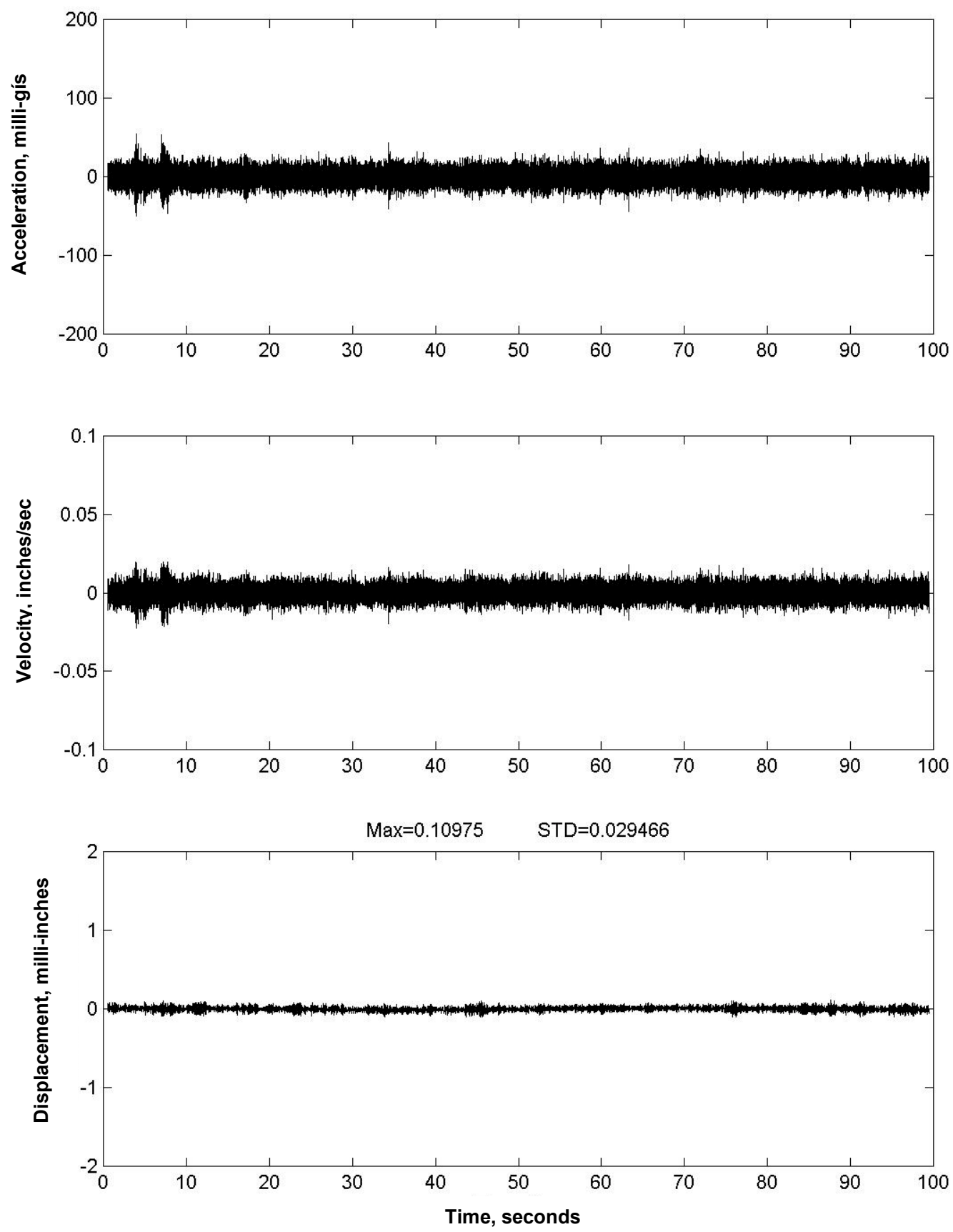

Figure 67. Transverse accelerations, Gate 5, raised position, 5.0-ft opening, 07/11/00 


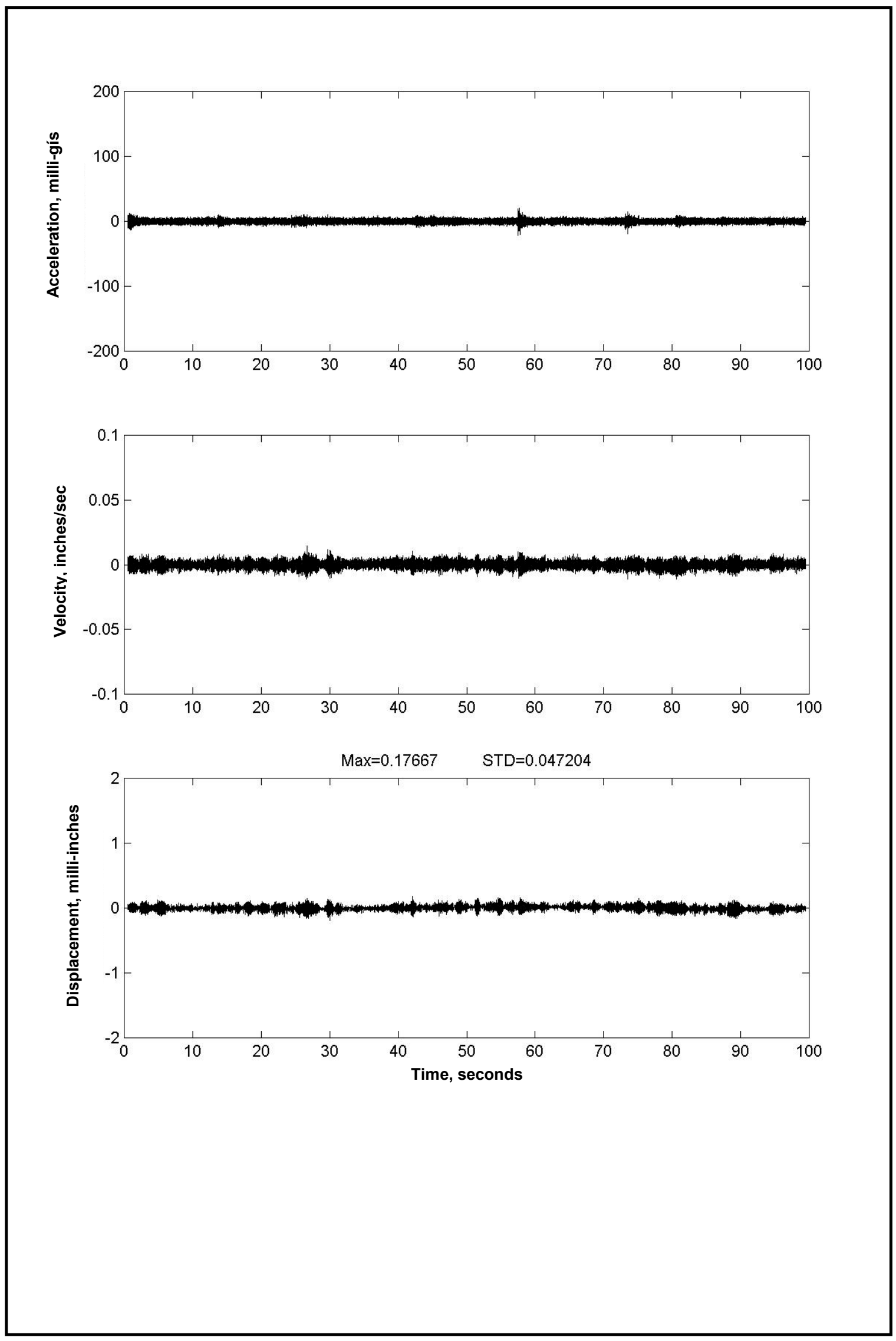

Figure 68. Vertical accelerations, Gate 7, raised position, 5.0-ft opening, 07/11/00 


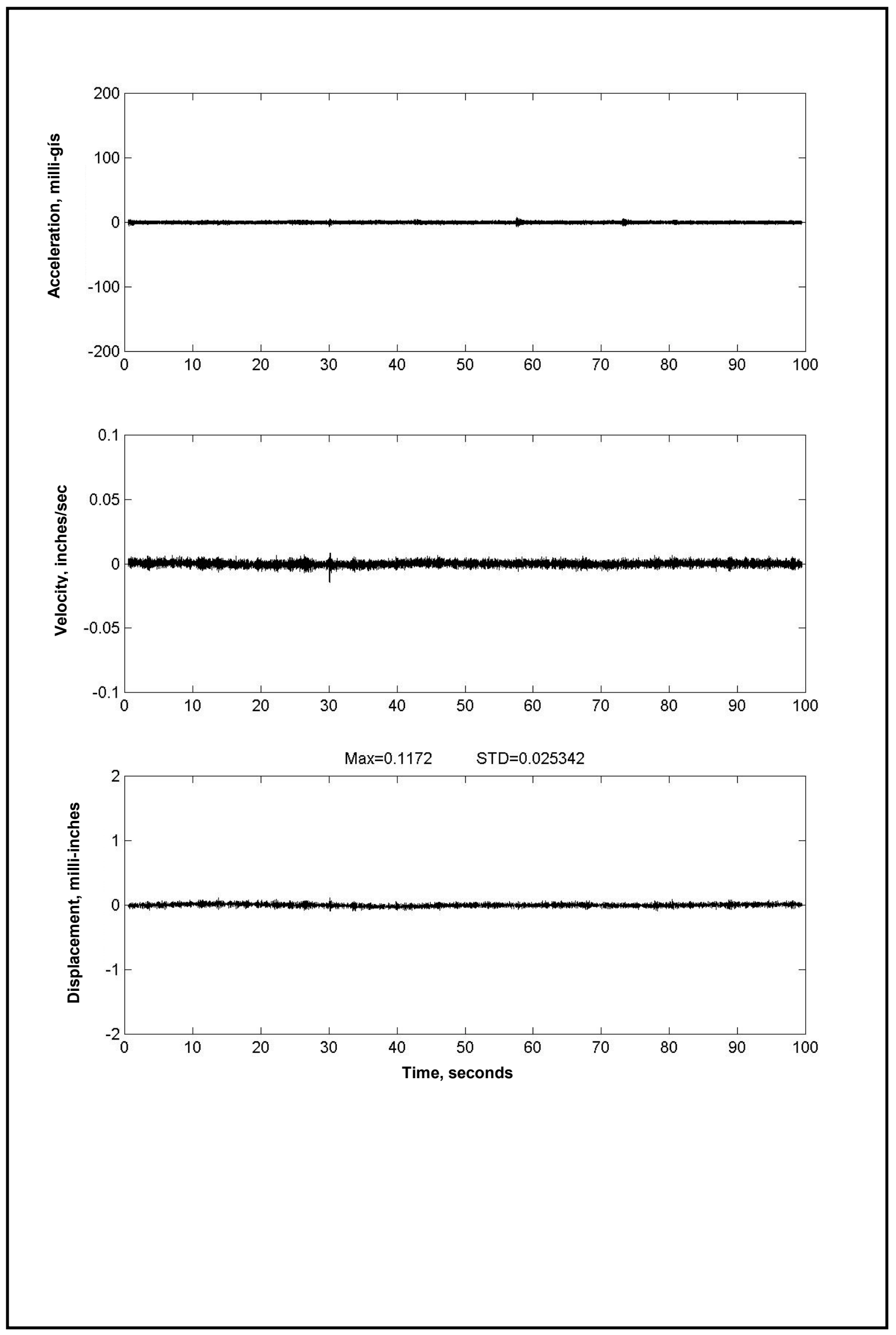

Figure 69. Radial accelerations, Gate 7, raised position, 5.0-ft opening, 07/11/00 

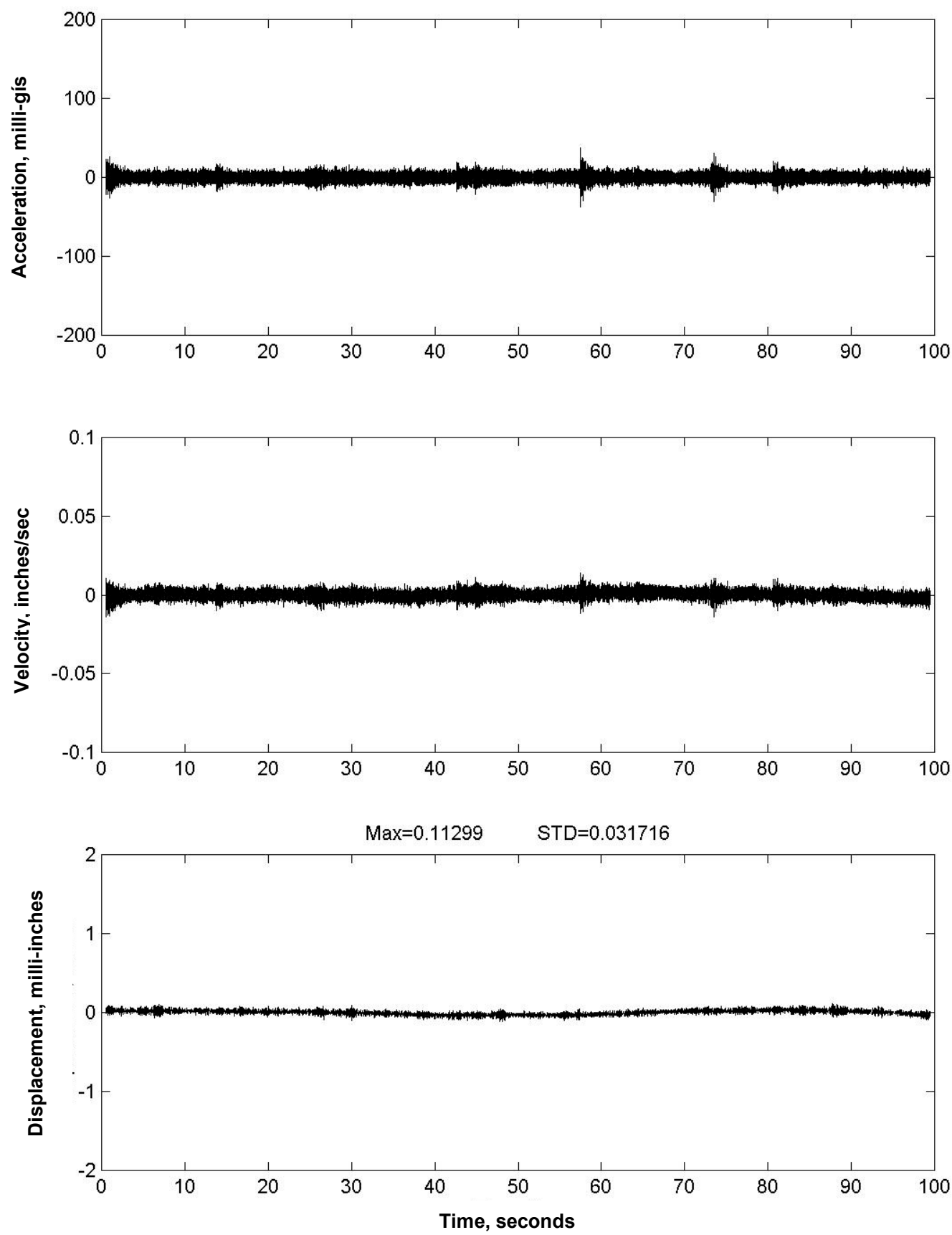

Figure 70. Transverse accelerations, Gate 7, raised position, 5.0-ft opening, 07/11/00 

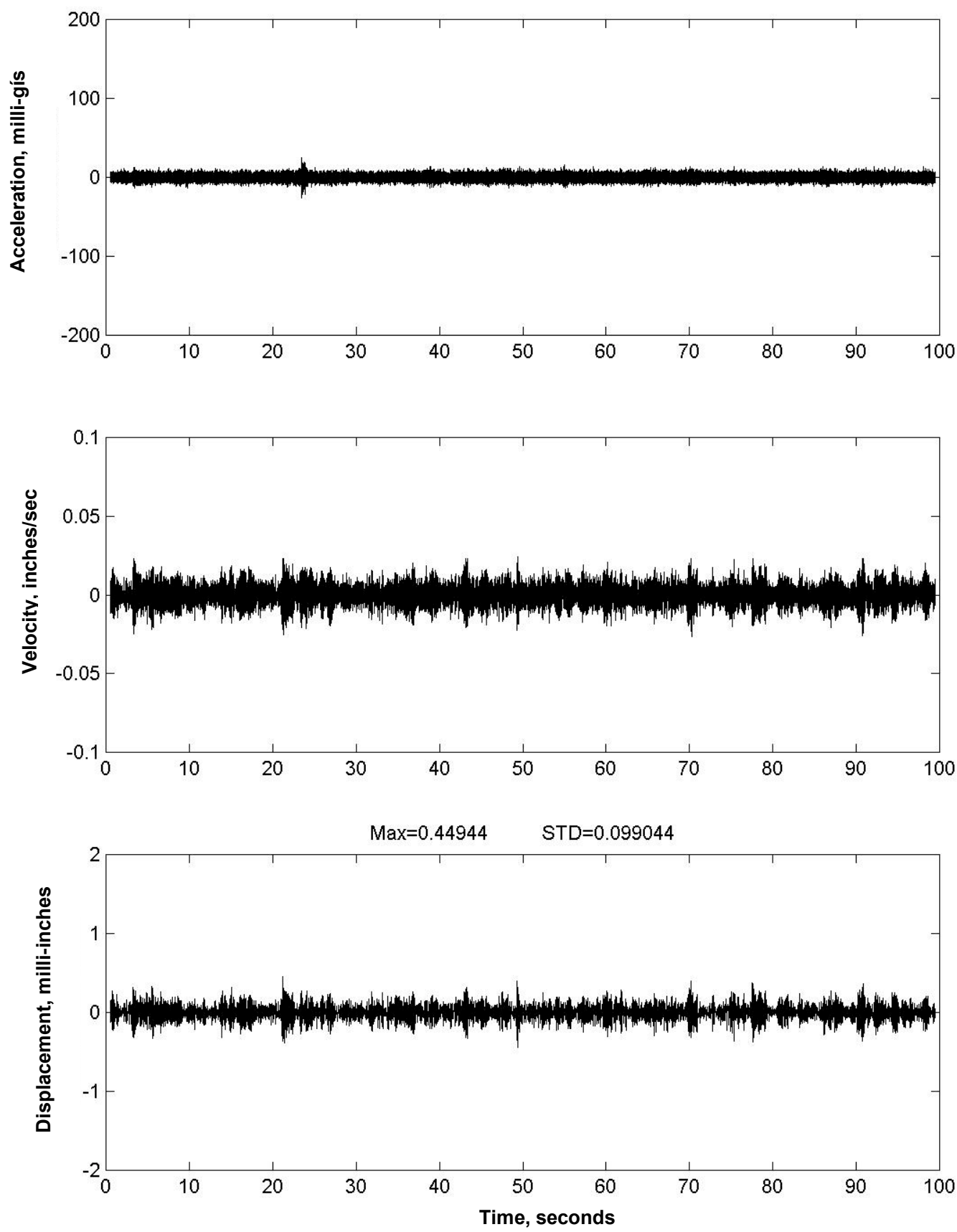

Figure 71. Vertical accelerations, Gate 3, raised position, 5.0-ft opening, 07/11/00 

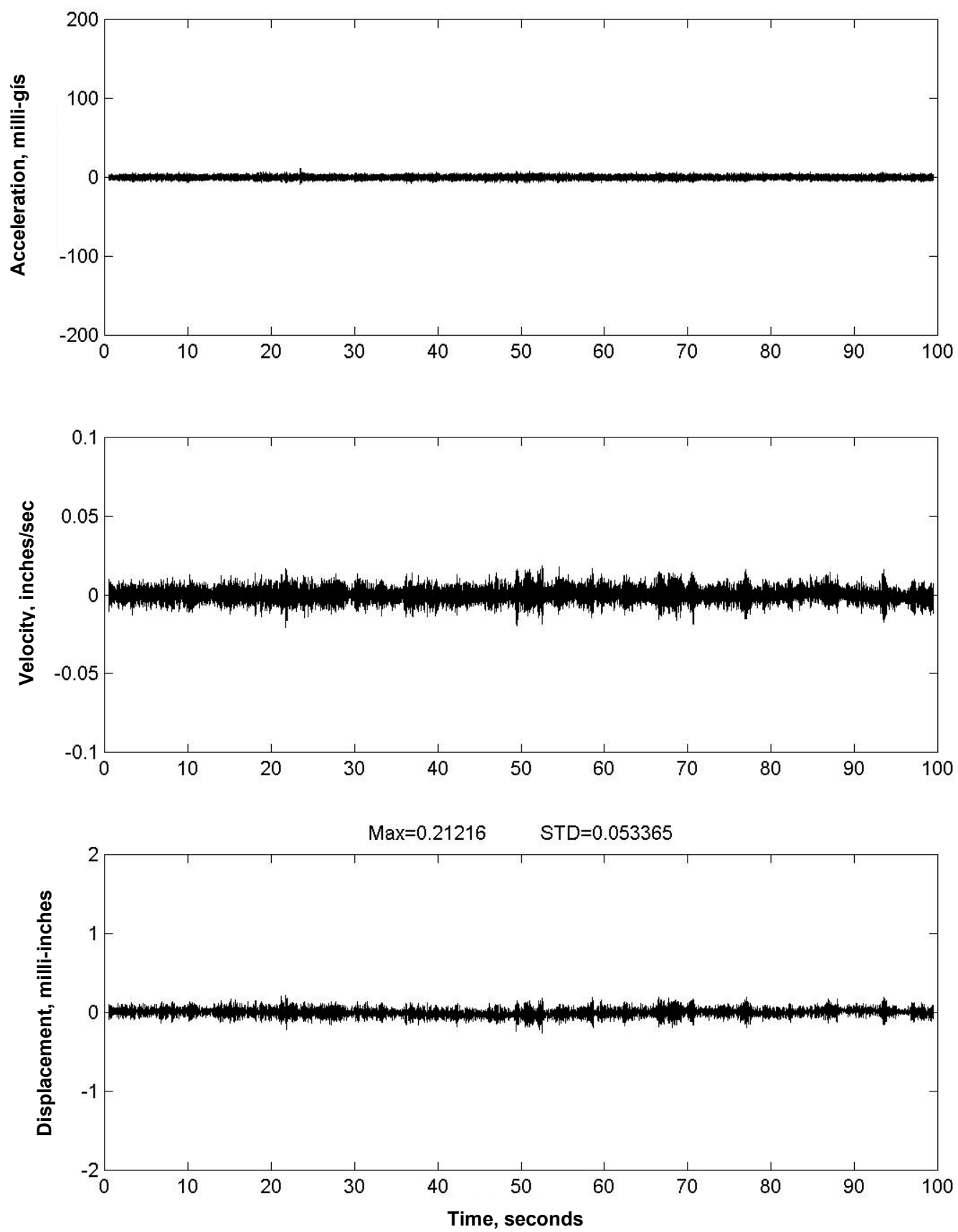

Figure 72. Radial accelerations, Gate 3, raised position, 5.0-ft opening, 07/11/00 


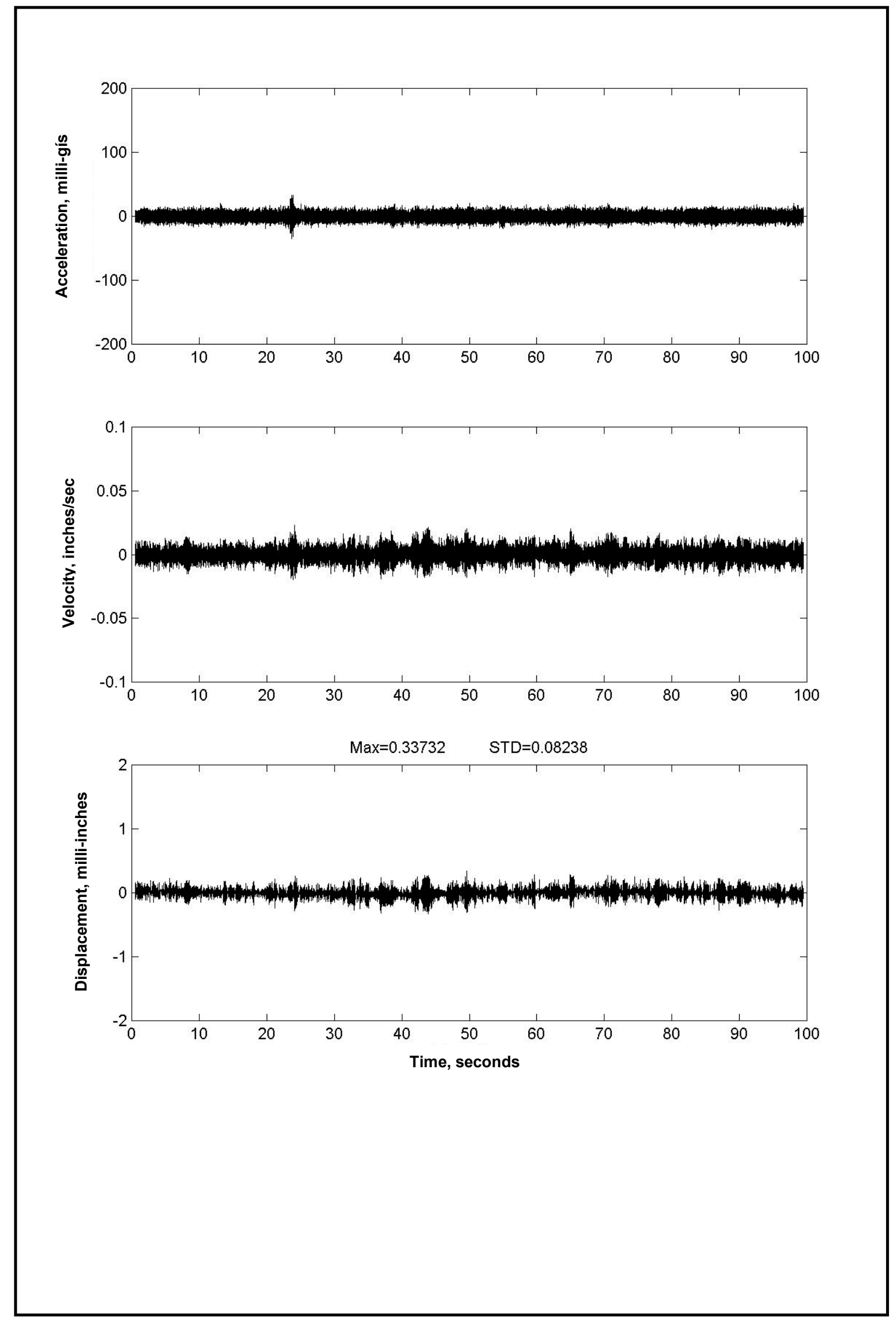

Figure 73. Transverse accelerations, Gate 3, raised position, 5.0-ft opening, 07/11/00 

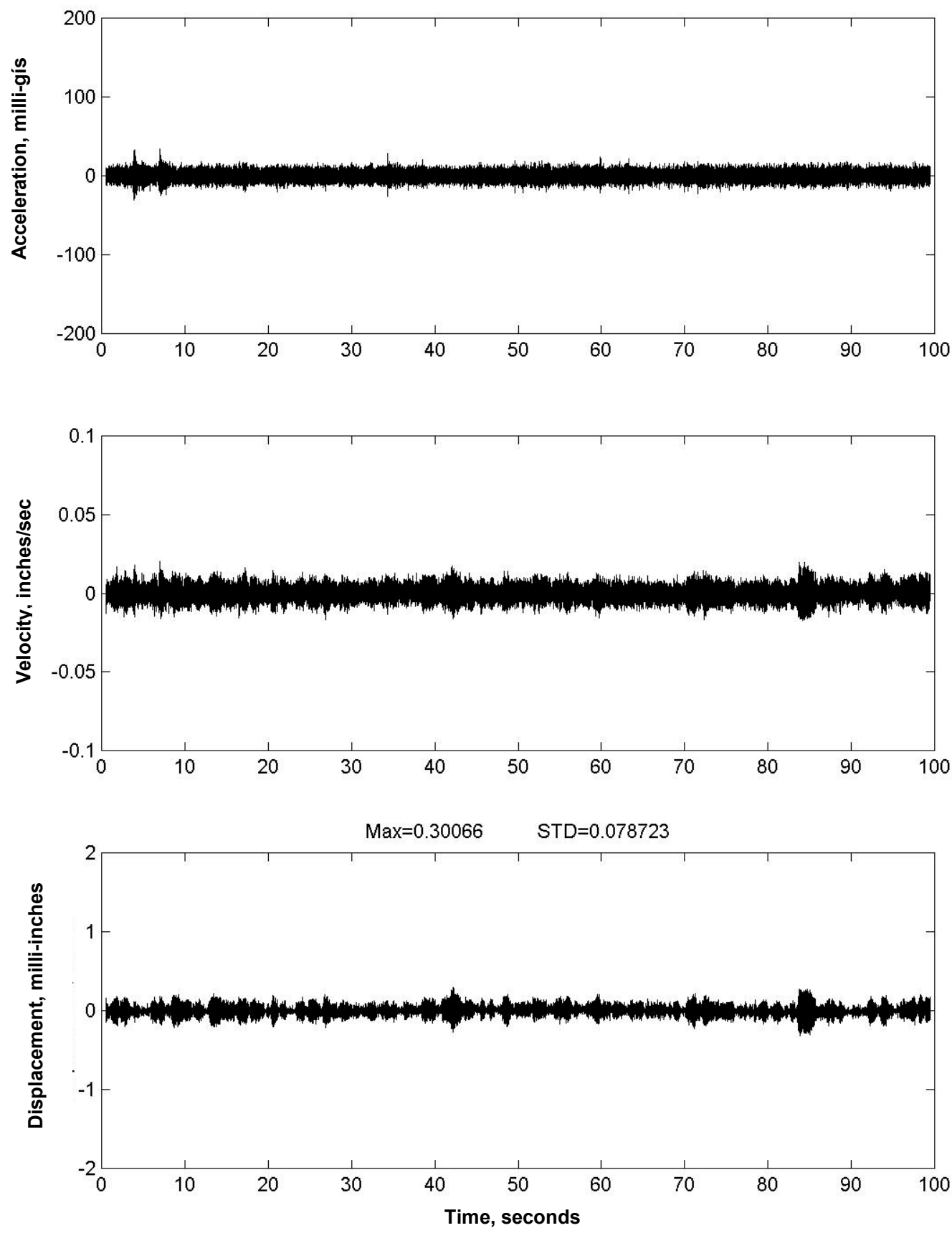

Figure 74. Vertical accelerations, Gate 5, raised position, 5.0-ft opening, 07/11/00 

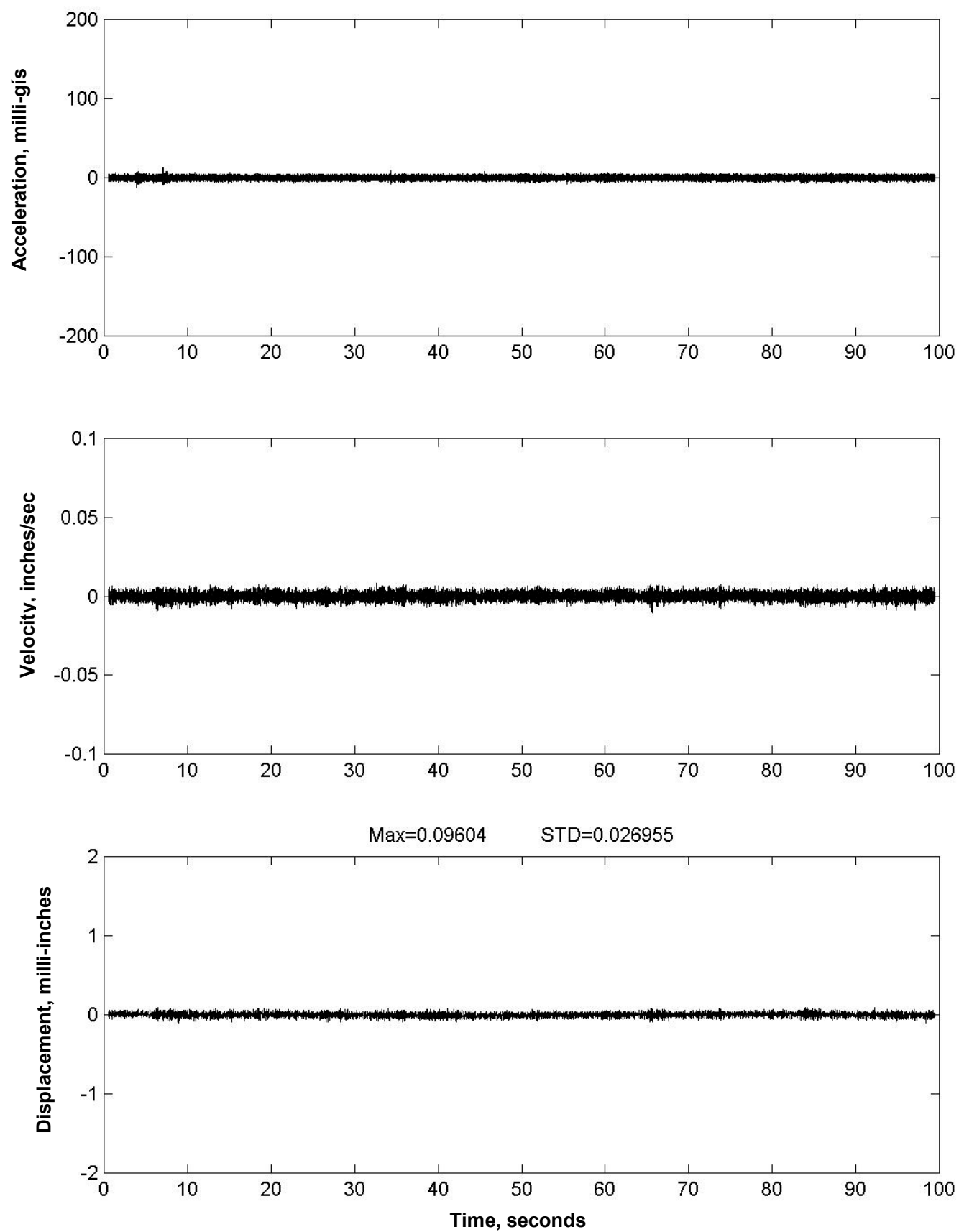

Figure 75. Radial accelerations, Gate 5, raised position, 5.0-ft opening, 07/11/00 

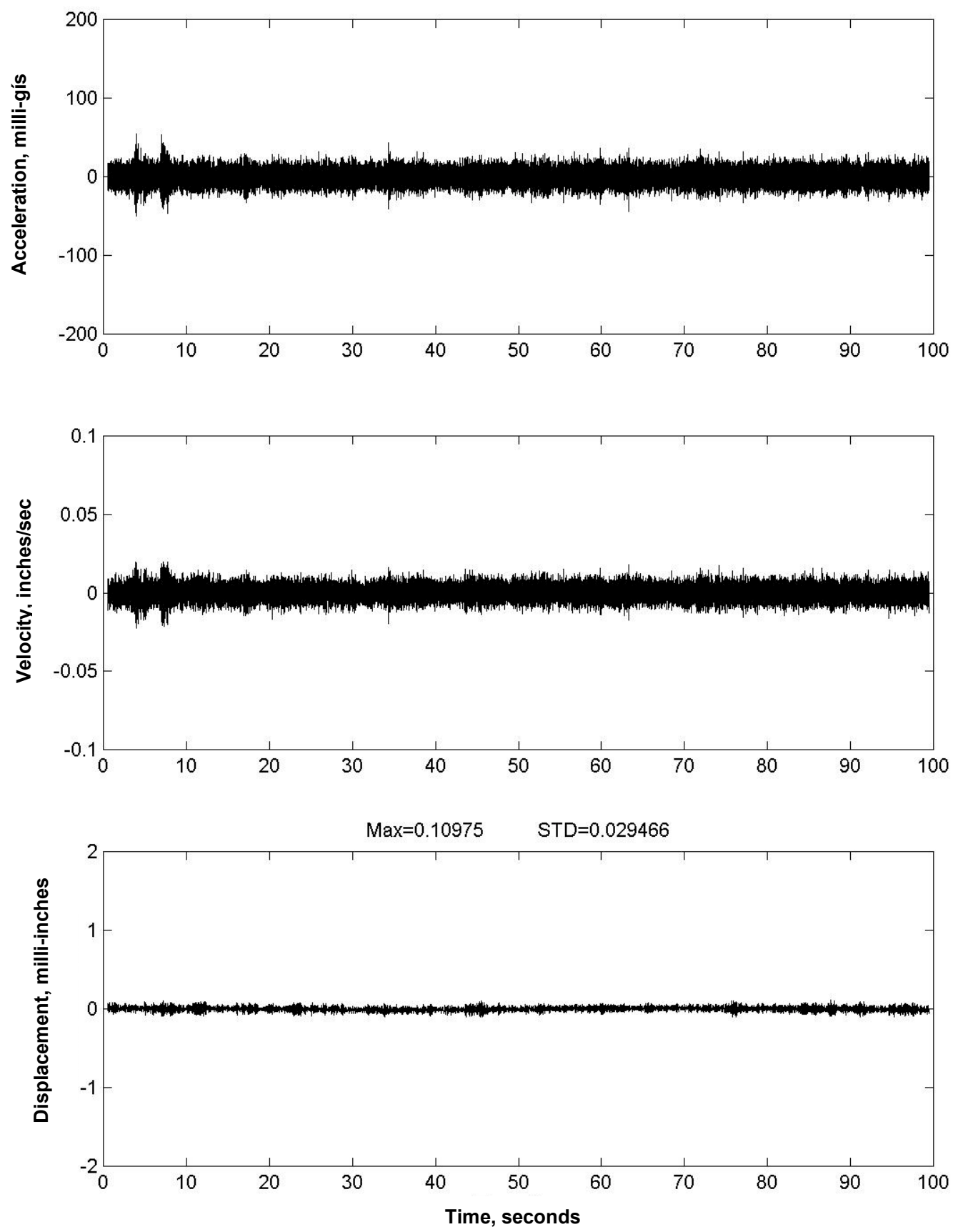

Figure 76. Transverse accelerations, Gate 5, raised position, 5.0-ft opening, 07/11/00 


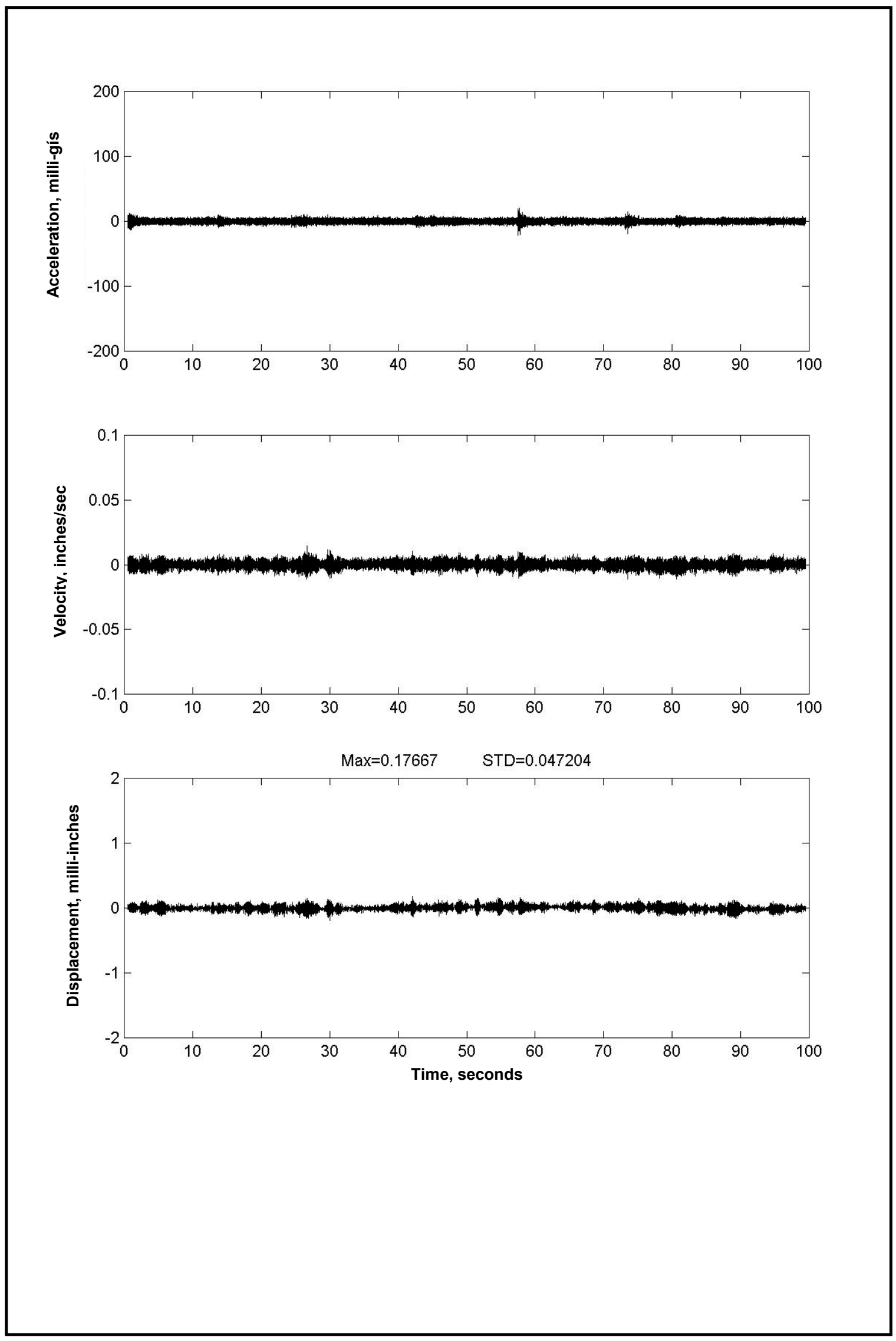

Figure 77. Vertical accelerations, Gate 7, raised position, 5.0-ft opening, 07/11/00 


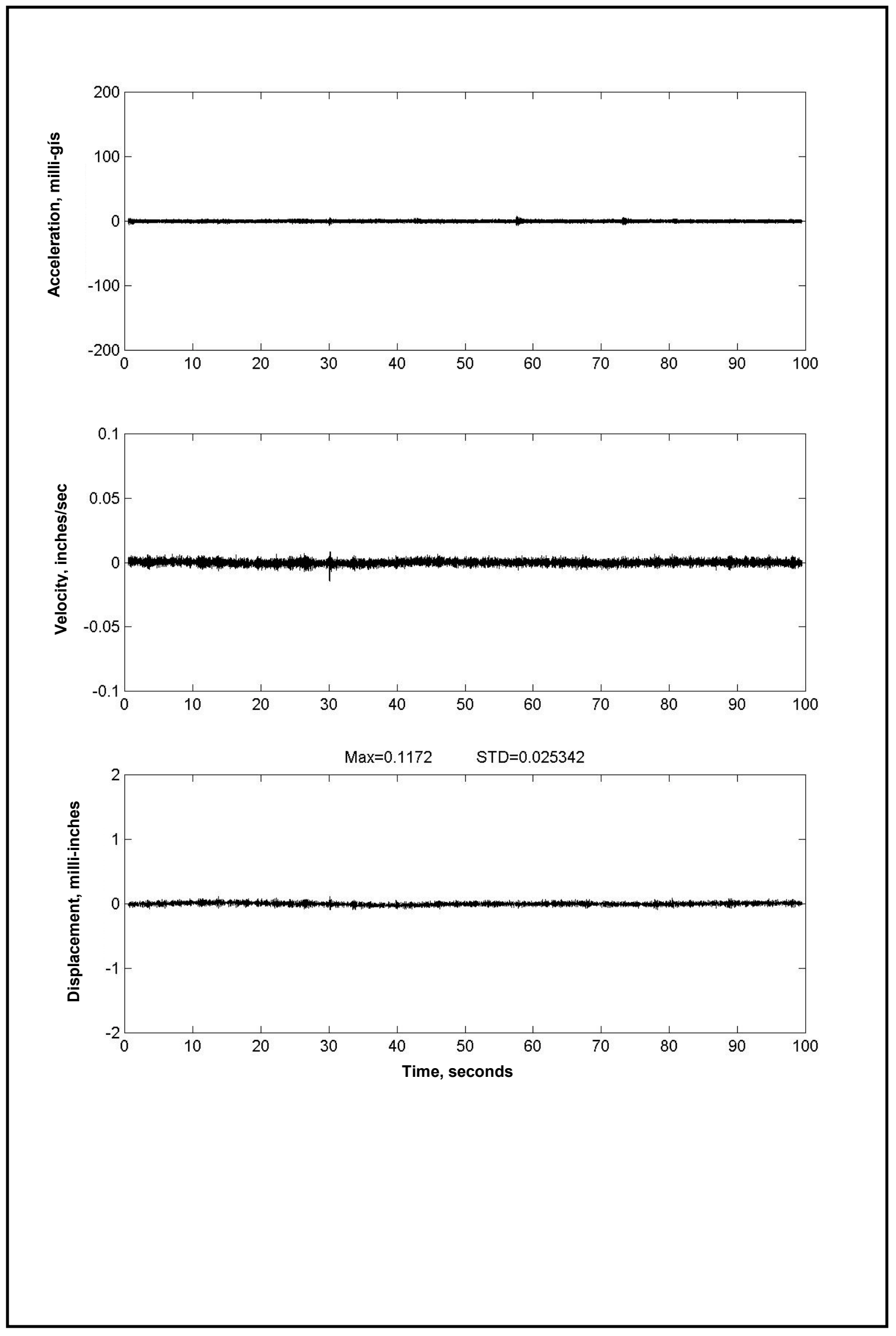

Figure 78. Radial accelerations, Gate 7, raised position, 5.0-ft opening, 07/11/00 

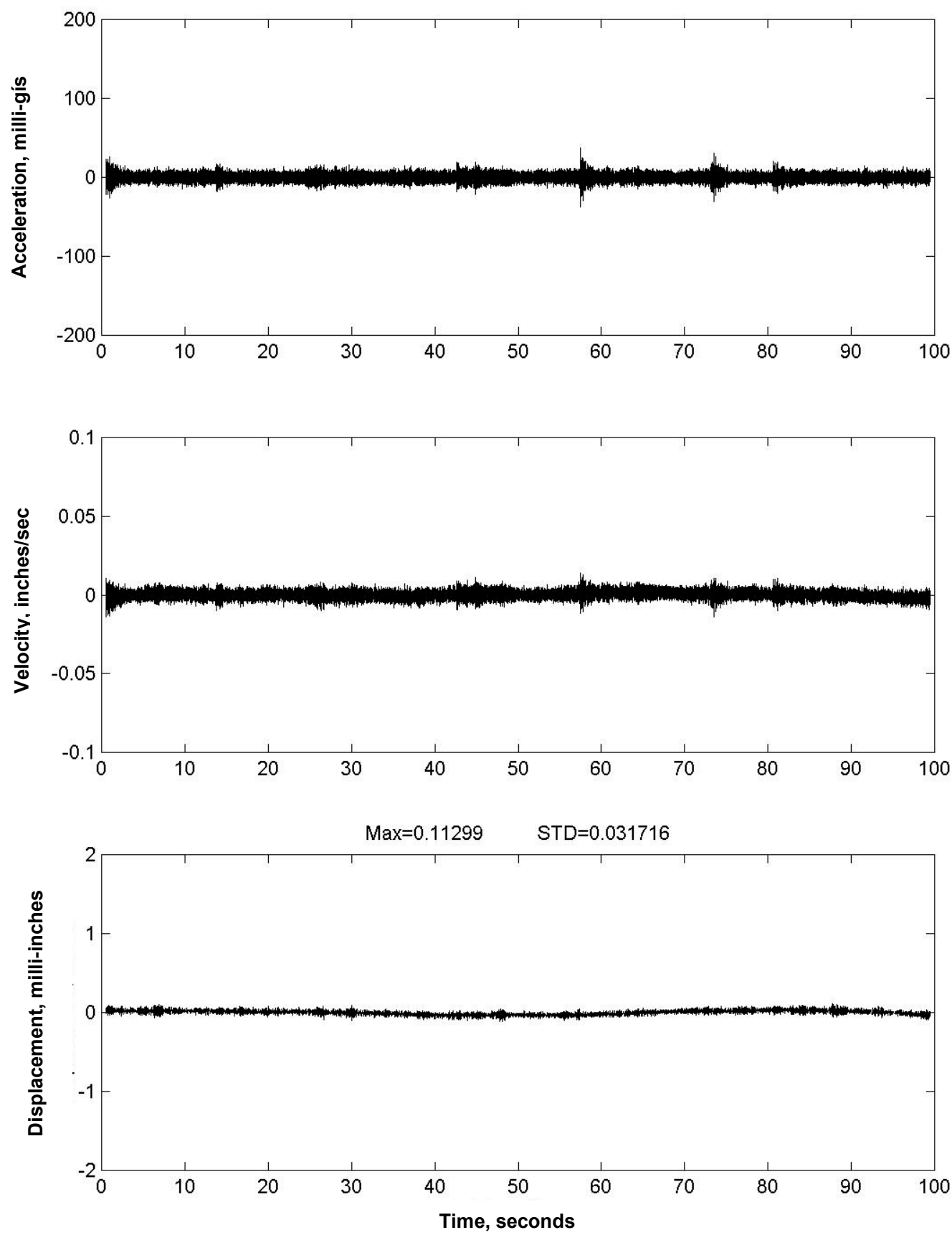

Figure 79. Transverse accelerations, Gate 7, raised position, 5.0-ft opening, 07/11/00 

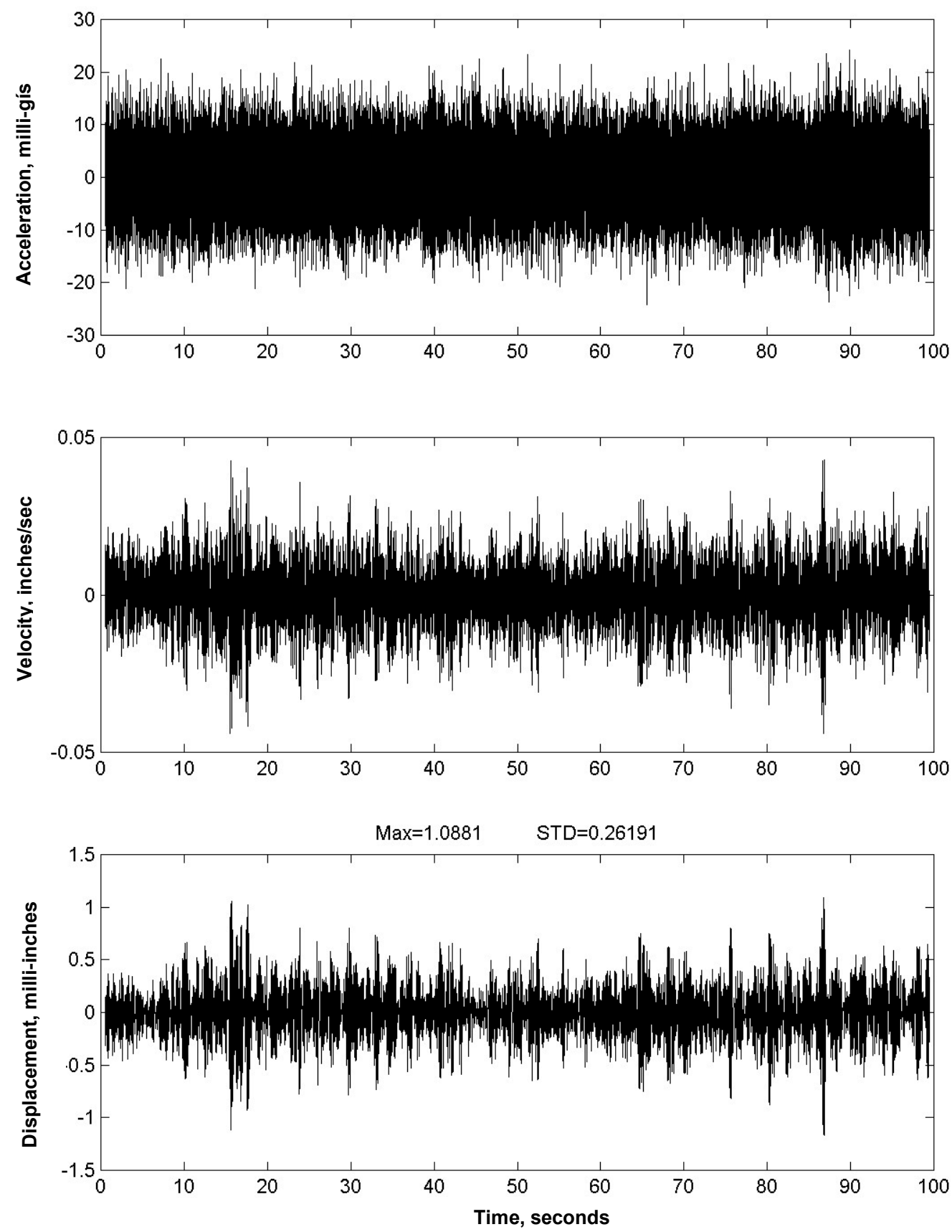

Figure 80. Vertical accelerations and displacements, Gate 5, submerged position, -2.0-ft submerged position, 02/14/00 

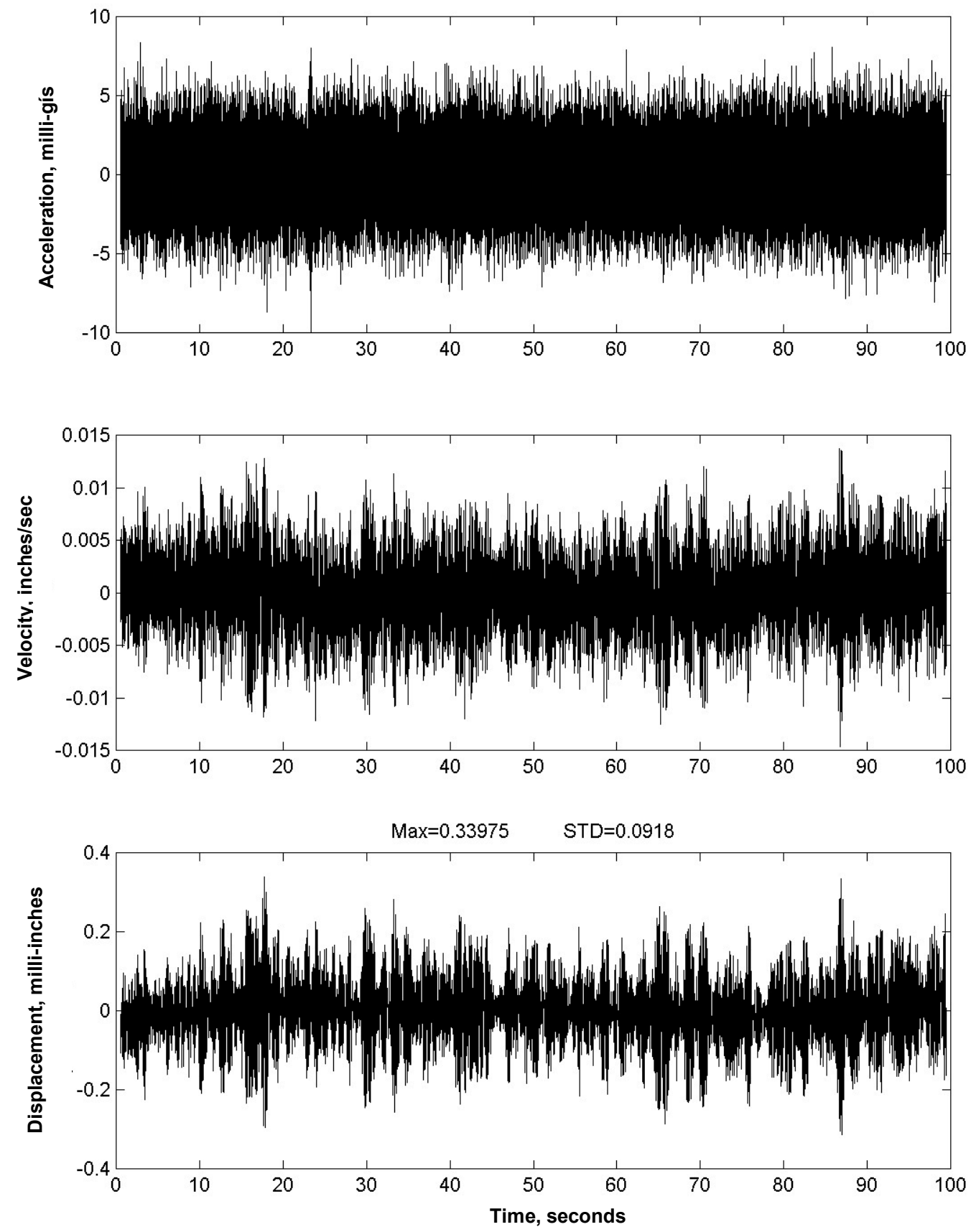

Figure 81. Radial accelerations and displacements, Gate 5, -2.0-ft submerged position, 02/14/00 

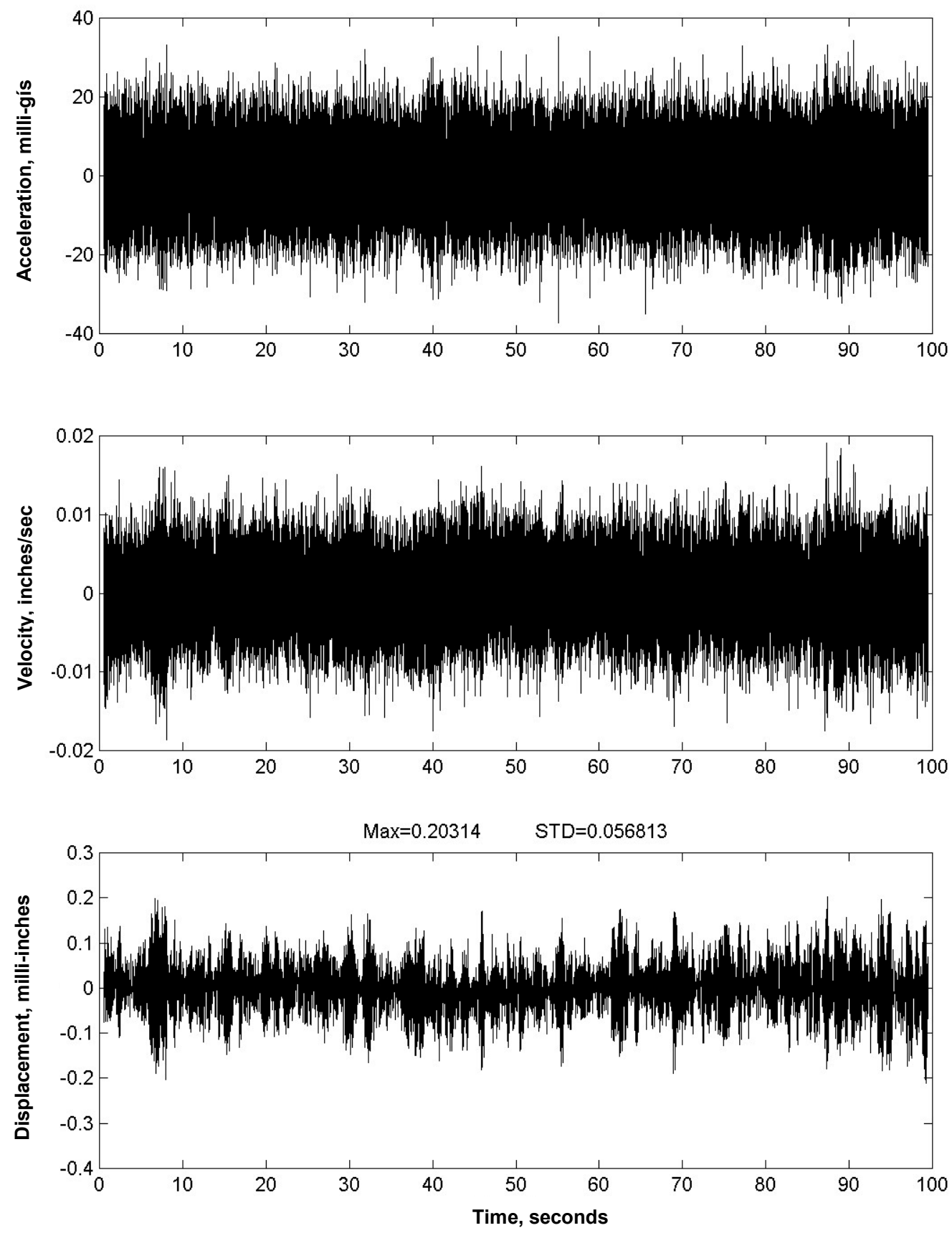

Figure 82. Transverse accelerations and displacements, Gate 5, -2.0-ft submerged position, $02 / 14 / 00$ 


\begin{tabular}{|c|c|c|c|c|c|c|c|c|}
\hline$G_{o}, f t$ & TW, el & $F_{2}, \mathrm{Ib}$ & $F_{3}, \mathbf{I b}$ & $F_{4}, \mathrm{Ib}$ & $F_{5_{\max }}, I b$ & $F_{5_{\text {min }}}, \mathrm{lb}$ & $f, \mathrm{~Hz}$ & $\Delta_{\mathbf{p}}, \mathrm{lb}$ \\
\hline 1 & 470 & 0 & 10115,300 & 10153,200 & 37,900 & 36,400 & "RANDOM & $1,1,500$ \\
\hline 1 & 473 & 5,200 & 110,100 & 164,800 & 54,700 & 54,100 & RANDOM & 600 \\
\hline 1 & 474 & 7,400 & 107,900 & 161,900 & 54,000 & 54,000 & RANDOM & 0 \\
\hline 2 & 470 & 0 & 115,300 & 156,100 & 40,800 & 39,300 & RANDOM & 1,500 \\
\hline 2 & 472 & 800 & 114,500 & 166,200 & 51,700 & 54,100 & RANDOM & 600 \\
\hline 2 & 474 & 5,200 & 110,100 & 164,800 & 54,700 & 54,100 & RANDOM & 600 \\
\hline 2 & 475 & 7,400 & 107,900 & 141,500 & 33,600 & 33,000 & RANDOM & 600 \\
\hline 4 & 470 & 0 & 115,300 & 156,200 & 40,900 & 39,400 & RANDOM & 1,500 \\
\hline 4 & 472 & 0 & 115,300 & 164,800 & 49,500 & 48,000 & RANDOM & 1,500 \\
\hline 4 & 474 & 800 & 114,500 & 163,300 & 48,800 & 47,300 & RANDOM & 1,500 \\
\hline 4 & 476 & 5,200 & 110,100 & 156,200 & 46,100 & 44,600 & RANDOM & 1,500 \\
\hline 5 & 470 & 0 & 115,300 & 162,000 & 46,700 & 43,700 & RANDOM & 3,000 \\
\hline 5 & 474 & 0 & 115,300 & 161,800 & 46,500 & 45,000 & RANDOM & 1,500 \\
\hline 5 & 478 & 7,400 & 107,900 & 161,500 & 53,600 & 52,700 & RANDOM & 900 \\
\hline 5 & 480 & 10,100 & 105,200 & 157,700 & 52,500 & 51,600 & RANDOM & 900 \\
\hline 6 & 470 & 0 & 115,300 & 163,300 & 48,000 & 45,400 & RANDOM & 2,600 \\
\hline 6 & 474 & 0 & 115,300 & 161,800 & 46,500 & 45,000 & RANDOM & 1,500 \\
\hline 6 & 476 & 800 & 114,500 & 163,300 & 48,800 & 47,900 & RANDOM & 900 \\
\hline 6 & 480 & 9,100 & 106,200 & 161,800 & 55,600 & 55,600 & 0 & 0 \\
\hline 7 & 470 & 0 & 115,300 & 163,800 & 48,500 & 47,700 & RANDOM & 800 \\
\hline 7 & 473 & 0 & 115,300 & 162,100 & 46,800 & 46,000 & RANDOM & 800 \\
\hline 7 & 476 & 2,900 & 112,400 & 162,000 & 49,600 & 48,800 & RANDOM & 800 \\
\hline 7 & 479 & 5,200 & 110,100 & 164,700 & 54,600 & 53,700 & RANDOM & 900 \\
\hline 7 & 481 & 9,100 & 106,200 & 161,600 & 55,400 & 53,900 & RANDOM & 1,500 \\
\hline 8 & 470 & 0 & 115,300 & 163,300 & 48,000 & 46,500 & RANDOM & 1,500 \\
\hline 8 & 473 & 0 & 115,300 & 166,300 & 51,000 & 51,000 & 0 & 0 \\
\hline 8 & 479 & 2,900 & 112,400 & 158,900 & 46,500 & 46,500 & 0 & 0 \\
\hline 8 & 482 & 9,100 & 106,200 & 141,300 & 35,100 & 35,100 & 0 & 0 \\
\hline 9 & 470 & 0 & 115,300 & 164,900 & 49,600 & 46,600 & RANDOM & 3,000 \\
\hline 9 & 472 & 0 & 115,300 & 163,300 & 48,000 & 46,500 & RANDOM & 1,500 \\
\hline 9 & 480 & 2,900 & 112,400 & 163,300 & 50,900 & 50,900 & 0 & 0 \\
\hline 9 & 483 & 9,100 & 106,200 & 144,300 & 38,100 & 38,100 & 0 & 0 \\
\hline 10 & 470 & 0 & 115,300 & 163,300 & 48,000 & 46,500 & RANDOM & 1,500 \\
\hline 10 & 472 & 0 & 115,300 & 167,800 & 52,500 & 51,000 & RANDOM & 1,500 \\
\hline 10 & 478 & 0 & 115,300 & 166,300 & 51,000 & 51,000 & 0 & 0 \\
\hline 10 & 483 & 7,400 & 107,900 & 147,300 & 39,400 & 39,400 & 0 & 0 \\
\hline
\end{tabular}




\begin{tabular}{|c|c|c|c|c|c|c|c|c|}
\hline \multicolumn{9}{|c|}{$\begin{array}{l}\text { Table } 2 \\
\text { Gate Cable Loads and Vibrations Type } 1 \text { (Original) Design Structure Flow Over Gate }\end{array}$} \\
\hline $\begin{array}{l}\text { Gate } \\
\text { Submergence, ft }\end{array}$ & TW, el & $F_{2}, \mathrm{Ib}$ & $F_{3}, \mathbf{l b}$ & $F_{4}, \mathrm{Ib}$ & $F_{5_{\max }}, I b$ & $F_{5_{\min }}, I b$ & f, $\mathrm{Hz}$ & $\Delta_{p}, \mathrm{Ib}$ \\
\hline 1 & 470 & 2,900 & 10112,400 & 132,900 & 20,500 & 1019,100 & 3.4 & $1,1,400$ \\
\hline 1 & 471 & 5,200 & 110,100 & 127,000 & 16,900 & 15,500 & 3.4 & 1,400 \\
\hline 2 & 470 & 5,200 & 110,100 & 141,600 & 31,500 & 30,100 & 3.1 & 1,400 \\
\hline 2 & 472 & 9,100 & 106,200 & 132,900 & 26,700 & 23,800 & 2.7 & 2,900 \\
\hline 2 & 473 & 10,100 & 105,200 & 130,000 & 24,800 & 22,800 & 2.7 & 2,000 \\
\hline 2 & 475 & 11,300 & 104,000 & 128,500 & 24,500 & 22,500 & 2.2 & 2,000 \\
\hline 3 & 470 & 7,400 & 107,900 & 144,600 & 36,700 & 33,700 & 2.9 & 3,000 \\
\hline 3 & 472 & 10,100 & 105,200 & 138,700 & 33,500 & 29,500 & 2.5 & 4,000 \\
\hline 3 & 474 & 11,300 & 104,000 & 145,800 & 41,800 & 38,800 & 2.5 & 3,000 \\
\hline 3 & 476 & 12,450 & 102,850 & 131,400 & 28,550 & 24,550 & 2.5 & 4,000 \\
\hline 4 & 470 & 9,100 & 106,200 & 141,700 & 35,500 & 31,500 & 2.5 & 4,000 \\
\hline 4 & 472 & 10,700 & 104,600 & 143,100 & 38,500 & 34,500 & 2.5 & 4,000 \\
\hline 4 & 474 & 11,850 & 103,450 & 138,700 & 35,250 & 32,250 & 2.2 & 3,000 \\
\hline 4 & 476 & 13,000 & 102,300 & 124,200 & 21,900 & 18,900 & 2.2 & 3,000 \\
\hline 5 & 470 & 10,100 & 105,200 & 147,100 & 41,900 & 38,100 & 2.2 & 3,800 \\
\hline 5 & 472 & 11,300 & 104,000 & 145,900 & 41,900 & 38,300 & 2.2 & 3,600 \\
\hline 5 & 475 & 13,000 & 102,300 & 134,300 & 32,000 & 28,500 & 1.8 & 3,500 \\
\hline 5 & 478 & 14,800 & 100,500 & 113,800 & 13,300 & 9,900 & 1.8 & 3,400 \\
\hline 6 & 470 & 10,700 & 104,600 & 144,400 & 39,800 & 32,600 & 1.6 & 7,200 \\
\hline 6 & 472 & 11,850 & 103,450 & 132,800 & 29,350 & 25,850 & 2.0 & 3,500 \\
\hline 6 & 476 & 14,200 & 101,100 & 110,800 & 9,700 & 8,100 & RANDOM & 1,600 \\
\hline 7 & 470 & 11,300 & 104,000 & 154,600 & 50,600 & 47,100 & 2.0 & 3,500 \\
\hline 7 & 472 & 12,450 & 102,850 & 165,000 & 62,150 & 56,250 & 2.0 & 5,900 \\
\hline 7 & 476 & 14,800 & 100,500 & 117,600 & 17,100 & 11,200 & 1.8 & 5,900 \\
\hline 7 & 477 & 15,300 & 100,000 & 109,500 & 9,500 & 8,100 & 1.8 & 1,400 \\
\hline 8 & 470 & 11,850 & 103,450 & 122,700 & 19,250 & 16,250 & RANDOM & 3,000 \\
\hline 8 & 473 & 13,600 & 101,700 & 122,700 & 21,000 & 15,100 & RANDOM & 5,900 \\
\hline 8 & 478 & 15,300 & 100,000 & 58,300 & $-41,700$ & $-41,700$ & 0 & 0 \\
\hline 8 & 483 & 15,300 & 100,000 & 49,700 & $-50,300$ & $-50,300$ & 0 & 0 \\
\hline
\end{tabular}




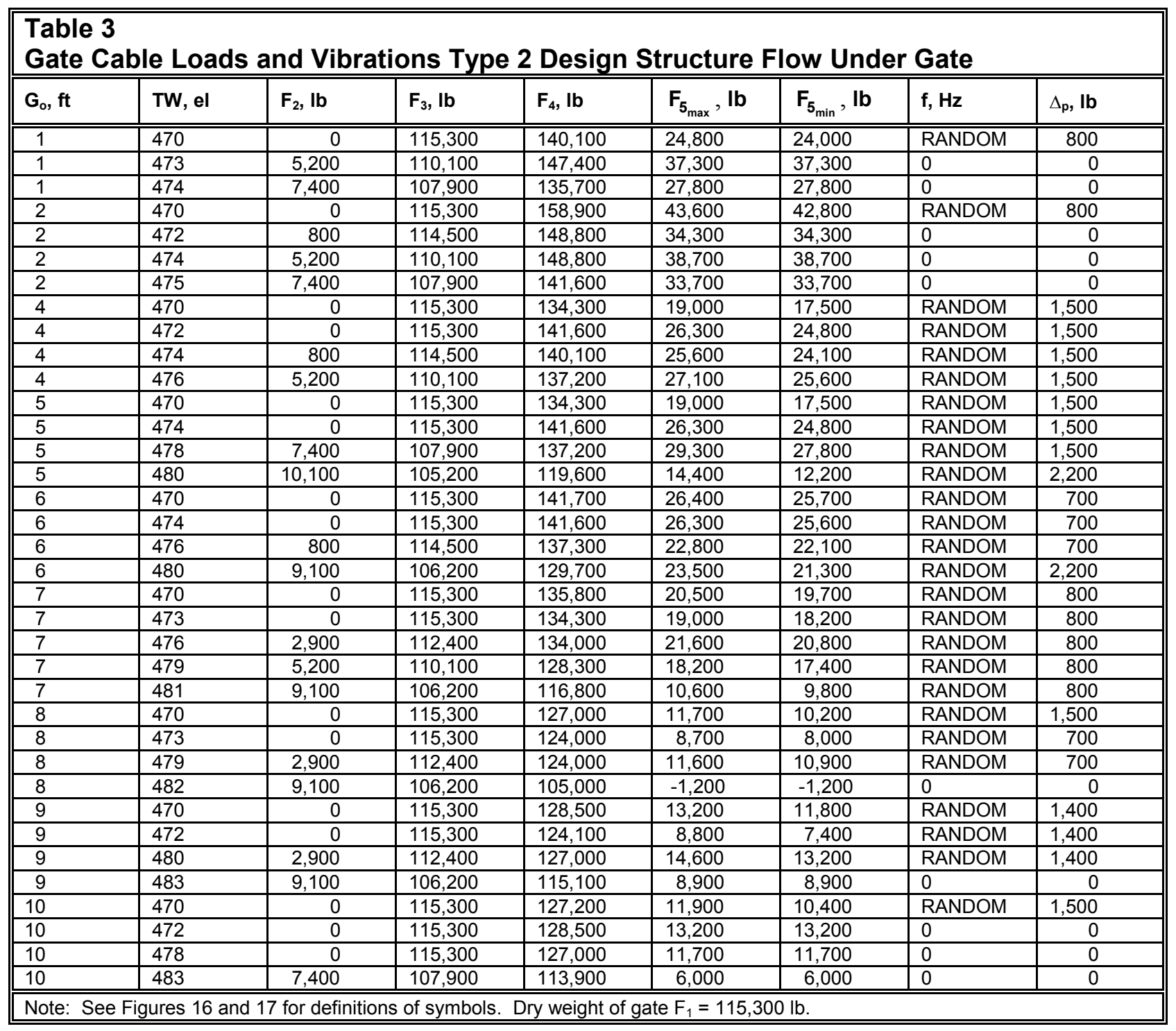




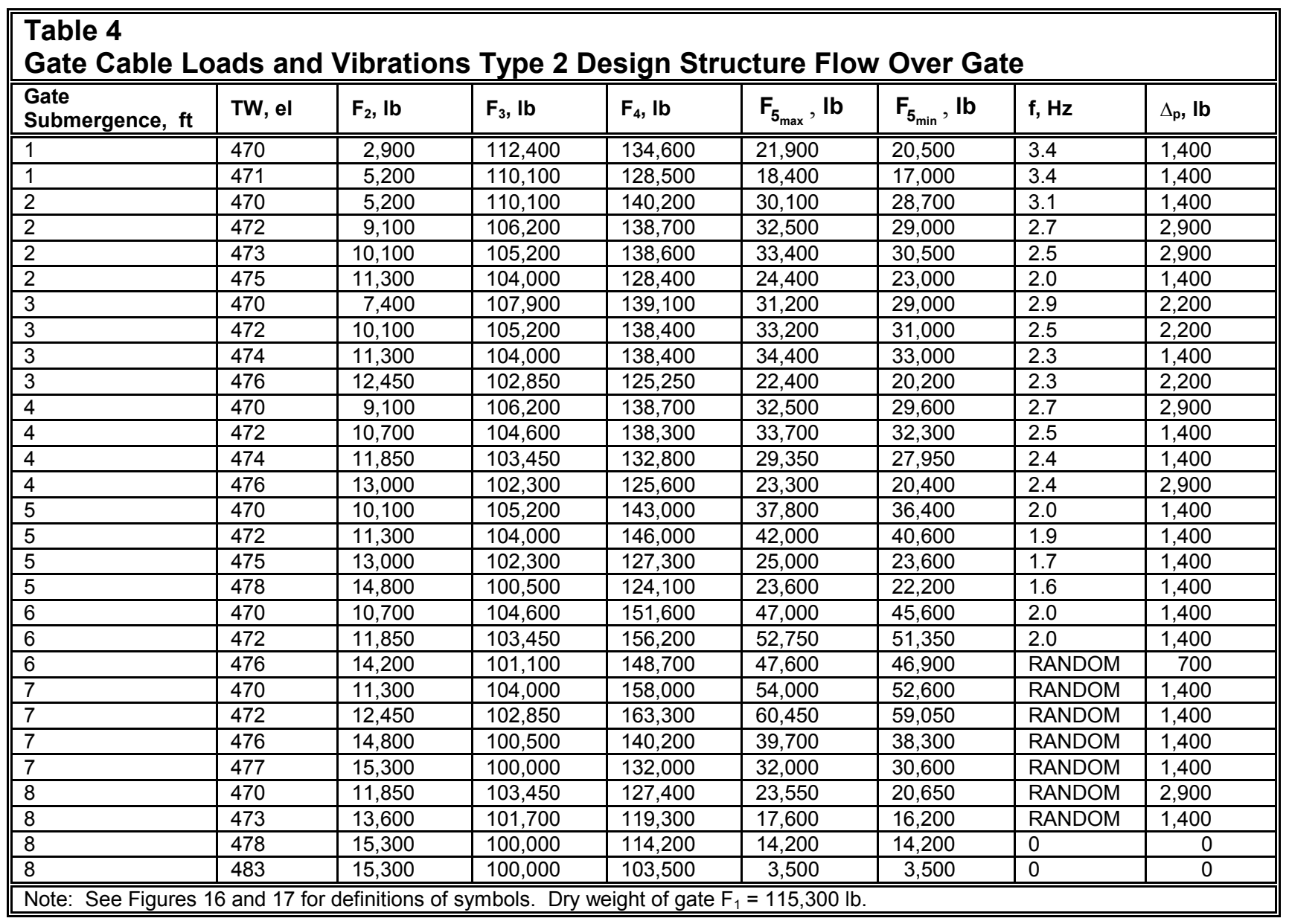




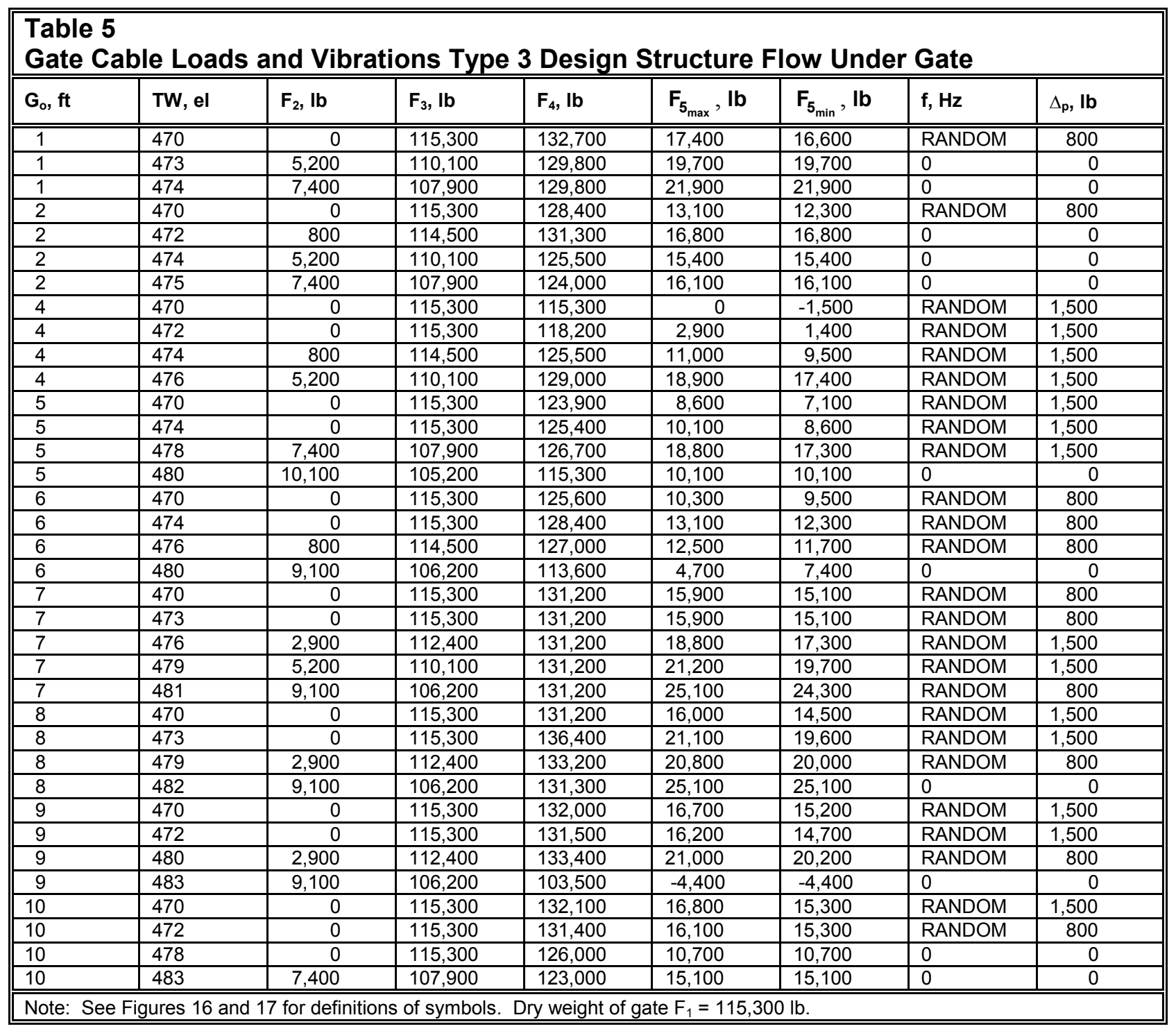




\begin{tabular}{|c|c|c|c|c|c|c|c|c|}
\hline \multicolumn{8}{|l|}{ Table 6} & \\
\hline $\begin{array}{l}\text { Gate } \\
\text { Submergence, ft }\end{array}$ & TW, el & $\mathbf{F}_{2}, \mathrm{Ib}$ & $F_{3}, \mathbf{I b}$ & $\mathbf{F}_{4}, \mathrm{Ib}$ & $F_{5_{\max }}, \mathrm{lb}$ & $F_{5_{\text {min }}}, I b$ & f, $\mathrm{Hz}$ & $\Delta_{\mathbf{p}}, \mathbf{l b}$ \\
\hline 1 & 4770 & 2,900 & 112,400 & 137,100 & 24,700 & 24,700 & 0 & $\overline{0}$ \\
\hline 1 & 471 & 5,200 & 110,100 & 132,800 & 22,700 & 22,700 & 0 & 0 \\
\hline 2 & 470 & 5,200 & 110,100 & 128,400 & 18,300 & 17,500 & RANDOM & 800 \\
\hline 2 & 472 & 9,100 & 106,200 & 131,300 & 25,400 & 25,100 & 0 & 0 \\
\hline 2 & 473 & 10,100 & 105,200 & 128,400 & 23,200 & 23,200 & 0 & 0 \\
\hline 2 & 475 & 11,300 & 104,000 & 115,200 & 11,200 & 11,200 & 0 & 0 \\
\hline 3 & 470 & 7,400 & 107,900 & 123,900 & 16,000 & 16,000 & 0 & 0 \\
\hline 3 & 472 & 10,100 & 105,200 & 121,000 & 15,800 & 15,800 & 0 & 0 \\
\hline 3 & 474 & 11,300 & 104,000 & 113,700 & 9,700 & 9,700 & 0 & 0 \\
\hline 3 & 476 & 12,450 & 102,850 & 112,850 & 10,000 & 10,000 & 0 & 0 \\
\hline 4 & 470 & 9,100 & 106,200 & 156,100 & 49,900 & 49,900 & 0 & 0 \\
\hline 4 & 472 & 10,700 & 104,600 & 148,800 & 44,200 & 44,200 & 0 & 0 \\
\hline 4 & 474 & 11,850 & 103,450 & 144,400 & 40,950 & 40,950 & 0 & 0 \\
\hline 4 & 476 & 13,000 & 102,300 & 138,500 & 36,200 & 36,200 & 0 & 0 \\
\hline 5 & 470 & 10,100 & 105,200 & 141,500 & 36,300 & 36,300 & 0 & 0 \\
\hline 5 & 472 & 11,300 & 104,000 & 132,700 & 28,700 & 27,200 & RANDOM & 1,500 \\
\hline 5 & 475 & 13,000 & 102,300 & 122,500 & 20,200 & 20,200 & 0 & 0 \\
\hline 5 & 478 & 14,800 & 100,500 & 120,000 & 19,500 & 19,500 & 0 & 0 \\
\hline 6 & 470 & 10,700 & 104,600 & 126,900 & 22,300 & 21,500 & RANDOM & 800 \\
\hline 6 & 472 & 11,850 & 103,450 & 118,100 & 14,650 & 14,650 & 0 & 0 \\
\hline 6 & 476 & 14,200 & 101,100 & 107,900 & 6,800 & 6,800 & 0 & 0 \\
\hline 7 & 470 & 11,300 & 104,000 & 116,100 & 12,100 & 12,900 & RANDOM & 800 \\
\hline 7 & 472 & 12,450 & 102,850 & 118,250 & 15,400 & 15,400 & 0 & 0 \\
\hline 7 & 476 & 14,800 & 100,500 & 83,000 & $-17,500$ & $-17,500$ & 0 & 0 \\
\hline 7 & 477 & 15,300 & 100,000 & 78,700 & $-21,300$ & $-21,300$ & 0 & 0 \\
\hline 8 & 470 & 11,850 & 103,450 & 150,400 & 46,950 & 46,950 & 0 & 0 \\
\hline 8 & 473 & 13,600 & 101,700 & 138,600 & 36,900 & 36,900 & 0 & 0 \\
\hline 8 & 478 & 15,300 & 100,000 & 131,000 & 31,000 & 31,000 & 0 & 0 \\
\hline 8 & 483 & 15,300 & 100,000 & 61,300 & $-38,700$ & $-38,700$ & 0 & 0 \\
\hline
\end{tabular}




\begin{tabular}{|c|c|c|c|}
\hline \multicolumn{4}{|c|}{$\begin{array}{l}\text { Table } 7 \\
\text { Life-Cycle Cost Analysis Summary }\end{array}$} \\
\hline Cost Item & $\begin{array}{l}\text { Existing Remote } \\
\text { Operation } \\
\text { Plan } 1\end{array}$ & $\begin{array}{l}\text { Manual } \\
\text { Operation } \\
\text { Plan } 2\end{array}$ & $\begin{array}{l}\text { Replace Remote } \\
\text { Operation } \\
\text { Plan } 3\end{array}$ \\
\hline 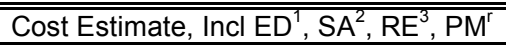 & $\$ 0$ & $\$ 0$ & $\$ 1,042,501$ \\
\hline No. of Construction Years & & & 1 \\
\hline Annual Maintenance Cost & 5,819 & 0 & 5,819 \\
\hline Annual Labor Cost & 12,074 & 185,869 & 12,074 \\
\hline \multicolumn{4}{|l|}{ Periodic Replacement Costs: } \\
\hline None Identified & 0 & 0 & 0 \\
\hline Project Life/Evaluation Period & 5 & 5 & 25 \\
\hline Federal Discount Rate & $6.875 \%$ & $6.875 \%$ & $6.875 \%$ \\
\hline \multicolumn{4}{|l|}{ Cost Analysis: } \\
\hline Capital Costs (Design and Const.) & 0 & 0 & $1,042,501$ \\
\hline Interest During Construction & 0 & 0 & 35,836 \\
\hline \multicolumn{4}{|l|}{ Discounted Replacement Costs: } \\
\hline Year Replaced & 0 & 0 & 0 \\
\hline & - & 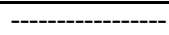 & 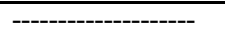 \\
\hline Present Value of Total Life-Cycle Costs & $\$ 0$ & $\$ 0$ & $\$ 1,078,337$ \\
\hline Annualized Life-Cycle Costs & $\$ 0$ & $\$ 0$ & $\$ 91,493$ \\
\hline Annual Maintenance and Labor Costs & 17,893 & 185,869 & 17,893 \\
\hline Total Annual Life-Cycle Costs & $\$ 17,893$ & $\$ 185,869$ & $\$ 109,386$ \\
\hline $\begin{array}{l}\text { Engineering Division } \\
2 \text { Supervision and Administration } \\
3 \text { Real Estate } \\
{ }^{4} \text { Project Management }\end{array}$ & & & \\
\hline
\end{tabular}

\begin{tabular}{|c|c|c|c|c|c|c|}
\hline \multicolumn{7}{|c|}{$\begin{array}{l}\text { Table } 8 \\
\text { Maintenance and Labor Cost Data }\end{array}$} \\
\hline \multicolumn{5}{|c|}{$\begin{array}{l}\text { Remote Operation Maintenance and Labor Costs } \\
\end{array}$} & \multicolumn{2}{|c|}{ Manual Operation Labor Costs } \\
\hline Year & Maint./Servc. & & Labor & Labor & No. Operators & 4 full-time \\
\hline & & & Non-icing & Icing & Annual Hours Reqd. & 8320 \\
\hline 1990 & $\$ 7,923$ & & (Mar-Nov) & (Dec-Feb) & $(4 \times 2080)$ & \\
\hline 1991 & $\$ 5,695$ & & & & Avg. Wage/Benefits & $\$ 22.34$ \\
\hline 1992 & $\$ 8,838$ & rate $^{1}$ & 22.36 & 22.36 & Annual Oper. Cost & $\$ 185,869$ \\
\hline 1993 & $\$ 6,537$ & hr/day & 1 & 3 & & \\
\hline 1994 & $\$ 8,050$ & days & 270 & 90 & & \\
\hline 1995 & $\$ 1,638$ & & & & & \\
\hline 1996 & $\$ 4,136$ & cost & $\$ 6,037$ & $\$ 6,037$ & & \\
\hline 1997 & $\$ 6,378$ & & & & & \\
\hline 1998 & $\$ 3,179$ & & & & & \\
\hline Total & $\$ 52,374$ & & & & & \\
\hline & & & & & & \\
\hline Average & $\$ 5,819$ & & & & & \\
\hline
\end{tabular}




\begin{tabular}{|c|c|c|c|c|c|c|}
\hline \multicolumn{7}{|c|}{$\begin{array}{l}\text { Table } 9 \\
\text { Marseilles Dam Instrumented Gate Operation Log }\end{array}$} \\
\hline Date & Time & $\begin{array}{l}\text { Gate } 1 \\
\text { Opening, } \mathrm{ft}\end{array}$ & $\begin{array}{l}\text { Gate } 3 \\
\text { Opening, ft }\end{array}$ & $\begin{array}{l}\text { Gate } 5 \\
\text { Opening, } \mathrm{ft}\end{array}$ & $\begin{array}{l}\text { Gate } 7 \\
\text { Opening, ft } \\
\end{array}$ & Comment \\
\hline 9/16/99 & 1510 & 0.0 & 0.0 & 0.0 & 1.0 & \\
\hline 9/16/99 & 1650 & 0.0 & 0.0 & 0.0 & 0.5 & \\
\hline 9/16/99 & 1755 & 0.0 & 0.0 & 0.0 & 0.0 & \\
\hline 9/17/99 & 1315 & 0.0 & 0.0 & 0.0 & 0.5 & \\
\hline 9/17/99 & 1317 & 0.0 & 0.0 & 0.0 & 1.0 & \\
\hline $9 / 17 / 99$ & 1320 & 0.0 & 0.0 & 0.0 & 0.0 & \\
\hline $9 / 22 / 99$ & 600 & 0.0 & 0.0 & 0.0 & 0.5 & \\
\hline $9 / 22 / 99$ & 1500 & 0.0 & 0.0 & 0.0 & 0.0 & \\
\hline $9 / 27 / 99$ & 2345 & 0.0 & 0.0 & 0.0 & 1.0 & \\
\hline $9 / 28 / 99$ & 1000 & 0.0 & 0.0 & 0.0 & 2.0 & \\
\hline 9/28/99 & 1115 & 0.0 & 0.0 & 0.0 & 3.0 & \\
\hline $9 / 28 / 99$ & 2215 & 0.0 & 0.0 & 0.0 & 0.0 & \\
\hline 9/28/99 & 2215 & 0.0 & 0.0 & 0.0 & 3.0 & \\
\hline $9 / 28 / 99$ & 2215 & 2.0 & 2.0 & 0.0 & 3.0 & \\
\hline $9 / 28 / 99$ & 2215 & 0.0 & 0.0 & 0.0 & 3.0 & \\
\hline $9 / 29 / 99$ & 1420 & 0.0 & 0.0 & 0.0 & 2.0 & \\
\hline 9/29/99 & 1710 & 0.0 & 0.0 & 0.0 & 0.0 & \\
\hline $9 / 30 / 99$ & 340 & 0.0 & 0.0 & 0.0 & 0.5 & \\
\hline $9 / 30 / 99$ & 455 & 0.0 & 0.0 & 0.0 & 2.0 & \\
\hline 9/30/99 & 1235 & 0.0 & 0.0 & 0.0 & 1.5 & \\
\hline 9/30/99 & 1330 & 0.0 & 0.0 & 0.0 & 0.5 & \\
\hline 9/30/99 & 1455 & 0.0 & 0.0 & 0.0 & 0.0 & \\
\hline $10 / 1 / 99$ & 100 & 0.0 & 0.0 & 0.0 & 1.0 & \\
\hline $10 / 1 / 99$ & 105 & 0.0 & 0.0 & 0.0 & 2.0 & \\
\hline $10 / 1 / 99$ & 755 & 0.0 & 0.0 & 0.0 & 1.0 & \\
\hline $10 / 1 / 99$ & 1005 & 0.0 & 0.0 & 0.0 & 1.5 & \\
\hline 10/1/99 & 1050 & 0.0 & 0.0 & 0.0 & 2.0 & \\
\hline $10 / 1 / 99$ & 1000 & 0.0 & 0.0 & 0.0 & 1.5 & \\
\hline $10 / 1 / 99$ & 1710 & 0.0 & 0.0 & 0.0 & 1.0 & \\
\hline $10 / 1 / 99$ & 1830 & 0.0 & 0.0 & 0.0 & 0.0 & \\
\hline $10 / 2 / 99$ & 910 & 0.0 & 0.0 & 0.0 & 1.0 & \\
\hline $10 / 2 / 99$ & 1110 & 0.0 & 0.0 & 0.0 & 1.5 & \\
\hline $10 / 2 / 99$ & 1130 & 0.0 & 0.0 & 0.0 & 2.0 & \\
\hline $10 / 2 / 99$ & 1625 & 0.0 & 0.0 & 0.0 & 1.5 & \\
\hline $10 / 2 / 99$ & 1705 & 0.0 & 0.0 & 0.0 & 1.0 & \\
\hline $10 / 2 / 99$ & 1800 & 0.0 & 0.0 & 0.0 & 0.0 & \\
\hline $10 / 3 / 99$ & 1230 & 0.5 & 0.0 & 0.0 & 0.0 & \\
\hline $10 / 3 / 99$ & 1305 & 1.0 & 0.0 & 0.0 & 0.0 & \\
\hline $10 / 4 / 99$ & 755 & 0.0 & 0.0 & 0.0 & 0.0 & \\
\hline $10 / 4 / 99$ & 1800 & 0.0 & 0.0 & 0.0 & 1.0 & \\
\hline 4-Oct & 2035 & 0.0 & 0.0 & 0.0 & 2.0 & \\
\hline $10 / 4 / 99$ & 2305 & 0.0 & 0.0 & 0.0 & 1.0 & \\
\hline $10 / 5 / 99$ & 540 & 0.0 & 0.0 & 0.0 & 0.5 & \\
\hline
\end{tabular}




\begin{tabular}{|c|c|c|c|c|c|c|}
\hline \multicolumn{7}{|c|}{ Table 9 (Continued) } \\
\hline Date & Time & $\begin{array}{l}\text { Gate } 1 \\
\text { Opening, ft } \\
\end{array}$ & $\begin{array}{l}\text { Gate } 3 \\
\text { Opening, ft }\end{array}$ & $\begin{array}{l}\text { Gate } 5 \\
\text { Opening, } \mathrm{ft} \\
\end{array}$ & $\begin{array}{l}\text { Gate } 7 \\
\text { Opening, ft } \\
\end{array}$ & Comment \\
\hline $10 / 5 / 99$ & 805 & 0.0 & 0.0 & 0.0 & 0.0 & \\
\hline $10 / 5 / 99$ & 1420 & 0.0 & 0.0 & 0.0 & 1.0 & \\
\hline 5-Oct & 1630 & 0.0 & 0.0 & 0.0 & 0.5 & \\
\hline $10 / 6 / 99$ & 730 & 0.0 & 0.0 & 0.0 & 0.0 & \\
\hline $10 / 6 / 99$ & 1515 & 0.0 & 0.0 & 0.0 & 0.5 & \\
\hline $10 / 7 / 99$ & 200 & 0.0 & 0.0 & 0.0 & 1.0 & \\
\hline $10 / 7 / 99$ & 1030 & 0.0 & 0.0 & 0.0 & 0.5 & \\
\hline $10 / 7 / 99$ & 1230 & 0.0 & 0.0 & 0.0 & 0.0 & \\
\hline $10 / 8 / 99$ & 210 & 0.0 & 0.0 & 0.0 & 1.0 & \\
\hline $10 / 8 / 99$ & 1110 & 0.0 & 0.0 & 0.0 & 0.0 & \\
\hline 10/9/99 & 750 & 0.0 & 0.0 & 0.0 & 1.0 & \\
\hline 9-Oct & 1325 & 0.0 & 0.0 & 0.0 & 0.5 & \\
\hline 10/9/99 & 1350 & 0.0 & 0.0 & 0.0 & 0.0 & \\
\hline $10 / 10 / 99$ & 910 & 0.0 & 0.0 & 0.0 & 0.5 & \\
\hline $10 / 13 / 99$ & 1545 & 0.0 & 0.0 & 0.0 & 1.0 & \\
\hline $10 / 13 / 99$ & 2025 & 0.0 & 0.0 & 0.0 & 0.5 & \\
\hline $10 / 13 / 99$ & 2140 & 0.0 & 0.0 & 0.0 & 0.0 & \\
\hline $10 / 15 / 99$ & 1705 & 0.0 & 0.0 & 0.0 & 1.0 & \\
\hline $10 / 15 / 99$ & 2105 & 0.0 & 0.0 & 0.0 & 0.0 & \\
\hline $10 / 17 / 99$ & 1630 & 0.0 & 0.0 & 0.0 & 1.0 & \\
\hline $10 / 17 / 99$ & 1810 & 0.0 & 0.0 & 0.0 & 0.5 & \\
\hline $10 / 17 / 99$ & 2135 & 0.0 & 0.0 & 0.0 & 0.0 & \\
\hline $10 / 19 / 99$ & 1200 & 0.0 & 0.0 & 0.0 & 0.5 & \\
\hline 10/19/99 & 1500 & 0.0 & 0.0 & 0.0 & 0.0 & \\
\hline $10 / 29 / 99$ & 1140 & 0.0 & 0.0 & 0.0 & 1.0 & \\
\hline 10/29/99 & 1805 & 0.0 & 0.0 & 0.0 & 0.0 & \\
\hline $11 / 23 / 99$ & 1345 & 0.0 & 0.0 & 0.0 & 0.5 & \\
\hline $11 / 23 / 99$ & 1900 & 0.0 & 0.0 & 0.0 & 0.0 & \\
\hline $11 / 26 / 99$ & 735 & 0.0 & 0.0 & 0.0 & 1.0 & \\
\hline $11 / 26 / 99$ & 915 & 0.0 & 0.0 & 0.0 & 0.5 & \\
\hline $11 / 26 / 99$ & 1110 & 0.0 & 0.0 & 0.0 & 0.0 & \\
\hline $12 / 4 / 99$ & 2330 & 0.0 & 0.0 & 0.0 & 1.0 & \\
\hline $12 / 4 / 99$ & 2347 & 0.0 & 0.0 & 0.0 & 1.5 & \\
\hline $12 / 5 / 99$ & 300 & 0.0 & 0.0 & 0.0 & 2.0 & \\
\hline $12 / 5 / 99$ & 540 & 0.0 & 0.0 & 0.0 & 3.0 & \\
\hline $12 / 5 / 99$ & 1805 & 0.0 & 0.0 & 0.0 & 2.0 & \\
\hline $12 / 5 / 99$ & 1840 & 0.0 & 0.0 & 0.0 & 2.5 & \\
\hline $12 / 5 / 99$ & 1922 & 0.0 & 0.0 & 0.0 & 3.0 & \\
\hline $12 / 5 / 99$ & 2245 & 0.0 & 0.0 & 0.0 & 2.0 & \\
\hline $12 / 6 / 99$ & 150 & 0.0 & 0.0 & 0.0 & 1.0 & \\
\hline $12 / 6 / 99$ & 800 & 0.0 & 0.0 & 0.0 & 2.0 & \\
\hline $12 / 6 / 99$ & 1200 & 0.0 & 0.0 & 0.0 & 3.0 & \\
\hline $12 / 6 / 99$ & 1330 & 0.0 & 0.0 & 0.0 & 2.0 & \\
\hline $12 / 6 / 99$ & 1540 & 0.0 & 0.0 & 0.0 & 3.0 & \\
\hline $12 / 6 / 99$ & 2145 & 0.0 & 0.0 & 0.0 & 2.5 & \\
\hline & & & & & & (Sheet 2 \\
\hline
\end{tabular}




\begin{tabular}{|c|c|c|c|c|c|c|}
\hline \multicolumn{7}{|c|}{ Table 9 (Continued) } \\
\hline Date & Time & $\begin{array}{l}\text { Gate 1 } \\
\text { Opening, ft } \\
\end{array}$ & $\begin{array}{l}\text { Gate } 3 \\
\text { Opening, ft } \\
\end{array}$ & $\begin{array}{l}\text { Gate } 5 \\
\text { Opening, ft } \\
\end{array}$ & $\begin{array}{l}\text { Gate } 7 \\
\text { Opening, ft }\end{array}$ & Comment \\
\hline $12 / 6 / 99$ & 2300 & 0.0 & 0.0 & 0.0 & 2.0 & \\
\hline $12 / 7 / 99$ & 1600 & 0.0 & 0.0 & 0.0 & 0.0 & \\
\hline $12 / 8 / 99$ & 920 & 0.0 & 0.0 & 0.0 & 1.5 & \\
\hline $12 / 8 / 99$ & 1645 & 0.0 & 0.0 & 0.0 & 1.0 & \\
\hline $12 / 8 / 99$ & 2000 & 0.0 & 0.0 & 0.0 & 0.5 & \\
\hline $12 / 8 / 99$ & 2045 & 0.0 & 0.0 & 0.0 & 0.0 & \\
\hline 12/9/99 & 320 & 0.0 & 0.0 & 0.0 & 0.5 & \\
\hline $12 / 9 / 99$ & 900 & 0.0 & 0.0 & 0.0 & 1.5 & \\
\hline $12 / 9 / 99$ & 1130 & 0.0 & 0.0 & 0.0 & 1.0 & \\
\hline $12 / 9 / 99$ & 1735 & 0.0 & 0.0 & 0.0 & 0.5 & \\
\hline $12 / 9 / 99$ & 2315 & 0.0 & 0.0 & 0.0 & 1.0 & \\
\hline $12 / 10 / 99$ & 0 & 0.0 & 0.0 & 0.0 & 1.0 & \\
\hline $12 / 10 / 99$ & 300 & 0.0 & 0.0 & 0.0 & 0.0 & \\
\hline $12 / 10 / 99$ & 1626 & 0.0 & 0.0 & 0.0 & 0.5 & \\
\hline $12 / 11 / 99$ & 0 & 0.0 & 0.0 & 0.0 & 1.0 & \\
\hline $12 / 11 / 99$ & 400 & 0.0 & 0.0 & 0.0 & 0.0 & \\
\hline $12 / 12 / 99$ & 1340 & 0.0 & 0.0 & 0.0 & 1.0 & \\
\hline $12 / 15 / 99$ & 600 & 0.0 & 0.0 & 0.0 & 1.0 & \\
\hline $12 / 15 / 99$ & 1510 & 0.0 & 0.0 & 0.0 & 0.5 & \\
\hline $12 / 15 / 99$ & 1520 & 0.0 & 0.0 & 0.0 & 0.0 & \\
\hline $12 / 17 / 99$ & 735 & 0.0 & 0.0 & 0.0 & 1.0 & \\
\hline $12 / 17 / 99$ & 1210 & 0.0 & 0.0 & 0.0 & 0.0 & \\
\hline $12 / 20 / 99$ & 20 & 0.0 & 0.0 & 0.0 & 0.5 & \\
\hline $12 / 20 / 99$ & 130 & 0.0 & 0.0 & 0.0 & 0.0 & \\
\hline 12/20/99 & 2350 & 0.0 & 0.0 & 0.0 & 0.5 & \\
\hline $12 / 21 / 99$ & 5 & 0.0 & 0.0 & 0.0 & 1.0 & \\
\hline $12 / 21 / 99$ & 400 & 0.0 & 0.0 & 0.0 & 0.0 & \\
\hline $12 / 24 / 99$ & 310 & 0.0 & 0.0 & 0.0 & 0.5 & \\
\hline $12 / 24 / 99$ & 345 & 0.0 & 0.0 & 0.0 & 1.0 & \\
\hline $12 / 24 / 99$ & 0510 & 0.0 & 0.0 & 0.0 & 0.5 & \\
\hline $12 / 24 / 99$ & 0600 & 0.0 & 0.0 & 0.0 & 0.0 & \\
\hline $12 / 30 / 99$ & 0030 & 0.0 & 0.0 & 0.0 & 0.5 & \\
\hline $12 / 30 / 99$ & 0300 & 0.0 & 0.0 & 0.0 & 0.0 & \\
\hline $1 / 6 / 00$ & 1315 & 0.0 & 0.0 & 0.0 & 1.0 & \\
\hline $1 / 6 / 00$ & 1832 & 0.0 & 0.0 & 0.0 & 1.0 & \\
\hline $1 / 6 / 00$ & 2030 & 0.0 & 0.0 & 0.0 & 0.5 & \\
\hline $1 / 6 / 00$ & 2230 & 0.0 & 0.0 & 0.0 & 1.0 & \\
\hline $1 / 6 / 00$ & 2355 & 0.0 & 0.0 & 0.0 & 0.0 & \\
\hline $1 / 8 / 00$ & 1615 & 0.0 & 0.0 & 0.0 & 0.5 & \\
\hline $1 / 8 / 00$ & 1900 & 0.0 & 0.0 & 0.0 & 1.0 & \\
\hline $1 / 8 / 00$ & 2155 & 0.0 & 0.0 & 0.0 & 0.5 & \\
\hline $1 / 9 / 00$ & 0425 & 0.0 & 0.0 & 0.0 & 0.0 & \\
\hline $1 / 9 / 00$ & 1630 & 0.0 & 0.0 & 0.0 & 1.0 & \\
\hline $1 / 9 / 00$ & 1850 & 0.0 & 0.0 & 0.0 & 1.5 & \\
\hline $1 / 10 / 00$ & 0200 & 0.0 & 0.0 & 0.0 & -8.0 & \\
\hline & & & & & & (Sheet 30 \\
\hline
\end{tabular}




\begin{tabular}{|c|c|c|c|c|c|c|}
\hline Date & Time & $\begin{array}{l}\text { Gate } 1 \\
\text { Opening, ft }\end{array}$ & $\begin{array}{l}\text { Gate } 3 \\
\text { Opening, ft }\end{array}$ & $\begin{array}{l}\text { Gate } 5 \\
\text { Opening, ft }\end{array}$ & $\begin{array}{l}\text { Gate } 7 \\
\text { Opening, ft }\end{array}$ & Comment \\
\hline $1 / 10 / 00$ & 0215 & 0.0 & 0.0 & 0.0 & 0.0 & \\
\hline $1 / 11 / 00$ & 0715 & 0.0 & 0.0 & 0.0 & 0.5 & \\
\hline $1 / 11 / 00$ & 0950 & 0.0 & 0.0 & 0.0 & 1.0 & \\
\hline $1 / 11 / 00$ & 1000 & 0.0 & 0.0 & 0.0 & 2.0 & \\
\hline $1 / 11 / 00$ & 1205 & 0.0 & 0.0 & 0.0 & 1.5 & \\
\hline $1 / 11 / 00$ & 1240 & 0.0 & 0.0 & 0.0 & 1.0 & \\
\hline $1 / 11 / 00$ & 1920 & 0.0 & 0.0 & 0.0 & 0.5 & \\
\hline $1 / 11 / 00$ & 2100 & 0.0 & 0.0 & 0.0 & 0.0 & \\
\hline $1 / 13 / 00$ & 2345 & 0.0 & 0.0 & 0.0 & 1.0 & \\
\hline $1 / 14 / 00$ & 0320 & 0.0 & 0.0 & 0.0 & 0.5 & \\
\hline $1 / 14 / 00$ & 0355 & 0.0 & 0.0 & 0.0 & 0.0 & \\
\hline $1 / 21 / 00$ & 1220 & 0.0 & 0.0 & -1.0 & -1.0 & \\
\hline $1 / 21 / 00$ & 1305 & 0.0 & -1.0 & -1.0 & -1.0 & \\
\hline $1 / 21 / 00$ & 1400 & -1.0 & -1.0 & -1.0 & 0.0 & \\
\hline $1 / 21 / 00$ & 1435 & -1.0 & -1.0 & -1.5 & -1.5 & \\
\hline $1 / 21 / 00$ & 1515 & -1.0 & -1.5 & -1.5 & -1.5 & \\
\hline $1 / 22 / 00$ & 0001 & -1.0 & -1.0 & -1.0 & -1.0 & \\
\hline $1 / 22 / 00$ & 0130 & -0.5 & -0.5 & -0.5 & -0.5 & \\
\hline 22-Jan & 0200 & -1.0 & -1.0 & -1.0 & -1.0 & \\
\hline $1 / 22 / 00$ & 0300 & -1.0 & -1.0 & -1.0 & -1.0 & \\
\hline $1 / 22 / 00$ & 0400 & -0.5 & -0.5 & -0.5 & -0.5 & \\
\hline $1 / 22 / 00$ & 0530 & -1.0 & -1.0 & -1.0 & -1.0 & \\
\hline $1 / 22 / 00$ & 0700 & -1.0 & -1.5 & -1.5 & -1.5 & \\
\hline $1 / 22 / 00$ & 0835 & -1.0 & -1.0 & -1.0 & -1.5 & \\
\hline $1 / 22 / 00$ & 0915 & -1.0 & -1.0 & -1.0 & -1.0 & \\
\hline $1 / 22 / 00$ & 1045 & -0.5 & -0.5 & -0.5 & -0.5 & \\
\hline $1 / 22 / 00$ & 1155 & 0.0 & 0.0 & 0.0 & 0.0 & \\
\hline $1 / 23 / 00$ & 400 & -1.0 & -1.0 & -1.0 & -1.0 & \\
\hline $1 / 23 / 00$ & 0500 & -1.0 & -1.0 & -0.5 & -0.5 & \\
\hline $1 / 23 / 00$ & 0700 & -1.0 & -1.0 & -1.0 & -1.0 & \\
\hline $1 / 23 / 00$ & 0730 & -0.5 & -0.5 & -1.0 & -0.5 & \\
\hline $1 / 23 / 00$ & 0830 & -0.5 & -0.5 & -0.5 & -0.5 & \\
\hline $1 / 23 / 00$ & 1010 & -3.0 & 0.0 & 0.0 & 0.0 & \\
\hline $1 / 23 / 00$ & 1105 & -0.5 & -0.5 & -0.5 & 0.0 & \\
\hline $1 / 23 / 00$ & 1200 & -0.5 & -0.5 & -0.5 & -0.5 & \\
\hline $1 / 23 / 00$ & 1340 & -0.3 & -0.3 & -0.3 & 0.0 & \\
\hline $1 / 23 / 00$ & 1400 & -0.3 & -0.3 & -0.3 & -0.3 & \\
\hline $1 / 23 / 00$ & 1800 & -0.4 & -0.4 & -0.4 & -0.4 & \\
\hline $1 / 23 / 00$ & 1925 & -0.7 & -0.7 & -0.7 & -0.7 & \\
\hline $1 / 23 / 00$ & 2135 & -1.0 & -1.0 & -1.0 & -1.0 & \\
\hline $1 / 23 / 00$ & 2145 & -1.2 & -1.2 & -1.2 & -1.2 & \\
\hline $1 / 23 / 00$ & 0001 & -1.2 & -1.2 & -1.2 & -1.2 & \\
\hline $1 / 23 / 00$ & 0100 & -0.5 & -0.5 & -0.5 & -0.5 & \\
\hline $1 / 23 / 00$ & 0230 & -1.0 & -1.0 & -1.0 & -1.0 & \\
\hline $1 / 23 / 00$ & 0400 & -1.0 & -1.0 & -1.0 & -1.0 & \\
\hline
\end{tabular}




\begin{tabular}{|c|c|c|c|c|c|c|}
\hline Date & Time & $\begin{array}{l}\text { Gate } 1 \\
\text { Opening, } \mathrm{ft}\end{array}$ & $\begin{array}{l}\text { Gate } 3 \\
\text { Opening, ft }\end{array}$ & $\begin{array}{l}\text { Gate } 5 \\
\text { Opening, ft }\end{array}$ & $\begin{array}{l}\text { Gate } 7 \\
\text { Opening, ft }\end{array}$ & Comment \\
\hline $1 / 24 / 00$ & 0800 & -1.0 & -1.0 & -1.0 & -1.0 & \\
\hline $1 / 24 / 00$ & 0820 & -1.0 & -1.0 & -1.0 & -1.0 & \\
\hline $1 / 24 / 00$ & 1330 & 0.5 & 0.5 & -1.0 & -1.0 & \\
\hline $1 / 24 / 00$ & 1610 & 0.5 & 0.5 & -0.5 & -1.0 & \\
\hline $1 / 24 / 00$ & 1830 & 0.5 & 0.5 & -0.5 & -0.5 & \\
\hline $1 / 25 / 00$ & 0200 & -0.5 & -0.5 & -0.5 & -0.5 & \\
\hline $1 / 25 / 00$ & 0800 & 1.5 & 1.0 & 1.0 & -2.0 & \\
\hline $1 / 25 / 00$ & 0915 & -0.5 & -0.5 & -0.5 & -2.0 & \\
\hline $1 / 25 / 00$ & 1150 & 0.0 & 0.0 & 0.0 & -5.0 & \\
\hline $1 / 25 / 00$ & 1200 & 0.0 & 0.0 & 0.0 & 0.0 & \\
\hline $1 / 25 / 00$ & 1240 & 1.0 & 0.5 & 0.5 & 0.5 & \\
\hline $1 / 25 / 00$ & 1400 & -0.5 & 0.5 & 0.5 & 0.0 & \\
\hline $1 / 25 / 00$ & 1435 & 0.0 & 0.0 & 0.0 & 0.0 & \\
\hline $1 / 25 / 00$ & 2205 & -0.5 & -0.5 & -0.5 & -0.5 & \\
\hline $1 / 26 / 00$ & 0200 & -1.0 & -1.0 & -1.0 & -1.0 & \\
\hline $1 / 26 / 00$ & 0815 & -1.0 & -1.0 & -1.0 & -1.5 & \\
\hline $1 / 26 / 00$ & 1900 & -1.0 & -1.0 & -0.5 & -0.5 & \\
\hline $1 / 27 / 00$ & 0920 & -1.0 & -1.0 & -0.5 & -1.0 & \\
\hline $1 / 27 / 00$ & 0932 & -1.0 & -1.0 & -0.5 & -2.0 & \\
\hline $1 / 27 / 00$ & 1400 & -1.0 & -1.0 & -1.0 & -2.0 & \\
\hline $1 / 27 / 00$ & 1530 & -2.0 & -2.0 & -2.0 & -2.0 & \\
\hline $1 / 27 / 00$ & 1640 & -1.5 & -1.5 & -1.5 & -1.5 & \\
\hline $1 / 28 / 00$ & 0105 & -1.5 & -1.5 & -1.0 & -1.0 & \\
\hline $1 / 28 / 00$ & 0340 & -1.0 & -1.0 & -1.0 & -0.5 & \\
\hline $1 / 28 / 00$ & 0615 & -1.0 & -1.0 & -0.5 & -0.5 & \\
\hline $1 / 28 / 00$ & 0740 & -1.0 & -0.5 & -0.5 & -0.5 & \\
\hline $1 / 28 / 00$ & 0940 & -1.0 & -0.5 & -0.5 & -0.5 & \\
\hline $1 / 28 / 00$ & 1200 & -0.5 & -0.5 & -0.5 & -0.5 & \\
\hline $1 / 28 / 00$ & 1720 & -1.0 & -1.0 & -1.0 & -1.0 & \\
\hline $1 / 28 / 00$ & 1750 & -1.5 & -1.5 & -1.5 & -1.5 & \\
\hline $1 / 28 / 00$ & 2005 & -1.0 & -1.0 & -1.0 & -1.0 & \\
\hline $1 / 28 / 00$ & 2050 & -0.5 & -0.5 & -0.5 & -0.5 & \\
\hline $1 / 28 / 00$ & 2315 & 0.0 & -0.5 & -0.5 & -0.5 & \\
\hline $1 / 29 / 00$ & 0400 & 0.0 & 0.0 & -0.5 & -0.5 & \\
\hline $1 / 29 / 00$ & 0846 & -0.5 & -0.5 & -0.5 & -0.5 & \\
\hline $1 / 29 / 00$ & 0900 & -0.5 & -0.5 & -0.5 & -1.0 & \\
\hline $1 / 29 / 00$ & 1005 & -0.5 & -0.5 & -1.0 & -1.0 & \\
\hline $1 / 29 / 00$ & 1100 & -1.0 & -1.0 & -1.0 & -1.0 & \\
\hline $1 / 29 / 00$ & 1200 & -1.0 & -1.0 & -1.5 & -1.5 & \\
\hline $1 / 29 / 00$ & 1330 & -1.5 & -1.5 & -2.0 & -2.0 & \\
\hline $1 / 29 / 00$ & 1753 & -1.0 & -1.0 & -2.0 & -2.0 & \\
\hline $1 / 30 / 00$ & 0730 & -1.0 & -1.0 & -1.0 & -2.0 & \\
\hline $1 / 30 / 00$ & 1350 & -0.5 & -1.0 & -1.0 & -1.0 & \\
\hline $1 / 30 / 00$ & 1410 & -0.5 & -0.5 & -0.5 & -0.5 & \\
\hline $1 / 31 / 00$ & 0020 & -0.5 & -0.5 & -1.0 & -1.0 & \\
\hline \multicolumn{7}{|c|}{$\begin{array}{ll} & \text { (Sheet } 5 \text { of } 7) \\
\end{array}$} \\
\hline
\end{tabular}




\begin{tabular}{|c|c|c|c|c|c|c|}
\hline Date & Time & $\begin{array}{l}\text { Gate 1 } \\
\text { Opening, ft }\end{array}$ & $\begin{array}{l}\text { Gate } 3 \\
\text { Opening, ft }\end{array}$ & $\begin{array}{l}\text { Gate } 5 \\
\text { Opening, ft }\end{array}$ & $\begin{array}{l}\text { Gate } 7 \\
\text { Opening, ft }\end{array}$ & Comment \\
\hline $1 / 31 / 00$ & 0110 & -1.0 & -1.0 & -1.0 & -1.0 & \\
\hline $1 / 31 / 00$ & 0335 & -1.5 & -1.5 & -1.5 & -1.5 & \\
\hline $1 / 31 / 00$ & 1500 & 0.0 & 0.0 & 0.0 & 0.0 & \\
\hline $1 / 31 / 00$ & 1950 & -0.5 & -0.5 & -0.5 & -0.5 & \\
\hline $1 / 31 / 00$ & 2300 & -1.0 & -1.0 & -1.0 & -1.0 & \\
\hline $2 / 1 / 00$ & 0005 & -1.0 & -1.5 & -1.5 & -1.5 & \\
\hline $2 / 1 / 00$ & 0020 & -1.5 & -1.5 & -1.5 & -1.5 & \\
\hline $2 / 1 / 00$ & 1130 & -1.0 & -1.0 & -1.5 & -1.5 & \\
\hline $2 / 1 / 00$ & 1430 & -1.0 & -1.0 & -1.0 & -1.0 & \\
\hline $2 / 1 / 00$ & 2245 & -0.5 & -0.5 & -0.5 & -0.5 & \\
\hline $2 / 1 / 00$ & 2305 & 0.0 & 0.0 & 0.0 & 0.0 & \\
\hline $2 / 2 / 00$ & 0250 & 0.0 & -0.5 & -0.5 & -0.5 & \\
\hline $2 / 2 / 00$ & 0400 & -1.0 & -1.0 & -1.0 & -1.0 & \\
\hline $2 / 2 / 00$ & 0635 & -1.5 & -1.5 & -1.5 & -1.5 & \\
\hline $2 / 2 / 00$ & 1515 & -1.0 & -1.0 & -1.5 & -1.5 & \\
\hline $2 / 2 / 00$ & 1700 & -1.0 & -1.0 & -1.0 & -1.0 & \\
\hline $2 / 2 / 00$ & 1915 & -0.5 & -0.5 & -1.0 & -1.0 & \\
\hline $2 / 2 / 00$ & 2120 & -0.5 & -0.5 & -0.5 & -0.5 & \\
\hline $2 / 2 / 00$ & 2210 & 0.0 & 0.0 & 0.0 & 0.0 & \\
\hline $2 / 3 / 00$ & 0640 & 0.0 & 0.0 & -0.5 & -0.5 & \\
\hline $2 / 3 / 00$ & 0830 & -0.5 & -0.5 & -1.0 & -1.0 & \\
\hline $2 / 3 / 00$ & 0935 & -1.0 & -1.0 & -1.0 & -1.0 & \\
\hline $2 / 3 / 00$ & 1105 & -1.5 & -1.5 & -1.5 & -1.0 & \\
\hline $2 / 4 / 00$ & 0225 & -1.0 & -1.0 & -1.0 & -1.0 & \\
\hline $2 / 4 / 00$ & 0530 & -1.0 & -1.0 & -0.5 & -0.5 & \\
\hline $2 / 4 / 00$ & 0635 & -0.5 & -0.5 & -0.5 & -0.5 & \\
\hline $2 / 4 / 00$ & 1430 & -1.0 & -1.0 & -1.0 & -1.0 & \\
\hline $2 / 4 / 00$ & 1600 & -1.0 & -1.5 & -1.5 & -1.5 & \\
\hline $2 / 4 / 00$ & 1700 & -1.5 & -1.5 & -1.5 & -1.5 & \\
\hline $2 / 5 / 00$ & 0230 & -1.5 & -2.5 & -1.0 & -1.0 & \\
\hline $2 / 5 / 00$ & 0850 & -1.0 & -1.0 & -1.0 & -1.0 & \\
\hline $2 / 5 / 00$ & 0900 & -0.5 & -0.5 & -0.5 & -0.5 & \\
\hline $2 / 5 / 00$ & 1300 & -0.5 & 0.5 & 0.0 & 0.0 & \\
\hline $2 / 5 / 00$ & 1745 & -0.5 & -0.5 & -0.5 & 0.0 & \\
\hline $2 / 5 / 00$ & 1940 & -1.0 & -0.5 & -0.5 & -0.5 & \\
\hline $2 / 6 / 00$ & 0225 & -1.0 & -0.5 & -0.5 & -0.5 & \\
\hline $2 / 6 / 00$ & 0250 & -1.0 & -1.0 & -1.0 & -1.0 & \\
\hline $2 / 7 / 00$ & 2000 & -1.0 & -1.0 & -1.0 & 0.0 & \\
\hline $2 / 7 / 00$ & 2100 & -1.0 & -1.0 & 0.0 & 0.0 & \\
\hline $2 / 7 / 00$ & 2200 & -1.0 & 0.0 & 0.0 & 0.0 & \\
\hline $2 / 7 / 00$ & 2300 & 0.0 & 0.0 & 0.0 & 0.0 & \\
\hline $2 / 8 / 00$ & 1800 & 0.0 & 0.0 & 0.0 & -1.5 & \\
\hline $2 / 8 / 00$ & 1900 & 0.0 & 0.0 & -1.5 & -1.5 & \\
\hline $2 / 8 / 00$ & 2100 & 0.0 & -1.5 & -1.5 & -1.5 & \\
\hline $2 / 8 / 00$ & 2130 & -1.5 & -1.5 & -1.5 & -1.5 & \\
\hline \multicolumn{7}{|c|}{\begin{tabular}{ll|} 
& (Sheet 6 of 7) \\
\end{tabular}} \\
\hline
\end{tabular}




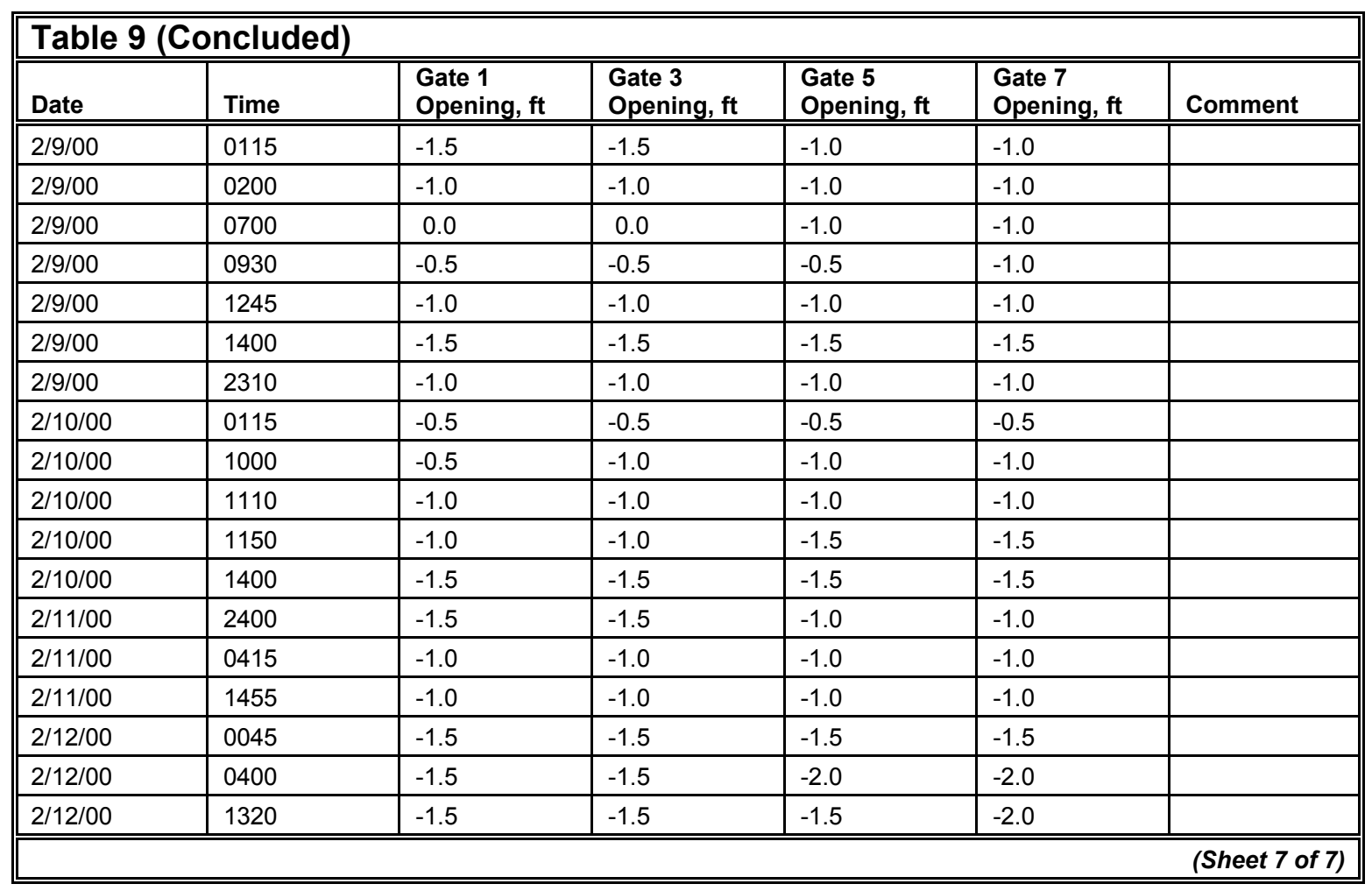




\begin{tabular}{|c|c|c|c|c|}
\hline Date & $\begin{array}{l}\text { Average } \\
\text { Air Temp. }\left({ }^{\circ} \mathrm{F}\right)\end{array}$ & $\begin{array}{l}\begin{array}{l}\text { Average W } \\
\text { Wind Speed } \\
(\mathrm{mph})\end{array} \\
\end{array}$ & $\begin{array}{l}\text { Wind } \\
\text { Dir. }\end{array}$ & Ice Cover \& Ice Activity \\
\hline 1-20 Jan. & & & & Open water \\
\hline 21-Jan-00 & 36.0 & 11.1 & NW & Thin, black sheet ice cover on pool \\
\hline 22-Jan-00 & 30.2 & 12.8 & & Gray sheet ice, flooded at edges and in front of dam gates \\
\hline 23-Jan-00 & 29.7 & 8.2 & NW & $\begin{array}{l}\text { At dawn, sheet ice intact } \\
\text { Between 09:47-10:09 wind pushes sheet ice upstream and } \\
\text { out of view }\end{array}$ \\
\hline 24-Jan-00 & 19.6 & 4.2 & W & $\begin{array}{l}\text { Gray sheet ice re-formed pool, except for ( } 20 \text {-ft-)width of open } \\
\text { water in front of dam gates }\end{array}$ \\
\hline 25-Jan-00 & 311.5 & 122.6 & NW & $\begin{array}{l}\text { At dawn, show-dusted ice cover with longitudinal cracks } \\
\text { At 11:40 towboat breaks out sheet ice. } \\
\text { By 13:00 most of the ice has passed the dam. } \\
\text { By 15:50, pool clear of ice }\end{array}$ \\
\hline 26-Jan-00 & 31.8 & 7.8 & & Thin black ice re-formed on pool \\
\hline 27-Jan-00 & 22.8 & 6.1 & & No-record, assume thin sheet ice \\
\hline 28-Jan-00 & 24.6 & 10.9 & $\mathrm{E}$ & $\begin{array}{l}\text { Throughout morning, gray sheet ice on pool } \\
\text { 12:57, ice starts to shift neat Gate } 1 \\
\text { 13:07 floods the upper edge of the sheet ice } \\
\text { 13:17 entire sheet moves towards dam } \\
\text { 13:31 ice sheet pushes through central dam gates } \\
\text { By 13:35 most of the sheet ice has passed the dam } \\
\text { Until 14:20 intermittent disperse floes continue to arrive at } \\
\text { dam } \\
\text { After 14:20 open water }\end{array}$ \\
\hline 29-Jan-00 & 23.0 & 8.0 & & Disperse flows pass central and right-side dam gates \\
\hline 30-Jan-00 & 14.6 & 10.8 & & Open water, disperse small floes early \\
\hline 31-Jan-00 & 3.4 & 12.1 & 06:38 & $\begin{array}{l}\text { 06:38, pool filled with accumulation of small floes } \\
07: 17 \text {, left side of accumulation shifts upstream } \\
07: 27 \text {, left half begins to move d/s past gates } \\
07: 30-0750 \text { right half moves past gates } \\
\text { 07:50, ice stalls on right, center ice moves, some through } \\
\text { Gate } 2 \\
\text { After 08:04 pool clear of ice, except for some floes on right } \\
\text { side }\end{array}$ \\
\hline 1-Feb-00 & 12.8 & 7.1 & & Open water, with minor floes passing 1, 23 early in day \\
\hline $2-F e b-00$ & 17.2 & 4.4 & $\mathrm{~W}$ & Open water \\
\hline $3-F e b-00$ & 5 & 8.8 & & Open water \\
\hline $4-F e b-00$ & 14.8 & 5.8 & NW & Open water \\
\hline $5-F e b-00$ & 14 & 10.2 & W & Open water \\
\hline $6-F e b-00$ & 19.6 & 9.6 & & Open water, minor small floes \\
\hline 7-Feb-00 & 21.6 & 8.2 & & Open water \\
\hline 8-Feb-00 & 23.7 & 11.3 & W & Open water \\
\hline 9-Feb-00 & 26.5 & 13.5 & $\mathrm{~W}$ & Open water \\
\hline $10-F e b-00$ & 22 & 10.8 & & Open water \\
\hline $11-F e b-00$ & 25.3 & 5.6 & NW & Open water \\
\hline 12-Feb-00 & 17.6 & 7.2 & $\mathrm{E}$ & Open water \\
\hline 13-Feb-00 & 31.1 & 7.7 & $\mathrm{E}$ & Open water \\
\hline 14-Feb-00 & 28.4 & 10.2 & W & Open water \\
\hline $15-F e b-00$ & 21.2 & 8.3 & & Open water \\
\hline $16-F e b-00$ & 24.1 & 10.8 & & No-record, Assume open water \\
\hline $\begin{array}{l}\text { 17-Feb-00 } \\
\text { And after }\end{array}$ & 29.7 & 5.3 & & No-record, Assume open water \\
\hline
\end{tabular}




\begin{tabular}{|c|c|c|c|c|c|c|c|}
\hline \multicolumn{8}{|c|}{$\begin{array}{l}\text { Table } 11 \\
\text { Marseilles Dam; Raised Gate F } \\
\text { Statistics }\end{array}$} \\
\hline \multicolumn{8}{|c|}{$\begin{array}{l}\text { Data Collected on 11/26/1999 at } 1134 \mathrm{hrs} \\
\text { Instrumented Gates: } 1,3,5,7 \\
\text { Gate Settings: } 0,0,0,0 \\
\end{array}$} \\
\hline \multicolumn{8}{|c|}{ Statistics } \\
\hline Channel No. & Minimum & Average & Maximum & Std Dev & RMS & Units & Gate No/ Sensor \\
\hline 1 & -0.41 & \begin{tabular}{|l|}
-0.232 \\
\end{tabular} & 0.011 & 0.013 & 0.232 & Degrees & Gate 1/ Tilt \\
\hline 2 & -36.261 & 18.219 & 71.536 & 11.274 & 21.425 & Milli-g's & Gate 1/ Vertical Acceleration \\
\hline 3 & -8.771 & 16.056 & 38.658 & 5.274 & 16.9 & Milli-g's & Gate 1/ Radial Acceleration \\
\hline 4 & -59.787 & 16.987 & 89.74 & 15.797 & 23.197 & Milli-g's & Gate1/ Transverse Acceleration \\
\hline 5 & -0.808 & -0.63 & -0.493 & 0.01 & 0.63 & Degrees & Gate 3/ Tilt \\
\hline 6 & 6.383 & 24.35 & 41.217 & 2.088 & 24.439 & Milli-g's & Gate 3/ Vertical Acceleration \\
\hline 7 & 15.349 & 22.707 & 29.56 & 1.302 & 22.745 & Milli-g's & Gate 3/ Radial Acceleration \\
\hline 8 & -3.473 & 13.545 & 29.458 & 2.45 & 13.765 & \begin{tabular}{|l|} 
Milli-g's \\
\end{tabular} & Gate 3/ Transverse Acceleration \\
\hline 9 & -0.764 & -0.654 & -0.552 & 0.008 & 0.654 & Degrees & Gate 5/ Tilt \\
\hline 10 & 3.843 & 14.4 & 24.232 & 2.047 & 14.545 & Milli-g's & Gate 5/ Vertical Acceleration \\
\hline 11 & 6.431 & 12.57 & 19.572 & 1.371 & 12.644 & Milli-g's & Gate 5/ Radial Acceleration \\
\hline 12 & -3.242 & 10.985 & 23.81 & 2.749 & 11.324 & Milli-g's & Gate 5/ Transverse Acceleration \\
\hline 13 & -1.689 & -1.523 & -1.381 & 0.009 & 1.523 & \begin{tabular}{|l|} 
Degrees \\
\end{tabular} & Gate 7/ Tilt \\
\hline 14 & -21.255 & 21.868 & 67.691 & 3.269 & 22.111 & Milli-g's & Gate 7/ Vertical Acceleration \\
\hline 15 & -2.671 & 15.925 & 37.518 & 1.446 & 15.99 & Milli-g's & Gate 7/ Radial Acceleration \\
\hline 16 & -92.128 & -13.201 & 59.278 & 5.542 & 14.317 & Milli-g's & Gate 7/ Transverse Acceleration \\
\hline
\end{tabular}

\begin{tabular}{|c|c|c|c|c|c|c|c|}
\hline \multicolumn{8}{|c|}{$\begin{array}{l}\text { Table } 12 \\
\text { Marseilles Dam; Raised Gate P } \\
\text { Data Collected on 12/04/1999 at } 2351 \mathrm{hrs} \\
\text { Instrumented Gates: } 1,3,5,7 \\
\text { Gate Settings : } 0,0,0,1.5\end{array}$} \\
\hline \multicolumn{8}{|c|}{ Statistics } \\
\hline Channel No. & Minimum & Average & Maximum & Std Dev & RMS & Units & Gate No/ Sensor \\
\hline 1 & -1.106 & -0.968 & -0.781 & 0.012 & 0.968 & Degrees & Gate 1/ Tilt \\
\hline 2 & -31.446 & 18.131 & 61.644 & 9.59 & 20.511 & Milli-g's & Gate 1/ Vertical Acceleration \\
\hline 3 & -5.617 & 16.204 & 36.225 & 4.389 & 16.788 & Milli-g's & Gate 1/ Radial Acceleration \\
\hline 4 & -46.831 & 16.952 & 84.302 & 13.562 & 21.709 & Milli-g's & Gate1/ Transverse Acceleration \\
\hline 5 & -1.584 & -1.498 & -1.334 & 0.012 & 1.498 & Degrees & Gate 3/ Tilt \\
\hline 6 & 4.59 & 24.357 & 43.041 & 1.883 & 24.429 & Milli-g's & Gate 3/ Vertical Acceleration \\
\hline 7 & 14.451 & 22.743 & 30.966 & 1.142 & 22.771 & Milli-g's & Gate 3/ Radial Acceleration \\
\hline 8 & -24.691 & 13.519 & 45.438 & 2.382 & 13.727 & Milli-g's & Gate 3/ Transverse Acceleration \\
\hline 9 & -1.539 & -1.44 & -1.361 & 0.008 & 1.44 & Degrees & Gate 5/ Tilt \\
\hline 10 & -4.69 & 14.513 & 34.035 & 3.249 & 14.872 & Milli-g's & Gate 5/ Vertical Acceleration \\
\hline 11 & 4.607 & 12.454 & 20.531 & 1.818 & 12.586 & Milli-g's & Gate 5/ Radial Acceleration \\
\hline 12 & -15.608 & 10.959 & 37.543 & 4.359 & 11.794 & Milli-g's & Gate 5/ Transverse Acceleration \\
\hline 13 & 5.784 & 6.632 & 7.534 & 0.771 & 6.677 & Degrees & Gate 7/ Tilt \\
\hline 14 & -2.239 & 21.939 & 48.613 & 5.078 & 22.519 & Milli-g's & Gate 7/ Vertical Acceleration \\
\hline 15 & 6.939 & 15.858 & 26.342 & 2.039 & 15.989 & Milli-g's & Gate 7/ Radial Acceleration \\
\hline 16 & -52.695 & -13.162 & 26.683 & 8.783 & 15.824 & Milli-g's & Gate 7/ Transverse Acceleration \\
\hline
\end{tabular}




\begin{tabular}{|c|c|c|c|c|c|c|c|}
\hline \multirow{2}{*}{\multicolumn{8}{|c|}{$\begin{array}{l}\text { Table } 13 \\
\text { Marseilles Dam; Raised Gate F } \\
\text { Data Collected on } 12 / 05 / 1999 \text { at } 0323 \mathrm{hrs} \\
\text { Instrumented Gates: } 1,3,5,7 \\
\text { Gate Settings: } 0,0,0,2.0 \\
\end{array}$}} \\
\hline & & & & & & & \\
\hline \multicolumn{8}{|c|}{ Statistics } \\
\hline Channel No. & Minimum & Average & Maximum & Std Dev & RMS & Units & Gate No/ Sensor \\
\hline 1 & -1.091 & -0.963 & -0.791 & 0.013 & 0.963 & Degrees & Gate 1/ Tilt \\
\hline 2 & -29.27 & 18.072 & 61.818 & 9.655 & 20.489 & Milli-g's & Gate 1/ Vertical Acceleration \\
\hline 3 & -3.935 & 16.185 & 37.937 & 4.359 & 16.762 & Milli-g's & Gate 1/ Radial Acceleration \\
\hline 4 & -45.137 & 16.908 & 81.271 & 13.556 & 21.672 & Milli-g's & Gate1/ Transverse Acceleration \\
\hline 5 & -1.579 & -1.485 & -1.359 & 0.012 & 1.485 & Degrees & Gate 3/ Tilt \\
\hline 6 & 15.532 & 24.347 & 34.986 & 1.68 & 24.405 & Milli-g's & Gate 3/ Vertical Acceleration \\
\hline 7 & 17.622 & 22.653 & 28.124 & 1.09 & 22.679 & Milli-g's & Gate 3/ Radial Acceleration \\
\hline 8 & 2.855 & 13.605 & 27.339 & 2.031 & 13.756 & Milli-g's & Gate 3/ Transverse Acceleration \\
\hline 9 & -1.52 & -1.441 & -1.38 & 0.008 & 1.441 & Degrees & Gate 5/ Tilt \\
\hline 10 & -0.358 & 14.577 & 28.726 & 2.938 & 14.87 & Milli-g's & Gate 5/ Vertical Acceleration \\
\hline 11 & 4.329 & 12.519 & 20.592 & 1.856 & 12.656 & Milli-g's & Gate 5/ Radial Acceleration \\
\hline 12 & -12.43 & 10.881 & 33.665 & 3.879 & 11.552 & Milli-g's & Gate 5/ Transverse Acceleration \\
\hline 13 & 8.981 & 9.177 & 9.332 & 0.008 & 9.177 & Degrees & Gate 7/ Tilt \\
\hline 14 & -11.318 & 21.982 & 53.49 & 5.704 & 22.71 & Milli-g's & Gate 7/ Vertical Acceleration \\
\hline 15 & 4.759 & 15.877 & 28.461 & 2.242 & 16.034 & Milli-g's & Gate 7/ Radial Acceleration \\
\hline 16 & -61.131 & -13.14 & 38.475 & 9.928 & 16.469 & Milli-g's & Gate $7 /$ Transverse Acceleration \\
\hline
\end{tabular}

\begin{tabular}{|c|c|c|c|c|c|c|c|}
\hline $\begin{array}{l}\text { Data Collecte } \\
\text { Instrumented } \\
\text { Gate Settings }\end{array}$ & $\begin{array}{r}\text { Ion } 12 / 5 / 19 \\
\text { Gates: } 1,3 \text {, } \\
0,0,0,3.0\end{array}$ & $\begin{array}{l}99 \text { at } 0557 \mathrm{~h} \\
5,7\end{array}$ & & & & & \\
\hline & & & & Stati & ics & & \\
\hline Channel No. & Minimum & Average & Maximum & Std Dev & RMS & Units & Gate No/ Sensor \\
\hline$\overline{11}$ & -1.091 & -0.962 & -0.189 & 0.054 & 0.963 & Degrees & Gate 1/ Tilt \\
\hline 2 & -22.859 & 18.136 & 63.617 & 9.102 & 20.292 & Milli-g's & Gate 1/ Vertical Acceleration \\
\hline 3 & -2.073 & 16.258 & 36.285 & 4.062 & 16.757 & Milli-g's & Gate 1/ Radial Acceleration \\
\hline 4 & -47.515 & 16.937 & 93.217 & 13.356 & 21.57 & Milli-g's & Gate1/ Transverse Acceleration \\
\hline 5 & -1.574 & -1.472 & -1.419 & 0.01 & 1.472 & Degrees & Gate 3/ Tilt \\
\hline 6 & 14.803 & 24.4 & 33.466 & 1.761 & 24.464 & Milli-g's & Gate 3/ Vertical Acceleration \\
\hline 7 & 17.592 & 22.654 & 27.765 & 1.139 & 22.683 & Milli-g's & Gate 3/ Radial Acceleration \\
\hline 8 & 2.207 & 13.648 & 25.191 & 2.146 & 13.816 & Milli-g's & Gate 3/ Transverse Acceleration \\
\hline 9 & -1.544 & -1.443 & -1.38 & 0.008 & 1.443 & Degrees & Gate 5/ Tilt \\
\hline 10 & -2.475 & 14.611 & 35.11 & 2.518 & 14.827 & Milli-g's & Gate 5/ Vertical Acceleration \\
\hline 11 & 4.916 & 12.547 & 20.685 & 1.73 & 12.665 & Milli-g's & Gate 5/ Radial Acceleration \\
\hline 12 & -16.689 & 10.871 & 39.132 & 3.22 & 11.338 & Milli-g's & Gate 5/ Transverse Acceleration \\
\hline 13 & 11.827 & 11.938 & 12.092 & 0.008 & 11.938 & Degrees & Gate 7/ Tilt \\
\hline 14 & -9.692 & 21.99 & 47.233 & 5.852 & 22.756 & Milli-g's & Gate 7/ Vertical Acceleration \\
\hline 15 & 5.925 & 15.985 & 26.342 & 2.294 & 16.149 & Milli-g's & Gate 7/ Radial Acceleration \\
\hline 16 & -62.026 & -13.123 & 32.882 & 10.295 & 16.679 & Milli-g's & Gate 7/ Transverse Acceleration \\
\hline
\end{tabular}




\begin{tabular}{|c|c|c|c|c|c|c|c|}
\hline \multicolumn{8}{|c|}{$\begin{array}{l}\text { Table } 15 \\
\text { Marseilles Dam; Raised Gate P }\end{array}$} \\
\hline \multicolumn{8}{|c|}{$\begin{array}{l}\text { Data Collected on } 06 / 02 / 2000 \text { at } 0130 \mathrm{hrs} \\
\text { Instrumented Gates : } 1,3,5,7 \\
\text { Gate Openings: } 0.0,0.0,2.0,5.0\end{array}$} \\
\hline \multicolumn{8}{|c|}{ Statistics } \\
\hline Channel No. & Minimum & Average & Maximum & Std. Dev & RMS & Units & Gate No. Sensor \\
\hline 1 & 0.001 & 0.162 & 0.357 & 0.034 & 0.166 & degrees & Gate 1/ Tilt \\
\hline 2 & -62.834 & 18.346 & 96.629 & 4.88 & 18.984 & Milli-g's & Gate 1/ Vertical Acceleration \\
\hline 3 & -14.508 & 14.032 & 38.027 & 2.509 & 14.254 & Milli-g's & Gate 1/ Radial Acceleration \\
\hline 4 & -93.692 & 19.656 & 147.12 & 7.589 & 21.071 & Milli-g's & Gate1/ Transverse Acceleration \\
\hline 5 & 0.629 & 0.778 & 0.889 & 0.009 & 0.778 & degrees & Gate 3/ Tilt \\
\hline 6 & -25.989 & 26.037 & 80.914 & 2.997 & 26.209 & Milli-g's & Gate 3/ Vertical Acceleration \\
\hline 7 & 1.675 & 22.545 & 38.297 & 1.566 & 22.599 & Milli-g's & Gate 3/ Radial Acceleration \\
\hline 8 & -64.831 & 17.749 & 111.093 & 4.137 & 18.224 & Milli-g's & Gate 3/ Transverse Acceleration \\
\hline 9 & 8.683 & 8.803 & 8.876 & 0.008 & 8.803 & degrees & Gate 5/ Tilt \\
\hline 10 & -7.002 & 17.252 & 42.275 & 5.516 & 18.113 & Milli-g's & Gate 5/ Vertical Acceleration \\
\hline 11 & 5.071 & 13.927 & 23.499 & 1.896 & 14.056 & Milli-g's & Gate 5/ Radial Acceleration \\
\hline 12 & -28.133 & 9.801 & 54.073 & 8.993 & 13.302 & Milli-g's & Gate 5/ Transverse Acceleration \\
\hline 13 & 17.071 & 17.253 & 17.443 & 0.008 & 17.253 & degrees & Gate 7/ Tilt \\
\hline 14 & -6.073 & 21.804 & 51.987 & 3.778 & 22.128 & Milli-g's & Gate 7/ Vertical Acceleration \\
\hline 15 & -0.675 & 19.148 & 37.364 & 1.547 & 19.21 & Milli-g's & Gate 7/ Radial Acceleration \\
\hline 16 & -51.257 & -11.448 & 47.358 & 6.78 & 13.305 & Milli-g's & Gate 7/ Transverse Acceleration \\
\hline
\end{tabular}

\begin{tabular}{|c|c|c|c|c|c|c|c|}
\hline \multicolumn{8}{|c|}{$\begin{array}{l}\text { Table } 16 \\
\text { Marseilles Dam; Raised Gate F } \\
\text { Data Collected on } 04 / 21 / 2000 \text { at } 1407 \mathrm{hrs} \\
\text { Instrumented Gates: } 1,3,5,7 \\
\text { Gate Openings: } 0.0,0.0,5.0,5.0\end{array}$} \\
\hline \multicolumn{8}{|c|}{ Statistics } \\
\hline Channel No. & Minimum & Average & Maximum & Std Dev & RMS & Units & Gate No./ Sensor \\
\hline 1 & 0.888 & 1.034 & 1.179 & 0.02 & 1.034 & degrees & Gate 1/ Tilt \\
\hline 2 & -35.188 & 17.844 & 67.736 & 3.966 & 18.279 & Milli-g's & Gate 1/ Vertical Acceleration \\
\hline 3 & -0.841 & 16.58 & 34.903 & 3.285 & 16.902 & Milli-g's & Gate 1/ Radial Acceleration \\
\hline 4 & -64.779 & 17.093 & 99.932 & 6.331 & 18.227 & Milli-g's & Gate1/ Transverse Acceleration \\
\hline 5 & 0.729 & 0.812 & 0.924 & 0.011 & 0.812 & degrees & Gate 3/ Tilt \\
\hline 6 & -30.852 & 24.423 & 71.978 & 2.364 & 24.538 & Milli-g's & Gate 3/ Vertical Acceleration \\
\hline 7 & 10.771 & 22.534 & 32.073 & 1.477 & 22.582 & Milli-g's & Gate 3/ Radial Acceleration \\
\hline 8 & -87.08 & 13.436 & 106.826 & 3.53 & 13.892 & Milli-g's & Gate 3/ Transverse Acceleration \\
\hline 9 & 17.413 & 17.458 & 17.557 & 0.008 & 17.458 & degrees & Gate 5/ Tilt \\
\hline 10 & -33.872 & 14.563 & 64.52 & 5.255 & 15.482 & Milli-g's & Gate 5/ Vertical Acceleration \\
\hline 11 & -1.268 & 12.71 & 31.847 & 1.811 & 12.838 & Milli-g's & Gate 5/ Radial Acceleration \\
\hline 12 & -90.186 & 10.619 & 91.076 & 8.7 & 13.728 & Milli-g's & Gate 5/ Transverse Acceleration \\
\hline 13 & 17.346 & 17.454 & 17.551 & 0.008 & 17.454 & degrees & Gate 7/ Tilt \\
\hline 14 & -14.599 & 22.014 & 60.146 & 5.373 & 22.66 & Milli-g's & Gate 7/ Vertical Acceleration \\
\hline 15 & 1.32 & 16.105 & 33.189 & 2.053 & 16.235 & Milli-g's & Gate 7/ Radial Acceleration \\
\hline 16 & -90.498 & -12.761 & 54.069 & 9.629 & 15.986 & Milli-g's & Gate 7/ Transverse Acceleration \\
\hline
\end{tabular}




\begin{tabular}{|c|c|c|c|c|c|c|c|}
\hline \multirow{2}{*}{\multicolumn{8}{|c|}{$\begin{array}{l}\text { Table } 17 \\
\text { Marseilles Dam; Raised Gate F } \\
\text { Data Collected on } 04 / 22 / 2000 \text { at } 0536 \mathrm{hrs} \\
\text { Instrumented Gates: } 1,3,5,7 \\
\text { Gate Openings: } 0.0,1.0,5.0,5.0\end{array}$}} \\
\hline & & & & & & & \\
\hline \multicolumn{8}{|c|}{ Statistics } \\
\hline Channel No. & Minimum & Average & Maximum & Std. Dev & RMS & Units & Gate No./ Sensor \\
\hline 1 & 0.788 & 1.03 & 1.219 & 0.038 & 1.031 & degrees & Gate 1/ Tilt \\
\hline 2 & -18.74 & 17.815 & 53.696 & 3.192 & 18.098 & Milli-g's & Gate 1/ Vertical Acceleration \\
\hline 3 & 3.034 & 17.014 & 30.878 & 1.766 & 17.106 & Milli-g's & Gate 1/ Radial Acceleration \\
\hline 4 & -38.778 & 16.731 & 61.659 & 4.955 & 17.449 & Milli-g's & Gate1/ Transverse Acceleration \\
\hline 5 & 6.011 & 6.123 & 6.281 & 0.01 & 6.123 & degrees & Gate 3/ Tilt \\
\hline 6 & 8.48 & 24.242 & 39.241 & 3.425 & 24.483 & Milli-g's & Gate 3/ Vertical Acceleration \\
\hline 7 & 15.199 & 22.468 & 29.71 & 1.387 & 22.511 & Milli-g's & Gate 3/ Radial Acceleration \\
\hline 8 & -11.595 & 12.862 & 41.524 & 5.198 & 13.872 & Milli-g's & Gate 3/ Transverse Acceleration \\
\hline 9 & 17.148 & 17.238 & 17.34 & 0.008 & 17.238 & degrees & Gate 5/ Tilt \\
\hline 10 & -36.348 & 14.24 & 63.022 & 5.132 & 15.136 & Milli-g's & Gate 5/ Vertical Acceleration \\
\hline 11 & -16.882 & 12.615 & 40.968 & 1.628 & 12.72 & Milli-g's & Gate 5/ Radial Acceleration \\
\hline 12 & -54.455 & 10.859 & 71.017 & 8.308 & 13.672 & Milli-g's & Gate 5/ Transverse Acceleration \\
\hline 13 & 17.405 & 17.503 & 17.594 & 0.008 & 17.503 & degrees & Gate 7/ Tilt \\
\hline 14 & -18.832 & 21.903 & 68.672 & 3.216 & 22.137 & Milli-g's & Gate 7/ Vertical Acceleration \\
\hline 15 & -9.794 & 15.75 & 37.088 & 1.378 & 15.81 & Milli-g's & Gate 7/ Radial Acceleration \\
\hline 16 & -68.864 & -12.955 & 50.49 & 5.71 & 14.157 & Milli-g's & Gate 7/ Transverse Acceleration \\
\hline
\end{tabular}

\begin{tabular}{|c|c|c|c|c|c|c|c|}
\hline \multirow{2}{*}{\multicolumn{8}{|c|}{$\begin{array}{l}\text { Table } 18 \\
\text { Marseilles Dam; Raised Gate } \\
\text { Data Collected on } 07 / 11 / 2000 \text { at } 2117 \text { hrs } \\
\text { Instrumented Gates : } 1,3,5,7 \\
\text { Gate Openings: } 0.0,5.0,5.0,5.0\end{array}$}} \\
\hline & & & & & & & \\
\hline \multicolumn{8}{|c|}{ Statistics } \\
\hline Channel No. & Minimum & Average & Maximum & Std. Dev & RMS & Units & Gate No./ Sensor \\
\hline 1 & 0.121 & 0.364 & 0.643 & 0.058 & 0.369 & degrees & Gate 1/ Tilt \\
\hline 2 & 0.986 & 18.47 & 36.319 & 1.821 & 18.56 & Milli-g's & Gate 1/ Vertical Acceleration \\
\hline 3 & 1.532 & 12.433 & 24.09 & 1.322 & 12.503 & Milli-g's & Gate 1/ Radial Acceleration \\
\hline 4 & 0.505 & 20.375 & 43.236 & 2.451 & 20.522 & Milli-g's & Gate1/ Transverse Acceleration \\
\hline 5 & 17.051 & 17.136 & 17.261 & 0.01 & 17.136 & degrees & Gate 3/ Tilt \\
\hline 6 & -224.2 & 26.467 & 300.464 & 3.707 & 26.726 & Milli-g's & Gate 3/ Vertical Acceleration \\
\hline 7 & -65.074 & 22.276 & 116.954 & 1.847 & 22.353 & Milli-g's & Gate 3/ Radial Acceleration \\
\hline 8 & -170.8 & 19.301 & 223.276 & 5.166 & 19.98 & Milli-g's & Gate 3/ Transverse Acceleration \\
\hline 9 & 17.066 & 17.116 & 17.205 & 0.009 & 17.116 & degrees & Gate 5/ Tilt \\
\hline 10 & -23.255 & 18.411 & 62.696 & 5.175 & 19.125 & Milli-g's & Gate 5/ Vertical Acceleration \\
\hline 11 & -5.194 & 14.378 & 34.413 & 1.756 & 14.485 & Milli-g's & Gate 5/ Radial Acceleration \\
\hline 12 & -67.488 & 9.097 & 94.318 & 8.53 & 12.47 & Milli-g's & Gate 5/ Transverse Acceleration \\
\hline 13 & 17.114 & 17.175 & 17.227 & 0.009 & 17.175 & degrees & Gate 7/ Tilt \\
\hline 14 & -14.875 & 21.722 & 51.957 & 2.444 & 21.859 & Milli-g's & Gate 7/ Vertical Acceleration \\
\hline 15 & 5.864 & 20.084 & 34.11 & 1.058 & 20.112 & Milli-g's & Gate 7/ Radial Acceleration \\
\hline 16 & -62.313 & -11.168 & 40.647 & 4.351 & 11.985 & Milli-g's & Gate 7/ Transverse Acceleration \\
\hline
\end{tabular}




\begin{tabular}{|c|c|c|c|c|c|c|c|}
\hline \multirow{2}{*}{\multicolumn{8}{|c|}{\begin{tabular}{|l|} 
Table 19 \\
Marseilles Dam; Raised Gate F \\
Data Collected on $07 / 11 / 2000$ at 2017 hrs \\
Instrumented Gates: $1,3,5,7$ \\
Gate Openings: $0.0,5.0,5.0,7.0$ \\
\end{tabular}}} \\
\hline & & & & & & & \\
\hline \multicolumn{8}{|c|}{ Statistics } \\
\hline Channel No. & Minimum & Average & Maximum & Std. Dev & RMS & Units & Gate No. Sensor \\
\hline 1 & -0.129 & 0.024 & 0.262 & 0.051 & 0.057 & degrees & Gate 1/ Tilt \\
\hline 2 & 10.008 & 18.409 & 30.256 & 1.474 & 18.468 & \begin{tabular}{|l|} 
Milli-g's \\
\end{tabular} & Gate 1/ Vertical Acceleration \\
\hline 3 & 8.26 & 12.342 & 16.22 & 0.799 & 12.368 & Milli-g's & Gate 1/ Radial Acceleration \\
\hline 4 & 6.835 & 20.459 & 35.777 & 1.998 & 20.556 & Milli-g's & Gate1/ Transverse Acceleration \\
\hline 5 & 16.975 & 17.044 & 17.166 & 0.01 & 17.044 & degrees & Gate 3/ Tilt \\
\hline 6 & -93.225 & 26.501 & 138.241 & 3.667 & 26.754 & Milli-g's & Gate 3/ Vertical Acceleration \\
\hline 7 & -18.64 & 22.234 & 58.402 & 1.801 & 22.306 & Milli-g's & Gate 3/ Radial Acceleration \\
\hline 8 & -108.74 & 19.427 & 113.713 & 5.108 & 20.087 & Milli-g's & Gate 3/ Transverse Acceleration \\
\hline 9 & 17.08 & 17.127 & 17.186 & 0.008 & 17.127 & degrees & Gate 5/ Tilt \\
\hline 10 & -47.356 & 18.484 & 75.366 & 5.01 & 19.151 & \begin{tabular}{|l|} 
Milli-g's \\
\end{tabular} & Gate 5/ Vertical Acceleration \\
\hline 11 & -6.277 & 14.453 & 34.784 & 1.73 & 14.556 & Milli-g's & Gate 5/ Radial Acceleration \\
\hline 12 & -115.78 & 8.977 & 130.526 & 8.125 & 12.108 & Milli-g's & Gate 5/ Transverse Acceleration \\
\hline 13 & 21.531 & 21.585 & 21.65 & 0.009 & 21.585 & degrees & Gate 7/ Tilt \\
\hline 14 & -39.566 & 21.677 & 84.222 & 4.18 & 22.076 & Milli-g's & Gate 7/ Vertical Acceleration \\
\hline 15 & -9.272 & 20.129 & 43.167 & 1.645 & 20.196 & Milli-g's & Gate 7/ Radial Acceleration \\
\hline 16 & -122.52 & -11.082 & 79.537 & 7.669 & 13.477 & Milli-g's & Gate 7/ Transverse Acceleration \\
\hline
\end{tabular}

\begin{tabular}{|c|c|c|c|c|c|c|c|}
\hline \multicolumn{8}{|c|}{$\begin{array}{l}\text { Table } 20 \\
\text { Marseilles Dam Submerged } \\
\text { Statistics }\end{array}$} \\
\hline \multicolumn{8}{|c|}{$\begin{array}{l}\text { Data Collected on } 02 / 7 / 2000 \text { at } 2320 \mathrm{hrs} \\
\text { Instrumented Gates : } 1,3,5,7 \\
\text { Gate Settings } 0,0,0,0\end{array}$} \\
\hline \multicolumn{8}{|c|}{ Statistics } \\
\hline Channel No. & Min & Ave & Max & Std Dev & RMS & Units & Gate/Sensor \\
\hline 1 & 0.292 & 0.443 & 0.613 & 0.013 & 0.443 & Degrees & Gate 1/ Tilt \\
\hline 2 & 5.918 & 18.408 & 31.417 & 2.878 & 18.631 & Milli-g's & Gate 1/ Vertical Acceleration \\
\hline 3 & 11.264 & 17.474 & 24.3 & 1.334 & 17.525 & Milli-g's & Gate 1/ Radial Acceleration \\
\hline 4 & -6.418 & 16.107 & 38.392 & 4.825 & 16.814 & Milli-g's & Gate1/ Transverse Acceleration \\
\hline 5 & 0.148 & 0.277 & 0.438 & 0.009 & 0.277 & Degrees & Gate 3/ Tilt \\
\hline 6 & 14.803 & 23.998 & 32.493 & 1.771 & 24.063 & Milli-g's & Gate 3/ Vertical Acceleration \\
\hline 7 & 18.759 & 23.056 & 27.496 & 0.924 & 23.075 & Milli-g's & Gate 3/ Radial Acceleration \\
\hline 8 & -0.471 & 12.213 & 24.102 & 2.382 & 12.443 & Milli-g's & Gate 3/ Transverse Acceleration \\
\hline 9 & 0.108 & 0.187 & 0.291 & 0.007 & 0.188 & Degrees & Gate 5/ Tilt \\
\hline 10 & -4.039 & 13.584 & 31.071 & 3.317 & 13.983 & Milli-g's & Gate 5/ Vertical Acceleration \\
\hline 11 & 6.308 & 12.583 & 19.417 & 1.279 & 12.647 & Milli-g's & Gate 5/ Radial Acceleration \\
\hline 12 & -13.065 & 11.618 & 34.682 & 4.868 & 12.596 & Milli-g's & Gate 5/ Transverse Acceleration \\
\hline 13 & -0.712 & -0.515 & -0.328 & 0.006 & 0.515 & Degrees & Gate 7/ Tilt \\
\hline 14 & 9.631 & 22.301 & 34.259 & 2.644 & 22.458 & Milli-g's & Gate 7/ Vertical Acceleration \\
\hline 15 & 8.934 & 14.815 & 20.232 & 1.155 & 14.86 & Milli-g's & Gate 7/ Radial Acceleration \\
\hline 16 & -34.384 & -13.468 & 6.711 & 4.564 & 14.22 & Milli-g's & Gate $7 /$ Transverse Acceleration \\
\hline
\end{tabular}




\begin{tabular}{|c|c|c|c|c|c|c|c|}
\hline \multirow{2}{*}{\multicolumn{8}{|c|}{\begin{tabular}{|l} 
Table 21 \\
Marseilles Dam Submerged G \\
Data Collected on $02 / 06 / 2000$ at 0225 hrs \\
Instrumented Gates: $1,3,5,7$ \\
Gate Settings: $-1.0,-1.0,-1.0,-1.0$ \\
\end{tabular}}} \\
\hline & & & & & & & \\
\hline \multicolumn{8}{|c|}{ Statistics } \\
\hline Channel No. & Min & Ave & Max & Std Dev & RMS & Units & Gate/Sensor \\
\hline 1 & -4.835 & -4.697 & -4.465 & 0.035 & 4.697 & Degrees & Gate 1/ Tilt \\
\hline 2 & -2.495 & 18.472 & 38.205 & 4.475 & 19.006 & Milli-g's & Gate 1/ Vertical Acceleration \\
\hline 3 & 8.651 & 17.452 & 26.162 & 1.837 & 17.548 & Milli-g's & Gate 1/ Radial Acceleration \\
\hline 4 & -17.651 & 15.979 & 48.198 & 6.465 & 17.237 & Milli-g's & Gate1/ Transverse Acceleration \\
\hline 5 & -5.454 & -5.233 & -5.059 & 0.009 & 5.233 & Degrees & Gate 3/ Tilt \\
\hline 6 & 8.724 & 23.868 & 40.062 & 3.506 & 24.124 & \begin{tabular}{|l|} 
Milli-g's \\
\end{tabular} & Gate 3/ Vertical Acceleration \\
\hline 7 & 17.383 & 22.886 & 28.304 & 1.226 & 22.919 & \begin{tabular}{|l|} 
Milli-g's \\
\end{tabular} & Gate 3/ Radial Acceleration \\
\hline 8 & -9.888 & 11.872 & 34.638 & 4.816 & 12.812 & Milli-g's & Gate 3/ Transverse Acceleration \\
\hline 9 & -5.08 & -5.025 & -4.955 & 0.008 & 5.025 & Degrees & Gate 5/ Tilt \\
\hline 10 & -68.428 & 13.426 & 110.866 & 5.606 & 14.55 & Milli-g's & Gate 5/ Vertical Acceleration \\
\hline 11 & -37.444 & 12.385 & 52.687 & 1.979 & 12.542 & Milli-g's & Gate 5/ Radial Acceleration \\
\hline 12 & -119.59 & 11.601 & 174.427 & 8.078 & 14.136 & Milli-g's & Gate 5/ Transverse Acceleration \\
\hline 13 & -4.514 & -4.316 & -4.217 & 0.007 & 4.316 & Degrees & Gate 7/ Tilt \\
\hline 14 & -29.015 & 22.155 & 69.991 & 3.43 & 22.419 & \begin{tabular}{|l|} 
Milli-g's \\
\end{tabular} & Gate 7/ Vertical Acceleration \\
\hline 15 & -7 & 14.554 & 34.785 & 1.565 & 14.638 & Milli-g's & Gate 7/ Radial Acceleration \\
\hline 16 & -106.41 & -13.605 & 71.005 & 5.571 & 14.701 & Milli-g's & Gate 7/ Transverse Acceleration \\
\hline
\end{tabular}

\begin{tabular}{|c|c|c|c|c|c|c|c|}
\hline \multirow{2}{*}{\multicolumn{8}{|c|}{\begin{tabular}{|l} 
Table 22 \\
Marseilles Dam Submerged G \\
Data Collected on $02 / 03 / 20001123$ hrs \\
Instrumented Gates: $1,3,5,7$ \\
Gate Settings $-1.5,-1.5,-1.5,-1.5$ \\
\end{tabular}}} \\
\hline & & & & & & & \\
\hline \multicolumn{8}{|c|}{ Statistics } \\
\hline Channel No. & Min & Ave & Max & Std Dev & RMS & Units & Gate/Sensor \\
\hline 1 & -5.898 & -5.784 & -5.597 & 0.018 & 5.784 & Degrees & Gate 1/ Tilt \\
\hline 2 & -3.365 & 18.462 & 40.091 & 4.311 & 18.959 & Milli-g's & Gate 1/ Vertical Acceleration \\
\hline 3 & 10.032 & 17.332 & 25.561 & 1.68 & 17.413 & Milli-g's & Gate 1/ Radial Acceleration \\
\hline 4 & -14.055 & 16.068 & 45.316 & 6.175 & 17.214 & Milli-g's & Gate1/ Transverse Acceleration \\
\hline 5 & -6.356 & -6.234 & -6.11 & 0.009 & 6.234 & Degrees & Gate 3/ Tilt \\
\hline 6 & 3.465 & 23.928 & 45.624 & 3.911 & 24.246 & Milli-g's & Gate 3/ Vertical Acceleration \\
\hline 7 & 16.186 & 22.967 & 30.129 & 1.409 & 23.01 & Milli-g's & Gate 3/ Radial Acceleration \\
\hline 8 & -15.627 & 12.225 & 41.759 & 5.021 & 13.215 & \begin{tabular}{|l|} 
Milli-g's \\
\end{tabular} & Gate 3/ Transverse Acceleration \\
\hline 9 & -6.337 & -6.276 & -6.164 & 0.01 & 6.276 & Degrees & Gate 5/ Tilt \\
\hline 10 & -19.802 & 13.504 & 44.327 & 5.723 & 14.667 & Milli-g's & Gate 5/ Vertical Acceleration \\
\hline 11 & -0.928 & 12.496 & 29.188 & 2.162 & 12.681 & Milli-g's & Gate 5/ Radial Acceleration \\
\hline 12 & -32.266 & 11.507 & 55.822 & 7.696 & 13.843 & Milli-g's & Gate 5/ Transverse Acceleration \\
\hline 13 & -5.685 & -5.616 & -5.561 & 0.007 & 5.616 & Degrees & Gate 7/ Tilt \\
\hline 14 & -13.741 & 22.162 & 59.778 & 3.855 & 22.494 & Milli-g's & Gate 7/ Vertical Acceleration \\
\hline 15 & -4.145 & 14.658 & 34.57 & 1.871 & 14.777 & Milli-g's & Gate 7/ Radial Acceleration \\
\hline 16 & -77.205 & -13.621 & 54.612 & 5.671 & 14.754 & Milli-g's & Gate $7 /$ Transverse Acceleration \\
\hline
\end{tabular}




\begin{tabular}{|c|c|c|c|c|c|c|c|}
\hline \multirow{2}{*}{\multicolumn{8}{|c|}{\begin{tabular}{|l|} 
Table 23 \\
Marseilles Dam Submerged Ga \\
Data Collected on $02 / 14 / 2000$ at $0130 \mathrm{hrs}$ \\
Instrumented Gates: $1,3,5,7$ \\
Gate Settings: $-1.5,-2.0,-2.0,-2.0$ \\
\end{tabular}}} \\
\hline & & & & & & & \\
\hline \multicolumn{8}{|c|}{ Statistic } \\
\hline Channel No. & Min & Ave & Max & Std Dev & RMS & Units & Gate/Sensor \\
\hline 1 & -5.988 & -5.85 & -5.657 & 0.011 & 5.85 & \begin{tabular}{|l|} 
Degrees \\
\end{tabular} & Gate 1/ Tilt \\
\hline 2 & -5.628 & 18.459 & 39.888 & 4.414 & 18.98 & \begin{tabular}{|l|} 
Milli-g's \\
\end{tabular} & Gate 1/ Vertical Acceleration \\
\hline 3 & 9.672 & 17.573 & 26.102 & 1.725 & 17.657 & Milli-g's & Gate 1/ Radial Acceleration \\
\hline 4 & -14.085 & 16.105 & 48.733 & 6.375 & 17.32 & Milli-g's & Gate1/ Transverse Acceleration \\
\hline 5 & -7.557 & -7.467 & -7.397 & 0.01 & 7.467 & \begin{tabular}{|l|} 
Degrees \\
\end{tabular} & Gate 3/ Tilt \\
\hline 6 & 2.796 & 23.997 & 46.172 & 3.983 & 24.325 & \begin{tabular}{|l|} 
Milli-g's \\
\end{tabular} & Gate 3/ Vertical Acceleration \\
\hline 7 & 15.708 & 23.092 & 32.283 & 1.428 & 23.136 & Milli-g's & Gate 3/ Radial Acceleration \\
\hline 8 & -20.159 & 12.099 & 41.906 & 5.637 & 13.348 & Milli-g's & Gate 3/ Transverse Acceleration \\
\hline 9 & -7.73 & -7.648 & -7.595 & 0.008 & 7.648 & Degrees & Gate 5/ Tilt \\
\hline 10 & -20.942 & 13.425 & 46.021 & 5.583 & 14.54 & \begin{tabular}{|l|} 
Milli-g's \\
\end{tabular} & Gate 5/ Vertical Acceleration \\
\hline 11 & 1.113 & 12.425 & 24.736 & 1.971 & 12.58 & Milli-g's & Gate 5/ Radial Acceleration \\
\hline 12 & -25.813 & 11.554 & 52.643 & 8.077 & 14.097 & Milli-g's & Gate 5/ Transverse Acceleration \\
\hline 13 & -8.267 & -8.204 & -8.067 & 0.008 & 8.204 & \begin{tabular}{|l|} 
Degrees \\
\end{tabular} & Gate 7/ Tilt \\
\hline 14 & 2.699 & 22.221 & 41.927 & 4.07 & 22.591 & Milli-g's & Gate 7/ Vertical Acceleration \\
\hline 15 & 5.465 & 14.747 & 23.272 & 1.871 & 14.865 & Milli-g's & Gate 7/ Radial Acceleration \\
\hline 16 & -45.984 & -13.539 & 20.292 & 6.11 & 14.854 & Milli-g's & Gate 7/ Transverse Acceleration \\
\hline
\end{tabular}




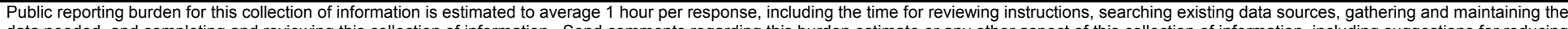

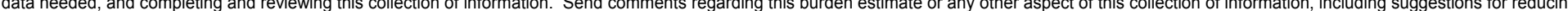

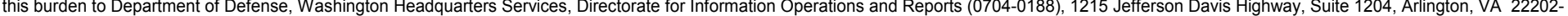

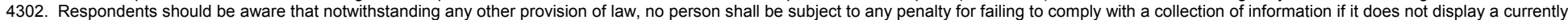
valid OMB control number. PLEASE DO NOT RETURN YOUR FORM TO THE ABOVE ADDRESS.

\begin{tabular}{l|l|l|l} 
1. REPORT DATE (DD-MM-YYYY) & 2. REPORT TYPE & 3. DATES COVERED (FrOm - To)
\end{tabular}

November 2001

Final report

4. TITLE AND SUBTITLE

Monitoring of Marseilles Dam Submersible Gates, Illinois River, Illinois

5a. CONTRACT NUMBER

5b. GRANT NUMBER

6. AUTHOR(S)

Deborah R. Cooper, Timothy L. Fagerburg, Terry N. Waller,

S. Wallace Guy, Andrew Tuthill

\section{PERFORMING ORGANIZATION NAME(S) AND ADDRESS(ES)}

Coastal and Hydraulics Laboratory

Environmental Laboratory

5c. PROGRAM ELEMENT NUMBER

U.S. Army Engineer Research and Development Center

3909 Halls Ferry Road

Vicksburg, MS 39180-6199;

Cold Regions Research and Engineering Laboratory

U.S. Army Engineer Research and Development Center

72 Lyme Road

Hanover, NH 03755-1290

9. SPONSORING / MONITORING AGENCY NAME(S) AND ADDRESS(ES)

5d. PROJECT NUMBER

5e. TASK NUMBER

5f. WORK UNIT NUMBER

31589

8. PERFORMING ORGANIZATION REPORT NUMBER

ERDC TR-01-15

U.S. Army Corps of Engineers

Washington, DC 20314-1000

10. SPONSOR/MONITOR'S ACRONYM(S)

11. SPONSOR/MONITOR'S REPORT NUMBER(S)

\section{DISTRIBUTION / AVAILABILITY STATEMENT}

Approved for public release; distribution is unlimited.

\section{SUPPLEMENTARY NOTES}

\section{ABSTRACT}

In 1998, Marseilles Dam, IL, was approved for inclusion in the Monitoring Completed Navigation Projects Program. The object of the monitoring plan for Marseilles Dam was to determine if the dam gates were performing (both functionally and structurally) as predicted by model studies used in the project design. Monitoring of the dam was conducted during the period June 1999 through June 2001 . Elements of the monitoring program included a Life-Cycle Cost analysis. Vibration data obtained from instruments on the gates appeared to validate a previous three-dimensional model study. A videotape analysis used to analyze gate efficiency for ice passage was successful. Trends in vibration data correlated well with model data. The Marseilles Dam submersible gates are currently functioning vibration-free and are in good structural condition. The Remote Operation System eliminated the need for 24-hr staffing of the dam and provides for operation of the dam at the lock, (2.4 mi) away and allows for relatively easy maintenance of strict pool tolerances. The submersible gates provide a safer mechanism for passing ice at lower discharged during winter conditions.

\section{SUBJECT TERMS}

Ice passage

Life-Cycle Cost analysis

Marsseilles Dam, IL
Monitoring Completed Navigation Projects Program

Submergible gates

Vibrations

\begin{tabular}{|c|c|c|c|c|c|}
\hline \multicolumn{3}{|c|}{ 16. SECURITY CLASSIFICATION OF: } & \multirow{2}{*}{$\begin{array}{l}\text { 17. LIMITATION } \\
\text { OF ABSTRACT }\end{array}$} & \multirow{2}{*}{$\begin{array}{l}\text { 18. NUMBER } \\
\text { OF PAGES }\end{array}$} & 19a. NAME OF RESPONSIBLE PERSON \\
\hline $\begin{array}{l}\text { a. REPORT } \\
\text { UNCLASSIFIED }\end{array}$ & $\begin{array}{l}\text { c. ABSTRACT } \\
\text { UNCLASSIFIED }\end{array}$ & $\begin{array}{l}\text { c. THIS PAGE } \\
\text { UNCLASSIFIED }\end{array}$ & & & $\begin{array}{l}\text { 19b. TELEPHONE NUMBER (include area } \\
\text { code) }\end{array}$ \\
\hline
\end{tabular}

